\title{
LAS INTERVENCIONES DE LOS TRABAJADORES SOCIALES EN EL CAMPO DE LA DISCAPACIDAD \\ Trayectorias y Temporalidades
}

Tesista: Mgter. Paula Mara Danel

Director: Dr. Alfredo J M Carballeda

Co - Directora: Dra. Carolina Ferrante 
Tesis "Las intervenciones de los trabajadores sociales en el campo de la discapacidad. Trayectorias y temporalidades" presentada como requisito parcial para la obtención del título de Doctor en Trabajo Social de la Facultad de Trabajo Social de la Universidad Nacional de La Plata, dirigida por el Dr. Alfredo Juan Manuel Carballeda y la Dra. Carolina Ferrante. 
A Sergio por el amor y el acompañamiento en cada proyecto.

A Valentín por los desafios a los que me invita a transitar en el ejercicio de la maternidad, por su fortaleza, dulzura y amor. A ambos en reconocimiento a todos los tiempos sustraidos por la urgencia de la tesis A mi madre, por alentar mi decisión de formación continua. 


\section{Resumen}

La presente tesis caracteriza y analiza los procesos de intervención profesional de los trabajadores sociales en el campo de la discapacidad. Se recuperan los antecedentes históricos que operaron en la configuración del tema discapacidad como asunto público y consecuentemente la producción del espacio socio - ocupacional del trabajo social. Se identifican dos momentos de la producción de la política de discapacidad, uno asociado a procesos de modernización/ desarrollo en el que la discapacidad aparece como objeto de asistencia/ custodia /atención y otro vinculado a la mercantilización en el que la discapacidad medicalizada se constituye en un punto más de ampliación del excedente (con líneas de continuidad y ruptura).

La categoría de campo de la discapacidad, es analizada desde la perspectiva relacional, en la que se problematiza el capital específico en juego, asociado a la definición de discapacidad. Se vinculó la discapacidad con las disputas que los trabajadores sociales vienen sosteniendo en el campo, desde la postulación de un trabajo social anti - opresivo que encara estrategias emancipadoras en su práctica.

La intervención en discapacidad desde la idea de trayectorias diferenciales en contextos desiguales, dotó de un avance sustantivo en los análisis de las situaciones particulares que se presentan en los servicios sociales y son abordadas por los agentes profesionales.

La dimensión corporal como sustrato de existencia de los agentes en general y de los trabajadores sociales en particular, ha sido puesta en juego en los análisis de la presente tesis. 
Palabras Claves: Discapacidad - Trabajo Social - Trayectorias - Cuerpo Temporalidad 


\section{Summary}

This thesis aims to characterize and analyze the processes of professional intervention of social workers in the field of disability. Recovered the historical background that operated in shaping the topic disability as a public issue and consequently the production of space socio - occupational of social work.

Two moments is identified in the production of disability policy, one associated with modernization/development where the disability appears as an object of assitence/ custody/care and another linked to the commodification in which the medicalized disability constitutes a point of expansion (with lines of continuity and rupture).

The category field of disability is analyzed from the relational perspective, in which the specific capital at stake, associated with the definition of disability becomes problematic. Disability was linked to disputes that social workers are holding in the field, from the application of a social work anti - oppressive facing emancipatory strategies in their practice.

The intervention in disability from the idea of differential paths in unequal contexts, endowed with a substantial advance in the analysis of particular situations that arised in social services and they are addressed by professional agents.

The body dimension as substrate of the existence of agents in general and of particularly social workers has been put into play in the analysis of this thesis.

Keywords: Disability - Social Work - Trajectories - Body - Temporality 


\section{Agradecimientos}

Esta tesis ha sido posible por el acompañamiento, amor y cuidados de mi familia. La postergación de tiempos libres, la monotemática preocupación de los últimos meses sólo fue tolerable para mi esposo e hijo por el amor que nos une y la pasión puesta en juego en cada elección vital. También gracias a mi madre, quien me inició en el campo de la discapacidad cuándo me llevaba a las "peñas de la integración” para que me enterara que el mundo era diverso.

Destaco que esta tesis también fue posible porque el Estado Nacional, a través de sus políticas redistributivas, ha desarrollado estrategias para incentivar el avance y culminación de trayectos formativos para los docentes universitarios. Además por la fortaleza en las convicciones de la Dra. Margarita Rozas, Mgter. Alejandra Wagner y todos los compañeros que diariamente ponen energía y trabajo en nuestra Facultad de Trabajo Social de la UNLP.

Del mismo modo, ha sido viable gracias a la generosidad de los compañeros trabajadores sociales que se desempeñan en el campo de la discapacidad y se prestaron a dialogar conmigo, pusieron en juego sus certezas, sus miedos, sus inquietudes. Sin ellos, esta investigación no hubiera sido posible.

Agradezco a los compañeros del equipo de investigación, en el marco del proyecto Promocional de Investigación y Desarrollo sobre identidades colectivas que tuve el honor de dirigir junto a Alejandra Wagner. Con ellos, aprendí a pensar entre varios, caóticamente (en algunas ocasiones), pero siempre con la certeza del respeto mutuo. 
También a los integrantes del equipo de Voluntariado: Lelio Sánchez, Emilio Sáenz, Agustina Favero Avico, Pablo Rodríguez, Mariano Ferrer, Vanesa Wesner, Viviana Atencio y todos los que han pasado un rato por allí; con quienes experimenté que es posible producir prácticas sociales diferentes, des acartonándose y poniendo el cuerpo en acción como estrategia de aprendizaje.

Destaco especialmente a los compañeros de la cátedra en la que trabajo hace 18 años - Antropología Social II - Claudia Tello, Adelaida Colángelo, Ivone Amilibia, Eugenia Martins. Silvana Sciortino, Pablo Rodríguez, Germán Rómoli y todos los que han transitado como ayudantes alumnos, ayudantes graduados y/o adscriptos. Estos compañeros han sido fundamentales en la ratificación del compromiso con la formación continua y la investigación, como manera de mejorar nuestras prácticas docentes, que al fin de cuentas es la razón de ser de la producción de esta tesis.

También a las colegas del equipo que dirigen la Dras. Rozas Pagaza, Margarita y Dra. Mariana Gabrinetti: Dra. Marcela Velurtas, Mgter. Marcela Oyhandy, Lic. Agustina Favero Avico, Lic. Verónica Campagna, Lic. Mariana Calvo y Lic. Susan López quienes fueron primordiales para ordenar las inquietudes intelectuales en el tema.

A los compañeros del servicio social en el que ejerzo la profesión, con quienes corporizamos las paradojas de la desigualdad y a quienes me une una apuesta colectiva que nos sostiene en una organización que se convierte en hostil con quienes tomamos la palabra.

Reconozco enormemente a los profesionales que integran la RedGeTS con quienes colectivamente venimos generando reflexiones en torno a las heterogeneidades del curso de vida, destacando especialmente los aportes intelectuales y personales del Profesor Jorge Paola. Especialmente señalo a los 
compañeros, colegas y amigos Analía Criado, Cecilia Molina, Verónica Cimatti, Nair Tordó y Graciano Braganza, quienes han acompañado el proceso reflexivo en diferentes momentos.

También quiero destacar a los estudiantes de la carrera que transitaron los Seminarios de Discapacidad, desarrollados desde 2004 hasta la actualidad. Estos espacios fueron creados y recreados en diferentes momentos, desde una mirada certera en torno a que la discapacidad es un concepto y que la intervención se torna en un espacio privilegiado desde dónde generar rupturas epistemológicas. Señalo especialmente a Laura Otero Zúcaro y Emilio Saénz quienes en este verano 2016 me acompañaron en la propuesta, generaron apuestas de desafío intelectual, propuestas serias, creativas, y novedosas.

Y un agradecimiento central para el Dr. Alfredo Carballeda, quien siempre alentó mi camino reflexivo, me invitó a profundizar los desafíos y estimuló un tránsito por la literatura para encontrar palabras a ciertos procesos que paralizaban análisis. Agradezco especialmente la apoyatura para producir sentidos desde la ratificación identitaria como trabajadora social.

Asimismo reconozco a la Dra. Carolina Ferrante, quien me contuvo frente al desgano, invitándome a pensar relacionalmente, desde la complicidad, el entusiasmo y en búsquedas sostenidas de argumentos teóricos.

Agradezco a todo el equipo del doctorado, que han acompañado el proceso de formación y facilitado muchas acciones.

Por último, comparto el interrogante ¿Para quién hago esta tesis? El mismo, surgió frente a cada intento de abandonarla para siempre. Y en ese instante aparecía una canción que marcó mi infancia, y creo que responde un poco: 
Yo canto para la gente

porque también soy uno de ellos.

Ellos escriben las cosas

y yo les pongo melodía y verso.

Si cuando gritan vienen los otros

y entonces callan.

Si sólo puedo ser más honesto que mi guitarra

Esta tesis ha sido escrita para aportar a las discusiones, para ratificar pertenencias a un colectivo profesional dispuesto a disputar en el campo de la discapacidad.

Paula Mara Danel 


\section{Contenido}

RESUMEN

SUMMARY

AGRADECIMIENTOS

INTRODUCCIÓN 15

Presentación del objeto de investigación 16

- Recuperando la traza de objetivos de la investigación

¿Porqué un campo, y qué incluimos en el mismo? 22

Aporte metodológico: ¿Auto - socio análisis?

Características metodológicas de la investigación 27

- Los interlocutores

Hacia el análisis e interpretación de las narrativas

CAPÍTULO I - CAMPO DE LA DISCAPACIDAD EN ARGENTINA 48

1. - Historicidad de la intervención estatal en materia de discapacidad.

1.1 ¿Constitución de mirada nacional sobre la discapacidad?

1.2 ¿Idearios de justicia social?

1.3 ¿Avances normativos en contextos dictatoriales?

1.4 El retorno a la democracia y la invisibilización

1.5 El neoliberalismo y sus contradicciones

1.6 Idearios de inclusión social ¿hegemónicos? 
2. - Configuración del campo: preguntas y respuestas desde la intervención

CAPÍtULO II DESIGUALDADES, PROTECCIONES E INTERVENCIONES

1. Cuestión social, estado y matrices teóricas del trabajo social 111

2. Protección social: paradojas entre el mercado y la ciudadanía 122

3. Las profesiones que se ocupan de "los otros"

4. La singularidad de la intervención en discapacidad

CAPÍTULO IIII LA INTERVENCIÓN ENLAZADA A TEMPORALIDADES

1. - Las personas con discapacidad, sujeciones y autonomías

2. - Temporalidades presentes en la configuración de la intervención en discapacidad

CAPÍTULO IV ESCENARIOS DE LA INTERVENCIÓN Y SU DIMENSIÓN CORPORAL

1.- Condiciones y medio ambiente de trabajo

2. - La voz de trabajadores sociales en torno a la discapacidad en situación interventiva

3. - Los cuerpos en escena, de la conmoción a las disputas de sentido

CONCLUSIONES 
Interlocutores de la investigación

Presentación de datos de interlocutores

269

- Distribución por tipo de empleador estatal

270

- Distribución por género

271 
La presente Tesis ha sido escrita utilizando el masculino como genérico a fin de evitar la sobrecarga gráfica que implicaría utilizar el femenino y el masculino en cada nominación.

Le solicitamos al lector, que comprenda esto como una simplificación gráfica ya que promovemos la igualdad de género en todas sus manifestaciones.

La autora 
Una vez oí decir a una famosa escritora afroamericana que desde niña, se había sentido extraña en su familia y en su pueblo, agregó que eso experimentan casi todos los escritores, aunque no se muevan nunca de su ciudad natal. Es condición inherente a este trabajo, aseguró; sin el desasosiego de sentirse diferente no habría necesidad de escribir. La escritura, al fin y al cabo, es un intento de comprender las circunstancias propias y aclarar la confusión de la existencia, inquietudes que no atormentan a la gente normal, sólo a los inconformistas crónicos, muchos de los cuales terminan convertidos en escritores después de haber fracasado en otros of icios. Esta teoría me quitó un peso de encima: no soy un monstruo, hay otros como yo. (Isabel

Allende, 2012:16) 


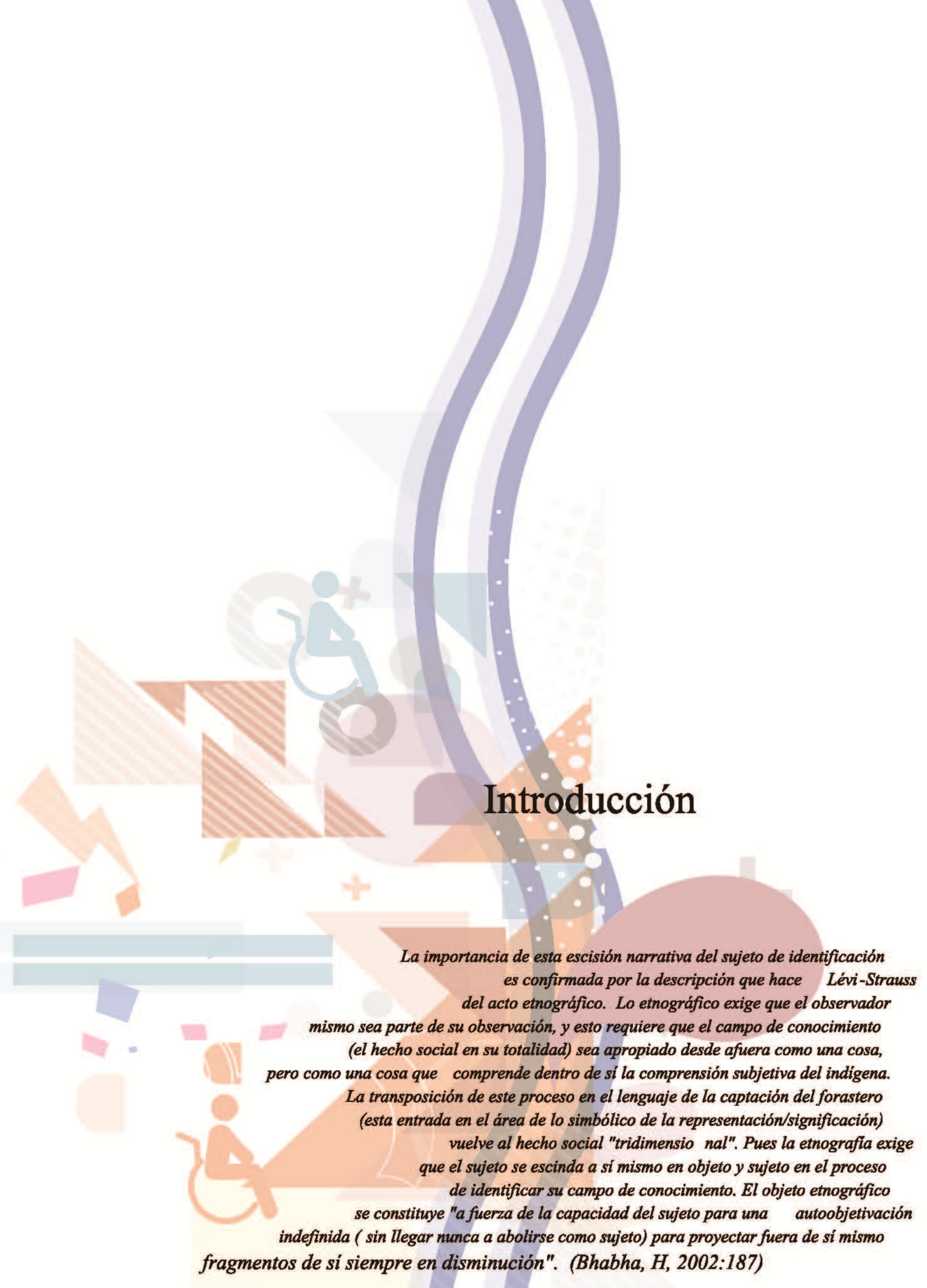




\section{Presentación del objeto de investigación}

El puntapié inicial del proceso de elaboración de esta investigación estuvo centrado en responder a una serie de interrogantes que se constituyeron en estimulantes para encarar este proceso complejo y sinuoso de producción académica: Me preguntaba sobre cuál es / era la mirada que prima/primaba en relación a la discapacidad. Veníamos ${ }^{1}$ identificando un discurso apegado a lo expresado en Convención de Derechos de las Personas con Discapacidad (ONU, 2007), pero al mismo tiempo se percibían ciertas inquietudes / incomodidades en el uso de los mismos. Algo así como una convivencia de miradas / narrativas sobre la discapacidad que transitaba desde la idea de situación de discapacidad como sinónimo de gama de derechos, así como la discapacidad en tanto experiencia trágica, no deseada, que conlleva una narrativa floreada de adjetivos revitalizantes que intentan suavizar esta tragedia. A esto se suman, la idea de discapacidad como asunto privado / familiar en el que la contención frente al padecimiento se instituye en un eje central, y paralelamente aparece la idea de discapacidad como opresión social consecuencia de la hegemonía de un cuerpo normal. (Ferrante, 2010; Ferreira y Ferrante, 2009; Conrad, 1992) En esas confluencias / disputas / entretejidos decidimos iniciar una exploración que nos permita ahondar sobre los sentidos asociados a la discapacidad que se encontraban presentes en las narrativas de los trabajadores sociales. ¿Cómo operaban esos sentidos en los procesos interventivos?

\footnotetext{
${ }^{1}$ A lo largo de la exposición referiré en primer persona del plural (nosotros) aunque las reflexiones sean producto y responsabilidad de la investigadora. La decisión de escribir en primera persona del plural, es un reconocimiento a los valiosos aportes de los colegas trabajadores sociales a los que entrevisté, de las compañeras del equipo de investigación dirigido por las Dras. Rozas Pagaza y Gabrinetti, de las /los integrantes de los proyectos de extensión y voluntariado que desarrollamos en los últimos 5 años y de los compañeros del equipo de investigación sobre identidades colectivas que tengo el privilegio de dirigir junto a la Mgter. Alejandra Wagner.
} 
En esa línea, entendimos oportuno avanzar hacia la recuperación de las trayectorias profesionales de los trabajadores sociales en el campo en cuestión. Identificamos un doble registro, uno asociado a los ámbitos académicos y políticos en los que las discusiones en relación a los DDHH estaban más vigentes pero sin establecer un vínculo, ni un diálogo con quienes sostienen las intervenciones (todos los días) en las organizaciones. Esto nos sugería cierta comodidad / ingenuidad de quienes protagonizan/ mos los espacios académicos. $\mathrm{Si}$ no se ponen en tensión ciertos saberes con las experiencias de implementación de políticas sociales es más sencillo construir discursos de verdad.

Por otra parte, nos interesaba conocer el registro de las intervenciones con la finalidad de dar cuenta de ciertas proximidades, continuidades, rupturas en torno a la producción de sentidos sobre discapacidad. Poner en valor la intervención, como espacio de producción de discursos, de realidades, de accesibilidades. En tal sentido, señalamos que la idea que sustenta la noción de registro de las intervenciones es la de visibilidad de las prácticas sociales, identificación de los modos en que se desarrollan las intervenciones, las texturas que producen y las narrativas que se enuncian.

Una de las hipótesis que aparecía recurrentemente en nuestras argumentaciones en el proceso de trabajo de campo era que muchos colegas no participaron de las discusiones sobre la relación entre discapacidad y autonomía. Esto implicaría cierto proceso que engloba la discapacidad a algo vinculado a una dependencia absoluta y las intervenciones se tiñerían de esa mirada. Una cuestión que fue necesario desarticular y analizar era si esta hipótesis no era más que un pre concepto que subyacía al construir una mirada sobre los discursos válidos. ¿Tal vez mi doble inscripción (académica y trabajadora social en ejercicio de la profesión) actuaba como un impedimento para valorar los saberes que se producen en los procesos de intervención? ¿La doble inscripción 
generaba una valorización excesiva de los saberes producidos en el espacio académico?

Para lograr esa desarticulación / deconstrucción fue imperioso explorar cómo se estaban dando las intervenciones de los trabajadores sociales en discapacidad. Constatamos que no se han desarrollado estudios en el tema desde el trabajo social en nuestra región. Los antecedentes relevados se concentran en España, fundamentalmente del Imserso (instituto de mayores y servicios sociales) y las Universidades de las distintas regiones españolas (Muyor Rodríguez, 2012; Verdugo Alonso, 2010). En los estudios españoles, la preocupación estaba centrada en los interrogantes que surgen de la dimensión herramental de la profesión, en los modelos vigentes. También encontramos antecedentes de producciones desde el modelo social de la discapacidad en: Mercer y Shakespeare, 1997; Barton, 1996/1998; Bradley, 1995; Corker, 1998; Davis, 1997; Imrie, 1997; Marks, 1997a, 1999; Moore, Beazley y Maelzer, 1998; Oliver, 1990, 1992, 1999. Los estudios desde el modelo social anglosajón encontramos una fuerte interpelación a los modos en que la sociología venía abordando al tema de la discapacidad, y proponen formas alternativas de definir el tema y desafiar las formas de discriminación vigentes. Oliver (1989) y Barton (1998) proponen que la discapacidad es una categoría social y política. En su clásico libro en habla hispana ${ }^{2}$, que influyó fuertemente a los investigadores y activistas del campo, instalaron una forma de relación entre los aportes del materialismo histórico y la discapacidad.

Del trabajo social argentino los exponentes teóricos más destacados del campo vienen siendo Enriqueta Blasco (2002, 2008), Amelia Dell Anno (2004), Indiana Vallejos, (2004), Mauricio Mareño (2010, 2015), Alfonsina Angelino (2009) quienes proponen una mirada social de la discapacidad, pero no surge

\footnotetext{
${ }^{2}$ El libro es Discapacidad y Sociedad compilado por Len Barton, editado en España por Morata en 1998
} 
una inquietud intelectual por la intervención profesional en el campo. $\mathrm{O}$ al menos, no en los términos en que la tesis deseaba abordar.

Los aportes increyentes del trabajo social en el campo de la discapacidad en nuestro país denotan un proceso de interés consolidado, sumado a un diálogo con otras disciplinas de las ciencias sociales.

Las producciones del modelo social se han incrementado en el último período, siendo sus principales exponentes profesionales de disciplinas médica, derecho, sociología, terapia ocupacional, pedagogía, etc.

Si por el lado de la producción escrita no encontraba respuestas, surgió la necesidad de acercarnos a las trayectorias, a las narrativas ${ }^{3}$, a los decires de los/as trabajadores/as sociales. En el primer momento las entrevistas las hicimos con quienes denominamos "pioneras" en tanto fueron quienes protagonizaron la configuración del espacio socio ocupacional del trabajo social en el campo esto es retomado en los capítulos de la tesis). Luego, las entrevistas las realizamos a quienes están transitando actualmente el espacio social de la discapacidad desde la intervención (algunas de ellas desde hace 25 años a la actualidad).

En ese proceso, emergió como interrogante ¿cuáles son las condiciones de la intervención? ¿Qué configuraciones materiales se dan en los espacios laborales? ¿Qué cuestiones “están siendo” en discapacidad? ¿Se visualizan cambios en esas configuraciones? ¿Estamos en momentos de transformaciones ${ }^{4}$ ? ¿En qué condiciones ejercemos la profesión en el campo de la discapacidad, y fundamentalmente qué aportes ha venido haciendo el trabajo social?

\footnotetext{
3 Entendiendo que la narrativa es más que una característica estructural del texto. Esta intrínsecamente incorporada al accionar humano (Gudmundsdottir, 1998)

${ }^{4}$ Esto se desarrollará en el capítulo I, pero mencionamos las transformaciones vinculadas a los cambios normativo - jurídicos que se han dado en los últimos 10 años. (Enfoque de derechos?)
} 
Los invitamos a transitar este texto, que producto de varias discusiones viene siendo lo que generamos colectivamente en momentos de cierres provisorios.

- $\quad$ Recuperando la traza de objetivos de la investigación

La investigación buscó indagar los nudos críticos que se generan en los procesos de intervención profesional de los Trabajadores Sociales (Cazzaniga, 2007) en el campo de la discapacidad. Ambos tópicos, intervención y discapacidad, se tornaron en tematizaciones relevantes para la tesis, y podríamos proponer que lo es para el colectivo de trabajadores sociales.

Como mencionamos en párrafos precedentes, el problema que identificamos en la interrelación de ambos temas es la carencia de reflexiones que en forma sistemática den luz a un espacio socio ocupacional de larga data.

En tal sentido, buscamos interrogar sobre las características que revisten los procesos de intervención en este campo particular. ¿Podríamos delinear modelos de intervención? Lo que encontramos fueron las directrices que conforman el campo problemático en discapacidad, los nudos críticos, y delineamos las matrices teóricas que le dan sustento.

La investigación desarrollada es de tipo cualitativa, y recupera las voces de quienes han protagonizado el aporte de nuestra disciplina al campo de la discapacidad. A los fines de adquirir mayor profundidad analítica, y ser fieles al movimiento que han tenido tanto el campo de la discapacidad como el Trabajo Social, recuperamos las rupturas y continuidades que permitan visualizar las modificaciones históricas y periodizar las mismas a partir del relato / narrativa de quienes protagonizaron dichos procesos en tensión con la información histórica -política- económica relevada. En tal sentido, esta recuperación se 
realizó en clave de trayectoria lo que habilitó un desempeño analítico de las mismas.

Análisis histórico y contemporáneo se conjugaron en una estrategia teórico - metodológica que incluyó revisión bibliográfica, entrevistas en profundidad, focus group, observación participante $\mathrm{y}$ análisis estadístico de inserción profesional y demográfica de discapacidad.

Con lo mencionado precedentemente, trazamos como Objetivo General “caracterizar y analizar los procesos de intervención profesional de los trabajadores sociales en el campo de la discapacidad". Para llegar al mismo, los Objetivos Específicos fueron:

- Caracterizar el campo de la discapacidad: análisis histórico y contemporáneo.

- Conocer las condiciones actuales de la intervención profesional en el campo de la discapacidad

- Dar cuenta en forma crítica de los modelos imperantes de la intervención profesional en el campo de la discapacidad.

- Comprender las dinámicas que adquieren los procesos de intervención.

Los objetivos fueron cumplidos en algún término, y otros no lograron ser respondidos en tanto que del análisis del trabajo de campo no surgieron con claridad "modelos de intervención". Esto no ha sido ponderado como negativo, en tanto incumplimiento de objetivos sino que ha sido un hallazgo en sí mismo. La intervención se convierte en intervenciones y produce sentidos diferenciales con fuerte arraigo reivindicativo en todas sus expresiones. 


\section{¿Porqué un campo, y qué incluimos en el mismo?}

Una de las primeras cuestiones que se fueron delineando en el proceso de indagación, fue la de definir cuál era el espacio social particular que se instituía como campo de intervención. En tal sentido, analizando de manera relacional la dinámica del campo profesional se vincularon las condiciones de trabajo de los profesionales de trabajo social singularizadas en la configuración de la discapacidad como configuración cultural. Por condiciones de intervención hacemos referencia a la materialidad sobre la cual se generan abordajes así como a las condiciones que generan el interés por desarrollar una trayectoria profesional.

"Los grandes dilemas que han tensionado la intervención profesional del trabajo social a lo largo de su historia como profesión se relacionan a manera de hipótesis, con su origen pragmático que fue estructurando un saber que luego se fue racionalizando en la sociedad moderna. El origen del campo fue tratado de manera muy rigurosa por autores como Marilda Iamamoto (2008). Este proceso de racionalización generó un debate basado en un conjunto de dicotomías entre: teoría/práctica, investigación/intervención, academial ejercicio profesional. Las respuestas a este conjunto de debates, a nuestro juicio, no han sido asumidas por el conjunto de profesionales. " (Rozas Pagaza y equipo: 2012:1)

Los debates disciplinares han generado denodados esfuerzos por comprender, interpretar y explicar las dinámicas sociales que se despliegan en 
los procesos de intervención. La categoría de intervención entendida como campo problemático ha resultado ordenador al momento de construir marcadores, coordenadas que hacían posible la configuración de un espacio / tiempo particular de la intervención del trabajo social en discapacidad.

Bourdieu (1990) define al campo relacionalmente centrando su análisis en la estructura de relaciones objetivas que establece las formas que pueden tomar las interacciones y las representaciones que los agentes tienen de su estructura y su posición en la misma, de sus posibilidades y sus prácticas. El campo asume también una existencia temporal lo que implica introducir la dimensión histórica en el modo de pensamiento propuesto por el autor. Esta temporalidad se convirtió en uno de los ejes analíticos destacables del proceso investigativo, toda vez que se impuso como preocupación teórica a lo largo de todo el proceso.

Desde esta perspectiva, apelar a la relevancia de las posiciones nos permitió comprender algunas miradas prescriptivas de la práctica profesional, e incluir la complejidad de las miradas en pugna que son parte de disputas que se expresan / desarrollan en el campo.

La perspectiva que Bourdieu propone, aporta a la lectura más dinámica en tanto permite entender que la intervención tiene una lógica que es necesario identificar para argumentar la posición que se ocupa como profesionales de la cuestión social.

$\mathrm{Su}$ lectura concatena diversos aspectos $\mathrm{y} / \mathrm{o}$ dimensiones que hacen particular la cuestión social en cada momento histórico y, en consecuencia afectan el campo profesional.

El autor aporta la posibilidad de vincular el espacio profesional con el capital simbólico, permitiendo situar el análisis en el conocimiento y 
experiencia adquirida de los agentes profesionales. . Capital simbólico enlazado a la categoría de trayectoria profesional nos permitió visualizar los mecanismos de legitimación, las formas de valoración del prestigio profesional, los mecanismos de construcción de autoridad y poder en el dominio del conocimiento disciplinar. Las reglas que supone el funcionamiento del campo, hacen posible la construcción de hegemonías en el mismo.

Asimismo, se analizaron las formas de construcción del interés en el campo del trabajo social, concepto relacionado con el de Capital simbólico, posición e illusio.

Nuestra preocupación ha sido rescatar la intervención como prácticas socialmente construidas, en definitiva entender la práctica profesional como estrategia en la que se juega, se disputa, se posiciona y despliegan fundamentos teóricos e instrumentación del hacer profesional. (Rozas Pagaza y equipo, 2012) en nuestro caso, situada en el campo de la discapacidad.

Iniciamos el trabajo de campo abordando cuestiones inherentes a las condiciones en las que se despliega la intervención profesional de los trabajadores sociales, comprendiendo las dinámicas internas y externas que se despliegan y operan en los procesos de intervención de los trabajadores sociales en el campo de la discapacidad. El recorte está vinculado a las políticas de protección social, políticas de derecho a ingresos, seguridad social, salud, empleo.

Es necesario historizar desde cuando empezó a tener presencia el trabajo social, o cuando empezó a tener una voz en el campo. Para comprender la presencia de la disciplina, y visualizar algunos hitos históricos. Es necesario señalar que en la actualidad, el Trabajo social está considerado dentro del equipo básico (Sistema de prestaciones básicas, certificado de discapacidad, etc.) Por lo 
que la relevancia para la disciplina se produce entre otros aspectos, a partir de la generación de espacios socio - ocupacionales. Entonces, ¿Podemos hablar de un campo de la discapacidad específico o está asociado al de la seguridad social, salud, educación? En el primer capítulo avanzamos en esta línea de análisis.

\section{Aporte metodológico: ¿Auto - socio análisis?}

Hemos puesto en evidencia la falta de estudios previos sobre este tema en particular, pero surgió la inquietud de incluir interrogantes que surgieron necesarios en términos personales. ¿Por qué el tema discapacidad? Y el momento en que formulaba la pregunta accedí ${ }^{5}$ a lecturas de los que vienen postulando una "antropología de y desde los cuerpos" (Citro y equipo). Allí entendí, que me pasó por el cuerpo la pregunta y obviamente la respuesta también estaba siendo transitada en y por mí.

"Estas impatias y estas antipatias, que dependen de la persona tanto como de sus obras, constituyen uno de los principios de múltiples elecciones intelectuales que permanecen absolutamente oscuras y son a menudo vividas como inexplicables, porque atañen a los dos habitus implicados" (Bourdieu, 2006:40)

Y allí inicié un recorrido que me permitió evocar desde cuándo la discapacidad había estado presente en mí. El cálido recuerdo de "mi tío" con secuela de polio, un temple de acero y una soltería que defendía a regañadientes, me hizo ver que la función paterna había sido ejercida ante mí por una persona

\footnotetext{
${ }^{5}$ Por las características del ejercicio de auto socio análisis, en este apartado escribiré en primera persona del singular.
} 
con discapacidad física, que usaba muletas y una prótesis que ocultaba fervientemente. Claramente, mi curiosidad infantil hacía que me esforzara por interrumpir su ritual de colocación y ver, siempre quise mirar aquello que era precoz para mi, de acuerdo al discurso adulto.

Pero tuve que ahondarme aún más, y escuchar un relato adulto que planteaba que lo mejor había sido que mi papá no sobreviviera al accidente, porque "Habría quedado mal". Y ese discurso punzante, producido desde la certeza me enojaba bastante. No podía poner en palabras eso que sentía con el cuerpo, pero intuyo que se trataba de un enojo frente a la hegemonía de un cuerpo normal. ¿Qué existencia corporal podía ser menos digna que vivir?

Y finalmente, la maternidad trajo consigo una experiencia compleja de decisiones sobre el cuerpo de otro / niño. La ausencia de visión en un ojo fue transitado con dolor, pero al mismo tiempo en la certeza de que nada podía ser peor que negar el derecho a la vida. La tenacidad del niño, mi niño, junto al mutuo amor profundo nos permitió descubrir que sólo es un funcionamiento corporal distinto. Cuando hacía apenas poco tiempo que habíamos transitado la experiencia, y rearmándonos, nos decidimos a acompañar a otros papás que tuvieran la misma experiencia. Eso fue liberador, y claramente nos permitió revisar aquello doloroso y convertirlo en lo que es en la actualidad, una experiencia en nuestro recorrido familiar.

Mi trayectoria vincular siempre tuvo un diálogo, una convivencia con la discapacidad. Seguramente no es azarosa la elección del tema de investigación, ni de intervención. Hago mías las palabras de Ascheri y Pugliese:

\footnotetext{
"la experiencia cotidiano - corporal que establecemos con el mundo como un "hay previo" - a toda conciencia
} 
reflexiva - que constituye el suelo a partir del cual se edifica el conocimiento científico. (2011:129)

Los procesos analíticos, sobre todo colectivos que he experimentado, me han permitido desandar enojos y convertirlos en compromisos éticos.

Percepciones, sensaciones y emociones constituyen un trípode que permite entender dónde se fundan las sensibilidades. Los agentes sociales conocen el mundo a través de sus cuerpos. Por esta vía un conjunto de impresiones impactan en las formas de "intercambio" con el contexto socio-ambiental” (Scribano, 2007:145/6)

\section{Características metodológicas de la investigación}

El diseño del trabajo de campo contempló una estrategia cualitativa, que trazó pasos de acercamiento a la experiencia de aproximación / distanciamiento al mundo de significado de los protagonistas del campo. Las primeras entrevistas fueron realizadas en el año 2012 y la última en febrero 2015. Estos tres años de trabajo de campo, interrumpidos, revisados, intensamente transitados han permitido varias apuestas teóricas, epistemológicas, éticas, políticas y corporales.

Entendemos por campo, en la investigación cualitativa como el recorte que se refiere al alcance, en términos empíricos, del recorte teórico correspondiente al objeto de la investigación (Minayo, 2009) 
En relación al proceso de investigación señalaremos a continuación las prácticas que hemos sostenido en estos tres años, es decir las apuestas estratégicas realizadas.

Subrayo que se realizaron 26 entrevistas semi - estructuradas, focalizadas y un grupo focal a integrantes de un Servicio Social de una institución especializada en rehabilitación. De las 26 entrevistas, 24 fueron a trabajadores sociales, egresados de la UNLP, la UBA. UnLu, UN de Córdoba, y del instituto terciario perteneciente a Cáritas de La Plata. Dos entrevistas han sido realizadas en tanto "entrevistas control" a los fines de sostener un registro paralelo y ágil de los temas que iban saliendo en el desarrollo de las entrevistas. En relación al grupo focal, destacamos que el mismo permitió la generación de puntos de confluencia de los siete colegas que participaron sobre el tema y de contrapuntos en torno a la mirada sobre procesos comunes. Asimismo, al realizar el grupo con colegas que portaban trayectorias diversas permitió interpretar las posiciones generacionales en torno a las tareas, los sujetos y las apuestas colectivas.

En articulación sostenida con el equipo de investigación que integré ${ }^{6}$ se diseñó una Guía de pautas para entrevistas a trabajadores sociales que sería utilizado por las investigadoras para el encuentro con los colegas que se desempeñan en los campos jurídicos, salud comunitaria y discapacidad.

Una vez consensuado un instrumento para el equipo, fue necesario tomar decisiones teóricas en torno a delimitar el objetivo del instrumento en diálogo con el objetivo de la investigación encarada, es decir "caracterizar y analizar los procesos de intervención profesional de los trabajadores sociales en el campo de

\footnotetext{
${ }^{6}$ El proyecto al que se hace referencia es el T061: "Las condiciones actuales de la intervención profesional en el Trabajo Social: La relación salarial y sus representaciones. Estudio de tres campos de intervención: Jurídico, discapacidad y de salud comunitaria". Dirigido por las Dras. Rozas Pagaza, M y Gabrinetti M-
} 
la discapacidad". El diseño de investigación ha sido exploratorio - descriptivo (el objeto de investigación ha sido poco explorado en nuestra región) porque resultó necesario identificar cómo se trama en la actualidad el campo de la discapacidad. En tal sentido, el trabajo de re - elaboración del instrumento de entrevistas ha sido un proceso que tuvo varios momentos. La amplitud del trabajo de campo, hizo posible revisar los ejes, ponderarlos, ampliarlos en función de la información que iba recuperándose.

Lo que hace que un trabajo de interacción (...) sea un instrumento privilegiado de recolección de información para las personas es la posibilidad que tiene el habla de ser reveladora de condiciones de vida, de la expresión del sistema de valores y creencias; y al mismo tiempo, de tener la magia de transmitir, por medio de un portavoz, lo que piensa el grupo dentro de las mismas condiciones históricas, socio - económicas y culturales que el interlocutor (Souza Minayo, 2012:69)

El tipo de entrevista elegida ha sido en profundidad, focalizando en la trayectoria profesional en el campo específico. Los ejes hicieron de soporte para avanzar en la idea misma de trayectoria. En tal sentido tomamos los aportes de Pierre Bourdieu quien plantea que la trayectoria nos permite evocar las posiciones sucesivamente ocupadas por un mismo agente (individual o colectivo) en un espacio social particular que es móvil y expuesto a transformaciones constantes (Bourdieu, 1977) En tal sentido la búsqueda teórica ha sido que en el encuentro con los colegas - y en las entrevistas de control - se genere una escucha/mirada atenta que permita identificar momentos claves, nudos críticos y otros aspectos que transciendan las percepciones individuales y nos permitan dar cuenta de la trayectoria que el trabajo social ha venido teniendo en el campo que nos ocupa. 
"En el análisis de las trayectorias es fundamental prestar especial atención a los períodos de cambio o inflexión (históricos o personales), por su repercusión en la continuidad o cambios de las trayectorias." (Lera, Genolet, Rocha, Schoenfeld, Guerriera y Bolcatto, 2007:38)

En ese sentido, el diseño del trabajo empírico contempló una serie de tópicos que actuaron como red metodológica. Compartimos los ejes que observamos, y las referencias conceptuales que se implicaron en esta producción:

- Condiciones de la intervención: En este eje se produjo un complejo conceptual que se reformulaba en términos de escenario, en el que se tensaban las Condiciones y medio ambiente de trabajo (CYMAT), la Organización institucional. (Dimensión de las CYMAT) y la Construcción de pertenencia a la organización (adscripción identitaria).

Por ello, en este primer bloque ${ }^{7}$ de condiciones de la intervención nos interesaba recuperar las trayectorias discursivas en relación al escenario singular en el que se despliegan las condiciones de trabajo. Desde el equipo de investigación se había puesto especial interés en las categorías "condiciones laborales" y “condiciones de trabajo": Las condiciones de trabajo ${ }^{8}$ serían miradas desde la concepción renovadora, por lo que pensamos al Trabajo desde la Dimensión económica, Dimensión social (colectivo de trabajo, en tanto cooperación articulada alrededor del proceso de trabajo) y Dimensión subjetiva. Estos ejes aparecieron con mucha fluidez en las entrevistas, las que fueron analizadas desde los análisis de la interdisciplinariedad como disputa por el

\footnotetext{
${ }^{7}$ Destaco en este punto el invalorable aporte que ha realizado al proceso metodológico la Dra. Mariana Gabrinetti, quien generosamente se dispuso a formarnos en este tema, a compartir sus saberes.

${ }^{8}$ Dentro de las CYMAT -desde la perspectiva en la que enmarco el trabajo-, se incluyen varias de las dimensiones que figuran en el listado inicial.
} 
poder, desde las implicancias personales con el tema y los reconocimientos laborales en torno a la relación laboral establecida.

Se buscó recuperar la mirada sobre los procesos de trabajo desplegados por los trabajadores sociales en el campo, dando cuenta de aquello que hace al oficio cotidiano. Este punto nos permitió recuperar los modos de gestión de la fuerza de trabajo (estabilidad o precariedad, estilos de gestión, etc.)

En relación a la Organización institucional, se indagó sobre las formas que adquiría la organización del trabajo, es decir vinculado a la división social y técnica del mismo (qué espacio se asignaba al trabajo social en la organización, a quién respondo demandas laborales, quién supervisa la tarea, etc.). En cuanto al contenido del trabajo: buscamos describir el puesto -tarea prescripta - tarea real/calificaciones/adecuación entre ambos términos. En este punto se abordó cuáles eran las tareas asignadas y cómo era ejecutado. Y en vinculación a la construcción de pertenencia a la organización (adscripción identitaria ) se recuperaron aquellos significados en torno a la Trama organizacional, cuales son los objetivos de la institución y cuáles son las tareas que se llevan a cabo para lograrlo - Reporte de la tarea realizada - Supervisión de la tarea - Lugar otorgado al profesional en la organización - Tarea esperada de la organización Organigrama institucional - Recursos humanos y materiales realmente disponibles en el lugar de trabajo. Estos ejes fueron fundamentales para pensar la categoría dominio sobre la tarea, ya que esto se enlazó a algunos de los puntos que aparecieron cómo hallazgos. Posiciones vinculadas a cambios generados en las estructuras organizacionales.

La intervención en tanto práctica social: En este eje se abordaron cuestiones en torno a los propósitos de la intervención (en términos genéricos), la singularidad de la misma en ese espacio organizacional (posible "distancia" entre el ideal y las condiciones concretas), la Construcción del interés 
(retomando la noción que trabajamos desde Bourdieu) - ¿Qué lo motiva a trabajar allí? ¿Y con estos sujetos? - La trayectoria profesional, la Relación con la temática y la dimensión simbólica

En relación al segundo bloque - de la intervención en tanto práctica social -, situamos que en relación a los Propósitos de la intervención se recuperaron las argumentaciones en torno a las razones de la convocatoria al trabajador social para la intervención, en este punto aparecieron varias cuestiones que hacen a la idea de matrices teóricas vigentes en la intervención. En relación a la Singularidad de la intervención en ese espacio organizacional recuperamos intensamente las "distancias" entre el ideal y las condiciones concretas de práctica profesional. En cuanto a la duración y configuración del tiempo de trabajo, pudimos recuperar las sustanciales diferencias entre los trabajadores del sector público, privado, de las ONG. Una cuestión relevante ha sido la vinculada a la construcción del interés (retomando la noción de illusio (Bourdieu, 1995). ¿Qué lo motiva a trabajar allí? ¿Y con estos sujetos? ¿Qué posición ocupa en el campo? ¿Qué visualiza que está disputando?

En ese contexto, recuperar la Trayectoria profesional, y la relación con la temática, permitió analizar lo que en el punto anterior de este texto trajimos en relación al concepto de trayectoria. Las trayectorias laborales forman parte de la vida de los sujetos, de modo que su abordaje permite comprender los pasajes de una posición a otra en un período de tiempo; así, afirma Godard (1996) que un individuo no es una sola historia sino que se constituye a partir de - al menos cuatro historias: la historia residencial, familiar, de formación e historia profesional.

Si bien las trayectorias laborales son individuales reconocemos que están afectadas por las condiciones materiales de su ejercicio, con la disposición de 
oportunidades, etc. Es en este sentido que entendemos a la trayectoria de trabajo no sólo como una categoría objetiva y mensurable, sino como una experiencia social que se construye en relación con la cultura, el mercado y la subjetividad de cada individuo y que forma parte del itinerario y trayectoria de vida de una persona en la que se entrelazan aspectos vinculados a la historicidad individual y social de los sujetos (Gabrinetti, 2006: 16).

Por último, la dimensión simbólica nos permitió capturar los atributos, las narrativas que sustentaban la propia intervención, la mirada construida sobre la práctica profesional. Asimismo, se avanzó en la recuperación de la "supuesta" mirada de los usuarios sobre la intervención del trabajador social. En este eje se produjeron cuestiones interesantísimas que son recuperadas en los capítulos $3 \mathrm{y}$ 4, y que tratan en relación a temporalidades, gestualidades y corporalidad.

- La discapacidad como temática: cómo se la cómo la concibe, cuáles con las principales demandas que llegan al servicio social, ¿Cómo se construye al usuario de la práctica?; qué particularidades tiene el tipo de práctica que se desarrollo. ¿qué y cómo? ¿La discapacidad ha variado? ¿En qué aspectos? ; ¿Discapacidad / discapacidades / discapacitados? ¿Sujetos en situación?

Este tercer bloque, nos habilitó a la recuperación de las narrativas sobre el concepto de discapacidad, avanzar sobre las formas en que es concebida desde la práctica interventiva, despojándonos de "manifestaciones políticamente correctas" y acercarnos a la complejidad, a las contradicciones, a las paradojas que supone el encuentro con otro. Asimismo, se pudieron recuperar las Principales demandas que llegan al servicio social, identificar cómo se construye al usuario de la práctica, las demandas. También se pudo escuchar las narrativas entorno a la discapacidad como estado, proceso ó invención. 
Ahora bien, estos ejes nos delinearon el acceso al campo, nos sostuvieron en los encuentros. Los mismos fueron espacios / tiempos de reflexividad y de diálogo. El encuentro con colegas ha sido un proceso de aprendizaje en sí mismo. Destacamos que la tesis no reflejará fielmente esta lógica de indagación, sino que traerá en la lógica expositiva una nueva trama que hará las veces de sustento narrativo de los hallazgos generados en el proceso investigativo.

Por otra parte, señalamos que simultáneamente a la realización del trabajo de campo, he participado en eventos académicos en los que presenté avances de la investigación y permitieron una reflexividad junto a especialistas.

También destaco la realización de dos Diplomaturas Superiores que realicé en Flacso - Chile ${ }^{9}$ y Flacso Argentina ${ }^{10}$ que actuaron como espacios actualización, constantes de debate y reflexión sobre el tema.

\section{- $\quad \underline{\text { Los interlocutores }}$}

Todo este recorrido es la que ha hecho posible la construcción de certezas e interrogantes sobre el tema que nos convoca. A continuación presentamos las características de los entrevistados, sus pertenencias organizacionales, años de graduadas e institución expedidora del título. En el Anexo I encontrarán un cuadro que sistematiza la información que compartimos en este apartado y sirve de guía para la referencia de las narrativas textuales que incluimos en los capítulos.

De las 27 entrevistas realizadas, recuperamos 29 espacios socio ocupacionales del campo de la discapacidad en los que los trabajadores sociales desempeñan su labor.

\footnotetext{
${ }^{9}$ Diploma Superior en Gerencia Social y Políticas de Discapacidad- Flacso Chile y Organización de estados americanos, desarrollada y aprobada entre los años 2011 y 2012.

${ }^{10}$ Diploma Superior en pedagogías de las Diferencias, Flacso Argentina- cursada y aprobada en los años 2014 y 2015.
} 

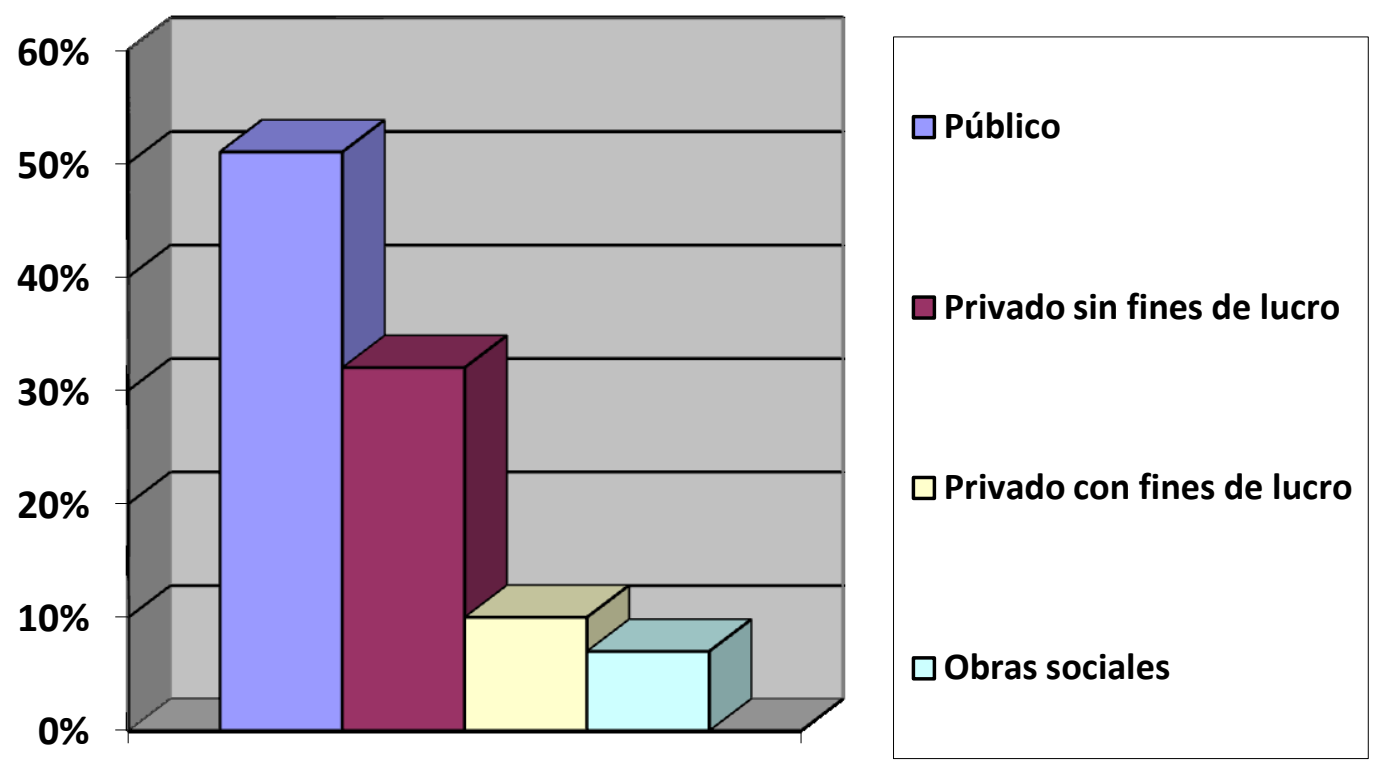

De la lectura del cuadro precedente se desprende la siguiente información: el $51 \%$ se desempeña en diferentes organismos del estado nacional, provincial y/o municipal, el $32 \%$ en el sector privado sin fin de lucro (asociaciones civiles, fundaciones, etc.), el $10 \%$ en instituciones privadas con fin de lucro (empresas) y el 7\% en obras sociales nacionales y/o provincial.

Del $51 \%$ que se desempeña en el estado, la distribución entre nación, provincia y municipio es la siguiente: 


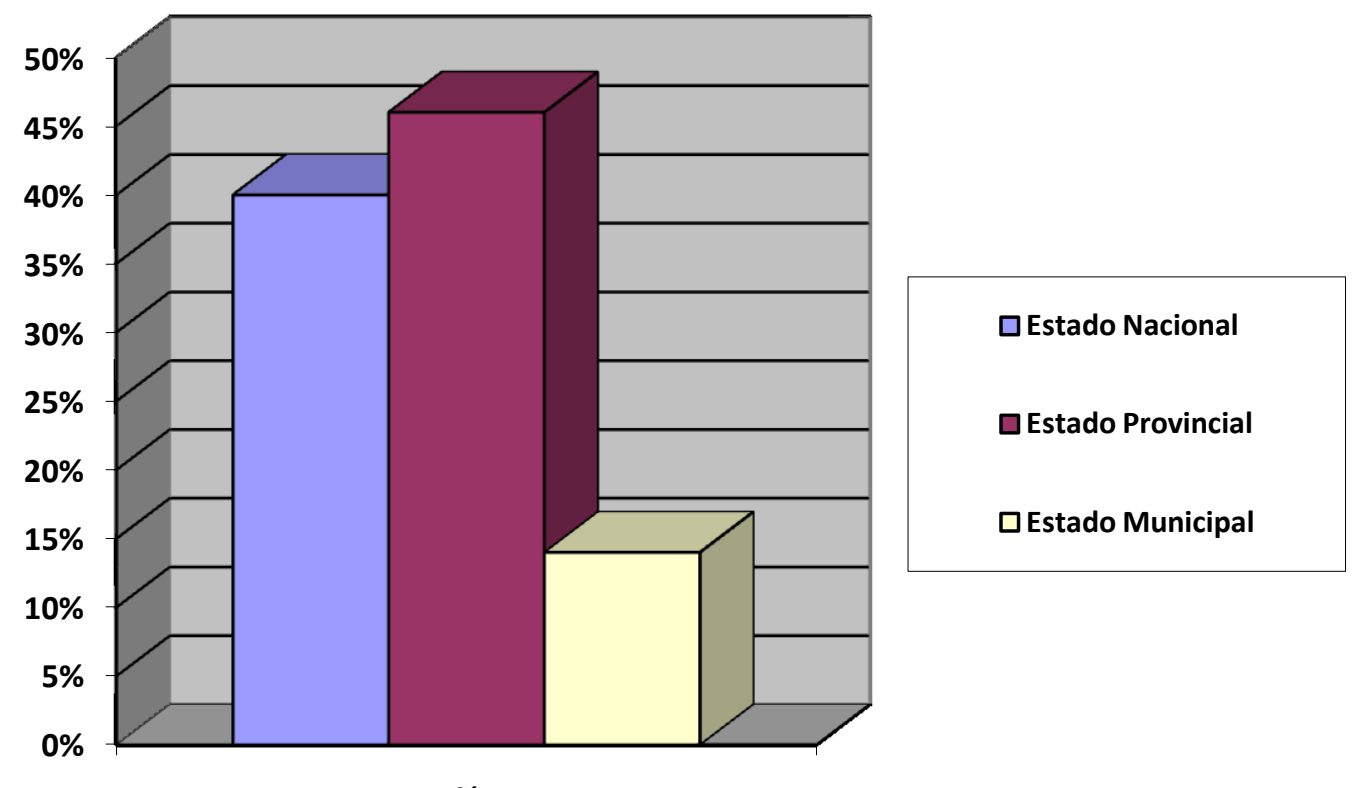

$\%$

El $40 \%$ de los entrevistados se desempeña en el estado nacional, el $46 \%$ en la Provincia de Buenos aires y el 14\% en los estados Municipales (La Plata y Ciudad Autónoma de Buenos Aires)

A los fines de la presentación de las características de las organizaciones desde las que los colegas entrevistados produjeron su mirada singular de la intervención en el campo, realizaremos un detalle de las mismas. Previamente incluimos la reflexión en torno a cómo el escenario de intervención opera cómo posibilitador de determinada mirada sobre el tema. En tal sentido, planteamos que la narrativa que compartieron los trabajadores sociales incluía los dos aspectos que Chatman (1978) le dota a las narrativas, es decir historia y discurso. Las evocaciones a las características centrales de la intervención vehiculizaban una mirada situada sobre el mundo social, y que recreaba desde 
su punto de vista cómo actor (Guber, 2002) la historia del espacio socio ocupacional. Siguiendo a Todorov (1966) planteamos que los modos narrativos afectan la forma en que el dicente nos expone, nos propone su punto de vista. Las narrativas producen realidad, la reflejan y nos invitan a comprender miradas situadas, en contextos interventivos (en tanto práctica social).

Cómo hemos planteado en párrafos precedentes los entrevistados presentaban trayectorias diferentes, por lo que presentaremos sus espacios laborales desde los que han construido su narrativa en torno a la relación entre intervención profesional y discapacidad.

De los colegas que se desempeñan en el estado provincial, ubicamos a una egresada en una universidad extranjera, que homologó / validó su título en nuestro país en la década del 90. La misma se desempeña en una institución que depende del área de Infancia del Ministerio de Desarrollo Social de la Provincia de Buenos Aires. Se trata de un instituto de menores especializado en el abordaje de jóvenes con discapacidad mental. Este tipo de Hogares han sido desarticulados con la "nueva Ley de infancia" - 13298 ${ }^{11}$-. Este hogar integraba los 17 institutos oficiales, recibiendo varones adolescentes con discapacidad. La institución está emplazada en localidad de la provincia de Buenos Aires con 654.324 habitantes.

También una colega, que si bien transita diferentes espacios socio ocupacionales, señala al hospital pediátrico público de la Provincia de Bs. As. de referencia a nivel provincial que concentra el desarrollo de prácticas de salud de calidad - como el espacio desde dónde narra.

\footnotetext{
11 Para conocer las particularidades de la ley mencionada sugiero su lectura en: http://www.gob.gba.gov.ar/legislacion/legislacion/l-13298.html y para analizar las paradojas que impone su implementación recomiendo la tesis de maestría de la Prof. Seoane Inés (2012) en: http://sedici.unlp.edu.ar/handle/10915/31538
} 
Otro de los trabajadores sociales, se desempeña en el Servicio Social de un Hospital Interzonal General de Agudos, Hospital público provincial, creado en 1980. Localizado en la capital de la provincia de Bs As con 654324 habitantes. No obstante, es de referencia inter zonal. La colega egresó a mediados de la década de los 90, de la entonces Escuela Superior de Trabajo Social de la UNLP.

Además entrevistamos a una colega que es Integrante de la Junta Certificadora de Discapacidad de Hospital Zonal de Agudos, de dependencia Provincial, sito en una localidad del interior de la provincia de Buenos Airesque cuenta con 88470 habitantes. La colega es egresada de Escuela Lodigiani (Caritas), década del 2000.

Otra de las interlocutoras del trabajo de campo ha sido una trabajadora social egresada en la década de los 90. Actualmente integraba la Junta Certificadora de Discapacidad, en Hospital Monovalente en Salud mental, localizado en la capital de la Provincia de Bs As. El Hospital es de referencia inter - zonal.

Uno de los trabajadoras sociales entrevistados se desempeña en el Consejo Provincial de Discapacidad el que ha sido creado por el Articulo 5to de la Ley 10.592 y su Decreto Reglamentario 1149/90. Organismo creado para asesorar al Poder Ejecutivo en el ejercicio de sus facultades privativas, con el objeto de promover e implementar una política integral sobre el tema en la Provincia. El Consejo tuvo momentos de actividad intensa, en el que generaron las directrices en la materia para todo el territorio. El mismo cuenta con 15.482.751 habitantes, de los que el $12 \%$ presenta limitación ó dificultad permanente. La colega egresó en la primera cohorte de la Licenciatura de la UNLP. 
Una de las últimas entrevistas que realicé, y que se instalan dentro de las más significativas, se trata de la realizada a un trabajador social que se desempeñó en las Áreas de Infancia y discapacidad del Ministerio de Desarrollo Social de la Provincia de Buenos Aires. Áreas que han modificado en estos 33 años desde el retorno a la democracia. Desde este Ministerio se generan las directrices en la materia para todo el territorio de la provincia, que cuenta con 15.482.751 habitantes, de los que el 12\% presenta limitación ó dificultad permanente. El colega egresó de la Escuela de salud Pública de la provincia de Buenos Aires, en la década de 1980.

El pluriempleo ha sido una característica de varios de los trabajadores sociales entrevistados, y la traslación de destacados profesionales del ámbito público provincial se intensificó en los últimos 10 años. En tal sentido, uno de los colegas se desempeñó en el Programa de Inclusión Laboral del Ministerio de Trabajo de la Provincia de Buenos Aires, espacio de generación de estrategias selectivas de acompañamiento al empleo, en el mismo las disputas más fuertes han estado en torno a generar respuestas a un tema complejo y sobre todo generar una definición del espacio profesional en explícita disputa con quienes portan la titulación de terapia ocupacional. Esta situación se tornó recurrente en otras entrevistas, aparecía cierta alianza con los profesionales de psicología y disputa con los terapistas ocupacionales. Esta línea sería interesante retomar en próximas investigaciones. El entrevistado egresó en la segunda parte de la década del 2000 en la UNLP.

Y por último del ámbito provincial entrevistamos a un docente en situación de discapacidad, que se desempeña en el área de Deportes de la provincia de Buenos Aires. Su ingreso laboral está asociado al cumplimiento del porcentaje establecido en la Ley 10592, generando estrategias de inclusión laboral en el estado provincia. La misma actuó como entrevista control. 
En relación a los entrevistados que se desempeñan en los estados municipales presentamos a uno que ejerce la profesión en un Hospital Psiquiátrico perteneciente a la red de salud pública del Gobierno de la Ciudad de Bs As. Es un hospital de emergencias psiquiátricas - hospital monovalente Cuenta con Sala de Internación de Hombres, Mujeres y Adolescentes. El Servicio de Guardia externa también posee unas camas de internación. Suma servicios de atención diurna. Los trabajadores sociales integran las guardias psiquiátricas interdisciplinarias. En particular el entrevistado egresó de la UBA en la década del 60, y se trata de una reconocida y prestigiosa profesional.

Señalamos a los colegas que se incluyeron en un grupo focal, los que eran egresados de la UBA entre la década del 60 y la del 2000. Todos integraban el servicio social de un Hospital especializado en rehabilitación perteneciente a la red de salud pública del Gobierno de la Ciudad de Bs As, el cual brinda atención integral especializada en rehabilitación a niños, adolescentes, adultos y mayores, a fin de aportar a los procesos de reintegración en mejores condiciones físicas - sociales - funcionales. Esta experiencia se tornó en fundante de varias de las preocupaciones, reflexiones sobre las condiciones de la intervención, sobre la producción de colectivizaciones, las disputas en torno a la producción de discursos de verdad sobre la discapacidad.

Y los colegas que se desempeñan laboralmente en el estado nacional identificamos a quienes lo hacen en áreas destinadas al abordaje de situaciones de discapacidad de Universidades nacionales. En las mismas evalúan los accesos a becas, y la búsqueda de apoyos suficientes y oportunos para generar inclusiones educativas. El colega es egresado en la primera mitad de la década del 2000. Otro de los entrevistados también trabaja en un área destinada al abordaje de situaciones de discapacidad en otra Universidad nacional y se encuentra entre los pluriempleados y egresó en la segunda mitad de la década del 2000. 
También entrevistamos a un trabajador Social que se desempeña en el ámbito legislativo, sumando aportes a la Comisión de Discapacidad, Salud y Educación de la cámara alta. Es un referente nacional del tema discapacidad, y egresó en la década del 80 en la UBA.

De los colegas que se desempeñan en las organizaciones privadas sin fines de lucro, presentamos a una (considerada dentro de las pioneras) egresada en la escuela de visitadoras de higiene de la Facultad de Ciencias Médicas de la UNLP, quien se desempeña en una organización no Gubernamental, que brinda servicios de escuela, hogar y centro de día. Su financiamiento está brindado por la obra social provincial y áreas de infancia de diversos gobiernos (nacional, municipales, provinciales). Su trayectoria data de 30 años, por lo que los cambios que ha tenido han sido varios y algunos controversiales. La Institución se emplaza en el interior de la Provincia de Buenos Aires, con 32.761 habitantes.

Una de las colegas- otra de las pioneras- egresó en la UBA en 1965, y se desempeña laboralmente en una institución dedicada a la asistencia integral de personas con discapacidad desde hace más de 75 años. Brinda en el país atención integral a más de 1500 personas con discapacidades de diferentes edades, quienes ingresaron por falta de recursos, en gran proporción, por ausencia de grupo familiar. Cuenta con 16 Hogares en todo el país. $\mathrm{Su}$ financiamiento está vinculado a las donaciones y fundamentalmente a la seguridad social - a través del Sistema Único de Prestaciones Básicas.

También entrevistamos a otra egresada de la Escuela de Salud Pública de la provincia de Bs As, que se desempeña en una Asociación Civil sin fines de lucro, que desarrolla tareas desde hace 55 años, prestando servicios educativos, laborales, centro de día y Hogar. La institución está emplazada en localidad de la provincia de Buenos Aires con 654.324 habitantes. 
Otra de las entrevistadas, egresada UNLP segunda mitad década del 2000) del grupo de las pluriempleadas- se desempeña también en un Centro de "Rehabilitación" (así se autodenomina), pero en verdad es un centro de día creado en 1991. Su organización está emplazada en la dinámica familiar de su creadora. Se auto denominan como "empresa familiar" pero formalmente son una asociación civil. Está emplazada en localidad indicada en párrafo precedente.

Uno de los colegas entrevistado egresó en la década del 90 en la UNLu, y se desempeña en una institución creada en 1991, Asociación que cuenta con prestigio regional. Desarrolla servicios de centro de Día, Hogar y taller protegido. La localidad del interior de la provincia de Buenos Aires, cuenta con 94333 habitantes.

Otro interlocutor, egreso en la década del 80 en la UBA, actualmente se desempeña en una entidad privada sin fin de lucro, destinada al deporte. La ciudad en la que trabaja tiene 2.890 .151 habitantes.

Asimismo entrevistamos a una trabajadora social egresada UNLP, década del 90, que se desempeña en un Centro de Día perteneciente a una Asociación sin fines de lucro creada en 1993. La misma ha recibido aportes del estado provincial para la adquisición de la vivienda, y actualmente se financia con los aportes de obra social provincial.

Otra de las egresadas en la segunda mitad de la década del 2000, se desempeña en un Centro Educativo terapéutico del interior de la Provincia de Buenos Aires, con 32103 habitantes. La institución plantea que su abordaje se sustenta en los principios del Psicoanálisis y el Neurodesarrollo. La colega integra el grupo de los pluriempleados, al igual de la trabajadora social que integra el equipo técnico de un Centro de Día perteneciente a una ONG que 
brinda servicios a jóvenes con discapacidad mental. Está emplazado en una localidad del conurbano sur, que cuenta con 426.005 habitantes.

También intercambiamos experiencias - en el marco de la entrevista en profundidad - con un colega que ejerce la profesión en un Centro de Rehabilitación generado en una localidad de la provincia como respuesta - en la década del 50 - a la epidemia de poliomielitis. Es una ONG prestigiosa en la ciudad, que ha gestionado en forma articulada con la provincia de Bs As muchos programas.

Por último otra de las entrevistas control ha sido realizada a un reconocido y prestigioso intelectual - en situación de discapacidad - que integra una ONG con amplio desarrollo reivindicativo en nuestro país.

De los colegas que ejercen la profesión en instituciones privadas con fines de lucro identificamos a quien egresó en la década de 1980 en la Facultad de Ciencias Médicas de la UNLP, y se desempeña en un Centro de Día privado, creado en el año 1991. Su Directora es una psicoanalista con trayectoria reconocida. La institución cuenta con prestigio local. La institución está emplazada en localidad de la provincia de Buenos Aires con 654.324 habitantes.

Por último, dos fueron las entrevistas realizadas a colegas que ejercen la profesión en obras sociales, una de ellas - Trabajadora Social - se desempeñó como funcionaria de obra social nacional en el área específica, en la gestión comprendida entre los años 1999 a 2001 . Otro de los entrevistados es un colega egresado de la escuela de salud pública de la provincia de Bs As, y ejerce la profesión en la Obra Social de los empleados públicos del estado. La misma, es un sistema abierto y arancelado ofrecido a toda la población de la Provincia de Buenos Aires, la cual cuenta con 58 años de antigüedad y 1.904 .112 afiliados. 
Las entrevistas han sido grabadas en audio, y simultáneamente tomadas notas en cuaderno de campo. Estas dos estrategias han permitido recuperar textualmente las narrativas a partir de los audios y señales corporales y contextuales de la escena transitada. Asimismo, destaco que si bien obtuve el consentimiento de todos los entrevistados para recuperar sus dichos, no corresponde identificarlos personalmente ya que el objetivo del trabajo es recuperar el punto de vista de los agentes sociales con titulación de trabajo social que se desempeñan en el campo de la discapacidad. Los cuadros que anteceden los incluyo a los fines de hacer una presentación general de los espacios de ejercicio de la profesión, que nos ayudan a comprender cuál es la experiencia interventiva y de discapacidad desde la que están hablando.

"los datos deberían ser presentados de tal manera que los entrevistados fueran capaces de reconocerse a ellos mismos, mientras que los lectores no deberían poder reconocer a los primeros" (Grinyer, 2002: 1)

\section{Hacia el análisis e interpretación de las narrativas}

El proceso de investigación, al sustentarse en un enfoque cualitativo, supuso un continuum de análisis e interpretación de las coordenadas que conforman el campo de la discapacidad y las intervenciones profesionales de los trabajadores sociales. En tal sentido, uno de los ejercicios que realizamos ha sido identificar, categorizar, inferir cuestiones relacionadas a los sentidos asociados a los proceso interventivos: a las Condiciones de la intervención, a las formas en que se construían pertenencias y desapegos con las organizaciones en las que se desempeñaban los entrevistados, organización (adscripción identitaria). También generamos saber interpretativo sobre los propósitos de la intervención, aquellos que se constituía en horizonte de las prácticas sociales, a las trayectorias profesionales, a las relaciones con la temática, al fin de cuentas a la dimensión 
simbólica de la intervención que adquiere materialidad en cada acto profesional. En consecuencia recuperamos los sentidos asociados al fenómeno de la discapacidad, a las concepciones, a las formas en que son concebidos los usuarios de las prácticas, y la forma en que los trabajadores sociales creen que son concebidos por los sujetos de las prácticas.

El proceso analítico e interpretativo, siguiendo a Minayo (2012) buscó:

- La lógica interna de los hechos, relatos y observaciones,

- Situamos los hechos, los relatos y observaciones en el contacto de los agentes sociales,

- Producimos relatos de los hechos en los que los actores se reconozcan.

El abordaje del material producido en el trabajo de campo, ha sido realizado con el uso de software Atlas Ti, el cual permitió un proceso ordenado en relación a las continuidades y discontinuidades que la misma elaboración de la tesis tuvo en estos años, facilitó la visualización de las codificaciones que se fueron realizando con el material. Estas implicaron un proceso analítico por medio del que la información es convertida en dato a partir de la fragmentación, la conceptualización y posteriormente integrada en lo que a Glaser, B. y A. Strauss (1967) denominan nuevas teorías.

El trabajo ha sido sostenido, con una amplia generación de codificaciones abiertas y axiales ${ }^{12}$. Los códigos que aparecen, y nos habilitaron diálogos entre las narrativas de colegas han sido:

\footnotetext{
${ }^{12}$ En el marco de la utilización del Software Atlas Ti, se procedió a realizar las codificaciones a partir del análisis de las entrevistas (narrativas). Este proceso analítico mediante el cual el dato fue fragmentado, conceptualizado e integrado luego en el proceso expositivo. forma de teoría. La
} 
- Condiciones laborales ó condiciones de la intervención: en este código incluimos las propias de la relación salarial, sumado a los límites de la intervención. Límites que los da el contexto de contratación, los abanicos de posibilidades

- Desigualdad / afrontamientos diferenciales de la situación de discapacidad: en este código incluimos las apreciaciones en torno a las variables de desigualdad social y diversidad cultural que aparecían en relación a las experiencias de discapacidad.

- Relación DDHH y discapacidad: uno de los tópicos que aparece de modo controversial. En este código aparecen afirmaciones en torno a la incidencia de la matriz de derechos en la intervención y al mismo tiempo las miradas contrapuestas.

- Política Pública / gestión: aparece constantemente en tanto escenario necesario y constitutivo de la intervención

-Familia / redes sociales: la referencia a las unidades domésticas y las redes sociales de apoyo ha sido una constante, pero las atribuciones de sentidos fueron diferentes.

- Sujeto con Discapacidad: aparece tensado, con el código Protagonismo de las personas con discapacidad, y al mismo tiempo se incluyen referencias de los procesos de subjetivación

- Protagonismo de las personas con discapacidad: aparece referenciado como una demanda, un pendiente y un llamamiento ético.

-Trayectorias profesionales: permitió reconocer que las rupturas epistemológicas se dan en la intervención. Los códigos

codificación abierta supone un proceso a través del cual los conceptos son identificados y sus propiedades y dimensiones descubiertas en el dato. Y la codificación axial es el proceso de conectar categorías con sus subcategorías. Strauss y Corbin (1990) 
axiales están vinculados al acompañamiento, contención, las tareas, y uno de los ejes más significativos a la hora de generar teorizaciones, ha sido las nociones de temporalidad.

Implicancia de la intervención / compromisos con los otros: este punto ha sido sustancial y en el proceso se fue diferenciando la referencia al concepto de habitus y al de illusio.

La idea de compromisos, en tanto búsqueda de rupturas del orden establecido, ruptura de los límites generados entre circuitos personales, laborales, pedagógicos configurados para las personas en situación de discapacidad; ha sido una constante en las narrativas y al mismo tiempo recurrentes en nuestras aproximaciones interpretativas. En tal sentido, la apuesta ha sido comprender las formas organizativas sociales, las configuraciones del campo y los desafíos éticos políticos que asume y asumió la profesión.

En relación al concepto de narrativa planteamos que el mismo se instaló como una de las ideas fuerza en torno a la materialidad de la intervención profesional, al tiempo que operó como cuestión central en el requerimiento de la voz de los profesionales que han sido protagonistas en la producción de los espacios socio - ocupacionales, de su crecimiento, consolidación y tensiones para tramar una historia colectiva y discursos dispares sobre acontecimientos asociados al campo. 


\section{Capítulo I: Campo de la discapacidad}

\section{en Argentina}

Existe, en efecto - se lo verificará en el largo término -, una fuerte correlación entre el lugar que se ocupa en la estructura social del trabajo y la participación en las redes de sociabilidad y en los sistemas de protección que "cubren" a un individuo ante los riesgos de la existencia. De alli la posibilidad de construir lo que yo llamaria metafóricamente

"zonas" de cohesión social. (Robert Castel, 2009:15) 
En el presente capítulo trabajaremos dos líneas fuertes, por un lado la recuperación histórica de la forma en que el estado configuró la intervención en discapacidad en nuestro país. Esto lo enlazamos con la hipótesis de que a medida que se incrementaba la intervención del estado se consolidaban los espacios socio ocupacionales para el trabajo social. En la segunda parte, incluimos las discusiones teórico- metodológicas para pensar la configuración del campo de la discapacidad, línea de análisis que sostenemos desde hace 12 años.

\section{1. - Historicidad de la intervención estatal en materia de discapacidad.}

En este apartado recuperamos los antecedentes históricos de nuestro país en relación a la discapacidad, lo que configura un espacio central en el entramado del campo. En tal sentido, iniciaremos enlazando los antecedentes que nuestra nación ha generado en torno a la producción del ser nacional y allí nos interrogamos si no existió la constitución de una mirada nacional sobre la discapacidad, la que supondría un proceso de normalización colonial. Posteriormente presentamos un apartado que titulamos iidearios de justicia social?, en el que intentamos postular la forma en que fue produciéndose la idea de derecho social atravesando las políticas de estado. Luego incluimos los avances normativos en contextos dictatoriales, lo que se constituye en paradoja en términos de análisis local pero que cobra sentido con las discusiones que a nivel internacional se venían dando en torno a la generación de instrumentos jurídicos de consenso ${ }^{13}$. Por otra parte, presentaremos algunos hitos en torno a

\footnotetext{
${ }^{13}$ En relación a la generación de instrumentos internacionales, destacamos la expresión de Bregain, G quien en ocasión de la presentación de la investigación de sus estudios post - doctorales en la Universidad Católica Argentina (CABA, 2015) planteó que "Los documentos internacionales de consenso, no son otra cosa que limitaciones a las utopías".
} 
lo que aconteció en el retorno a la democracia postulando la idea de cierta invisibilización del tema, sobre todo en tanto sujetos políticos. Y recuperamos los hitos que impusieron las prácticas del neoliberalismo (en su versión "de los 90”) y las contradicciones que instaló en términos de ampliación de respuestas en clave mercantilizada. Para cerrar este apartado, incluimos un interrogante en torno a los procesos de inclusión social desarrollados en la década del 2000, que no necesariamente produjeron rupturas sustanciales con los modelos mercantilizados. (¿Una década ganada en materia de discapacidad?) Las temporalidades presentadas en relación a la política de discapacidad tienen como objetivo tramar los pulsos que se fueron desarrollando en torno a la construcción de hegemonías en el campo. Los momentos que se presentan denotan la generación de agentes individuales $\mathrm{y} / \mathrm{o}$ colectivos que fueron disputando sentidos, recursos, legalidades, configuraciones administrativas y nominaciones en el campo.

Entendemos que las producciones teóricas que enlazan la producción de discapacidad como ideología, no hacen otra cosa que re editar una preocupación de larga data en las ciencias sociales en relación a las cuestiones propias de la configuración socio -cultural. Por ello, la recuperación histórica nos permite dialogar en ese entramado que supone tal configuración.

Por último planteamos que pensamos en dos grandes momentos en esta historización, uno relacionado a los procesos de modernización / desarrollo en el que la discapacidad aparece como objeto de asistencia / custodia / atención y otro vinculado a la mercantilización en el que la discapacidad medicalizada se constituye en un punto más de ampliación del excedente, con líneas de continuidad y ruptura. 


\section{1 ¿Constitución de mirada nacional sobre la discapacidad?}

Siguiendo la propuesta de de la Vega, entendimos necesario tramar los procesos socio - políticos desatados en la configuración del estado nacional con la disposición del "ser nacional".

"La barbarie fue el primero de los rostros que tuvo la anormalidad en América Latina, mucho antes de la constitución del saber universitario o dispositivo manicomial" (de la vega, 2010:45)

En esa misma línea argumentativa, las ideas que postula Aníbal Quijano sobre la clasificación social de la población mundial a partir de la idea de raza nos instala una argumentación posible para pensar como se tramitaban las diferencias. Entendiendo por raza:

\footnotetext{
“una construcción mental que expresa la experiencia básica de la dominación colonial y que desde entonces permea las dimensiones más importantes del poder mundial, incluyendo su racionalidad específica, el eurocentrismo" (Quijano, 2011:219)
}

Podríamos afirmar que en el proceso de construcción de diferencias, el discurso naturalista se instituye como condición de posibilidad para inferiorizar. El autor mencionado precedentemente, establece relaciones entre la colonialidad, la idea de raza y la configuración del modo de producción capitalista.

Lo vinculamos con lo que aporta Boaventura de Souza Santos sobre "sociología de la inexistencia", en la que plantea: 
“estamos asi ante las cinco 5 formas sociales principales de no existencia producidas o legitimadas por la razón eurocéntrica dominante: lo ignorante, lo residual, lo inferior, lo local o particular y lo improductivo. Se trata de formas sociales de inexistencia porque las realidades que conforman aparecen como obstáculos con respecto a las realidades que cuentan como importantes: las científicas avanzadas, superiores, globales o productivas” (de Souza Santos, 2010:24)

Las nociones de discapacidad pueden ser pensadas desde el mismo modo conceptual en que fue argumentada, narrada y creada la idea de raza. La construcción de un discurso que apega a nociones biológicas - pertenecientes a la naturaleza - las expectativas que sobre esos sujetos se construyen opera de modo similar a lo que ocurre con "la raza".

A estas afirmaciones las podemos poner en diálogo con lo que propone A. Carballeda en relación a los orígenes de la intervención en lo social en nuestro Río de La Plata.

"Uno de los ejes que impresiona como significativo remite a la noción de Soberanía, ya que esta sintetiza gran parte de las discusiones politicas y económicas del siglo XIX, llegando a la actualidad alrededor de la idea de Ciudadanía. Esas discusiones atraviesan la construcción de las Instituciones Modernas y le dan sentido a las prácticas que se ejercen en éstas. El origen del Trabajo Social se inserta también en esas cuestiones." (Carballeda, 2014:cap1) 
La recuperación de los antecedentes de intervención en lo social en nuestro territorio, considera el modo en el que fueron moldeándose los dispositivos. Esto nos permitió dar cuenta de la mirada que se construyó sobre la discapacidad, las maneras en que se preveía "intervenir" y los idearios de resolución de problemáticas que estaban presentes en la toma de decisiones.

La Sociedad de Beneficencia podría ser considerada como un laboratorio del control social, desde donde surgirán las primeras categorías de "desorden", "pobreza", "diferencia"; en fin, comenzará a aplicarse desde la práctica concreta el concepto de civilización. Concepto que será sinónimo de Europa. Noción, que se antepondrá al de "barbarie", que será sinónimo de América y en parte de España. Concepto que superará lo declamatorio para comenzar a construir un modelo de acción en la práctica. Es así que se va a imponer la civilización, a veces en forma violenta, otras de manera sutil. (Carballeda, 2014 cap. 6)

La influencia del positivismo, encarnado en la "generación del 80" supuso un movimiento que permitió el enlace del discurso médico higienista con el político, a saber:

La aparición del discurso médico higienista que articulará lo biológico con lo político, pondrá sus ojos en la orilla, en la periferia de la sociedad. La higiene médica, articulada con la educación y con las primeras medidas de Acción Social destinadas a la Minoridad dará los antecedentes de la creación de la Asistencia Social. Estos nuevos discursos traían como novedoso, que ya no se trataba sólo de Instituciones cerradas; (Hospitales Psiquiátricos, Hogares de 
Menores, Escuelas de Internado), los ideales del darwinismo social $^{14}$, salian de las instituciones y recorrian la periferia, portando su estandarte de adaptación y coerción social, difundiendo su catecismo moderno, enalteciendo la vida sana. (Carballeda, 2014 cap.1)

Uno de los puntos que será retomado en el próximo capítulo es la inminencia y persistencia de las discusiones entabladas - en el clásico libro El salvaje de Aveyron -, entre Pinel e Itard en torno a la lo innato o adquirido de la infancia deficiente. ¿Cuánto de esta tensión entre naturaleza y cultura sigue vigente en la configuración de respuestas a la discapacidad? ¿Cuánto de esta relación naturaleza / cultura opera en la construcción de respuestas desde la intervención? ¿Cuánto ensombrece las miradas fatalistas en relación a la discapacidad?

De la Vega (2010:67) nos plantea que "fue en la escuela pública, igual que en ámbitos psiquiátricos, criminológicos o literarios, donde se trazó - con la ayuda de los médicos, sin dudas - la frontera entre lo normal y lo anormal". Un ejemplo de ello podría ser: "Según Down, un mongólico es un individuo que regresa a las características morfológicas de una raza primitiva" (Planella Jordi y Pié Asun, 2012: 19)

El desarrollo de la tesis permitió visualizar cómo las situaciones de discapacidad fueron circunscriptas por tres ejes fundantes:

\footnotetext{
${ }^{14}$ El darwinismo social es la teoría que propone el uso de la teoría de la evolución de Charles Darwin (1809 - 1882) al campo social. Esto fue utilizado en el siglo XIX como ejercicio justificativo de las prácticas imperialistas. Partían de la idea que los individuos y colectividades con mayor capacidad serían los más aptos para sobrevivir. Por lo que los que carecían de estas cualidades estarían condenados a la extinción o a la supeditación
} 
- La cuestión jurídica, con la inicial pregunta de quiénes son y qué merecen estos "otros" diferentes, diversos y desiguales (Rosato, 2004).

- La cuestión médica que inscribe las demarcaciones entre lo normal y lo patológico y que delinea los contornos del cuerpo normal.

- $\quad$ La cuestión social que instala las preguntas sobre los modos en que transitan los ciclos vitales estos sujetos, las formas que adquieren sus vincularidades y los desafíos integrativos en sociedades desiguales.

Los ejes fundantes constituyen una posible vía de entrada analítica para pensar la configuración cultural de la discapacidad, los entramados, las disputas. Siguiendo la idea de campo de la discapacidad, señalamos que estos tres ejes condensan las tensiones inmanentes del propio campo.

\section{2 ¿Idearios de justicia social?}

El estado nacional, en el período comprendido entre mediados de los años 40 y 50, cuya administración estuvo en manos del primer gobierno peronista construyó un ideario de justicia social ${ }^{15}$ que atravesó todo el proceso de producción de las políticas públicas. La configuración de los temas inherentes a la intervención estatal estuvieron impregnados por estas ideas, proponiendo dispositivos desarrollados por el propio estado ó administrados por la Fundación Eva Perón. El eje central va a estar puesto en la categoría trabajo, por lo que el despliegue de respuestas estatales va a estar centrado en generar empleo, ampliar el abanico de derechos sociales y constituir a la clase obrera en actor social enmarcado en el movimiento justicialista. En esa línea, las políticas de salud se institucionalizarán como un objeto de intervención estatal.

\footnotetext{
15 "Evita afirmaba como dirigente política que debía asumir su condición de "deudora" con el pueblo. El justicialismo había llegado para reparar todos los daños que la oligarquía y los gobiernos entreguistas habían hecho al pueblo.. ... . ella se había propuesto jugar el rol de administrar la Justicia Social, que a la vez era requerido por las bases peronistas cada día con mayor exigencia." Ferioli, 1990:127)
} 
Bregain (2012) plantea que el gobierno peronista estuvo desinteresado del derecho a la rehabilitación de los lisiados en el marco de la política sanitaria diseñada por el Dr. Ramón Carrillo. Al mismo tiempo, señala que el Secretario de Salud Pública se proclama a favor de la obligatoriedad de que el $2 \%$ del personal de la administración pública y las industrias privadas sean "inválidos recuperados". El autor instala una tensión entre la primacía del derecho al trabajo (con una clara decisión moralizante de instalarse como la forma digna de transitar la vida) y la ausencia de dispositivos de rehabilitación integral que posibiliten la re - orientación laboral.

Recuperando a Ramacciotti (2009) la política sanitaria del peronismo puede ser analizada si se tienen en cuenta los cambios en las concepciones acerca de la salud pública, la consolidación del perfil de los médicos como gestores de políticas públicas y las innovaciones que instalaron Carrillo y sus colaboradores en el desarrollo de la profesión médica (ampliación del espacio socio - ocupacional). Y al mismo tiempo, compartimos la periodización que propone la autora en torno a que en el período 1946 - 50 la Secretaria (luego Ministerio) amplia su incidencia en la producción de política pública y en 1950 se produce un quiebre a partir de la asignación de fondos a la Fundación Eva Perón, en detrimento de la Secretaría del Salud Pública. ¿Qué disputas motorizaron estos cambios? ¿Qué idearios de salud se ponen en pugna en ese momento histórico? ¿Cuánto de la guerra de posiciones del propio peronismo se expresaron en estas disputas? ¿qué actores sociales proponían un modelo u otro?

Bregain propone una hipótesis en relación a que "los lisiados" no son incluidos en la configuración del movimiento obrero organizado, sus preocupaciones en torno al retorno al trabajo no son tomadas por los sindicatos y no se constituyen como actor social en sí mismos. En la arena de lucha que supone la configuración de la agenda pública las personas con discapacidad no operan en términos de demandas colectivas para ese momento histórico. 
Al mismo tiempo, las recuperaciones de testimonios de personas con discapacidad platean una respuesta integral por parte de la Fundación:

"Mi mejor Papá Noel fue Evita porque el mejor regalo que he recibido fue la ayuda solidaria de Eva Perón, que miró a un chico humilde que según algunos médicos no sobreviviría, y le dio la posibilidad de estudiar para que luego se ganara la vida. Me quiero ir de este mundo con la tranquilidad de haber hecho lo más que pude, como Evita, para que, desde donde ella esté, diga que haberme ayudado no fue en vano, sino que valió la pena." 16

Siguiendo a Carballeda (1995:7) "La aparición en forma más sistemática de Políticas Sociales, a través de programas y planes de gobierno, las podemos hallar a partir de 1946, en especial desde las acciones de la Fundación Eva Perón, el Primer Plan Quinquenal y la gestión del Ministerio de Salud de la Nación. El particular impacto de las Políticas Sociales en nuestro país puede relacionarse con la forma en que éstas atravesaron a todo el entramado social no solamente en términos de eficiencia, sino en la generación de nuevos sentidos, tanto en las propias instituciones, como en aquellos que eran cubiertos por éstas."

Las transformaciones asociadas a la intervención en lo social en clave de justicia social, circunscribe modos singulares de transitar estos procesos. No aparece con fortaleza una mirada particularizada sobre las "situaciones de discapacidad" sino que se lo inscribe en un colectivo vinculado a la necesidad de generar reparación de su desigualdad. En tal sentido, podríamos inferir que la discapacidad se instituye como asunto del gobierno peronista en la medida que se presente empobrecida.

\footnotetext{
${ }^{16}$ Para ampliar consultar http://marcospaz.com.ar/?p=41681
} 
En el relato de la fundación aparece una mirada fundamentalmente sobre las mujeres, los niños y los mayores. La enfermedad, en tanto que limitante del ejercicio del empleo, aparece tematizada. ¿Podríamos inferir que la idea de discapacidad esté asociada a invalidez laboral?

"En 1946 cuando se trata de solucionar el problema del
lisiado de forma "integral”, se piensa la organización de
la asistencia al lisiado alrededor de tres profesionales: los
médicos, los asistentes sociales y los maestros." (Bregain, 2012:116)

Esta afirmación nos abre una hipótesis sobre el inicio de la configuración del espacio socio - ocupacional del trabajo social. Relacionado con la información del Ministerio de Trabajo y Previsión, Dirección Nacional de Asistencia Social de 1951 podemos visualizar a diferentes dispositivos que se instituyeron en espacios socio - ocupacionales ${ }^{17}$. Los mismos denotan una construcción social de la discapacidad en clave del modelo médico. Aparece una idea de corrección, re - adaptación propia de la cuestión rehabilitatoria clásica.

A continuación presentamos información de las instituciones del Ministerio:

\begin{tabular}{|c|c|c|c|}
\hline $\begin{array}{l}\text { Casa de Admisión: } \\
\text { escuela hogar Úrsula } \\
\text { Llona de Inschasuti }\end{array}$ & Capital Federal & 64 niños y niñas & $\begin{array}{l}\text { Estudio psico -físico } \\
\text { completo de los niños } \\
\text { antes de ser derivados } \\
\text { a los establecimientos }\end{array}$ \\
\hline
\end{tabular}

\footnotetext{
${ }^{17}$ No es objeto de esta investigación un recorrido exhaustivo, con técnica historiográfica, pero se presentan estos antecedentes para aportar a la historización de la intervención del Trabajo Social en este campo y generar rupturas con idearios iniciáticos propios de nuestro tiempo. Fuente: Ministerio de Trabajo y Previsión. Dirección Nacional de Asistencia Social, Bs As, 1951, citado en Golbert, 2008.
} 


\begin{tabular}{|c|c|c|c|}
\hline & & & de la Dirección. \\
\hline $\begin{array}{l}\text { Escuela Granha E y } \\
\text { M.R. Patiño }\end{array}$ & Lomas de Zamora & 60 niñas & $\begin{array}{l}\text { Para menores con } \\
\text { características } \\
\text { comunes. Para niñas } \\
\text { de seis a doce años, } \\
\text { susceptibles } \\
\text { reeducación de para } \\
\text { reintegrarlas al medio } \\
\text { ambiente, recuperadas } \\
\text { opara continuar la } \\
\text { reeducación en el } \\
\text { medio aconsejado. }\end{array}$ \\
\hline $\begin{array}{l}\text { Escuela - Granja - } \\
\text { Taller Santa Rita }\end{array}$ & $\begin{array}{l}\text { Boulogne Sur Mer, } \\
\text { Bs As }\end{array}$ & 140 niñas & $\begin{array}{l}\text { Para menores con } \\
\text { características no } \\
\text { comunes. Para niñas } \\
\text { de doce a veintidós } \\
\text { añoso, susceptibles de } \\
\text { reeducación, a fin de } \\
\text { conseguir } \\
\text { reincorporación al } \\
\text { medio ambiente, en } \\
\text { condiciones } \\
\text { favorables. }\end{array}$ \\
\hline $\begin{array}{l}\text { Instituto Doctor } \\
\text { Sanchez Picado }\end{array}$ & Capital Federal & $\begin{array}{l}20 \text { varones internos y } \\
40 \text { externos }\end{array}$ & $\begin{array}{l}\text { Para menores de } \\
\text { características no } \\
\text { comunes de seis a } \\
\text { doce años. }\end{array}$ \\
\hline
\end{tabular}




\begin{tabular}{|c|c|c|c|}
\hline $\begin{array}{l}\text { Escuela Agrícola } \\
\text { ganadera M.L. y M. } \\
\text { C. Inchausti }\end{array}$ & Marcos paz, bs As & 60 varones & $\begin{array}{lr}\text { Para menores de } \\
\text { características } \\
\text { comunes de seis a } \\
\text { doce años } & \text { y } \\
\text { susceptibles } & \text { de } \\
\text { reeducación. }\end{array}$ \\
\hline $\begin{array}{l}\text { Instituto Ramayon } \\
\text { López valdivieso }\end{array}$ & Luján, Bs As & 120 varones & $\begin{array}{l}\text { Para varones de } \\
\text { características no } \\
\text { comunes de doce a } \\
\text { veintidós años con } \\
\text { vista a } \\
\text { recuperación. }\end{array}$ \\
\hline $\begin{array}{l}\text { Instituto para } \\
\text { oligofrénicos medios } \\
\text { colonia agrícuola } \\
\text { Rómulo Otamendi }\end{array}$ & Bs As & 20 varones & $\begin{array}{l}\text { Para varones de } \\
\text { características no } \\
\text { comunes de trece a } \\
\text { veintidós años, } \\
\text { oligofrénicos medios. }\end{array}$ \\
\hline $\begin{array}{l}\text { Colonia Hogar } \\
\text { Ricardo Gutierrez }\end{array}$ & Marcos Paz, Bs As & 480 varones & $\begin{array}{l}\text { Para varones de doce } \\
\text { a veintidós años que } \\
\text { presentan } \\
\text { inadaptación social. }\end{array}$ \\
\hline Casa San Sebastián & Córdoba & 60 niñas & $\begin{array}{l}\text { Hogar para niñas } \\
\text { débiles mayores de } \\
\text { diez años y hasta los } \\
\text { veintidós, con }\end{array}$ \\
\hline
\end{tabular}




\begin{tabular}{|c|c|c|c|}
\hline & & & $\begin{array}{l}\text { problemas de } \text { salud } \\
\text { que necesitan aire } \\
\text { serrano. }\end{array}$ \\
\hline $\begin{array}{l}\text { Escuela de } \\
\text { Aprendizaje Industrial } \\
\text { Eva perón }\end{array}$ & Capital Federal & 120 alumnos & $\begin{array}{l}\text { Habilitar al ciego para } \\
\text { su desenvolvimiento } \\
\text { en los talleres de la } \\
\text { institución. }\end{array}$ \\
\hline Hogar Santa Cecilia & Villa Lynch, Bs As & 99 internados & $\begin{array}{l}\text { Para niñas no videntes } \\
\text { en edad pre - escolar y } \\
\text { escolar y niños de tres } \\
\text { a seis años. }\end{array}$ \\
\hline Hogar Santa Ana & San Martín, Bs As & 140 internas & $\begin{array}{l}\text { Hogar de Ancianas no } \\
\text { videntes }\end{array}$ \\
\hline Hogar San José & San Martín, Bs As & $154 \mathrm{v}$ internos & $\begin{array}{l}\text { Internado de ancianos } \\
\text { no videntes }\end{array}$ \\
\hline $\begin{array}{l}\text { Hogar General } \\
\text { manuel Belgrano }\end{array}$ & San Martín, Bs As & 104 internos & $\begin{array}{l}\text { Internado para } \\
\text { varones no videntes } \\
\text { desde sesis a veinte } \\
\text { años } \\
\text { aproximadamente. } \\
\text { Atención y educación. }\end{array}$ \\
\hline
\end{tabular}




\begin{tabular}{|l|l|l|l|}
\hline $\begin{array}{l}\text { Hogar José Manuel } \\
\text { estrada }\end{array}$ & Capital Federal & & $\begin{array}{l}\text { Hogar de semilibertad } \\
\text { para jóvenes ciegos y } \\
\text { club de carácter } \\
\text { social, cultural y } \\
\text { deportivo. }\end{array}$ \\
\hline $\begin{array}{l}\text { Escuela } \\
\text { Gemplementaria }\end{array}$ & Capita Federal & 100 alumnos & $\begin{array}{l}\text { Educación, } \\
\text { adaptación, } \\
\text { readaptación del no } \\
\text { videntes adultos de } \\
\text { ambos sexos. }\end{array}$ \\
\hline
\end{tabular}

Selección propia de Fuente: Ministerio de Trabajo y Previsión. Dirección Nacional de Asistencia Social, Bs As, 1951, citado en Golbert, 2008

La Fundación Eva Perón ha sido analizada por Plotkin (2007), Ferioli (1990) y Caimari (1995), Moreno (2009) entre otros. Nos interesa destacar algunos ejes de análisis ya que entendemos que en este tiempo se inaugura un ideario de justicia social que enmarcará desarrollos posteriores de la política pública en general y del trabajo social como profesión.

El tema de la poliomielitis se instituye en un punto nodal en términos de la recuperación de la trayectoria del tema discapacidad en tanto asunto público (Testa, 2012; Alvarez, 2015). Bregain recupera el impacto de la crisis de poliomielitis en los años 1955 - 56 y las acciones que la autodenominada "Revolución Libertadora" lleva adelante: la creación del CNRL (Comisión Nacional de Rehabilitación del Lisiado), la tipificación del objeto de sus acciones, es decir los niños afectados por la poliomielitis, la búsqueda de 
desarrollo asistencial en el interior del país, todo en un marco de austeridad por reducción presupuestaria.

La influencia del desarrollismo posibilita una mirada modernizadora expresada en la ampliación de dispositivos de rehabilitación. En ese sentido, podría incluirse el desarrollo de prácticas deportivas adaptadas como un modo de inclusión social que denota una idea de progreso a partir del esfuerzo. ${ }^{18}$

E1 “desarrollismo" permeó las apuestas políticas de varias organizaciones e instauró un modo de gestionar la intervención en lo social. En el caso del Trabajo Social, las influencias del desarrollo y la organización de la comunidad han inscripto un modelo de acción que sustenta muchas de las prácticas comunitarias que se despliegan en nuestros días. En este punto identificamos dos vertientes claramente diferenciadas que aportaron elementos al tema de la intervención en la comunidad en América latina. (Danel, Paola, 2009) Por un lado, aparece la idea de "desarrollo de la comunidad" de la mano de las experiencias coloniales inglesas y por otro las ideas provenientes de EEUU vinculados a la "Organización de la Comunidad". Estas dos vertientes confluyen en lo que Bonfiglio (1982) denomina “Organización y Desarrollo de la Comunidad" de la mano de los aportes de los organismos internacionales.

El "Desarrollo" se gesta en la década de 1920 a través de las acciones que lleva adelante la oficina colonial británica tendientes a organizar a las poblaciones sometidas. Las acciones más destacadas estaban centradas en el cumplimiento de objetivos educacionales básicos, encaminados a consolidar la hegemonía cultural y política del imperio. Todo esto en un contexto internacional signado por las luchas anticoloniales y anticapitalistas.

\footnotetext{
${ }^{18}$ Para ampliar sobre el tema se recomienda tesis doctoral de Ferrante (2012) y la tesis de maestría de Solans (2013). En ambas tesis se recuperan la producción de prácticas sociales asociadas al deporte, en su expresión de alto rendimiento y cómo estrategia socializadora, en el marco de la producción de cuerpos posibles de ser re adaptados, en marcos de auto - afirmación identitaria de colectivos reivindicativos.
} 
El desarrollo de la comunidad se instituye como tal en las décadas de 1930 e inicios de la de 1940. Considerando el contexto de su surgimiento advertimos que el objetivo central perseguido era consolidar situaciones de dominación y control estatal de las contradicciones sociales. Es recién después de la segunda guerra mundial que los Estados, ahora independientes, emprenden este tipo de estrategias en busca de construir e integrar cada uno de sus países.

"Lo que merece destacarse es que el desarrollo de la
comunidad en cuanto técnica de intervención tiene su origen
inmediato en la crisis del sistema colonial del siglo XX. Con
la descolonización estas técnicas son reformuladas
intentando superar el paternalismo de los programas
iniciales y desde la óptica de independencia y
reconstrucción nacional” (Bonfiglio 1982).

La organización de la comunidad surge desde una disciplina en particular en un territorio singular, hablamos del trabajo social estadounidense. El momento histórico caracterizado por la puesta en juego de las manifestaciones de la cuestión social, cuestión obrera de principios del siglo XX. Surgen así los Consejos de Planeamiento de la Comunidad o Consejos Locales para el bienestar de la comunidad. Su objetivo era coordinar las acciones de los diferentes servicios asistenciales. Los mismos se fueron profesionalizando hacia los años 40'. Para el trabajo social se configura en un método de intervención cuya preocupación central es la comunidad. Claramente esta apuesta metodológica (trabajo social comunitario) ha sido un objeto en disputa en el seno de la disciplina, habida cuenta que fue tramitando las tensiones adaptativas con las emancipatorias.

Después del golpe de 1955, en el marco de la sangrienta "Revolución Libertadora", se reconvirtió a la Fundación Eva Perón en el Instituto Nacional 
de Acción Social con dependencia de la Presidencia. Se genera un abrupto corte con los modos de gestión que se habían instaurado. Esto implicó un cambio profundo desde la idea de justicia social a la de búsqueda modernizadora, correctiva y bajo sospecha. Se sumó a este proceso el impulso modernizador del desarrollo de la comunidad que se difunde con mayor énfasis en la década del 50.

Asimismo, señalamos que Cáritas fue creada en $1956^{19}$ y desde sus propios medios de comunicación oficial refieren que surge para dar amparo a los que quedaron sin respuesta tras el abrupto cierre de la fundación y para generar apoyo a los presos políticos. La iglesia católica y el desarrollo de acciones de caridad tienen una presencia constante en el desarrollo de prácticas sociales en el campo de la discapacidad. Esto lo veremos referenciado en la investigación de Testa (2012) quien indaga el origen de una de las instituciones de asistencia social - ALPI -, en la que "médicos y filántropas constituyeron una alianza médico-social y desarrollaron el interés fundamental de practicar una modalidad de tratamiento -en un contexto donde todo estaba por hacerse- sostenidos en un andamiaje que amalgamaba ideas cristianas con innovaciones de la medicina y la rehabilitación" (Testa, 2012: 299) En tal sentido, podemos tramar una influencia del discurso caritativo, médico, moral y que legitimaba un modelo de atención sanitaria ubicando una parte del peso de la deficiencia dentro de los límites de la unidad familiar y la responsabilidad individual. Esta tendencia será retomada fuertemente en las décadas posteriores. Un interrogante posible podría ser si los antecedentes que propusieron pensar a la intervención en lo social como restitutiva de una situación injusta, se perdieron con el pulso de las prácticas autoritarias de la dictadura. Y por otra parte, destacar que los trazos de la configuración de la discapacidad como asunto estatal se dan en estos años de rupturas dictatoriales y continuidades subrepticias.

\footnotetext{
19 Para ampliar se sugiere: http://www.caritas.org.ar $/ \mathrm{htm} / \mathrm{somos} 03 . \mathrm{htm} \# 2$ http://www.anuariodeinvestigaciones.com/2011/07/caritas-satisfaccion-y-necesidades-de.html
} 


\subsubsection{Idearios de justicia social y las luchas de las organizaciones}

Continuamos nuestro recorrido analítico por las décadas del 60 / 70, momento en que varias de nuestras entrevistadas iniciaron su ejercicio profesional. No obstante, es necesario dejar registro de los acontecimientos del año 1956 momento en que se desarrolló la epidemia de poliomielitis en nuestro país provocando altos índices de mortalidad y de movilidad en la población. Este hecho fue altamente significativo al punto que se implementaran las primeras políticas sanitarias y primeros programas de rehabilitación. De esta manera se crean las primeras instituciones oficiales como: El Servicio Nacional de Rehabilitación al Lisiado y se desarrollan otras que ya existían. (Benavidez Estefanía y Vall Ana Elizabeth, 2010)

La polio ${ }^{20}$ ha sido el evento sanitario más significativo de la segunda mitad del siglo XX generando un amplio abanico de respuestas frente a una infección que no discriminaba entre pobres y ricos. Esta cuestión es central a la hora de observar la trayectoria de las políticas de asistencia y rehabilitación que se han desarrollado. Las instituciones más relevantes en el campo de la discapacidad especialmente asociadas a la rehabilitación física) se han generado en ese tiempo y se sitúan en las ciudades más pobladas en ese momento (Buenos Aires, Mar del Plata, La Plata, Santa Fe, Rosario) Todas estas instituciones vinculadas a la damas de beneficencia, esposas de médicos y otros benefactores de la época.

\footnotetext{
${ }^{20}$ Para ampliar se sugiere: Buzzi A, Rosenwurcel H. Historia de la Poliomielitis. Revista Asociación Médica Argentina. 1967;81(8):393-395. [Material de Archivo]. Localizado en: Buenos Aires: Biblioteca Central Juan José Montes de Oca, Facultad de Medicina, Universidad de Buenos Aires y Ministerio de Bienestar Social, Subsecretaría de Salud Pública, Departamento de Atención Médica. Historia de la epidemiología de la poliomielitis en la República Argentina. Boletín Epidemiológico Nacional. 1977;8(5). [Material de Archivo]. Localizado en: Buenos Aires: Biblioteca Central Juan José Montes de Oca, Facultad de Medicina, Universidad de Buenos Aires
} 
Mientras que la Sociedad de beneficencia distinguía entre pobres merecedores y no merecedores, la Fundación Eva Perón se refería a los humildes que había que dignificar y Frondizi confiaba en el desarrollo, el gobierno de Illia habla de mejorar los niveles de bienestar a los que tienen derecho el individuo, los grupos y comunidades. El sujeto de estas intervenciones ya no es más el pobre sino el conjunto de los habitantes del país" (Golbert, 2008:37)

Esto que señala Golbert entendemos que sintetiza de modo preciso los recorridos que fue teniendo la política social en nuestro siglo XX. El corrimiento de miradas estereotipadas a la pobreza, pasando por búsquedas reparatorias a recaer en una clara postura modernizadora en la que el propio impulso hacía innecesario dar cuenta de los desventajados.

Volviendo al tema de la epidemia de poliomielitis que se desarrolla en los primeros meses del año 1956, de acuerdo a los datos que presenta Testa (2011) se registraron 6500 casos. La autora señala que estas cifras pusieron en evidencia la insuficiencia de recursos, lo cual entendemos que resulta excesiva la demanda a un sistema de salud que incipientemente se desarrollaba desde mediados de la década del 40. Carrillo, primer secretario de salud del país, planteaba que en la "Política Sanitaria Argentina (1949)" que el desarrollo de la salud pública estaba fundada en tres principios: 1. Todos los hombres tienen igual derecho a la vida y a la sanidad; 2 . No puede haber política sanitaria sin política social; 3 . De nada sirven las conquistas de la técnica médica si ésta no puede llegar al pueblo por medio de dispositivos adecuados ${ }^{21}$. Por ello, en el período comprendido entre 1946 y 1955 se crearon 4.229 establecimientos sanitarios con 130.180 camas. Claramente, estos dispositivos de atención no

\footnotetext{
${ }^{21}$ Se recomienda la lectura de las Directivas para preparar el plan sanitario sintético para el periodo 1952 y 1958. Por razón del Golpe de estado este proceso fue interrumpido. Ver: http://www1.hcdn.gov.ar/dependencias/dip/documentos/DG.109.05.00-1.pdf
} 
resultaron suficientes para afrontar la epidemia de poliomielitis, pero es oportuno contextualizar el desarrollo de la configuración de lo público a los fines de evitar valoraciones que podrían resultar inconducentes.

Testa plantea que la epidemia de poliomielitis dio origen a las estrategias educativas y sanitarias de desarrollar perfiles profesionales que puedan desplegar acciones asociadas a la rehabilitación. De allí que identifica estas décadas como las posibilitadoras de la instalación de la carrera de terapia ocupacional y podríamos agregar que se sientan las bases de configuración del campo de la discapacidad en nuestro país.

La influencia inglesa en el desarrollo disciplinar de la terapia ocupacional es innegable, sumado a los aportes norteamericanos, lo que marcó un modo especial de concebir la salud, la rehabilitación, los derechos, en tiempos de proscripción y alternancia de gobiernos dictatoriales. Para el Trabajo Social, la dinámica no fue distinta. Todos los intentos de construir un aporte desde nuestra América, con idearios de justicia social fueron acallados violentamente por las dictaduras cívico -militares. Eso no significó que las/os trabajadores/as sociales en cada espacio singular, en cada organización, trabaje desde idearios de ruptura pero en contextos que no propiciaban discursos altisonantes en clave emancipatoria.

Podríamos incluir una referencia a los procesos que llevaron adelante las carreras de Trabajo Social, tanto en la UNLP cómo en la UBA. Al momento de transitar los procesos formativos de grado las colegas incluidas en el conjunto de las pioneras, pertenecían a las dos universidades nacionales mencionadas. Cursaban y egresaban a mediados de la década de 1960. Para el caso de la Universidad Nacional de La Plata, la carrera dependía de la Facultad de Ciencias Médicas iniciando su desarrollo en el marco de la Cátedra de Higiene Médica y Preventiva, en 1938. La formación era profundamente para-médica, con 
impronta de control social en el marco de la instalación de idearios de salud pública. Para el año 1963, y con influencia de las indicaciones y sugerencias de la Organización Mundial de la Salud, se conforma la titulación de Visitador de Higiene Social y Enfermería. Desde esta titulación, la carrera comienza a ser mixta, dejando de lado la exclusividad femenina de la matriculación. Este es uno de los ejes que han sido analizados por Grassi, 1992 (feminización de la profesión), y que en los últimos años han sido revisados en torno a tensar los procesos que las carreras de trabajo social en la década del 60 y 70 encararon y las discusiones societales, políticas que se daban. No podríamos escindir las discusiones del trabajo social reconceptualizado con las rupturas que la intervención en lo social se han dado entre el gobierno peronista y la dictadura del 55 y posteriores, y las vocaciones para médicas que lejos estaban de ceder poder.

En el caso de la UBA, la carrera tuvo un mismo origen para - médico en el primer cuarto del siglo XX, y es recién en 1959 que tras una reformulación en el plan de estudios se promueve la titulación de Licenciatura en Servicio Social. Esta experiencia, siguiendo a Arias, Giraldez, Arancibia y Moscona (2009), dependía de la carrera de Medicina. La UBA tuvo como característica llamativa la simultaneidad de dependencia de la carrera, de medicina y de Derecho y Ciencias Jurídicas. De la experiencia de título de Licenciatura tres de nuestras pioneras entrevistadas fueron egresadas inaugurales de tal experiencia.

El trabajo social disputa su matriz teórica, su identidad atribuida (Martinelli, 1997) y sobre todo los tipos de formación, discutiendo con el lugar subordinado que implicaba ser "para jurídica ó para médica”. El proceso que albergó todas estas discusiones fue el de reconceptualización que ha sido analizado por Carballeda, (2006), Parra (2007), Aquín (2011) y otros referentes de la profesión. Lo que señalan todos los autores mencionados, es que los procesos de ruptura iniciados entre mediados de la década del 60 y mediados de 
la década de 1970 era altamente prometedor, pero que se vio trágicamente interrumpido por los procesos dictatoriales que se desataron en nuestro continente.

Siguiendo a Scelsio (2013) planteamos que el trabajo social se ha inscripto en amplias discusiones en las que se nutrió de influencias marxistas - en la clara búsqueda de postura críticas-, pero sobre a miradas / narrativas / idearios nacionales y latinoamericanos que interrogaron desde nuestro lugar en el mundo la manera en que la profesión dirimía los desafíos que la cuestión social en cada momento histórico generaba.

Volviendo al hilo conductor asociado al tema de la discapacidad, en el momento histórico mencionado con anterioridad, planteamos que uno de los movimientos que amerita una especial atención es el Frente de Lisiados Peronistas. Sus luchas por la inclusión laboral, surge desde un grupo de personas con discapacidad que se desempeñaban en la escuela profesional que funcionaba en la calle Ramsay $^{22}$, al respecto señalan que las condiciones laborales eran de explotación, por lo que comenzaron a organizarse.

\begin{abstract}
"La dictadura militar desde marzo de 1976 realizó un plan sistemático de persecución, torturas y desapariciones. Dentro de ese universo de personas también incluyeron a ciudadanos con discapacidad. Algunos comprometidos con alguna causa, otros por simplemente pensar distinto. El caso más conocido fue el de José Liborio Poblete Roa, de nacionalidad chilena, militante de la Unión Nacional de Discapacitados. En 1971, José había formado junto con otros compañeros el Frente de Lisiados Peronistas, que
\end{abstract}

\footnotetext{
${ }^{22}$ En calle Ramsay de la Ciudad autónoma de Buenos Aires actualmente funciona el servicio Nacional de rehabilitación.
} 
llegó a estar constituido por más de 200 personas que concurrían a marchas con sus muletas, sus sillas de ruedas y sus perros lazarillos. Durante esos años, el "Frente de Lisiados Peronistas" se puso a la cabeza de las reivindicaciones de ese sector y logró en 1974 la ley laboral para personas con discapacidad más importante de América Latina y un ejemplo para todo el mundo si de conquistas laborales se trata". ${ }^{23}$

El Frente de Lisiados Peronistas inaugura un proceso de colectivización de las personas con discapacidad que resulta interpelador de las formas legítimas de acción colectiva. Sus prácticas militantes, las acciones de resistencia y su origen de clase proletaria marcarán un itinerario de participación política cuya bandera será el derecho a trabajar.

"El 30 de septiembre de 1974, se promulgaba la Ley Laboral 20923 por unanimidad de las dos cámaras; entonces los compañeros alcanzaron la gloria. El artículo que cambiaba la historia señalaba que toda empresa estatal, mixta o privada debía tener el cuatro por ciento de su personal discapacitado.(Alonso y Cuenya, 1974:35)

La colectivización de las personas con discapacidad se ha ampliado en los últimos 40 años, en experiencias que nuclean la participación socio - familiar y aquellas que ponen énfasis en el protagonismo de las personas con discapacidad.

\footnotetext{
23 Para amnpliar ver: (http://www.arinfo.com.ar/notix/noticia/00229 ellos-y-ellas-tambin-sondesaparecidos.htm )
} 
La adscripción identitaria que supuso la práctica política del Frente de lisiados peronistas instauró una forma de protagonismo que se presentó como novedoso, aún hasta nuestros días.

"El primer salto conceptual se dio en los 70, al crearse el Frente de Lisiados Peronistas. Esta agrupación incorporó la defensa de los derechos de las PCD como política reivindicatoria. Por respuesta, la Triple A y la dictadura secuestraron, torturaron y desaparecieron a muchos de sus militantes (Joly, 2008:34)

La conjugación de la pertenencia al movimiento peronista junto con idearios de transformación a partir de la ocupación del espacio público, con antecedentes de justicia social cristalizada en acciones en gobierno, operaron para que se produzca un colectivo que vino a ocupar el espacio que por derecho propio el mismo peronismo había gestado.

“queríamos un lugar en el mundo, ser protagonistas de la vida, persiguiendo la quimera de dar vuelta la tortilla. Romper con lo previsto, con aquello que los poderosos tenían asignado para nosotros. Dejar atrás el paternalismo, la desvalorización. Formas que encubren la injusticia social a la cual estábamos sometidos. Dejar el lugar de oprimidos adquiriendo el rol de sujetos activos, asumiéndonos como parte de la clase trabajadora." (Alonso y Cuenya; 2015, 14) 
La trama entre acción política, la participación en un movimiento que asume la pertenencia de clase como el marcador central de la identidad ${ }^{24}$, se conjugaron con la necesidad de impugnar los modos en que el orden social producía la discapacidad.

La historia política del país con sus más cruentas prácticas genocidas se instalaron para limitar esta experiencia que posibilitaba moldear las prácticas asociadas a la discapacidad, desde el protagonismo llevando nuevamente a la idea de déficit, de cuidado y de asistencia.

\section{3 ¿Avances normativos en contextos dictatoriales?}

La primera norma jurídica nacional en materia de discapacidad en nuestro país, ha sido la Ley 22431 que fuera publicada en el Boletín Oficial el día 16 de Marzo de 1981. En la misma se define un sistema de protección "integral” de las personas discapacitadas tendiente a asegurar su atención médica, educación y seguridad social, así como a concederles las franquicias y estímulos que permitan en lo posible neutralizar la desventaja que la discapacidad les provoca y les den oportunidad, mediante su esfuerzo, de desempeñar en la comunidad un rol equivalente al que ejercen las personas normales. (Artículo 1)

Podríamos comenzar enfatizando que el texto de la ley se incluye en los postulados construidos desde el modelo médico. Pero, previo a categorizar anodinamente entendemos necesario inscribir la promulgación de la Ley en el contexto socio - histórico - político y económico que hizo posible su aparición.

\footnotetext{
${ }^{24}$ La experiencia del Frente de Lisiados Peronistas amerita una relación innegable con lo que la literatura de ciencias sociales llamará en la década de 1980 cómo "nuevos movimientos sociales". Estos eran considerados como "acciones colectivas con alta participación de base que utilizan canales no institucionalizados y que, al mismo tiempo que van elaborando sus demandas, van encontrando formas de acción para expresarlas y se van constituyendo en sujetos colectivos, es decir, reconociéndose como grupo o categoría social." (Jelin 1986:18) El Frente, comprendía características propias del movimiento nacional justicialista pero en calve de demanda específica.
} 
En el momento de promulgación de la Ley, se desarrollaba la última dictadura cívico - militar que se iniciara el 24 de marzo de 1976. Un tiempo complejo, en el que se desarrollara la más sangrienta intervención militar, surge una ley de protección integral para las personas en situación de discapacidad. En ese sentido, mana la necesidad de incluir información en torno a las acciones que durante los años 1980 y 1981 se desarrollaron, es decir que gravitando una crisis social, económica y política, el régimen dictatorial se estaba agotando. El poder de la Junta militar no se expresaba en forma compacta, tal como lo hiciera en los inicios de la dictadura (1976). El sostenimiento de los crímenes de lesa humanidad comenzaba a trascender los límites nacionales, gracias a la incansable lucha de Madres de Plaza de Mayo.

La Junta comenzaba a generar negociaciones con la dirigencia política que se incluyó al gabinete (Movimiento de Integración y Desarrollo - MID -), junto a fuerzas conservadoras como el Autonomismo Correntino.

En el contexto internacional, señalamos que en 1976 la Asamblea General proclama 1981 Año Internacional de los Impedidos Resolución 31/123 de la Asamblea General ${ }^{25}$. La Asamblea solicitaba el establecimiento de un plan de acción a nivel nacional, regional e internacional en el que se genere especial hincapié en la igualdad de oportunidades, la rehabilitación y la prevención de la discapacidad. El lema elegido fue "la plena participación y la igualdad", definidas como el derecho de las personas con discapacidad a participar plenamente en la vida y el desarrollo de su sociedad, a gozar de unas condiciones de vida similares a las de los demás ciudadanos, y a tener los mismos derechos.

El contexto internacional y la complejización de la política nacional tras el agotamiento de la dictadura cívico - militar hicieron posible que se sancionara la ley, que a la fecha tiene vigencia. Retomamos a Bregain (2010) quien señala

${ }^{25}$ Para ampliar sobre el particular: http://www.un.org/spanish/disabilities/default.asp?id=529 
que junto al "clima de época" que permitía reivindicar los derechos de las personas con discapacidad, se incluían acciones enmascaradoras de la sangrienta dictadura. Los jerarcas de la dictadura, intentaban generar un contra relato en torno al respeto de los derechos humanos en el país.

Por otra parte, aparece un claro proceso de configuración del tema discapacidad en asunto público y al mismo tiempo la tensión entre focalización y producción de políticas.

\subsection{El retorno a la democracia y la invisibilización}

El retorno a la democracia no tuvo significativos avances en términos normativo - jurídicos en la materia pero si claramente generó la consolidación de espacios de participación. Ahora bien, estos espacios (consejos municipales, provinciales, nacionales) no recuperaron el ideario del frente de lisiados peronistas sino que moldearon formas de participación "en nombre de".

Claramente el retorno democrático trajo consigo el armado de programas nacionales, provinciales y municipales, con distintos modelos de abordaje (rehabilitador / social). Señalamos que el marco jurídico, seguía (y sigue) siendo la Ley 22431 - Sistema de protección integral de los discapacitados ¿Qué implicancias tuvo esto en el retorno a la democracia? La idea central de los abordajes en este tiempo fue la igualdad de oportunidades, lo que supone una mirada liberalizada de las relaciones sociales. Las disputas del campo de la discapacidad, en este momento, estaban centradas en el reconocimiento de un 
sector poblacional pero desde idearios de protección y búsqueda de tránsitos normalizados ${ }^{26}$.

Colocando la mirada en el territorio de la provincia de Buenos Aires, hemos reconstruido a partir de las narrativas de nuestras entrevistadas/os y de intercambios que he realizado con investigadores del campo ${ }^{27}$.

"De lo que yo pude ver es que justamente cuando yo entre a trabajar en el Área de Discapacidad lo que fue el inicio de Acción Social después digamos en la etapa de recuperación de la democracia, o sea yo entre en el año '84, a trabajar cuando Acción Social recién se estaba armando y ya habia un Área de Discapacidad como departamento dentro de una Dirección de Familia." (Entrevistada TS código: 1313)

Gaviglio (2014:108) plantea que en 1984 se configura el Programa “Concientización Comunitaria e Integración de la persona discapacitada" que buscaba dar respuesta a las personas con discapacidad que habían concluido la etapa educativa, procurándose su inserción social y socio - laboral. Los sub programas que instituye son 6 (seis) de los que a todas luces somos herederos en nuestro tiempo:

a) centro de día

b) Albergue

\footnotetext{
${ }^{26}$ El principio de normalización fue utilizado fuertemente en la décda del 80 en varios países del mundo, y el mismo planteaba que las personas con discapacidad transiten su vida "lo más próxima a la normal como sea posible". Si bien este principio tuvo acepciones diferentes, la tensión más fuerte estaba dada en si lo que debe ser normalizado son las condiciones de vida o los comportamiento de los sujetos. Desde la mira actual, y con fuerte influencia post - estructuralista lo que ponemos en discusión es el concepto mismo de normalidad.

27 En este punto señalo a la co - directora de esta Tesis Dra. Ferrante, a la Lic. Gaviglio del Observatorio de la UN de Quilmes y a la Lic. Laura Sosa de la Facultad de humanidades y Ciencias de la Educación de la UNLP:
} 
c) Taller protegido

d) Difusión

e) Menores discapacitados institucionalizados

f) Atención a la persona discapacitada y/o su grupo familiar en estado carencial.

Surge de la información recabada que la producción de política de discapacidad en la provincia, en el marco del retorno democrático, se configuró con una clara alianza de diseño y gestión con las organizaciones de familiares de personas con discapacidad, y una clara decisión de generar alternativas prestacionales que eviten la institucionalización (internación).

En ese marco, junto con otros organismos provinciales trabajaron en la redacción de la Ley 10592 "régimen Jurídico Básico e Integral para las Personas Discapacitadas" que fuera finalmente aprobada en 1987 y reglamentada en 1990 por el Decreto 1149. Los trabajadores del área entienden que la promulgación de la Ley ha sido un punto sustancial en la definición de una política integral sobre discapacidad en la provincia de Bs As. Otro punto de inflexión lo señalan con la creación del Consejo Provincial del Discapacitado.

Un punto a repasar es sobre lo que plantea Gaviglio (2014) en relación a una fuerte prevalencia de recursos destinados a la atención de personas con discapacidad mental $^{28}$.

"Ello se debe al vasto desarrollo institucional del movimiento de asociaciones de atención a la discapacidad mental, sino a que muchas de las necesidades de las

\footnotetext{
${ }^{28}$ Destacamos que las personas con dificultad ó limitación permanente de tipo cognitivo en la Provincia de Bs As, asciende al 23,42\% del total de personas con dificultades o limitaciones $\begin{array}{llllll}\text { permanentes } & (1.164 .083) \quad \text { Para ampliar se sugiere: censo } 2010\end{array}$ http://www.censo2010.indec.gov.ar/resultadosdefinitivos.asp
} 
personas con otro tipo de discapacidades demandan alternativas de orden sanitario, educativo o de acceso al empleo competitivo con muchas dificultades de ser abordadas." (Gaviglio: 2014:45)

Siguiendo con la recuperación histórica, se destaca que las políticas que ha ido configurando la Dirección de Discapacidad (con los diferentes nombres y jerarquías que fue teniendo) sostuvo a la discapacidad como un asunto que debía ser abordado en forma articulada entre el estado y la sociedad civil, especialmente con las familias de las personas con discapacidad. Esta afirmación implicó el reconocimiento de una tensión en el campo de la discapacidad, habida cuenta que la familiarización de los cuidados y la protección social denota miradas asociadas a la caridad y los merecimientos.

\section{$\underline{1.5 \mathrm{El} \text { neoliberalismo y sus contradicciones }}$}

El modo de producción capitalista, en su fase monopolista trasnacional, ha logrado inmiscuir sus intereses en todas las esferas de la vida social, volviendo rentable las prácticas que sostenemos. En materia de discapacidad, la década del 90 dio inicio a la configuración de marcos regulatorios al desarrollo del sub - sector privado como productor de servicios destinados a la discapacidad. En tal sentido, el INSSJyP ${ }^{29}$ a través del - Proidis - generó el diseño de dispositivos de atención interdisciplinaria tendiente a posibilitar itinerarios previsibles a los sujetos en situación de discapacidad. Muchos de esos servicios o dispositivos no existían al momento de promulgación de la norma, por lo que se generó un "nuevo mercado" en el que la atención socio -sanitaria - educativa y de rehabilitación comienza a ser rentable.

\footnotetext{
${ }^{29}$ Instituto nacional de Servicios Sociales para Jubilados y pensionados (INSSJyP)
} 
Las prestaciones en rehabilitación integral que prevé el PROIDIS, y luego fuera ratificado por el marco básico son las que se muestran en el cuadro que sigue - representando las posibles prestaciones en rehabilitación integral, de acuerdo a la edad, discapacidad y posibilidades de las personas afectadas ${ }^{30}$.

\begin{tabular}{|c|c|c|c|c|c|c|}
\hline $\begin{array}{l}\text { Tipo de } \\
\text { discapacidad }\end{array}$ & & 0 a 3 años & 3 a 6 años & 6 a 14 años & $\begin{array}{l}14 \text { a } 24 \\
\text { años }\end{array}$ & $\begin{array}{l}24 \text { años o } \\
\text { más }\end{array}$ \\
\hline \begin{tabular}{|l} 
Mentales \\
Sensoriales \\
Motores con \\
compromiso \\
mental
\end{tabular} & $\begin{array}{l}\text { Con } \\
\text { posibilidad } \\
\text { de } \\
\text { educación } \\
\text { sistemática }\end{array}$ & $\begin{array}{l}\text { Estimulaci } \\
\text { ón } \\
\text { temprana }\end{array}$ & $\begin{array}{l}\text { Educación } \\
\text { Inicial }\end{array}$ & $\begin{array}{l}\text { Educación } \\
\text { General } \\
\text { Básica }\end{array}$ & $\begin{array}{l}\text { Formación } \\
\text { laboral }\end{array}$ & $\begin{array}{l}\text { Ubicación } \\
\text { laboral: } \\
\text { comp. } \\
\text { proteg. }\end{array}$ \\
\hline & \begin{tabular}{|l} 
Sin \\
posibilidad \\
de \\
educación \\
sistemática
\end{tabular} & & \begin{tabular}{|l} 
Estimulaci \\
ón \\
temprana
\end{tabular} & $\begin{array}{l}\text { Centro de } \\
\text { Día } \\
\text { Centro } \\
\text { terapéutico } \\
\text { educativo }\end{array}$ & $\mid \begin{array}{l}\text { Centro de } \\
\text { día - } \\
\text { Centro } \\
\text { terapéutico } \\
\text { - educativo }\end{array}$ & $\begin{array}{l}\text { Ubicación } \\
\text { laboral } \\
\text { protegida }\end{array}$ \\
\hline \begin{tabular}{|l} 
Motores \\
Viscerales \\
Sens. \\
Adquirid.
\end{tabular} & $\mid \begin{array}{l}\text { Con } \\
\text { posibilidad } \\
\text { de } \\
\text { educación y } \\
\text { rehabilitació }\end{array}$ & $\begin{array}{l}\text { Estimulaci } \\
\text { ón } \\
\text { temprana }\end{array}$ & \begin{tabular}{|l} 
Estimulaci \\
ón \\
temprana \\
Educación \\
Inicial \\
Escuela
\end{tabular} & $\begin{array}{l}\text { Centro de } \\
\text { rehabilitaci } \\
\text { ón } \\
\text { EGB. } \\
\text { Escuela }\end{array}$ & \begin{tabular}{|l} 
Centro de \\
rehabilitaci \\
ón \\
Capacitació \\
n laboral
\end{tabular} & $\begin{array}{l}\text { Centro de } \\
\text { Rehabilitaci } \\
\text { ón } \\
\text { Ubicación } \\
\text { laboral }\end{array}$ \\
\hline
\end{tabular}

${ }^{30}$ Ver: http://www.discapacitados.info/nacionales/funda.html 


\begin{tabular}{|c|c|c|c|c|c|c|}
\hline & $\mathrm{n}$ & & Común & Común & & \\
\hline $\begin{array}{l}\text { Mentales } \\
\text { (psicóticos) }\end{array}$ & $\begin{array}{l}\text { Cuadros } \\
\text { Agudos }\end{array}$ & \begin{tabular}{|l} 
Estimulaci \\
ón \\
temprana \\
Tratamient \\
o \\
ambulatori \\
o
\end{tabular} & \begin{tabular}{|l} 
Estimulaci \\
ón \\
temprana \\
Tratamient \\
o \\
ambulatori \\
o
\end{tabular} & $\mid$\begin{tabular}{|l} 
plínica \\
psiquiátrica \\
Hospital de \\
día \\
Comunidad \\
Terapéutica \\
Tratamient \\
o \\
ambulatori \\
o
\end{tabular} & \begin{tabular}{|l} 
Clínica \\
psiquiátrica \\
Hospital de \\
día \\
Comunidad \\
Terapéutica \\
Tratamient \\
o \\
ambulatori \\
o
\end{tabular} & \begin{tabular}{|l} 
Clínica \\
psiquiátrica \\
Hospital de \\
día \\
Comunidad \\
Terapéutica \\
Tratamiento \\
ambulatorio
\end{tabular} \\
\hline $\begin{array}{l}\text { Discapacitad } \\
\text { os en } \\
\text { general, sin } \\
\text { familia o } \\
\text { hábitat }\end{array}$ & \begin{tabular}{|l} 
Con \\
requerimient \\
os \\
asistenciales
\end{tabular} & Pequeños & ogares - Res & idencias - Ho & gares & \\
\hline
\end{tabular}

Las prestaciones resaltadas están previstas en el Sistema Único de Prestaciones Básicas para personas con Discapacidad, incluidas en la Ley 22901 y su decreto reglamentario. Selección de la autora

La década del 90 produjo estas prestaciones básicas de atención integral destinadas a personas con discapacidad, partir de la sanción en 1997 de la Ley 24.901 instaurando el Sistema de Prestaciones Básicas en Habilitación y Rehabilitación Integral a favor de las Personas con Discapacidad. ¿Qué supuso esto? La conformación de un directorio, que discute criterios, normas y 
aranceles $^{31}$. La segunda década infame (Grassi, 2003) implicó la pérdida de capacidad regulatoria estatal, por lo que este directorio asumía la toma de decisiones que en otros contextos, debió ser con exclusividad obligación / derecho estatal.

También, la conformación del marco básico hizo que los itinerarios de los agentes estén pautados por la mirada técnica profesional en forma central. ¿Cuánto de la autonomía del sujeto aparece en estas políticas?

La década del 90 y la articulación de dispositivos de atención pueden ser leídas desde varias líneas:

- por un lado generó un entramado de dispositivos que venían generándose pero que los colocó en clave de responsabilidad de las obras sociales, la participación por un centro de rehabilitación o a estrategias de estimulación temprana, entre otras, pasaba a ser un derecho,

- pero por otro lado, la respuesta no resulta homogénea en el país, Ya que la obligatoriedad de brindar estos servicios sólo es para los que son beneficiarios de obras sociales nacionales. Para aquellos que no cuentan con obra social o pre paga, el acceso está vedado. La realidad es diferente de acuerdo a cada provincia. Para el caso de la Provincia de Buenos Aires, que nunca adhirió al Sistema, los ciudadanos bonaerenses que carecen de obra social no son titulares de este derecho. Actualmente, las Provincias que han adherido a esta Ley

\footnotetext{
${ }^{31}$ El Directorio de Prestaciones Básicas está conformado por Representantes de CONADIS (Comisión Nacional Asesora para la Integración de las Personas con Discapacidad), la Secretaría de Políticas, Regulación e Institutos. Ministerio de Salud de la Nación, Programa INCLUIR SALUD (EX- PRO.FE), Superintendencia de Servicios de Salud, SUR (Ex Administración de Programas Especiales), el Servicio Nacional de Rehabilitación y Promoción de la Persona con Discapacidad, el Programa Nacional de Garantía de Calidad de la Atención Médica, el Instituto Nacional de Servicios Sociales para Jubilados y Pensionados, la Superintendencia de Riesgos del Trabajo, el Consejo Federal de Discapacidad, el Consejo Federal de Salud, y las Organizaciones No Gubernamentales prestadoras de servicios.
} 
Nacional son: Catamarca, Chaco, Chubut, Córdoba, Corrientes (Decreto Ley $n^{0} 156 / 01$ ), Entre Ríos, Formosa (Decreto Decreto No 858/00), Jujuy, La Pampa, La Rioja, Mendoza, Misiones, Neuquén, Río Negro, Salta, San Juan, San Luis, Santa Cruz, Santa Fe y Tucumán ${ }^{32}$.

Lo que deja en evidencia el Sistema único es la creación de un consenso sobre los itinerarios posibles, lo que configura un espacio - tiempo rígido, pero tal consenso no es para todos los ciudadanos con discapacidad. La sola portación del certificado no habilitaría los accesos que promete.

\subsection{Idearios de inclusión social ¿hegemónicos?}

Existen consensos en el análisis de la política pública desde 2003 en adelante, que el estado argentino ha recuperado su capacidad de conducción de los procesos macroeconómicos, y que ha logrado incluir el enfoque de derechos en el diseño de todas las políticas. Al mismo tiempo, se identifica que el sector salud es el que menos transformaciones ha generado, sosteniendo un diseño mercantilizado que siguió sosteniendo un esquema de transferencias de ingresos similar al de la década anterior. Este diseño de gastos en salud y priorización de sectores, atraviesa el sistema prestacional en discapacidad. Sistema que sólo es accesible para las personas con discapacidad que cuentan con cobertura de obras sociales o pre - pagas. Esto marca que el campo de la discapacidad disputó en esta década fuertemente las implicancias de los procesos de inclusión social.

Asimismo, destacamos que en el período 2003 a 2015 se han generado avances en materia legislativa, sobre todo desde 2008 cuando Argentina adhiere a la Convención de derechos de las personas con discapacidad. Esto generó atravesamientos de discursos asociados a los derechos en los programas específicos, en las normativas de cada organización. Aparece un ideario

\footnotetext{
${ }^{32}$ Para ampliar sobre el particular se sugiere http://www.conadis.gov.ar/sistema.html
} 
traducido en palabras que manifiestan un tránsito desde las personas con discapacidad como objetos de caridad, tratamientos y protecciones a las personas en tanto sujetos de derechos. Este cambio, este recorrido viene siendo transitado de manera intensa, con disputas fuertemente argumentadas por diferentes agentes sociales. No obstante, los modos habituales, instalados en los diseños de dispositivos de atención tensan ambas miradas. Otro de los avances en estos 12 años ha sido la Asignación universal por hijo con discapacidad, la que permitió generar cobertura de seguridad social a todos los niños, niñas, jóvenes y adultos con discapacidad ${ }^{33}$, más allá de cuál sea la situación laboral de los padres. Es decir, los hijos de los trabajadores empleados o desempleados tienen acceso a una transferencia mensual se ingresos. Esto colocó en un pie de igualdad a todos los niños. Particularizando a las situaciones de discapacidad, los montos ascienden a $\$ 2100$ mensuales, para quienes tengan ingresos salariales de hasta 5.800 mensuales y de 936 para quienes perciban de 7.000 a 15.000 de salario. Para aquellos padres que no posean ingresos, también pueden tramitar la asignación $^{34}$.

Desde 2003, se amplió sustancialmente la cobertura de pensiones no contributivas nacionales, las que hasta ese momento sólo se generaban cuándo quedaba una pensión vacante. En este período se crearon más de un millón de pensiones no contributivas, a través de la Comisión Nacional de Pensiones,

\footnotetext{
${ }^{33}$ La Asignación Familiar por Hijo o Hijo con Discapacidad es el pago mensual, de acuerdo a los montos vigentes, que abona ANSES al trabajador registrado y titulares de las siguientes prestaciones: Desempleo, Aseguradora de Riesgos del Trabajo, Sistema Integrado Previsional Argentino o Pensión Honorífica de Veteranos de Guerra del Atlántico Sur. El pago es por cada hijo menor de 18 años, aunque éste trabaje en relación de dependencia o sea beneficiario de cualquier prestación de la seguridad social. En caso de cobrar la asignación familiar por hijo con discapacidad no hay edad límite para percibirla y la persona con discapacidad debe tener vigente la Autorización por Discapacidad emitida por ANSES. Para ampliar información se sugiere: http://www.anses.gob.ar/prestacion/hijo-hijocon-discapacidad-86
}

${ }^{34}$ Datos a noviembre 2015 
organismo dependiente del Ministerio de Desarrollo Social de la nación ${ }^{35}$. El crecimiento de las pensiones otorgadas ha sido del $250 \%$ en el período de referencia ${ }^{36}$. La percepción de las pensiones va integrada a la cobertura en salud, con el Programa Incluir Salud, es decir un Sistema de Aseguramiento Público que garantizaría el acceso a los servicios de salud a todos los perceptores de estas pensiones. No obstante, de las entrevistas a los colegas, surge con claridad que el "Incluir Salud" (ex Profe) no logra dar la cobertura con la equidad que promulga en sus normas. Cómo la gestión del programa se realiza en forma articulada con los gobiernos de las 24 jurisdicciones/ provincias, la calidad de prestaciones son diversas, desiguales e inequitativas. Algunas de estas cuestiones asociadas a la falta de financiamiento y otras a la burocratización para concretar el acceso. Esta situación nos lleva a pensar en clave de accesibilidad

"la noción de accesibilidad se presenta como una vía de entrada para re pensar las Políticas Sociales y las de Salud poniendo a la perspectiva del sujeto social en relación a su situación y visión del proceso salud enfermedad especialmente desde su condición sociocultural y las relaciones entre las Politicas Sociales y las posibilidades de reconstrucción de la sociedad en un lugar central. En principio la accesibilidad, se cimenta como una vinculación, es decir como un lazo social entre el sistema de salud o de acción social y los usuarios de ésta” (Carballeda, 2014:2).

Otro aspecto a destacar es la reglamentación de la Ley 26.657 Derecho a la Protección de la Salud Mental, que instala un nuevo ideario en torno a las

\footnotetext{
35 Para ampliar sobre el otorgamiento de pensiones, se sugiere: http://www.desarrollosocial.gob.ar/tramitepensiondiscapacidad

${ }^{36}$ La cobertura de las pensiones no contributivas, se suma en una lógica incremental de todo el sistema de seguridad social a para ampliar sugerimos:
} http://www.sigen.gov.ar/red_federal/pdfs_red/proteccion_social.pdf 
formas asistenciales, las estrategias profesionales y los derechos de los sujetos que son incluidos en este campo. Siguiendo a Weber (2013) planteamos que los principios que estarían orientando las práctica profesionales, en concordancia con el cuerpo de la ley, reafirma que: las personas con padecimiento mental pueden ser tratados fuera del manicomio, que es necesario y posible trabajar interdisciplinariamente y que es un imperativo estructurar las intervenciones desde una concepción de sujeto no deficitaria. La Ley de salud mental, junto a la Convención de la ONU se han constituido en dos herramientas centrales en las disputas que se vienen dando frente a la vulneración de derechos, tanto en las disputas sostenidas por los trabajadores sociales cómo por parte de los organizaciones de la sociedad civil.

Otro punto destacable, de este proyecto político ha sido la modificación del Código Civil, en el que incluyeron los Sistemas de Apoyos para el ejercicio de la capacidad jurídica. En este punto, señalamos estamos experimentando un proceso de transición desde el paradigma ó ideario del interés superior hacia el de la voluntad y las preferencias . Esto posibilitaría que las personas con discapacidad puedan ejercer su capacidad jurí dica en condiciones de igualdad con los demás. Esta mirada, invita a iniciar intervenciones desde la certeza que el sujeto con el que trabajamos tiene capacidad de decisión, es autónomo y no debo reemplazar su voluntad. Este horizonte, se recrea en cada práctica.

Otro avance significativo ha sido en materia comunicacional, sobre todo desde la sanción de la Ley 26522, de Servicios de comunicación Audiovisual en el que instala criterios de accesibilidad:

Artículo 66: Accesibilidad: Las emisiones de televisión abierta, la señal local de producción propia en los sistemas por suscripción y los programas informativos, educativos, culturales y de interés general de producción nacional 
deben incorporar medios de comunicación visual adicional en el que se utilice subtitulado oculto (closed caption), lenguaje de señas y audio descripción, para la recepción por personas con discapacidades sensoriales, adultos mayores y otras personas que puedan tener dificultades para acceder a los contenidos. La reglamentación determinará las condiciones progresivas de su implementación Ley 26522

Esta ley en general, y la referencia a las personas con discapacidad en particular, integra junto a otras políticas la ampliación de derechos al consumo de bienes culturales. En este sentido, podríamos ratificar esta idea de década ganada. Obviamente, la configuración de las políticas, el diseño de la agenda pública hace que sea controversial ratificar que la globalidad del proyecto político kirchnerista haya sido de avances. Lo que es innegable, es la instalación de un discurso progresista dispuesto a batallar contra miradas de la caridad ó liberales.

Otro Programa que destacamos es el Conectar Igualdad, en el mismo las escuelas de educación especial han sido incluidas en el Programa Nacional Conectar Igualdad $^{37}$ por el que se entregan Netbooks a los alumnos de las escuelas Secundarias, de escuelas especiales y de los institutos de Formación Docente de todo el territorio nacional. Este diseño de política nacional acorta la brecha digital, entendida esta como una expresión de los accesos diferenciales a los consumos culturales. El Programa Conectar Igualdad inicio sus actividades en el año 2010, identificando como problema a abordar la falta de acceso a las tecnologías de la información y comunicación por parte de las escuelas, en este caso, de educación especial. Las netbooks que recibieron los alumnos tienen un escritorio pensado específicamente de acuerdo a sus necesidades pedagógicas,

\footnotetext{
${ }^{37}$ Para ampliar sobre el programa que se desarrolla en la República Argentina, sugiero consultar: http://www.conectarigualdad.gob.ar/
} 
como por ejemplo Bancos de imágenes históricas, softwares, videos educativos de Educ.ar ${ }^{38}$ y Encuentro ${ }^{39}$, actividades escolares, juegos, libros clásicos de la literatura universal, nacional y latinoamericana, entre otros recursos, están a disposición de alumnos y maestros, con la particularidad de contar con sintetizador de voz, audiolibros y otras especificaciones de acuerdo al tipo de discapacidad $^{40}$.

En el año 2011, se creó el Programa Nacional de Asistencia para las Personas con Discapacidad en sus Relaciones con la Administración de Justicia en la Secretaría de Justicia, Decreto 1375/2011, por el que se hizo visible un problema histórico en torno a las barreras comunicacionales, actitudinales y económicas en el acceso a la justicia.

Simultáneamente a estas estrategias de ampliación de ciudadanía en torno a la acción estatal, se sostiene paradojalmente la reproducción de un estado de cosas relacionado a la producción de servicios mercantilizados, por lo que surgió la necesidad de referenciar el Sistema Interamericano Sobre igualdad, no discriminación y derechos de las personas con discapacidad. En tal sentido, por un lado planteamos que nuestro país adhirió a la Convención Interamericana para la eliminación de todas las formas de discriminación contra las personas con discapacidad (1999 a 2001) ${ }^{41}$ se han dado múltiples avances en materia de derechos de las personas con discapacidad, fundamentalmente porque el Estado nacional se ha puesto en acción. Pero por otro lado, identificamos a malestares en torno a la configuración de políticas de discapacidad, que algunos agentes del campo plantearan como discapacitantes. Los accesos diferenciales, las prácticas cotidianas negadoras de procesos de autonomía fueron las evocaciones que nos dejaron evidenciar estas paradojas propias del campo.

\footnotetext{
${ }^{38}$ Para ampliar sobre estos recursos educativos, se sugiere consultar: http://www.educ.ar/

${ }^{39}$ Canal Encuentro, se sugiere consultar página: http://www.encuentro.gov.ar/

40 Para ampliar sobre el tema, se recomienda: http://www.conectarigualdad.gob.ar/seccion/sobreprograma-6

${ }^{41}$ Para mayores precisiones de fechas: http://www.oas.org/juridico/spanish/firmas/a-65.html
} 
Otro de los saltos cualitativos de este momento ha sido la inclusión de los postulados de la CIF - Clasificación Internacional del funcionamiento y la Salud - en el desarrollo de las juntas evaluadoras de discapacidad.

La consideración de los sujetos desde la perspectiva de las limitaciones y restricciones adoptada durante la Dictadura argentina, ha sido reemplazada por los términos funciones, estructuras corporales así como actividades y participación que desplazan al léxico usado previamente en el CIDDM (deficiencia, discapacidad y minusvalia) (Santarrone, y Kaufmann, 2005:86)

Este corrimiento semántico que señalan los autores pone en evidencia las narrativas disputando en los últimos años. Y allí nos preguntamos si los idearios de inclusión social produjeron hegemonía en el campo, y si como señala el kirchnerismo se trató de una década ganada. ¿Podemos hablar de ganadores y perdedores? Nuestra propuesta ha sido o complejizar en términos de la identificar de posiciones que se produjeron en el campo.

\subsection{Suscripción del estado argentino a la convención}

De acuerdo a la información recabada ${ }^{42}$ en el Informe Preliminar sobre la situación de las personas con discapacidad en la Argentina $^{43}$ expresan las dificultades por las que atravesaba nuestro país al inicio de la década del 2000, identificando situaciones de vulneración de los derechos fundamentales de las personas con discapacidad.

\footnotetext{
${ }^{42} \mathrm{http}$ ///www.foropro.org.ar/informe.html, informe de agosto 2003

43 Informe elaborado por el Comité de Evaluación del Seguimiento de la Convención Interamericana para la Eliminación de Todas las Formas de Discriminación Contra las Personas con Discapacidad integrado por las cuatro organizaciones de la sociedad civil firmantes del Convenio que resolvió su creación. Es decir, el Departamento de Discapacidad de la Central de Trabajadores Argentinos (CTA), el Área de Discapacidad de AMIA -Comunidad Judía, el Foro Permanente para la Promoción y la Defensa de los Derechos de las Personas con Discapacidad (Foro-Pro) y la Comisión para las Personas con Discapacidad del Arzobispado de Buenos Aires.
} 
Como señalamos en párrafos anteriores Argentina, mediante la Ley $\mathrm{N}^{\mathrm{o}}$ 26.378 aprobó la Convención sobre los Derechos de las Personas con Discapacidad y su Protocolo Facultativo ${ }^{44}$, que tiene como propósito, promover, proteger y asegurar el goce pleno y en condiciones de igualdad de todos los derechos humanos y libertades fundamentales, de todas las personas con discapacidad, y promover el respeto de su dignidad inherente.

La Convención fue aprobada en el año 2008, siendo interesante la recuperación de uno de los discursos que se pronunciaron en la Cámara de Diputados.

"El discurso políticamente correcto de la igualdad y de la no discriminación no se concretiza en las prácticas cotidianas. El derecho a determinar la propia vida, a casarse, a la propiedad, a la vivienda, a la vida sexual efectiva, a la libertad de pensamiento y de opinión, a la participación política, a la información accesible, al trabajo, a la salud, a la educación y a la dignidad, y al bienestar, son derechos de utilería” (Diputado Morgado, 2008)

Claramente lo que se discutía no era sólo un tratado internacional sino la posibilidad de contener en la dimensión jurídica una idea de sujeto de derecho que incluya a las personas con discapacidad. Se reconoció en esa sesión que "La ciudadanía de las personas con discapacidad aún no es una ciudadanía completa" (Diputado Morgado, 2008). El discurso de la Convención presenta un alto contenido igualitarista que impregnó en las narrativas de quienes proponían su adhesión. En ese punto retomamos la propuesta de Hans Joas quien plantea:

\footnotetext{
${ }^{44}$ El 19 de noviembre de 2014, mediante la Ley 27044 se le otorgó jerarquía constitucional en los términos del artículo 75, inciso 22 de la constitución nacional, a la convención sobre los derechos de las personas con discapacidad.
} 


\begin{abstract}
"Propongo concebir la fe en los derechos humanos y en la dignidad universal del hombre como el resultado de un proceso de sacralización específico, en el cual cada ser humano en particular, paulatinamente $y$ de una manera cada vez más motivadora y sensibilizadora, fue comprendido como sagrado, y esa comprensión fue institucionalizada en el derecho" (2015:19)
\end{abstract}

Pablo Rosales (2007) analiza la Convención señalando que “el artículo 4 determina las obligaciones de los Estados de las que destacamos: exige a los estados: Tener en cuenta, en todas las políticas y todos los programas, la protección y promoción de los derechos humanos de las personas con discapacidad", esto significa que la discapacidad deberá ser un tema de todas las áreas de gobierno (a diferencia de lo que ocurre actualmente, que la discapacidad es tratada casi únicamente por las áreas específicamente establecidas para ello), obligación que presupone la determinación de un presupuesto específico para la temática en cada área de gobierno. Respecto a la elaboración y aplicación de políticas para hacer efectivos los derechos que surgen de este instrumento, la Convención exige escuchar a las personas con discapacidad, incluidos los niños y las niñas con discapacidad, a través de las organizaciones que las representan (aclaración extraña cuando en otros artículosque ya analizaremos- la Convención le otorga a los niños y niñas mayor autonomía).

Entonces, diremos que las obligaciones estatales deberán expresarse a largo plazo en la cotidianeidad de la gestión del estado. Y en ese sentido planteamos que el artículo 3 de la Convención - Principios Generales - resulta estratégico para una rápida difusión y socialización del “espíritu” de la convención. 
En Junio 2011 se aprobó el Decreto 806/2011 configurando a la Comisión Nacional Asesora para la Integración de las Personas con Discapacidad (Conadis) como organismo gubernamental encargado de las cuestiones relativas a la aplicación de la Convención. En el mismo acto se creó el Observatorio de la Discapacidad, y por Decreto 1585/2011 de designó en tal función a la Prof. Silvia Bersanelli. Considerando que la Conadis es el organismo rector de la aplicación de la Convención en nuestro país, el Consejo Federal toma un rol relevante. El mismo se halla Integrado por los funcionarios que ejerzan la autoridad en la materia en el más alto nivel, en cada una de las provincias, la Ciudad Autónoma de Buenos Aires y los representantes de las organizaciones no gubernamentales de o para personas con discapacidad, elegidos de conformidad con el artículo $6^{\circ}$ de la ley 24.657.

De acuerdo a las entrevistas que realizamos y los informes recabados en el proceso investigativo podríamos afirmar que en la materialidad de las intervenciones profesionales la macro - estructura no tiene referencia cotidiana, habida cuenta que la apelación a organismos superiores no es una práctica habitual.

La provincia de Bs As, a través del área de discapacidad conserva 4 programas (Hogares, Centro de día, taller protegido y actividades ecuestres). Actualmente, $\quad y$ de acuerdo a lo presentado por Gaviglio (2014:111/2), desarrolla el programa hogares en 30 de los 138 Municipios con los que cuenta la provincia. Centro de Día en 49 de los 138 , Taller Protegido en 115 distritos sobre 138. Y actividades ecuestres en 3 de los $138^{45}$. La mirada de los/as entrevistados plantean que esta Dirección ha dejado de construirse en referencia como así lo había sido en el retorno a la democracia. Una de las

45 Para ampliar sobre el modo de financiamiento se sugiere consultar http://www.mds.gba.gov.ar/PoliticasSociales/discapacidad.php 
razones las sitúa en la falta de respuestas, en la escasez de recursos, en la discontinuidad en las estrategias de abordaje.

"En general, en la provincia en materia de recursos estamos pobres, muy pobres. Tenemos una vía para canalizar determinados pedidos: hacer uso de la ley de cheques, que es nacional pero se hace uso, bueno, es para todos. Es para todos; sobre todo ahora que, afortunadamente, se amplió y aparecieron un montón de programas que no estaban previstos: ahora hay 22 programas previstos, y eso está bueno. Pero en realidad, tenés pocas vías." (Entrevistada TS: 158)

Sin lugar a dudas, el ámbito de empleo y accesibilidad se constituyen en los más relevantes. El trabajo, en nuestras sociedades regidas por el modo de producción capitalista, se instituye en un medio de vida, a la vez que funciona como organizador y articulador de sentido en la vida cotidiana y al mismo tiempo tiene implicancias en la subjetividad.

Es por esta intersección fundante del trabajo -fuente de satisfacción libidinal y de expresión o lazo social reconocido culturalmente- que el mismo aparece como un privilegiado escenario en el que se juegan los procesos subjetivos $^{46}$. Pensar en el trabajo, implica dialogar con el ámbito educativo y la creación de competencias laborales, algo del orden del saber - hacer.

\footnotetext{
${ }^{46} \mathrm{Al}$ respecto nos basamos en Gabrinetti,M. y Ros. C. "Representaciones del trabajo en empleados públicos", en Domínguez Mon,A y otros (comp.) "La salud en crisis. Un análisis desde la perspectiva de las ciencias sociales". III Jornadas Interdisciplinarias de salud y población, Ed. Dunken, Bs.As., 2000 .
} 
La última década ha marcado un fuerte arraigo del discurso de derechos humanos en los procesos de diseño de políticas de discapacidad y trama el horizonte ético - político de la profesión.

$Y$ los trabajadores sociales en ese sentido también, no se construye igual. Porque dentro de la carrera no está la mirada social, es increíble, pero no está esto, no está, no está. Entonces vos cuando salis al ruedo, al mundo, construís desde lo que sos y desde lo que pudiste construir en tu vida. - Entrevistado TS - Código: 97)

Esta afirmación, de unos de los referentes teóricos y políticos del campo instala un interrogante ineludible en torno a ¿Cómo se construye la discapacidad en clave interventiva? ¿Cómo se materializan las disputas del campo de la discapacidad? ¿Cómo inciden los procesos formativos de grado y posgrado en las argumentaciones de los colegas?

\section{2. - Configuración del campo: preguntas y respuestas desde la intervención}

Hace aproximadamente 10 años venimos pensando a la discapacidad como campo en los términos de Pierre Bourdieu. En esa línea, hemos generado producciones (Danel, Katz, 2004, 2006, 2011), que nos permitieron comprender la dinámica del mismo e interrogarnos sobre la pertinencia del concepto. En esta oportunidad, trazaremos algunas coordenadas que nos posibilitan continuar explorando el concepto, intentando aproximaciones más cabales al mismo. 
Coincidiendo con las ideas postuladas por Carlos Skliar (2002) e Indiana Vallejos (2004) la discapacidad es comprendida como "una retórica cultural 47", es decir, una producción social que se sostiene en las relaciones de asimetría y desigualdad. Nos diferenciamos de las posturas que intentan explicar la discapacidad desde un hecho biológico individual, ya que creemos que las mismas están sustentadas en cierto darwinismo social ${ }^{48}$ despojando a la discapacidad de su dimensión social y atribuyendo a la organicidad como la única causante de la misma. Retomando Rosato (1999) quien plantea que la discapacidad ha sido pensada como construcción de una otredad diferente medida con la imagen de un "nosotros" blanco y occidental. La discapacidad fue etnocéntricamente mirada, medida y abordada. Desde el advenimiento de la modernidad y de las sociedades disciplinarias (Foucault, 1999) comienza un proceso de encausamiento y clasificación entre sujetos capaces de adaptarse a los requerimientos de la sociedad capitalista y los sujetos que se corren de la norma, es decir, los que no responden al estereotipo de hombre medio, blanco, occidental. Todo aquello que se aparte de la norma será expulsado, castigado, separado, señalado.

El objetivo que nos trazamos es desentrañar los sentidos que instalan los agentes sociales en el campo de la discapacidad, comprender las prácticas y estrategias de ortodoxia que se configuran en el mismo en pos de garantizar el mantenimiento del "estado de cosas" y cuáles son las estrategias que buscan subvertir las mismas. (si existieran)

\footnotetext{
47 "es posible asignar un campo específico y relativamente autónomo a la cultura, entendida como una dimensión de la vida social, si la definimos por referencia a los procesos simbólicos de la sociedad. De este modo la cultura se concibe como una dimensión analítica de la vida social, aunque relativamente autónoma y regida por una lógica (semiótica) propia, diferente de las lógicas que rigen, por ejemplo, a las dimensiones económica y política de la sociedad, ambas situadas en el mismo nivel de abstracción. En este nivel, la cultura se contrapone a la naturaleza y a la no-cultura. (Gimenez, 2007:4)

48 El darwinismo social postulaba, que era posible la utilización del principio de la evolución orgánica de Cahrles Darwin al orden social. Su exponente más relevante ha sido Herbert Spencer (1820-1903, quien argumentaba que las sociedades eran organismos que evolucionaban con el tiempo a partir de una lucha librada con su entorno y que el progreso era consecuencia de "la lucha por la supervivencia", a medida que el "adaptado — el fuerte — avanzaba, mientras que el débil sucumbía.
} 
Esta línea de análisis nos permitió dilucidar el proceso de constitución de hegemonía dentro del campo, las ratificaciones de los discursos científicos y profesionales, los mecanismos de legitimación y las contiendas.

Tomamos el concepto de campo propuesto por Bourdieu:

"en términos analíticos, un campo puede definirse como una red o configuración de relaciones objetivas entre posiciones. Estas posiciones se definen objetivamente en su existencia y en las determinaciones que imponen a sus ocupantes, ya sean agentes o instituciones, por su situación (situs) actual y potencial en la estructura de la distribución de las diferentes especies de poder (o de capital) -cuya posesión implica el acceso a las ganancias específicas que están en juego dentro del campo-y, de paso, por sus relaciones objetivas con las demás posiciones (dominación, subordinación, homología, etc.).” (Bourdieu, Pierre y Loïc Wacquant, 1995:64)

Decidimos hablar del "campo de la discapacidad" en referencia a una porción del espacio social delimitada a partir de una red de relaciones, intrínsecamente conflictivas, entre posiciones ocupadas por agentes sociales que se disputan nominaciones, clasificaciones y acciones sobre la discapacidad. (Danel, Katz, 2011:80)

Hablar de discapacidad en tanto categoría socialmente construida implica pensarla como producto de procesos sociales singulares, es decir desde el interjuego constante entre estructuras y agentes. El autor mencionado plantea que lo que define a un campo es el capital específico en juego y las luchas por su apropiación o conservación. En tal sentido requerimos, para avanzar en el análisis, definir cuál era ese capital. Ahora bien, de las entrevistas que 
realizamos emanaba con claridad una pretensión por la definición de las necesidades de las personas en situación de discapacidad. Esta pretensión incluía a distintos agentes con titulaciones diferentes que ocupaban espacios diferenciales dentro del campo y construían con sus prácticas y discursos los límites entre la discapacidad y la "no discapacidad". (Danel, Katz, 2011:80) Planteamos en ese artículo que el capital específico en juego en el campo era la definición del "bienestar" de la población que porta discapacidades. Es decir, una disputa de saber/poder que dirime cómo se define la discapacidad y a partir de allí qué necesidades presenta el sujeto que la porta dando por supuesto que la definición de este bienestar solo podrá efectuarse si se posee un conocimiento científico y profesional sobre la misma. Bienestar vinculado a la idea de calidad de vida, de “estar bien”.

En este punto, es necesaria una revisión a la luz de la profundización del proceso analítico. ¿Es pertinente pensar la categoría de campo? La idea de un único capital en disputa, ¿es posible? ¿Podemos pensar la idea de "bienestar" sin caer en discursos vinculados a equilibrios bio - psico sociales? ¿La historia del concepto bienestar, no nos obtura la posibilidad de comprender aquello por lo que se desatan las controversias en el campo? En esa línea de análisis, lo que surgía en las narrativas de los / las entrevistadas /os era un fuerte cuestionamiento hacia los dispositivos de atención especializados y la duda sobre si aquellos que eran "asistidos" debían estar allí. Los interrogantes más fuertes tenían que ver con quiénes eran estos sujetos, qué necesidades tenían y si las respuestas que desplegaban/mos eran las adecuadas. Por tanto, pudimos comprender que emergían sentidos en torno a la definición misma de discapacidad. 
Continuamos preguntándonos ¿Cuánto de la Teoría de la Jerarquización de las Necesidades ${ }^{49}$ de Abraham Maslow (1968) están presentes en la idea de bienestar que iniciamos ponderando?

“El nacimiento de los estudios sobre bienestar está estrechamente vinculado al bienestar global de las personas considerando la vida como un todo. Paralelamente, el estudio con profundidad de distintos aspectos de la vida ha sido muy productivo (piénsese en la satisfacción con el trabajo, o con la relación de pareja). El famoso modelo inicial de Andrews y Withey (1976) fue superado en poco tiempo, al demostrarse que el funcionamiento multidimensional del bienestar no quedaba reflejado en una simple suma de los bienestares de cada ámbito de la vida. Ello dio lugar a modelos teóricos cada vez más complejos.” (Casas, 1999:5)

Varias discusiones se han recuperado desde las ciencias sociales en torno a la categoría de calidad de vida, por lo que veníamos pensando a la misma como la percepción individual de la propia posición en la vida dentro del contexto del sistema cultural y de valores en que se vive y en relación con sus objetivos, esperanzas, normas y preocupaciones. Se trata de un concepto de amplio espectro, que incluye de forma compleja la salud física de la persona, su estado psicológico, su nivel de independencia, sus relaciones sociales, sus creencias personales y su relación con las características destacadas de su entorno» (OMS, 1994).

\footnotetext{
49 Con sus cinco niveles de necesidades: fisiológicas, de seguridad, sociales, de estima y de autorrealización.
} 
Calidad de vida en tanto ideario colectivo de bienestar. Si la idea de bienestar implica la puesta en juego de procesos sociales y subjetivos, ¿es posible pensar que aquello que se disputa en el campo es la idea de bienestar? ¿O al fin de cuentas, lo que está en disputa es la definición misma de discapacidad?

"A mí me gusta mucho la definición que adopta la Convención. Esto de que es una resultante de la interacción entre nosotros, que podemos tener alguna deficiencia, y el contexto que presenta barreras. Lo creo en serio, no lo digo como cliché. Realmente lo creo, porque creo que cada uno de nosotros puede hacer un montón de cosas, buenas o malas, en tanto y en cuanto disponga de los recursos que lo hagan accesible. Con oportunidades equiparadas, todos podemos hacer cosas buenas y cosas malas también." (Entrevistada TS, código 198)

Si nuestra nueva hipótesis es que el capital en juego es la definición misma de discapacidad, entendemos que poner en tensión las prácticas de los trabajadores sociales en torno a la discapacidad nos dará pistas sobre el modo en que funciona y se despliega el campo.

En tal sentido, es necesario explicitar las formas en que viene siendo pensada la discapacidad, y desde allí tramar la definición de la misma. Elegimos referirnos en términos de modelos, siguiendo la propuesta metodológica de Menéndez (1990) a fin de ordenar en términos explicativos las tendencias que presenta.

Palacios (2008) propone los modelos de: Prescindencia - con los submodelos eugenésico y de marginación - ; Rehabilitador y Social. Estos pulsan junto a la historia de occidente y proponen pasajes desde dominios 
religiosos a justificaciones científicas. Esta propuesta es re - significada en función del tema abordado y las especificaciones espacio - temporales que nos interesaron investigar, por lo que hablaremos de modelos médico y modelo social.

Por modelo médico de la discapacidad comprenderemos las prácticas y discursos que se producen desde el dominio de la naturaleza, por lo que se instala la falta, la deformación, el mal funcionamiento como razón de ser de la discapacidad. En tal sentido, el modelo médico de la discapacidad incluye a un conjunto de prácticas, no necesariamente concordantes en sus formas, pero que tienen la misma matriz en el modo en que producen y reproducen a la discapacidad. Es decir, la discapacidad desde este modelo es la consecuencia individual de algo que funciona en el plano corporal de manera deficitaria (por ausencia ó forma inadecuada). Esta mirada supone un particular comportamiento de los agentes.

El modelo médico de la discapacidad, lo podemos enlazar con las características que propone Menéndez (1990) para el Modelo médico hegemónico, lo que supone un proceso histórico - social que medicaliza las prácticas de los agentes. En tal sentido, incluiremos esta manera de pensar la discapacidad en los procesos medicalizantes que se han dado en varias esferas de la vida, lo que implicó un proceso expansivo en el diagnóstico y tratamiento médico de situaciones que previamente no eran consideradas problemas de salud (Iriart y Ríos, 2000). Dentro de este modelo, podríamos delinear un sub modelo individual y uno rehabilitador. En el sub - modelo individual incluimos las prácticas que tienden a culpabilizar por las deficiencias, ó sólo analizarlas desde el dominio médico, con un claro ejemplo de lo que sucede con las deficiencias adquiridas por los adultos mayores que cómo respuesta se generan los encierros en los propios domicilios ó en instituciones delineadas para tal fin. En cuanto al sub - modelo rehabilitador pensamos en las prácticas que 
se generan en pos de normalizar los funcionamientos corporales desde prácticas de estímulo - respuestas en las que la voluntad individual será fundante de los procesos de recuperación, como ejemplo podemos incluir las estrategias de estimulación temprana que proponen a los papás como rehabilitadores, ó a todas las prácticas incluidas en el mundo de la fisiatría. En el capítulo II retomaremos estas formas de pensar a la discapacidad con las matrices teóricas desde las que fue pensada / narrada / intervenida la discapacidad y la intervención.

\begin{tabular}{|l|l|}
\hline \multicolumn{2}{|c|}{ Modelo médico de la discapacidad } \\
\hline Sub - modelo individual & Sub modelo rehabilitador \\
\hline
\end{tabular}

Por modelo social de la discapacidad vamos a retomar las discusiones que propone Oliver (1983) reconociendo que las causas de la discapacidad no son biológicas, sino sociales. La primera cuestión a destacar como diferencial en este modelo, es que la deficiencia pertenece al dominio de la naturaleza, siendo que la discapacidad es entendida como un dominio de lo social. La carencia de un órgano, su mal funcionamiento ó la lentificacioón de funciones serán del dominio médico, mientras que las limitaciones que se le impongan al sujeto con deficiencias no serán de su responsabilidad sino producto de la organización social. En este modelo social, podemos identificar dos sub - modelos uno asociado a los postulados de la CIF al que denominamos bio - psico social y el otro más vinculado a las luchas reivindicativas que denominamos como de diversidad funcional. El sub- modelo bio psico social plantea que la discapacidad se construye de la interacción entre un sujeto con deficiencias, en un contexto que impone barreras y eso limita su participación. En cambio, el sub - modelo de la diversidad funcional va a plantear que la opresión social 
sobre los cuerpos imponiendo patrones de normalidad, desdibuja la riqueza de la diversidad de la humano, por lo que cómo forma de emancipación la ratificación discursiva de que hay funcionamientos corporales diversos, es un modo de impugnación.

\section{Modelo social de la discapacidad}

Sub modelo bio - psico social $\quad$ Sub - modelo de diversidad funcional

"yo siento que la discapacidad, y en esto que yo estoy que es la discapacidad mental, yo lo veo como una persona, la cual es vulnerable en relación a que no puede por sí misma acceder a todos sus deseos y a todas sus necesidades y por lo cual necesita del resto. No lo tengo teóricamente conceptuado; quizás es una falencia mía. Me parece que una persona con discapacidad es eso: es una persona que tiene una discapacidad, que en este caso es mental, y que por lo tanto necesita de los demás." (Entrevistada TS: código 1516)

Estas narrativas de colegas son incluidas a los fines de ilustrar la multiplicidad de miradas que se ponen en juego en los procesos interventivos.

En párrafos anteriores planteábamos que la producción y reproducción de sentidos sobre las personas en situación de discapacidad han estado signadas por prácticas racistas, en ese sentido Eduardo Menéndez plantea: 
"el racismo debe ser referido a las formas de relaciones sociales y culturales que implican negación, discriminación, subordinación, compulsión y explotación de los otros en nombre de pretendidas posibilidades y disponibilidades ya sean biológicas, sociales y culturales. Toda relación que signifique cosificar a los otros, es decir negarle la categoría de persona, de igual, toda relación que permita inferiorización y uso de los otros, es racismo" (Menéndez, E: 1973:12).

Recuperando esta definición se puede observar la cosificación del sujeto en el cotidiano de discursos y prácticas sociales. Un ejemplo está asociado a la deshumanización que se produce en los modos de vincularse, de abordar situaciones, de encontrarse. La perspectiva que ponemos en juego para comprender la discapacidad, se distingue completamente de la insuficiencia y de la enfermedad y la considera una producción socio cultural (Vain y Rosato, 2005). En tal sentido nos parece oportuno sumar algunas reflexiones en torno a la idea de construcción social. El modelo social viene ofertando este modo de postular a la discapacidad, contraponiéndose al modelo médico. En tal sentido:

"La metáfora de la construcción social se ha agotado porque todo lo humano ha sido construido. Si bien aún, puede cumplir una función didáctica relevante en contextos especificos, contribuyendo a desnaturalizar sentidos comunes, debería evitarse calificar como "construida" o “inventada" a cualquier tradición, cultura o identidad de la que el observador se sienta distante o a disgusto, mientras se mantiene un silencio sepulcral sobre las tradiciones naturalizadas del propio investigador" (Grimson, 2011:25) 
Nos interesa interrogar, discutir esta idea de construcción social en relación a la noción de discapacidad. Comprendemos que en la batalla cultural de diferenciarnos de la mirada proveniente del modelo médico se ha configurado una estrategia de comunicación que resalta la construcción social de la discapacidad en contrapunto con la mirada centrada en el déficit. Ahora bien, la propuesta de Grimson (2011) entendemos que resulta reveladora y desafiante en clave de buscar argumentaciones sólidas sobre este tema.

"una configuración cultural es un espacio en el cual hay tramas simbólicas compartidas, hay horizontes de posibilidad, hay desigualdades de poder, hay historicidad. Se trata de una noción útil contra la idea objetivista de que hay culturas esenciales, y contra el postulado posmoderno de que la cultura son fragmentos diversos que sólo los investigadores ficcionalizan como totalidades. La noción de configuración busca enfatizar tanto la heterogeneidad como el hecho de que ésta se encuentra, en cada contexto, articulada de un modo específico" (Grimson, 2011:28)

Las configuraciones culturales que se han generado en relación a la discapacidad deben ser comprendidas en tanto producciones históricas que han sedimentado modos de comprensión disímiles y que las articulaciones que han dado aportan a la constitución de hegemonía. En este punto toma sentido las investigaciones que retoman los paradigmas construidos sobre la discapacidad, o los modelos de abordajes (Puig de la Bellacasa, 1987 ó Palacios Agustina, 2009). La noción de configuración viene a situar de manera enraizada las articulaciones posibles.

El campo de la discapacidad se ha instituido en espacio de inserción laboral de los colegas desde la institucionalidad del Trabajo Social como profesión. En 
tal sentido, la carencia de producciones teóricas que recuperen la sistemática inserción da cuenta, entre otras cosas, de cierta subalternización de esta inserción profesional. Tomar la palabra, en tanto disciplina cuya naturaleza es la intervención, amerita la ocupación de espacios en el mundo académico que viabilicen la circulación de saberes. La confluencia de una disciplina subalternizada junto a un campo de intervención con sujetos que son pensados exclusivamente desde sus carencias, han operado para que los saberes construidos desde la práctica hayan sido invisibilizados, desoídos o ni siquiera enunciados. (Danel, 2013)

\begin{abstract}
"Decir una palabra es ponerle voz, darle voz. Hacerla escuchar. Y la voz está en el cuerpo, está encarnada. Decir una palabra y hurgar por dentro de lo dicho es el único modo que disponemos para impedir que una palabra se nos imponga como lo que 'debería ser', se volatilice en el frenesi voraz de estos tiempos y se pierda, irremediablemente, pues ya nadie puede o desea pronunciarlas." (Skliar, 2014 clase virtual pp.1)
\end{abstract}

La palabra enunciada, puesta a circular posibilita el desarrollo de contiendas, de alianzas, de ratificación de saberes, de interrogaciones. En tal sentido, la búsqueda encarada en el trabajo de campo estuvo asociada a poner en diálogo las palabras, las enunciaciones que desde la intervención profesional en el campo de la discapacidad se vienen produciendo. Interrogamos nuestra propia idea de la subalternización del trabajo social, ya que durante el transcurso investigativo advertimos que la profesión había tenido un lugar central en los procesos de producción de políticas. Lo que sí había cambiado, eran las formas de legitimación y construcción de prestigio profesional; algo así como desde la co -autoría en las leyes sin copyright a la presentación incesante de papers de autoría individual. 
Circunscribimos la mirada a las políticas enlazadas al desarrollo de la autonomía, es decir a la posibilidad de tomar decisiones más allá de las particulares condiciones de salud o funcionales. En esa línea encontramos una trayectoria de la política pública vinculada a la negación de la autonomía, a un recorrido sinuoso que negó palabra, decisión y derechos a quienes eran colocados del otro lado, en el sitio diseñado para alojar a quienes eran considerados anormales (en términos foucualtianos)

La autonomía es condición para la definición de ciudadanía, por lo que nos interrogamos acerca de si aquellos que fueron considerados sujetos de asistencia en el mismo proceso de definición no quedaron excluidos del status de ciudadanía. Robert Castel plantea que la "asistencia" recubre un conjunto diversificado de prácticas que se inscriben con una estructura común: la existencia de ciertas categorías de poblaciones carecientes y la necesidad de hacerse cargo de ellas. (Castel, 2009:33). En esa misma línea, Fleury expresa que "con base en el criterio de la autonomía, se justificó [...] también la negación de la ciudadanía a los portadores de necesidades especiales” (2004: 7).

Ahora bien, ¿cómo se tramita esta tensión inmanente de la desigualdad? ¿Cómo construimos lógicas de protección social, alejándonos de liberalismos, y al mismo tiempo tramamos desde la autonomía? ¿Es posible autonomía ciudadana cuándo se pone en duda la capacidad del sujeto? Y allí creemos que lo que permite mediar, tramitar estas tensiones es la intervención. Esta intervención toma materialidad en las esferas públicas, particularmente en las escenas estatales. Los estados considerados cómo aquello que transciende a los "gobiernos", sistemas administrativos, jurídicos, burocráticos y coercitivos permanentes que no sólo tratan de estructurar las relaciones entre la sociedad civil y la autoridad pública sino también de estructurar muchas relaciones cruciales dentro de la sociedad civil. (Stepan, 1978). Siguiendo a Bourdieu, decimos que: 
"El estado, entonces, si insisten en mantener esa designación, sería el conjunto de los campos en los que tiene lugar las luchas en las cuales lo que está en juego es - para basarnos en la famosa formulación de Max Weber - el monopolio de la violencia simbólica legítima, es decir el poder de constituir $y$ de imponer como universal $y$ universalmente aplicable dentro de determinada "nación", mejor dicho dentro de las fronteras de un territorio dado, un conjunto común de normas coercitivas" (Bourdieu:2008, 151)

Esta mirada sobre el Estado nos permite identificar las dinámicas en pugna por monopolizar la violencia simbólica, especialmente en los procesos de producción de políticas de protección social / cuidado en relación a la discapacidad. ¿quiénes pugnan por este monopolio? ¿Cómo se construye la estaticidad? ¿qué agentes sociales producen argumentos sobre la discapacidad, la autonomía, las necesidades de protección social, la red reticular de seguridad social?

En esa línea, en el proceso de investigación surgió la necesidad de analizar los posibles impactos de la Convención de Derechos de las personas con discapacidad $^{50}$ en los diferentes territorios / espacios sociales. ¿la impregnación del enfoque de derechos viene siendo idéntico en los diferentes espacios? Es igual la mirada que hegemoniza el estado en salud, previsión, trabajo o educación en relación a la discapacidad? Reconocemos que en los 15 años desde el inicio del siglo XXI en nuestra América viene construyéndose un reconocimiento de derechos que permitió restituir situaciones de opresión, explotación, y en otros

\footnotetext{
${ }^{50}$ La Convención propone que los estados deben garantizar el goce pleno de derechos por parte de las personas con discapacidad, en igualdad de condiciones con las demás, de su derecho inherente a la vida. Para ampliar sobre este tema, se sugiere: http://www.un.org/spanish/disabilities/documents/gid/conventionfaq.pdf
} 
casos darles visibilidad. "Aun cuando persisten grandes brechas, los esfuerzos por extender la cobertura de la población adquieren centralidad y la apuesta por disminuir la segmentación en el acceso y la calidad de las políticas de protección social gana nuevos adeptos" (Cecchini, Filgueira, Martínez y Rossel, 2015:26)

En tal sentido, destacamos que el discurso impuesto por la Convención tiene un alto contenido igualitarista basado en el reconocimiento de la diversidad como constitutiva de lo humano. Palacios (2008:205) plantea que en el seno de las Naciones Unidas en los últimos 20 años se ha incrementado paulatinamente la incorporación de las necesidades de las personas con discapacidad en su marco normativo. "Se ha hecho hincapié, por un lado en la singularidad de sus derechos ante determinadas situaciones, pero por otro $-\mathrm{y}$ esto resulta fundamental - en la necesidad de que el Estado adopte medidas de protección especiales a los fines de garantizar el ejercicio de derechos universales por parte de dichas personas"

En esa misma línea, existe un consenso generalizado de las organizaciones de personas con discapacidad en que la Convención debe ser interpretada como (por ahora) la última manifestación de una tendencia mundial, a favor de restaurar la visibilidad de las personas con discapacidad, tanto en el ámbito de los valores, como en el ámbito del Derecho.

Por ello, a partir de la promulgación en el año 2006 se han generado acciones tendientes a que los estados miembros incorporen a las normas jurídicas nacionales el texto de la Convención. Esto implica un primer paso tendiente a influenciar los valores de autonomía personal a todas las acciones estatales y de la sociedad civil.

El impulso que las organizaciones de personas con discapacidad le han dado a la Convención, y su posterior adhesión en Argentina, explica las disputas 
de sentido que se desatan cotidianamente en la puesta en acto de las políticas del sector.

A juicio de Quinn y Degener, podría afirmarse que gran parte de la exclusión de las personas con discapacidad se encontraba $-\mathrm{y}$ aun encuentrafinanciada por programas de asistencia social, dirigidos más al aprisionamiento que a la liberación (Palacios, 2008:203). Una vez más se instala la tensión entre prácticas de asistencia y el derecho a la protección. Siguiendo a Arias (2012) intensificamos la tensión y planteamos que la asistencia es un derecho, y no sólo supone prácticas de aprisionamiento, o mejor dicho la asistencia es un derecho $\mathrm{y}$ es posible generar intervenciones emancipatorias en ese marco. En el capítulo tercero avanzaremos en esta línea.

Recuperaremos analíticamente cuáles son las posiciones que estructuran el campo de la discapacidad a los fines de comprender su dinámica, prácticas y estrategias.

En esa línea, Martha Nussbaum nos desafía planteando:

“Los niños y los adultos con graves deficiencias mentales
también son ciudadanos. Cualquier sociedad decente debe
responder a sus necesidades de asistencia, educación,
respeto, actividad y amistad. Sin embargo, los teóricos del
contrato social imaginan a los agentes encargados de
diseñar la estructura básica de la sociedad como “libres,
iguales e independientes”, y a los ciudadanos cuyos
intereses representan como "miembros plenamente
cooperantes de la sociedad a lo largo de una vida
completa”. (Nussbaum, 2012:109)


Capacidad de contratar y producir sentidos sobre el estado se dirimen en lo que en la presente tesis será analizado como proceso de producción de políticas de discapacidad. 


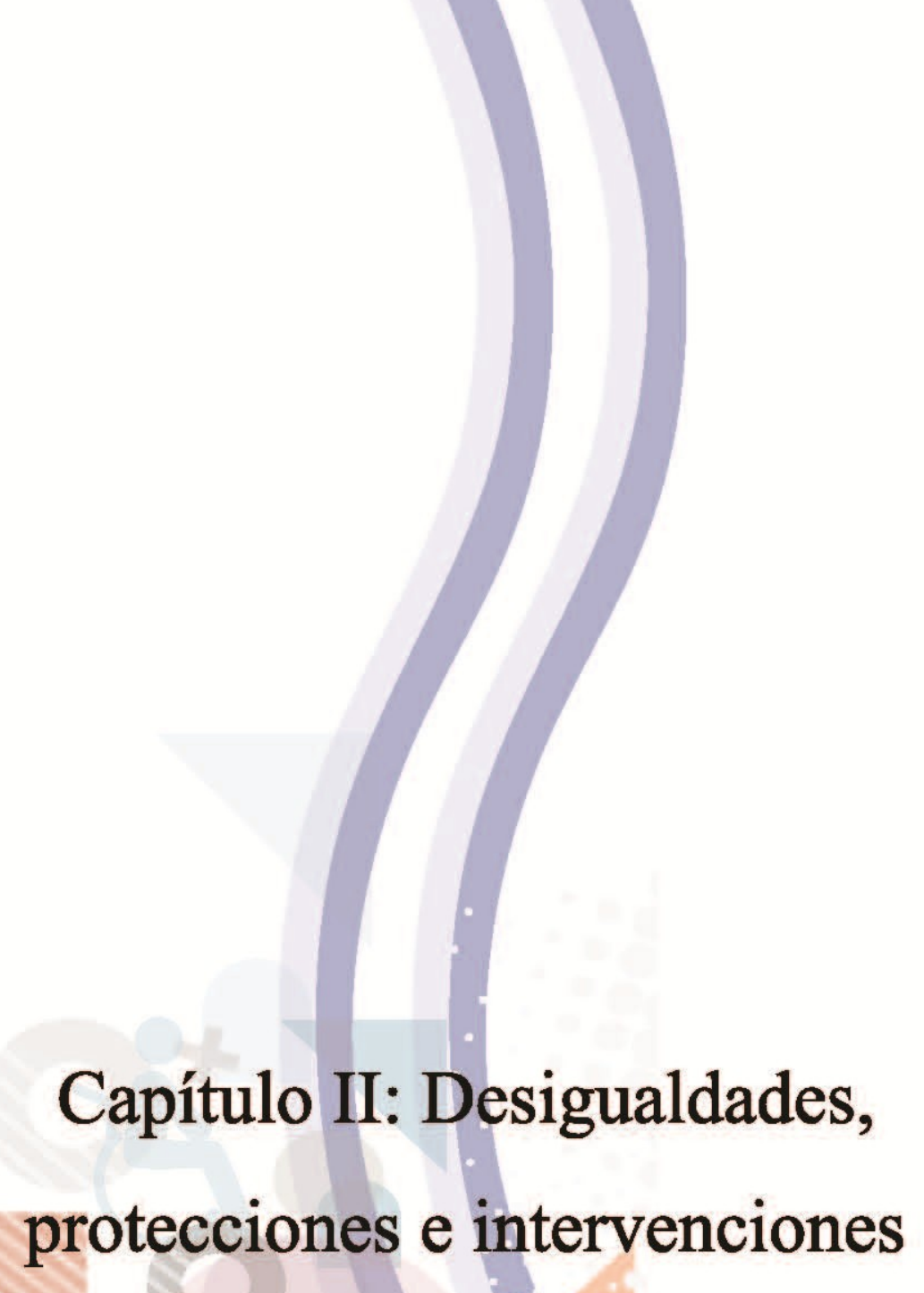

"las experiencias de los márgenes son aquellas que socavan el territorio seguro de las certe zas culturales y las identidades sociales" (Anna Lowenhaup Tsing, 1993:225) 


\section{Cuestión social, estado y matrices teóricas del trabajo social}

La desigualdad es una característica inmanente del modo de producción capitalista, y para algunos autores de las ciencias sociales se constituye en el eje central de la cuestión social contemporánea (Netto, 1999; Iamamotto, 1992) En esa línea planteamos que se abren varios debates, entre los que destacamos:

- Si las manifestaciones de la cuestión social están vinculadas a la idea de aporía (Castel, 1997) se tematizan fuertemente las tramas complejas de la integración social en la sociedad salarial. Para el caso de la discapacidad se pondría en escena en torno a los riesgos de la desintegración social, asociado al pauperismo y a la amenaza al orden político y moral. ¿Las manifestaciones se dan cuándo se tramitan los procesos de vulnerabilidad social de las personas en situación de discapacidad? ¿o la cuestión social se pone en escena cuándo se dirimen las lógicas públicas y privadas en torno a los procesos de reproducción social de las personas y sus redes sociales de apoyo? (Carballeda,2010; Cazzaniga, 2012)

- Cuando las manifestaciones de la cuestión social las asociamos a la contradicción capital - trabajo (en tanto fundamento y razón de ser) la relación se establece por cómo la explotación del hombre por el hombre genera condiciones desfavorables para los pertenecientes a una clase social en particular. Para el caso de la discapacidad se tematiza como una de las formas de opresión social en el que los modos de producción, distribución y consumo de la riqueza dejan por fuera a las personas en esta situación. Complejizando un poco más el tema, podríamos agregar 
que en el modo de producción capitalista en su fase transnacional, las manifestaciones de la cuestión social aparecen en torno a las formas en que la discapacidad comienza a ser un objeto de ganancia. (Netto, Iamamotto)

Estas dos miradas son las más representativas en las discusiones que, sobre la cuestión social contemporánea, se vienen desarrollando en el trabajo social. En el caso de la presente investigación, surgió la necesidad de poner en diálogo las manifestaciones de la cuestión social en el campo específico y articular analíticamente con los fundamentos que adquiere en el modo de producción capitalista - en su fase transnacional - en nuestra América. Identificamos singularidades que el tratamiento del tema discapacidad tiene, lo que en el primer capítulo señalábamos como historicidad de la intervención estatal en materia de discapacidad. La relación establecida con el concepto de raza nos advierte que la discapacidad complejiza su abordaje por instalar debates entre miradas en clara disputa, y al mismo tiempo porque re -edita aquellas discusiones que plantean enfrentamientos entre quienes postulan que la discapacidad es un tema inherente a la naturaleza - por la expresión biológica del déficit- y quienes plantean que se trata de la mirada que han construido las diferentes formaciones sociales en torno a patrones de normalidad.

Nos interesa visualizar cómo se configura la cuestión social, ya que desde allí observaremos la trayectoria de la atención social y consecuentemente las formas que ha adquirido nuestra profesión.

En ese sentido, siguiendo a Godoy, Manes, Murdocca y Robles (2013) identificamos 4 matrices teóricas presentes en el Trabajo Social argentino:

$\begin{array}{ll}- & \text { Positivista } \\ - & \text { Funcionalista estructural }\end{array}$




\section{- Dialéctica \\ - Tecnocrática neoliberal}

Los autores mencionan que existe una quinta influencia que no se instituye en matriz, asociada al constructivismo, estructural constructivista, psicología social pichoniana y aportes de la educación popular freireana ${ }^{51}$.

Previo a desplegar las relaciones que establecimos entre el concepto de matrices teóricas, trabajo social y discapacidad, entendemos prioritario explicitar la idea de matriz teórica. La misma nos permite identificar desde la imagen de alojar las categorías conceptuales que conforman la trama que establecen los fundamentos de determinada corrientes de pensamiento (Argumedo, 1999) La autora plantea que una matriz teórica encuentra el punto de partida cuándo construye interrogantes sobre "lo social”. ¿Pensamos lo social como contigüidad de individuos? ¿Creemos que lo social dirime su funcionamiento en tanto organismo vivo? ¿Pensamos lo social desde lo material - estructural? ¿Centramos la mirada en el equilibrio o en el conflicto? Estos son algunos de los interrogantes - posibles - entre múltiples opciones.

Las matrices de pensamiento son formas de re - elaboración $y$ sistematización conceptual de determinados modos de percibir el mundo, de idearios, y aspiraciones que tienen raigambre en procesos históricos y experiencias políticas de amplios contingentes de población y se alimentan de sustratos culturales que exceden los marcos estrictamente científicos e intelectuales (Argumedo, A 2009:81)

\footnotetext{
${ }^{51}$ Para ampliar sugiero: http://trabajosocial.sociales.uba.ar/PMMIP.pdf
} 
Esta idea de matrices de pensamiento situadas en este lugar del mundo nos habilita a re - elaborar las categorizaciones que sobre las formaciones sociales de las que formamos parte, generamos. Las cuestiones relacionadas a la configuración estatal y las formas de abordaje de la discapacidad en nuestro país, que ha sido trabajado en el capítulo 1, responde a un intento de aproximación a las formas en que fue tramada conceptualmente la discapacidad de manera situada.

Nos interesa abordar cómo estas matrices las visualizamos impactando en el campo de la discapacidad, fundamentalmente en los modos en que ha sido comprendida la misma y las consecuencias disciplinarias- en clave interventiva que produjo. Por ello, entendemos que la intervención profesional del trabajo social en discapacidad ha sido impulsada desde las siguientes matrices teórico metodológicas:

Matriz teórica positivista: vinculado a los procesos de desacralización del mundo. Esta matriz teórica instala a la racionalidad científica como modo legítimo de conocimiento. En el caso de la discapacidad podríamos vincularlo a lo que se presenta como modelo médico que va a plantear que la discapacidad está vinculada a la consecuencia de una enfermedad, considerando que la misma puede / debe ser medida (métrica de la discapacidad), identificada hasta en el más mínimo detalle (diagnosticada).

el enfoque médico representado en la CIDDM alude a la discapacidad en términos de consecuencias de enfermedad. Le atribuye una mono-causalidad biológica situada en lo que el saber médico denomina: anomalía, ya sea ésta física, psíquica o sensorial. Es decir, la construye como consecuencia de un déficit a ser erradicado -en la medida de 
lo posible- a partir de la rehabilitación médica (Mareño, 2015:415)

Esta impronta biológica corporal asociada a la enfermedad y sus consecuencias en las prácticas posibles, va a delinear los modos en que se produzca el abordaje social de la discapacidad. Si la misma es patrimonio médico, nuestra intervención va a estar asociada a producir compensaciones a esta tragedia individual. A principios del siglo XX en nuestro país, con un rostro más hostil que producía encierros como única respuesta.

Esta matriz teórica positivista nos despoja del objeto de intervención ${ }^{52}, y$ nos coloca cómo suplementarios de la labor médica. Al mismo tiempo, coloca en el plano individual las situaciones sociales que atraviese, con un alto grado de responsabilización sustraída de contextos. Podría indicar que el positivismo como matriz produce intervenciones en lo social del tipo tradicional, poniendo en acto el poder disciplinario.

En ese sentido, aparecen los instrumentos de la intervención en línea con las formas de concebir a la discapacidad, por lo que la entrevista hará las veces de confesionario en el que el discapacitado compartirá sus padeceres y será aleccionado sobre la forma en que debe actuar para compensar sus falencias. Los aportes foucaultianos se tornan centrales para analizar las formas en que la dimensión instrumental del trabajo social se tiñe de disciplina para corregir, culpabilizar al sujeto y aminorar conflictos. Al mismo tiempo, y en términos de socio - históricos, debemos señalar que esta matriz no responde a un tiempo lejano y ajeno sino que aparece entrelazado en varias intervenciones actuales.

\footnotetext{
52 Esta idea fue trabajada en el marco de la Jornada "El campo de intervención del Trabajo Social en discapacidad ¿Futura Especialidad? Organizada por el Colegio de Trabajadores Sociales de la Provincia de Córdoba, - noviembre 2015 - en la que se generaron intercambios fructíferos con la Lic. Lorna Sidebotton y el Lic. Mauricio Mareño. http://cpsscba.org/confluenciasvirtual/?p=4308
} 
¿O acaso cuándo entrevistamos a los familiares de una persona con discapacidad y evitamos dialogar con la persona no estamos mirando el déficit en vez de al sujeto?

siempre lo cuento, que cuando yo en la Defensoría atendía, generalmente eran mujeres... 7, 8 de cada 10 son mujeres con el hijo adulto con $X$ discapacidad, intelectual la mayoría, yo atendía a la mujer que venía por un problema, suponete, de IOMA que no le daban... no le otorgaban determinado medicamento al hijo, yo la entrevista la realizaba con la persona y jamás miraba a los ojos del que estaba al lado, no lo hacía, porque para mí era más rápida, era más sencillo, porque tenía 500 personas afuera y me quería ir a la mierda. Bueno, y un día me hacen caer la ficha. Yo ese día... la primera práctica profesional que tuve que modificar es girar la cabeza y mirar a los ojos al otro. Es así- Entrevistado TS código: 97)

En relación a los instrumentos de la intervención, la matriz positivista los colocará en tanto realidad de la intervención, los trabajadores sociales somos en tanto entrevistamos, visitamos, e informamos.

Las preguntas que surgen son ¿cómo generar rupturas epistemológicas? ¿cómo producir sentidos diferenciados en torno a la experiencia de la discapacidad?

Matriz teórica Funcional estructuralista: siguiendo a Godoy, Manes, Murdocca y Robles (2013) esta matriz instalará la búsqueda de relaciones de dependencia e interdependencia de los fenómenos sociales como manera de explicarlos. Y la búsqueda de esta matriz será detectar la disfunción para 
lograr el mantenimiento del sistema. Para el trabajo social, este tiempo ha generado un proceso de desarrollo tecnológico con centralidad hegemónica, por lo que se lo asocia a la tecnocracia. Situándonos en la discapacidad podríamos asociar esta matriz en la generación de estrategias comunitarias características del desarrollismo y todas las prácticas vinculadas a las respuestas frente a la epidemia de poliomielitis que fuera mencionada en el primer capítulo.

Al mismo tiempo, y acercándonos a este tiempo presentaremos las discusiones vinculadas a la Clasificación Internacional del Funcionamiento y la Salud (CIF) aprobada por la Organización Mundial de la Salud que opera como marco conceptual de los procesos de certificación de discapacidad en nuestro país $^{53}$. La Cif propone la generación de un lenguaje unificado para quienes se acercan al tema de la valoración funcional de los sujetos, y propone un marco conceptual común desde concepciones de universalidad, lo que supondría el reconocimiento de modos diferentes de corporalidad y funcionamientos. Sin embargo, es necesario señalar que esta universalidad se diluye en manos de la hegemonía de la normalidad.

La Cif propone un enfoque bio - psico - social, remarcando los fundamentos biológicos, los condicionantes sociales y las motivaciones psicológicas que operan en los procesos de discapacitación. Se trata de una clasificación, que intenta constituirse en alternativa no etnocéntrica, que se

\footnotetext{
${ }^{53}$ Por Resolución Na 675/2009 el Ministerio de Salud de la Nación - BO 19/5/09 - 2009- aprobó el "Modelo de certificado único de discapacidad y el protocolo de la certificación y evaluación de la discapacidad" con base en la Clasificación Internacional del Funcionamiento, de la Discapacidad y de la Salud. La aplicación en todo el país ha concluido con la reciente incorporación de la Ciudad Autónoma de bs As (julio 2015). El mayor impacto (por densidad poblacional) se dio cuándo adhirió la provincia de Bs As (2013). Al mes de septiembre 2015 en el registro contaba con 700.000 certificados únicos de discapacidad emitidos con este modelo, los que co - existen con los emitidos con anterioridad en base a CIDDIM)
} 
incluye en la familia de las clasificaciones que produjo la $\mathrm{OMS}^{54}$ tendientes a producir información estadística en salud pública que sustente la toma de decisiones.

Esta clasificación surge en el proceso de revisión de la CIDDIM, tendiente a generar diálogos entre las variables en juego, lo que la inscribiría en la matriz funcional estructuralista. Lo que instala la Cif es el juego entre los aspectos biológicos (déficit), los psicológicos y sociales (barreras y facilitadores), en forma dinámica. Plantea que para describir a un sujeto es necesario dar cuenta de los dominios de salud y del de los relacionados a la salud.

La Cif es un pormenorizado despliegue de variables que, en los propios términos de la medicalización, instala la necesidad de ampliar las variables que ponderen las situaciones de los sujetos. Define 4 (Cuatro) componentes para describir el dominio de salud y los dominios relacionados a la salud:
b. funciones
s. estructuras
d actividades y participación
e. ambientales

La Cif plantea que la información que produce es neutral, ya que identifica los défcit y las potencialidades, y que la descripción es fiel a aquello que aparece en la realidad. En los documentos que ha producido la OMS ${ }^{55}$ plantean que la inducción debe ser evitada, ya que la propuesta de la misma es descriptiva.

\footnotetext{
${ }^{54}$ La Cif se articula con la CIE 10 que ha sido producida a fines estadísticos. Para ampliar sugerimos http://www.paho.org/hq/index.php?option=com_content\&view=article\&id=9168\&Itemid=2562\&lang= es ó http://www.dgis.salud.gob.mx/contenidos/cemece/fic index.html

${ }^{55}$ Para ampliar consultar: http://www.coper.org.ar/datos/fotos/200_1.pdf y de órganos oficiales y de articulación internacional http://www.relacsis.org/index.php/noticias-full/item/527-discapacidad-y$\underline{\text { salud }}$
} 
Desde el modelo de la CIF en el año 2001 se habla de personas en situación de discapacidad, esto implica que el fenómeno no hace parte de la naturaleza misma de quien la vivencia, sino que es un agregado a sus circunstancias, en otras palabras, conceptualmente la discapacidad deja de ser una sustantividad y pasa a ser una situación, esto ya implica para la cultura de la salud un avance en la determinación de los fenómenos que acontecen en la conformación anatómica de las personas. (García y Gil Obando, 2007:53)

El enfoque bio - psico -social, construido desde los organismos internacionales y con implicancias en la política de salud pública nacional, instauró una disputa con la matriz positivista medicalizada. Esto habilitó la inclusión de trabajadores sociales en las Juntas Evaluadoras siendo central y obligatoria su participación. Las juntas, también son integradas por médicos y psicólogos. Nuestro país tiene la obligatoriedad de certificar discapacidad a partir de la promulgación de la Ley $N^{o} 22.431 / 81$ - Sistema de Protección Integral de los Discapacitados - la Ley No 25.504/01 Modifica el artículo $3^{\circ}$ de la Ley $\mathrm{N}^{\mathrm{o}} 22.431$ (establece el Certificado Único de Discapacidad).

De acuerdo a la información pública del Servicio Nacional de Rehabilitación ${ }^{56}$, el Certificado único de discapacidad es un documento público que se tramita voluntariamente, que implica una evaluación Interdisciplinaria realizada por una Junta Evaluadora de Personas. El certificado no se otorga por diagnóstico, sino que la condición de salud es la puerta de entrada para la evaluación del perfil de funcionamiento de la persona. La junta evaluadora determina si existe o no una discapacidad teniendo como parámetro lo

$56 \quad$ Se sugiere ver: http://www.alua.org.ar/documentos/Presentacion $\% 201$ upus $\% 20 \mathrm{~S} \% 20 \mathrm{~N} \% 20 \mathrm{R} \% 20 \% 20$ final.pdf http://www.snr.gob.ar/cud/ 
establecido en las normativas vigentes. El mismo no es permanente, sino que su vigencia puede ser de hasta cinco años.

Ahora bien, el cambio en la forma de certificación fue transitada de manera compleja y contradictoria:

la orden fue dejar de funcionar la junta tradicional, que estaba conformada por 3 médicos fisiatras, por lo menos en mi hospital y en la mayoría, por profesionales médicos; se deja de emitir, y en muchos hospitales todavía no estaban capacitados y conformados los equipos porque aparte el personal que conforma la junta tuvo que tener una capacitación; a nosotros nos evaluaron con un examen (Entrevistada TS: código 13)

Después de 2 años, trabajamos bien y hemos logrado armar equipo. Hay otras juntas donde creo que incluso no hay trabajador social, o si hay, me parece que tienen un rol bastante subalterno (Entrevistada TS: código 13)

$\mathrm{Y}$ en este proceso complejo, hacemos propios los interrogantes que generó uno de los entrevistados en el trabajo de campo:

En el caso del otorgamiento del certificado, si no cambia nada, ¿qué podría cambiar?, te pregunto. Esa pregunta nunca me la hice. ¿Qué podría cambiar?, ¿qué esperarías vos que podría cambiar en los criterios de otorgamiento del certificado en una junta que es médica exclusivamente, o en una junta que es interdisciplinaria? (Entrevistado 611)

Del párrafo anterior destacamos dos cuestiones centrales: 
a. La potencialidad del trabajo de campo en tanto producción de interrogantes fundantes, que habilitan palabras, inauguran posibilidades de co - pensar.

b. La visualización de los límites de la matriz funcional estructuralista, presentada como enfoque bio - psico social en discapacidad. ¿Qué esperamos decir ó que nos diga la puesta en juego de esta perspectiva?

Matriz teórica dialéctica: siguiendo a Godoy, Manes, Murdocca y Robles (2013) esta matriz va a estructurar su producción desde el reconocimiento del conflicto, el poder y la ideología. En esta línea podríamos enlazar con los disabilty studies ingleses, con las postulaciones del modelo social de la discapacidad que propone que la discapacidad es una construcción social. En esta línea, los abordajes de la teoría social van a incluirse en dos líneas: reconocer que el contexto discapacita, a quienes portan un défcit ó plantear que la discapacitación está asociada a la invención del déficit. Este último se incluye en la propuesta de pensar a quienes son etiquetados como personas con discapacidad como pertenecientes a la clase oprimida. Los aportes del marxismo, el post - estructuralismo, el trabajo social anti - opresivo, la hemenéutica van a verse representados en esta matriz. Fundamentalmente, toda producción teórica que discute los procesos de naturalización serán pensados desde este lugar.

La importancia fundamental del modelo social en la lucha por la igualdad y por un mundo no opresivo, no discriminatorio, radica en el hecho de que va más allá de la propia cuestión de la discapacidad y se centra más bien en el establecimiento y mantenimiento de un mundo social en el 
que todas las personas experimentan la realidad de los valores inclusivos y de las relaciones. (Barton, 2009:144)

Estas matrices nos permitieron identificar los lugares desde dónde se narraban las escenas de la intervención, las formas que aparecían construida la intervención, los modos de nombrar a los sujetos, a las políticas, a las organizaciones. En ese sentido, plateamos que las narrativas adquieren una dimensión material, desde el momento mismo de su enunciación. Sobre todo, porque las narrativas que recuperamos traían al encuentro referencias constantes a las prácticas sociales.

\section{Protección social: paradojas entre el mercado y la ciudadanía}

Para los trabajadores sociales, el tema de la desigualdad aparece de manera recurrente en nuestras intervenciones. Siguiendo a lo planteado en términos de cuestión social la desigualdad constituye una de las centrales manifestaciones de la misma. Por lo tanto, viene siendo una preocupación recurrente tanto de la intervención profesional como de la producción de conocimiento disciplinar, estando puesto el eje del debate en recuperar las prácticas sociales de los sujetos que transitan su vida acumulando desventajas, con un claro objetivo de restituir derechos, ampliar ciudadanía.

¿Qué planteamos sobre la desigualdad? ¿Por qué creemos que se produce? La economía capitalista en nuestro continente se ha desarrollado incesantemente de la mano del compadrazgo del imperialismo europeo (Worsley, 1994). Esto habilita la inclusión, nuevamente, de los aportes del concepto de colonialidad. La misma, impuso un modo particular de clasificación poblacional que habilitó, legitimó prácticas sociales. 
La globalización en curso es, en primer término, la culminación de un proceso que comenzó con la constitución de América y la del capitalismo colonial/ moderno y eurocentrado como un nuevo patrón de poder mundial (Quijano, 2011:201)

Los interrogantes sobre la desigualdad, se tiñen por un lado de:

- Las preocupaciones asociadas al desarrollo económico, incluyendo el ingreso per cápita, las inversiones y la desigualdad social medida por el coeficiente de Gini. Estas apreciaciones nos permiten visualizar la producción social de la riqueza y la apropiación desigual de la misma. Para el caso argentino, podríamos identificar dos tensiones inmanentes por un lado las preocupaciones sobre la falta de inversión empresarial por contar con un estado con presencia y capacidad de regulación. Por otro lado, y frente a experiencias de aumento de la desigualdad, la necesidad de incrementar la regulación estatal para proteger a los trabajadores.

- Las inquietudes sobre los procesos de inclusión que estructura el orden social. Estas preocupaciones se reflejaron en las ciencias sociales, en el célebre libro de Larissa Adler de Lomnitz "Cómo Sobreviven Los Marginados" - en el que instalaba los itinerarios de los sujetos en situación pobreza para afrontar la sobrevivencia.

Las preocupaciones sobre el desarrollo económico, con sus tensiones regulatorias y anti - regulatorias, y sobre los pobres tensan las miradas sobre la desigualdad. ¿Pero sólo se trata de cuestiones vinculadas a ingresos per cápita? ¿La desigualdad se dirime en términos de ingresos u operan otros procesos? 
El mercado es el piso, pero también el límite de la posible igualdad social entre las gentes. Para los explotados del capital y en general para los dominados del patrón de poder, la modernidad generó un horizonte de liberación de las gentes de toda relación, estructura o institución vinculada a la dominación y a la explotación, pero también las condiciones sociales para avanzar en dirección a ese horizonte. La modernidad es, pues, también una cuestión de conflicto de intereses sociales. Uno de ellos es la continuada democratización de la existencia social de las gentes. En ese sentido, todo concepto de modernidad es necesariamente ambiguo y contradictorio. (Quijano, 2011: 217)

La disputa estado - mercado como organizador de las relaciones sociales de producción, es un eje central en la discusión sobre las formas que adquiere el control de la subjetividad supeditado a este patrón de poder. El ideal libertario que supone el mercado, se diluye en cada acto desigual, en cada injusticia social, en cada explotación laboral.

La nueva fase del Capitalismo, Monopolista Transnacional (Piqueras, 2002), se instauró y amplió a escala planetaria desde la crisis del petróleo. Las relaciones laborales se modificaron sustancialmente,

La vieja sociedad fordista donde el trabajador asalariado era el sujeto de referencia es sustituida por una nueva sociedad postfordista caracterizada por una multifragmanentación o multiactividad nómada de múltiples formas de trabajo (autónomos no asalariados, precarios, desempleados, etc.). (Noguera Fernández, 2015:4) 
Esta particularidad de las relaciones laborales nos instaló, para la presente investigación, cuestiones interesantes tanto para pensar:

- La configuración del campo de la discapacidad, las posiciones que se ocupan y los circuitos previstos de reproducción del capital,

- Los espacios previstos para los profesionales que nos desempeñamos en el campo, y las lógicas públicas y privadas

- Las profecías auto - cumplidas en relación al desempleo masivo de las personas en situación de discapacidad

El nomadismo de las formas de trabajo y las relaciones asociadas a los sistemas de protección social, han sido sustancialmente abordados por Sennett (2009) en su clásico libro "El Respeto”, el que acompañó narrativamente todo el proceso analítico. En tal sentido, la recuperación de las formas diferenciales de anudar un proyecto vital con las trayectorias laborales aparece presentada de manera central en las entrevistas realizadas en el trabajo de campo.

Sennett nos plantea:

Aunque no me di cuenta entonces, en nuestras visitas a la oficina de derechos civiles levantaron el telón que cubría el mismo dilema con que se enfrentaba mi madre y la joven asistente social: el cómo trasponer las fronteras de la desigualdad con respeto mutuo (2009:34)

Por ello, la pregunta sobre las condiciones de trabajo atraviesan a los usuarios de los servicios sociales y a los profesionales que se ocupan de los otros (Dubet, 2012). Este punto será ampliado en el próximo apartado. 
Ahora bien, ¿Por qué el Estado desarrolla cierto tipo de política social? Podríamos incluir un agregado vinculado a ¿por qué al estado en general y sus funcionarios en particular le interesa la "protección social" de ciertos grupos? Considerando el escenario actual moldeado por los preceptos que impone la Convención de Derechos en favor de las Personas con discapacidad ${ }^{57}$ (ONU, 2006) podríamos afirmar que se visualiza cierto distanciamiento entre las lógicas que operan en la definición, el diseño de las políticas sociales y las estrategias de abordaje territorial, de la cotidianeidad de la intervención profesional (vinculado al mundo de la vida).

Amartya Sen (2011) manifiesta que la razón ha sido la posibilitadora de diagnósticos de injusticia y justicia e identifica dos miradas / enfoques divergentes en torno a la misma. Hace referencia, por una parte, al “institucionalismo trascendental" que concentra su atención en lo que identifica como justicia perfecta y en la búsqueda de la naturaleza de lo justo. En este enfoque incluye a Hobbes, Locke, Rousseau, Kant y a Rawls. Por otra parte, identifica a los enfoques de la comparación basada en realizaciones. Expresa que este segundo enfoque también reúne obras de teóricos de la ilustración como Adam Smith, Condorcet, Bentham, Marx y John Stuart Mill, entre otros líderes del pensamiento innovador de los siglos XVIII y XIX (Sen, 2011:39). Los autores mencionados pertenecen a construcciones teóricas divergentes pero, según el autor, el punto de partida de sus búsquedas es igual, es decir no analizan cómo sería una institución perfectamente justa sino cómo promover la justicia.

\footnotetext{
${ }^{57}$ Tras un proceso de cuatro años, el 13 de diciembre de 2006 se aprobó la Convención Internacional sobre los Derechos de las Personas con Discapacidad (ONU). Se trata del primer tratado de DDHH del Siglo XXI y el que demandó menos tiempo de elaboración, discusión y consenso en la historia internacional.
} 
Ahora bien, situando la mirada en los aportes de Rawls (1995) decimos que la propuesta es que la justicia sea la primera virtud de las instituciones sociales. Rawls ha sido identificado como perteneciente a la perspectiva deontológica (opuesta a la teleológica). Sandel plantea que "las libertades de la ciudadanía igualitaria están de esta manera en peligro cuando se fundan en principios teleológicos (...) En la perspectiva deontológica las libertades equitativas tienen un fundamento diferente" (Sandel, 200:35/6)

Igualdad y equidad se instituyen en pares dicotómicos en la construcción jurídico - social en relación a la discapacidad. La desigualdad propia del modo de producción capitalista no alcanza a explicar cabalmente la situación de las personas con discapacidad. En los argumentos de Rawls se visualiza "la primacía de la justicia, el rechazo de la teología y la prioridad del yo" (Sandel, 2000:38).

los principios de justicia identificados por Rawls incluyen la prioridad de la libertad (el primer principio) que da la prelación a la máxima libertad de cada persona, condicionada a igual libertad para todos, en comparación con otras consideraciones económicas o de equidad social. (Amartya Sen: 2011:88)

Hemos planteado que a partir de la Convención se generó (o plasmó) un ideario de recomendaciones tendientes a la generación de condiciones de igualdad y ciudadanía plena de las personas con discapacidad. Esto implica que debieran desarrollarse políticas públicas que persigan la eliminación de barreras (físicas, comunicacionales, etc.) y permitieran el despliegue de estrategias de participación social. Estas acciones estatales tendrían como horizonte el principio de dignidad humana y la autonomía que no es contrapuesto con las 
acciones de desarrollo económico que son deseables para generar intervenciones estatales sustentables.

Estamos en el modo de producción capitalista, en el estadio más desigual de la historia, que paradójicamente instala la idea de libertad frente al mercado. Hemos planteado las discusiones relacionadas a la desigualdad, pero ¿qué es la protección social?

protección social como las políticas y acciones públicas destinadas a dar respuesta a distintos niveles de vulnerabilidad, riesgos y privaciones, vinculados al desempleo, la enfermedad, la maternidad, la crianza de los hijos, la viudez, las discapacidades, el envejecimiento, entre otros. (Artigas, 2005:7)

Las estrategias de protección social estatal instalan un dique de contención a los avasallamientos del mercado, por lo que reconocemos que las manifestaciones de la cuestión social pugnan por inscribirse en las agendas de gobierno y estatal. ¿Pero qué aspectos de la discapacidad se inscriben en la agenda pública? ¿La discapacidad en sí misma es objeto de protección? ¿Debiera serlo?

En el análisis del trabajo de campo aparecen cuestiones vinculadas a la idea de política pública y gestión en el que co - relacionamos aspectos eminentemente de política pública / estatal, su financiamiento, sus modos de concebir al sujeto de la práctica o población objetivo.

Y en pocas entrevistas aparece la categoría de ciudadanía para pensar los procesos interventivos. Esta cuestión nos traía incesantemente preocupaciones 
en torno a qué miradas operan para que la ciudadanización de las personas con discapacidad no sea directriz. ¿No lo era?

La ciudadanía es intrínseca a la condición humana, y todas las referencias que hemos traído a los teóricos del contrato social y los idearios de justicia instalan certezas en tal sentido. Podríamos traer al análisis las relaciones que se dan entre las prácticas ciudadanas y los marcos de derechos humanos. ¿por qué no aparece como parte de la narrativa habitual la idea de ciudadanía?

Las prácticas sociales de un agente o de una clase de agentes, dependen de las posibilidades específicas que posea, posibilidades que están en relación con el volumen y la estructura de su capital y con los habitus incorporados (Gutierrez, 2006:96)

Toma otro tenor esta dificultad identificada ya que los trabajadores sociales, en tanto clase bourdiauna, disputan sentidos dentro de lo posible, lo esperable, lo decible, lo pensable. No obstante, al tiempo que no aparece en el discurso, podemos afirmar que la preocupación por los espacios sociales que ocupan las personas con discapacidad es constitutiva de las narrativas de los trabajadores sociales. Las denuncias sobre los procesos de reclusión, marginación, discriminación, maltrato, han sido realizadas en toda la trayectoria profesional. De hecho, las alternativas a la institucionalización han sido producidas por los colegas. Pero estas denuncias ¿fueron realizadas por entender al otro en su carácter ciudadano? ¿lo tolerable en torno a los circuitos de exclusión, se produce en tanto el otro no merece ese trato ó por lo que me genera ser testigo de una injusticia? ¿Cómo aparecen los otros en estos reclamos? ¿Se generan estrategias para que la participación sea en primera persona, de manera autónoma ó hablamos por ellos? 
La tensión mercado - ciudadanos es producida en el modo de producción y atraviesa las prácticas sociales (individuales y colectivas). Para pensarlo en relación a la discapacidad, planteamos que es necesario comprender las formas, las dimensiones analíticas que se ponen en juego:

En la actualidad la condición de discapacidad está dada por la particularidad de un sujeto con relación a la norma, a lo normal. Es "el impedimento", el déficit, el diagnóstico. Es la dimensión personal de la discapacidad. La situación de discapacidad es la dimensión interrelacional, situacional y dinámica: es el modo evidente en el que "las barreras" se ponen en juego a través de un espacio de relación entre dos o más personas "de carne y hueso”. La posición de discapacidad es estructural, su origen está en nuestra estructura social, en nuestras representaciones, en nuestros valores, en nuestra idiosincrasia, en nuestras normas, en nuestra cultura, en nuestros esquemas cognitivos. En términos de Bourdieu: en nuestro habitus, que es el principio no elegido de toda elección, las estructuras sociales internas que nos disponen a pensar como pensamos (Brogna, 2006:4)

Siguiendo los aportes de Brogna (2006) afirmamos que la posición de discapacidad se produce en las escenas en las que se niega el reconocimiento de su condición de "ser persona", de decidir la propia vida. La negación de la participación plena evidencia la relación entre ciudadanía y discapacidad.

En concordancia a la activación de los mecanismos de protección social, podemos plantear un déficit histórico en relación a los siguientes accesos: 
- A la vivienda, como una necesidad históricamente negada a los sectores populares y a las personas con discapacidad en particular. Si bien en los últimos años con los programas de vivienda del estado nacional ha generado cupos beneficiando accesos, no resulta suficiente.

- A los espacios físicos, la relación entre criterios de diseño universal y el reconocimiento de la heterogeneidad de los sujetos. Podríamos incluir aquí el Programa de Accesibilidad a las universidades nacionales, las estrategias que algunos municipios se fueron generando, pero claramente no resulta suficiente. ¿acaso la barrera física puede ser leída como materialización de una barrera anterior?

- A los bienes culturales y simbólicos. En este punto, el mayor avance ha estado garantizado con el Programa Conectar Igualdad, que analizamos desde el equipo de extensión que articulamos con la Facultad de Ingeniería de la UNLP ${ }^{58}$.

Dubet (2011:103) tematiza la relación entre la igualdad de posiciones y la autonomía individual, lo que instala una preocupación central en el capitalismo.

La autonomía individual supone que se posee algo, y con la suficiente seguridad como para formular proyectos $y$ sentirse libre. Así, la protección de los empleos y de las posiciones, "la propiedad social" (que la "sociedad salarial" descrita por Robert Castel ha garantizado tan bien durante el siglo XX), es una condición necesaria para aquella autonomía.(Dubet, 2011:103) (2015)
} 
Los sistemas de protección social operan de forma saludable en sociedades en los que la acumulación de desventajas se torna en profecías culpabilizadoras sobre los itinerarios posibles.

\section{Las profesiones que se ocupan de "los otros"}

Los trabajadores sociales somos considerados dentro del programa institucional como los profesionales que se ocupan de los otros. La categoría de otredad ha sido un eje constante en las reflexiones de esta tesis, por lo que las preocupaciones sobre lo que significa ocuparse de los otros serán analizadas, tramadas, reflexionadas en este apartado.

Dubet (2007) señala que las instituciones inscriben un orden simbólico y una cultura en la subjetividad de los individuos, ya que institucionalizan, instituyen. Esta cuestión instala, al igual que la perspectiva relacional, la paradoja entre la certeza del sujeto libre y lo social hecho cuerpo.

"la institución tiene la función de instituir y socializar. La institución es definida entonces por su capacidad de hacer advenir un orden simbólico y de formar un tipo de sujeto ligado a este orden, de instituirlo" (Dubet, 2006:40)

En esa línea, el autor marca la fortaleza productiva de las instituciones por las que transitamos, sumándole una característica interesante en términos disciplinares.

"según esta acepción, la noción de institución no designa solamente un tipo de aparato o de organización sino que 
también caracteriza un tipo especifico de socialización y de trabajo sobre el otro" (Dubet, 2006:41)

En las instituciones que se desempeñan los trabajadores sociales entrevistados, y en las organizaciones con las que fuimos teniendo relaciones, aparece un valor sagrado, que en términos de Bourdieu será el capital específico en juego. Dicho valor está asociado a las posibilidades de compensar faltas, organizar la vida cotidiana de "los otros" y definir con claridad quiénes son los usuarios legítimos de las organizaciones.

Ahora bien, Dubet (2007) plantea que el programa institucional apela a la idea de vocación por parte de los profesionales que nos ocupamos de los otros. Por ello, existe una apelación a lo sacrificial, que es hecho cuerpo por varias de las colegas entrevistadas. Por ejemplo: la decisión de migrar más de $500 \mathrm{~km}$. a fin de demostrar que un hogar convivencial ${ }^{59}$ se torna más digno que un hogar permanente, a costa de dejar a hijos pequeños. Dos cuestiones aparecen en esta decisión, que nos instala en debates en torno al cuidado y la feminización del mismo.

Por una parte, planteamos que para pensar el diseño de los dispositivos se ponen en juego esas cuestiones de lo sagrado institucional, algo así como las disputas por la definición de la discapacidad, las prácticas posibles, los itinerarios. Y al mismo tiempo se pone en acción una apelación a las prácticas de cuidado asociadas a los que Hochschild, R (1990) señala como actos pequeños, sutiles, conscientes e inconscientes que tienden a naturalizarse de tal forma que se invisibilizan. El proceso de naturalización de estas prácticas nos lleva a interpelarnos a fin de poner en valor lo que implican las relaciones de cuidado.

\footnotetext{
${ }^{59}$ Hogar Convivencial: se trata de un dispositivo residencial en el que los sujetos en situación de discapacidad ocupan un lugar de autonomía en la resolución de las necesidades cotidianas. Se trata de un tipo institucional que cuenta con poco personal de asistencia directa, y despliega estrategias profesionales tendientes a la resolución colectiva de las necesidades, a la toma de decisiones consensuadas.
} 
Cuidado que puede ser pensado en clave de derechos, pero la sutileza de su carácter produce que se diluyan en acciones naturalmente de las mujeres y que no requieren esfuerzos. El corrimiento del plano de la naturaleza de las esferas múltiples del cuidado, permite la impugnación de la mirada que coloca como natural la propensión femenina al cuidado. ¿Somos las mujeres quienes desarrollamos competencias favorables al cuidado ó es la construcción social que nos coloca en ese sitio? ¿Y cómo enlazarlo con la lógica que opera en los profesionales que nos ocupamos de los otros?

pero bueno quedo armado el hogar, funcionó, se trabajó muy bien, digamos, lo que pudimos ver en ese momento era primero, que la modalidad convivencial ayuda a todo lo que es autovalimiento, de una manera, yo salía con las chicas a comprar, por ejemplo, íbamos al supermercado, y aprendian a elegir la verdura, pagar eso que en una institución grande no lo pueden hacer porque no se puede hacer eso, las chicas aprendieron a manejarse en un montón de aspectos además de que estando cerca, muy cerca de sus familias era mucho más fácil porque las chicas que llevamos a (...) estaban en (.....) . (Entrevistada TS código: 1313)

Es interesante cómo el cuidado aparece en clave de autonomía, de promoción en la toma de decisiones, en experiencias que tienen más 25 años. Y aquí nos surge una cuestión recurrente entre quienes ejercen la profesión desde hace 40 a 25 años atrás, reconocen el proceso de producción de sentidos, de las batallas sostenidas en el marco de la hegemonía médica - rehabilitadora. Sus narrativas nos invitan a pensar que las rupturas epistemológicas con el modelo médico y avasallante han sido realizadas desde las prácticas profesionales del trabajo social, hace más de 40 años. Y al mismo tiempo nos convoca a re pensar las relaciones generacionales que el Trabajo social viene sosteniendo. 
La convención en realidad es como un disparador que recopila un montón de cosas que ya se venían dando. O sea, ya el Programa de Acción Mundial estaba, no es que descubrimos América con la convención, no. Pero de alguna manera la convención agrupó y definió con mayor claridad algunos nuevos enfoques en el tema éste (Entrevistada TS código: 219)

Han sido reveladoras estas apreciaciones en clave de recuperar las trayectorias que el trabajo social en nuestro país ha sostenido. $\mathrm{Y}$ en ese punto es notable señalar la idea de Dubet (2007) en torno al paso de la vocación al dominio del oficio. "la vocación se convierte en profesión y la profesión es percibida como un modo de realización personal" (Dubet, 2007:53) Esta idea de pasaje de la vocación a la profesión no está procesada desde idea evolucionista de las proto - formas de la profesión, sino del movimiento helicoidal que las formas de intervención en lo social han sostenido al pulso de las formas estatales, las necesidades del modo de producción y los límites de tolerancia frente al sufrimiento social.

Si, yo me traslade a (.....), organicé la institución y después me vine, o sea la dejé organizada con el personal o sea, llegamos allá y éramos 3 personas todas en comisión, 1 de (......) y 2 de acá de (....), que vivíamos en la casa de unas chicas, viste, o sea que hubo que buscar personal, seleccionarlo porque, vivíamos, era una casa, una casa de familia con 2 habitaciones

Entrevistadora - Está bueno, has puesto mucho el cuerpo.

TS 1313 - La verdad que sí, sobre todo porque fue una época difícil desde lo económico, nos pagaban en dos veces, viste, 
mucha inestabilidad... también nosotros. (Entrevista código: 1313)

Por otra parte, marcamos el proceso de derivación del cuidado que supone la toma de decisiones de las trabajadoras sociales de tomar desafíos que la coloquen en el ámbito público. Las trabajadoras sociales, en general ratificamos nuestra sutileza del cuidado tanto en el espacio público como en el privado. Por lo que la desnaturalización es necesario que nos atraviese.

La provisión del cuidado (tanto en las instituciones, como en el trabajo remunerado al interior de los hogares) sigue siendo realizado por mujeres. Por lo mismo es que esta reorganización del cuidado se conjuga con el proceso de feminización de las migraciones (Sanchiz y Rodriguez Enriques, 2010:6)

En síntesis, la decisión migratoria asociada al desarrollo profesional nos llevó a discutir la posición femenina frente al cuidado y la lógica de disputa en el diseño de dispositivos.

Surge la necesidad de retomar las discusiones en torno a la profesionalización del trabajo social, es decir las disputas entre las miradas que retoman los aportes Lukács, G. (2004) en relación a la categoría trabajo en su condición de fundante del ser social. Esta postura instala al trabajo social como trabajo que en su realización desarrolla otras características y capacidades propias de los seres sociales, la conciencia, el lenguaje y la cooperación. En esa línea De Martino y Espasandín (2013:7) plantean que:

La práctica profesional no es ajena a las transformaciones que procesan las políticas sociales, en tanto espacio socio - 
ocupacional de los trabajadores sociales. Al contrario, está condicionada por los regímenes de protección social que adopta el Estado según la fase de acumulación capitalista. La fase recesiva del capital a partir de la década del 1960 inaugura el régimen neoliberal, con el cual las políticas de bienestar social son desmanteladas o reducidas a politicas asistenciales compensatorias.

Las autoras retoman, desde el materialismo histórico dialéctico, la tesis de (Iamamoto y Carvalho, 1995) que el trabajo social emerge como un tipo de especialización del trabajo colectivo, inscripto en determinado momento de desarrollo de la división social y técnica del trabajo (Iamamoto; Carvalho, 1995).

Otra postura que se instala es el reconocimiento de la generación de un espacio social destinado a la intervención social, en tanto necesidades del modo de producción, de la instalación de los estados nacionales, fundamentalmente en nuestro continente en el que la cuestión social se invistió de cuestión nacional (Carballeda, 2014)

Si consideramos a la profesionalización como el proceso a través del cual una "ocupación" u oficio se convierte en profesión, es decir el momento en que se reconoce que para su ejercicio es necesario atravesar por un proceso de formación con el fin de adquirir determinados conocimientos $\quad y$ el desarrollo de determinados conocimientos y el desarrollo de ciertas competencias, destrezas, y habilidades; investigaciones recientes sobre los orígenes de nuestra disciplina arrojan resultados muy interesantes con relación al movimiento simultáneo y 
paralelo que se produce a fin del silgo XIX en EEUU entre la profesionalización del Trabajo Social y la profesionalización y consolidación de otras disciplinas como filosofía, sociología, psicología, periodismo, etc (Travi, 2006:28)

Y en la lectura de las discusiones sobre el origen de la profesión, surgió un interrogante que creo acierta en la verdadera inquietud de esta tesis ¿Cuándo nos convertimos en trabajadores sociales? Los antropólogos ${ }^{60}$ que se dedican a la investigación, dicen que el rito de pasaje está asociado a la primera etnografía. Geertz plantea que la antropología es lo que hacen los antropólogos, ahora bien. ¿Cuándo se es trabajador social? ¿Cuándo se es trabajador social en el campo de la discapacidad? En párrafos anteriores señalábamos que la intervención, en tanto práctica social, habilitaba e inauguraba rupturas epistemológicas en relación a los modos habituales de resolver las manifestaciones de la cuestión social.

En tal sentido, Dubet (2007) señala que los profesionales que se ocupan de los otros se convierten en trabajadores encargados de construir ellos mismos el marco simbólico de su actividad. Tal vez, lo que nos convierte en trabajadores sociales es esa mezcla entre los procesos formativos de grado, los escenarios institucionales regulados, los encuentros con los otros (sujetos de nuestras prácticas) y la destreza argumentativa de cada uno por aportar a construir el marco simbólico que hace posible la toma decisiones sobre otros y/o con otros.

Asimismo, surge en las entrevistas la necesidad de incluir procesos formativos post - graduación, pero que son satisfechos en el mercado de posgrado por las clásicas formaciones para - médicas. El desarrollo de

\footnotetext{
${ }^{60}$ Retomo la experiencia de los antropólogos ya que comparto con ellos tareas docentes, de extensión e investigación desde hace 18 años, lo que me convocó a mirar comparativamente las trayectorias de dos profesiones que tienen una inquietud analítica constante.
} 
propuestas formativas con anclaje en las ciencias sociales y particularmente en Trabajo Social no abundan, lo que marca las pinceladas de la profundidad del modelo médico -psicológico en el campo.

Para cerrar este apartado diremos, junto a Dubet (2007) que las teorías de la justicia podrían colaborar a definir los marcos de las actividades institucionales. La heterogeneidad de las miradas en el campo de discapacidad, y especialmente en las instituciones que ocupan posiciones en el mismo, ameritan incluir consensos que tensionen la definición de criterios de justica social. El marco jurídico es uno más de los criterios en juego.

Parafraseando a (Larrosa, 2014) planteamos que la intervención se da en un entre, es algo que se da entre las personas, entre los lenguajes, entre los cuerpos, entre los lugares, entre los saberes. El autor nos habla del cuidar, que supone una tramitación respetuosa y amorosa del encuentro con el otro. Por lo que plantea:

"Entonces cuidar es una forma de guardar las distancias (... ) de perder las distancias malas (las del poder, las de la indiferencia, las de la hostilidad, las de la vigilancia, las que nos separan mal de nosotros mismos, del mundo y de los otros) y de tomar las buenas (las de la conversación, las de la libertad, las de la compañia, las de la atención, las de la hospitalidad, las que nos acercan bien a nosotros mismos, al mundo y a los otros). (Larrosa, 2014:10)

La investigación que realizamos ha sido de tipo etnográfica, la que generó una "implicación corporal que permite que junto con sus herramientas tradicionales (observación participante y entrevistas en profundidad) se incluyan formas de participación con una implicación corporal creciente" (Mora, 20 13:31) 
Dialogar con los colegas, asumir sus narrativas como puntos de vista situados nos habilitó reflexiones sobre los orígenes de la profesión en tanto habilitación de trayectorias diversas. En tanto heredera de los colegas que produjeron criterios de verdad en las instituciones, esta tesis intenta ser un homenaje.

\section{La singularidad de la intervención en discapacidad}

Del trabajo de campo surgieron algunas líneas interesantes en torno a aquellas cuestiones que aparecían como distintivas del ejercicio profesional. Y nos surgió un nuevo interrogante ¿existe un solo trabajo social? ¿Qué particularidades aparecen como distintivas de la intervención en el campo de la discapacidad?

En el próximo capítulo retomaremos cuestiones en torno a las temporalidades, pero avanzaremos en delinear los ejes constitutivos de la intervención, o sus dimensiones.

En esa línea Oliva (2006) plantea que asistencia, gestión y educación, son las funciones que el trabajo social ha constituido en forma articulada en su devenir. Las mismas articulan una multiplicidad de acciones ${ }^{61}$ que, suponen, un dominio herramental de la profesión asociada a la realización de entrevistas, prácticas vinculadas a la orientación, asesoramiento, transmisión de información pertinente, articulación con otros dispositivos de atención a fin de derivar a los sujetos que ameritan otras respuestas, acompañamiento diacrónico a sujetos con situaciones sociales complejas, visitas domiciliarias, asignación de recursos,

\footnotetext{
${ }^{61}$ Algunas de estas actividades fueron tomadas de la sistematización que propone Oliva (2006), pero mayormente son recreadas de la información que surgió de las entrevistas a los/as colegas.
} 
prestaciones, producción de informes sociales, registros múltiples de las prácticas que se realizan con los sujetos, el resto del equipo, los directivos, conformación de equipos interdisciplinarios, supervisión de servicios socio sanitarios, definición de dispositivos de atención, propuestas a creación de normativas y/o su modificación, producción de informes de gestión, coordinación de grupos específicos, supervisiones individuales a sujetos que demandan intervenciones, integración de equipos de supervisión interdisciplinarios, y otras que retomaremos en el proceso de análisis. Estas acciones adquieren sentido, en el marco de las funciones que señalamos y de la inclusión de la función de cuidado que aparece como constitutiva de la intervención. ¿Por qué incluimos la categoría de cuidado como función inherente? ¿Es exclusivo del campo de la discapacidad?

Exploraremos estos interrogantes desarticulando los sentidos asociados a las tareas, los desempeños, las trayectorias interventivas que surgen del trabajo de campo. Al mismo tiempo, que la categoría de cuidado será tramada con las discusiones sobre la desnaturalización de las relaciones de género.

para los concurrentes, en general, es como que el trabajador social, sobre todo la trabajadora social, es por momentos alguien más de la institución, digamos, un maestro más, un acompañante terapéutico más. Pero por ahí lo vinculan también con la posibilidad de hacer otra cosa afuera, ¿no?, de salir. Esto de verte y decirte: “¿y cuándo nos vamos al cine?”, “¿cuándo me llevás a la plaza?”, ¿no?, desde ese lado, por ahí. Sí, yo creo que, digamos, para ellos, esto del control social no tiene nada que ver, sino por algo... por suerte, algo lindo para ellos, estar pensando el trabajo social. (Entrevista TS-código: 522) 
La narrativa de la entrevistada trae a discusión dos cuestiones centrales, por un lado la cuestión de género y el otro la mirada del otro sobre la profesión. Ese otro se corporizará en los sujetos de las prácticas, los profesionales de otras disciplinas, los decisores políticos y/o organizacionales, etc. ¿Cómo se desarrolla la relación nosotros - otros en la intervención del trabajo social? ¿Cómo se singulariza esa relación en el campo que nos ocupa?

creo que hay una capacidad de los trabajadores sociales para contener problemáticas complejas. Al mismo tiempo, se dan como procesos institucionales que si la problemática que aparece es muy compleja, se deriva al trabajo social (...) porque excede los marcos de la atención médica. Y en general los casos que contienen a un discapacitado son complejos, tienen complejidad. Un buen abordaje implica un abordaje complejo. Yo creo que estas dos cuestiones confluyen. Como que hay una predisposición en la formación para contener este tipo de problemas. Después la ubicación es otra historia: si lo ven como un problema individual, como un problema grupal, como un problema comunitario. (Entrevista TS código: 521)

En las entrevistas aparece fuertemente el reconocimiento de la complejidad de las situaciones que son derivadas a los servicios sociales, pero fundamentalmente aparece la mirada de las otras disciplinas en torno a las competencias profesionales para abordar esa complejidad. En tal sentido las prácticas sociales vinculadas a la intervención en lo social, se expresan en una narrativa que inscribe regímenes de producción de sentidos, vínculos y miradas sobre el otro. En esa línea, inscribimos lo que postula el trabajo social anti opresivo relacionando las prácticas desde el reconocimiento de las inequidades estructurales y diferencias que se producen en la sociedad. Esta 
postura del trabajo social plantea que estas diferencias e inequidades se emparentan con procesos discriminatorios y opresivos (Dominelli, 1998). Henry Parada (2011) plantea que el encuentro con los sujetos de la intervención amerita la visibilización de los privilegios que los profesionales de la cuestión social tenemos frente a los sujetos que demandan de nuestros servicios. En esa línea, la puesta en escena de la relación de poder que los trabajadores sociales ejercemos nos habilita a recorrer un camino emancipatorio en relación a las ligazones estructurales, vinculares y relacionales.

Varios de los entrevistados plantearon que la vigilancia epistemológica se veía facilitada cuándo junto al ejercicio de la profesión se realizaban otras actividades, las que nucleamos en:

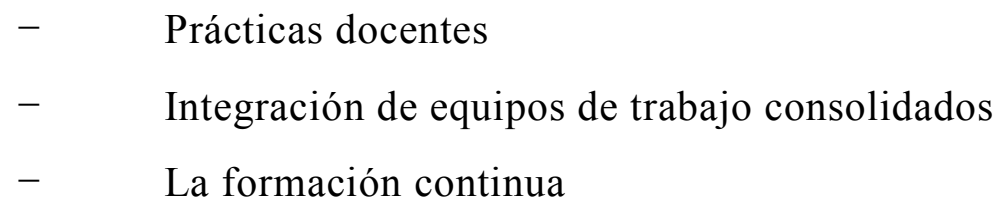

Los colegas planteaban que la vigilancia epistemológica se dirimía en acciones tendientes a la preservación subjetiva, como trabajadores y de los usuarios de los servicios sociales.

¿Qué entendemos por vigilancia epistemológica? Y cómo se singulariza esta en el ejercicio de la profesión? Siguiendo los aportes de la obra de Bourdieu tomamos el concepto de reflexividad, la que articula perspectivas objetivistas y subjetivistas, lo que en otros apartados de esta tesis planteamos como perspectiva relacional. Esta reflexividad, que es tomada por varios autores (Guber, 2004), se traduce en nuestra profesión con el concepto de problematización. En el trabajo de campo, apareció en algunas entrevistas la actitud problematizadora de las situaciones complejas de la intervención, dejando de lado el reconocimiento 
analítico de las posiciones que los trabajadores sociales ocupamos en el campo. Esto, por una parte debido a la escasa historización de los espacios socio ocupacionales lo que restringe la mirada de las trayectorias de los colegas que antecedieron en el campo. Y por otra parte, debido a las tensiones que se presentan entre quienes ejercen la profesión y quienes transitan los espacios de investigación. La mirada estereotipada y culpabilizadora que suelen tener las producciones de la autodenominada perspectiva histórico - crítica ha profundizado la distancia entre los intelectuales legitimados y los profesionales que traman cotidianamente al trabajo social.

Las rupturas epistemológicas, en clave de problematización, instalan la idea del objeto de intervención en tanto objeto teórico construido. Esto permite tensionar las múltiples condicionantes de la vida social, las situaciones de los sujetos de nuestras prácticas y las posiciones que ocupamos en las organizaciones, en los diseños de las políticas, y al fin de cuentas las posiciones en el campo de la discapacidad. La materialidad de la intervención, leída desde las cuatro funciones esenciales que planteamos asistencia, gestión, educación y cuidado, propone la necesidad de producir rupturas epistemológicas y epistemofílicas a partir del reconocimiento de la corporalidad, que será trabajado en el capítulo IV. 


\section{Capítulo III: La intervención enlazada a temporalidades}

Preciso tiempo necesito ese tiempo que otros dejan abandonado porque les sobra o ya no saben que hacer con él; tiempo en blanco, en rojo, en verde hasta en castaño oscuro no me importa el color cándido tiempo, que yo no puedo abrir y cerrar como una puerta

(Benedetti)...) 1

1 Ver en: Lee todo en: Tiempo sin tiempo - Poemas de Mario Benedetti http://www.poemas-del-alma.com/mario-benedetti-tiempo-sintiempo.htm\#ixzz3kxslEVfy 
En el presente capítulo avanzaremos en tres ejes centrales, uno asociado a los procesos de autonomización de las personas con discapacidad que aparecen en las narrativas de las entrevistas realizadas para esta tesis, sumado a las reflexiones que junto a compañeros del equipo de investigación ${ }^{62}$ venimos sosteniendo en torno a la trama de politicidad incremental de los colectivos de personas con discapacidad. Otro de los ejes es el vinculado a los aportes que desde la profesión del trabajo social se realizan en clave emancipatoria, interpelando los modos hegemonizados de la intervención social y por último presentamos las discusiones que sobre el objeto de la intervención se generaron. Ahora bien, estos tres ejes han sido pensados, nombrados desde la fuerte discusión que sostenemos en relación a la temporalidad. En esta línea analítica nos hemos interrogado sobre los modos en que percibimos el mundo, las disposiciones a la percepción y la acción lo que nos puso en diálogo (una vez más) con los aportes bourdianos. ¿De qué manera percibimos el presente, el futuro de los otros con quienes intervenimos? ¿Es el mismo tiempo el que pensamos para los que portamos la titulación de trabajadores sociales que para los sujetos de nuestra práctica? ¿Cómo operan las estrategias de distinción?

La anticipación pre - perceptiva, referida a potencialidades inscriptas en lo percibido, se inserta en una conciencia perceptiva cuya modalidad es la creencia y se opone por lo tanto al proyecto entendido como proyección de posibles imaginados en una consciencia que no afirma nada concerniente a la existencia o no existencia de su objeto. En la anticipación pre-perceptiva el futuro no es puesto temáticamente como futuro; el se integra como

\footnotetext{
${ }^{62}$ Dentro del equipo de investigación sobre Identidades colectivas, se han generado tres líneas de análisis que avanzan sobre los procesos de adscripción identitaria de las personas mayores, los migrantes de países limítrofes y las personas en situación de discapacidad. Este último eje es coordinado por la autora de la presente tesis, lo que ha permitido una enriquecimiento de la mirada sobre la discapcidad en clave de acción colectiva.
} 
potencialidad actual en la unidad de lo percibido.

(Bourdieu, 1963:37)

La frase incluida en el párrafo precedente nos invita a analizar, junto a Bourdieu, las formas etnocéntricas de percepción junto a la necesidad de incluir la cadencia de los modos diferenciales de traer a discusión el futuro. En el campo de la discapacidad las relaciones establecidas con la noción de futuro han sido claves para pensar el desarrollo prestacional, las alternativas de escolarización, atención en salud y dispositivos asistenciales.

\section{1. - Las personas con discapacidad, sujeciones y}

\section{autonomías}

En el trabajo de campo aparecieron sentidos asociados a la idea de trayectorias de las personas con discapacidad, en clave de preocupación, indignación frente a las barreras e inquietud de cara a lo posible. Comprendimos que las trayectorias, en tanto posiciones que ocupan agentes en un espacio social complejo, histórico y en transformación (Bourdieu, 1977), nos habilitan reflexiones sobre las singularidades de las personas en situación de discapacidad, contrastando con las constricciones sociales. Todo esto vinculado al concepto de posición de discapacidad que propone Brogna (2006). En tal sentido, recuperamos en las entrevistas una tensión constante entre la desigualdad social, la diversidad socio - cultural y los procesos de subjetividad presentes en el encuentro interventivo.

Destacamos que surgieron cuestiones en relación a las personas, desatando afrontamientos diferenciales que supusieron ciertas exigencias al derecho que no necesariamente es percibido como favorable o facilitador. Con esto se quiere señalar que la discapacidad, en tanto experiencia incluye a sectores sociales diversos los que asumen una relación diferente en torno a los derechos 
sociales y/o mecanismos de protección social. A modo de ejemplo, recuperamos lo que varios de los entrevistados planteaban que "la clase media" no se coloca en el lugar que esperamos frente al derecho a la asistencia.

Después está el perfil de clase media que ya viene no con la noción de derecho sino la noción de "me corresponde", como más de exigencia (Entrevistada TS - código 13)

Esto habilita dos recorridos analíticos, por un lado retomando la idea de trayectoria social de los agentes y las relaciones en torno a cómo la experiencia de la discapacidad instala un corte, un cambio, un nuevo posicionamiento que lo coloca en las escenas de las instituciones de protección social a agentes que nunca habían estado allí. El encuentro de los profesionales que se ocupan de los otros, con agentes que nunca fueron "los otros" de las instituciones produce un malestar en ambos términos de la relación. El otro recorrido analítico, implica el reconocimiento de un sujeto que no es el esperado, no es el habitual de las instituciones, produce relaciones desde la paridad, y esto genera una incomodidad en los trabajadores sociales. En el anterior capítulo marcábamos, desde los aportes de Dubet (2007) que las instituciones de las que formamos parte desarrollan una función de instituir, producir sujetos y socializar. El orden simbólico que imponen las instituciones se trastoca cuándo los sujetos interpelan lo instituido. ¿Qué produce el inesperado sujeto de la práctica? ¿Cómo se relaciona esto con la idea de compensaciones que suponen las políticas asistenciales en discapacidad?

Retomaremos estas inquietudes en relación a idea de sujeto en situación de discapacidad, en cuyo recorrido nos llevó a dialogar con Foucault, Butler y Zizek (2011). Siguiendo lo que planteamos en párrafos precedentes, exploramos la cuestión de cómo moldeamos a los sujetos en pos de intentar que entren, encajen en nuestras categorías conformadas previamente. Algunas 
categorizaciones provienen de los "tipos de usuarios" que prevén las organizaciones en las que trabajamos, que podríamos bucear en las lecturas de los reglamentos de las organizaciones, de los protocolos, etc. Pero existen otras categorías, que responden a formas de pensar a los sujetos más allá y más acá de los marcos jurídicos. La categoría de Ideal regulatorio, que propone Foucault es intensamente oportuna para analizar las formas en que los procesos interventivos producen a los sujetos. Esto nos permitió identificar aquellas prácticas en las que intentamos modificar las prácticas sociales del "otro" con el que trabajamos a un ideal constituido desde "nuestro punto de vista como actor" (Guber, 2004). ¿Qué sucede cuando ese ideal regulatorio se expresa en demarcaciones entre aquello que es, considerado normal / anormal? ¿Bello o feo? Estéticamente aceptable / inaceptable. ¿Cómo estas demarcaciones se expresan en la configuración de nuestros procesos de intervención?

"El hombre del que se nos habla y al que se nos invita a liberar es ya en sí el efecto de un sometimiento mucho más profundo que él mismo. Un "alma" que lo habita y lo conduce a la existencia, que es una pieza en el dominio que el poder ejerce sobre el cuerpo. El alma, efecto e instrumento de una anatomía política; el alma prisión del cuerpo" (Foucault: 2005:36)

Anatomo - política y bio - política como estrategias de producción de los sujetos, moldeados a requerimiento del modo de producción capitalista. ¿Los sujetos sólo son los que se acercan a los servicios sociales en el lugar de usuarios? ¿O también los sujetos producidos desde ideales regulatorios somos también los profesionales del trabajo social?

Butler (2010:62) plantea "El poder opera en la constitución de la materialidad misma del sujeto, en el principio que simultáneamente forma y 
regula al "sujeto" de la sujeción". Esto nos permite poner en cuestión la idea misma del déficit. Cuando pensamos en las personas que portan un déficit como "con discapacidad", lo hacemos en relación al contexto. Es decir, el déficit sólo se hace evidente frente a las barreras del entorno (físicas, comunicacionales, etc). Con esta postura, progresista en relación a las miradas tradicionales, damos por "dado" al déficit. Butler nos invita a pensar que estrategias de poder operan en la constitución de la materialidad expresada en el déficit.

Problematizar la materia de los cuerpos puede implicar una pérdida inicial de certeza epistemológica, pero una pérdida de certeza no es lo mismo que el nihilismo político. Por el contrario, esa pérdida bien puede indicar un cambio significativo y prometedor en el pensamiento político. Esta deslocalización de la materia puede entenderse como una manera de abrir nuevas posibilidades, de hacer que los cuerpos importen de otro modo (Butler, 2010:57)

Regulación de los cuerpos, sujeción de los mismos, nos permiten ahondar en las coordenadas presentes en la configuración del campo problemático del Trabajo social en relación a la discapacidad. Planteamos que la performatividad de nuestras intervenciones aparece cuándo nombramos a los sujetos por sus déficits, ó tomamos como trayectorias unívocas para los sujetos las previstas en el Sistema de Prestaciones Básicas (1997). Es decir, que nuestras prácticas reiterativas y referenciales mediante la cuales nuestros discursos producen los efectos que nombra. Si nuestras intervenciones consideran al "otro" como incapaz, heterónomo, configuraremos a los sujetos de nuestra práctica como dependientes de nuestras decisiones. 
Me pasa cuando se les mueren los padres, yo que atiendo adultos. En la familia me llaman: " $X X X^{63}$, falleció la abuela, no sabemos cómo decirle al tío”. He ido: he agarrado el auto y me he ido a (xxxxx) a la noche porque no se animan. A ver, yo siempre digo: "el derecho es de ustedes; ustedes pueden decidir no decírselo, pero ustedes sepan la postura nuestra; nosotros creemos que él tiene derecho a saber, él tiene derecho a decidir si quiere darle un beso a su mamá muerta o no”, “ay, pero tenemos miedo lo que pueda hacer”. Y ahí les hago una de las psicólogas: “¿qué se imaginan que pueda hacer el disca?", más que tirarse al piso, llorar; si es epiléptico, convulsionar; en el peor de los casos, tirar el cajón al piso, ¿qué más puede hacer? (EntrevistaTS - código 213)

¿Qué sujetos aparecen en las escenas interventivas? ¿A cuáles se convoca? ¿por qué aparece el trabajo social cómo aquel que posibilita desandar procesos autónomos y de adultización? La tensión entre autonomía y heteronomía es constante en las intervenciones al tiempo que la construcción de referencia aparece como uno de los capitales de la intervención, que será trabajado en el capítulo 4.

Además, la producción de lo no simbolizable, de lo indecible, lo ilegible, es siempre, una estrategia de abyección social. ¿es siquiera posible distinguir entre las reglas socialmente contingentes de formación del sujeto, entendidas como producciones reguladoras del sujeto a través de la exclusión y la forclusión y un conjunto de "leyes" y "estructuras" que constituyen los mecanismos

${ }^{63} \mathrm{XXX}$ se indica para reemplazar el nombre del entrevistado 
invariables de forclusión a través de los cuales cualquier sujeto llega a ser tal? (Butler: 2010: 271)

En artículos anteriores (Danel, 2011) planteaba que la discapacidad ha ocupado un lugar silenciado, acallado, y ocultado en las producciones académicas $^{64}$ del trabajo social. Y me interrogaba si esto tenía que ver con los sujetos que transitan nuestros espacios socio - ocupacionales, que vienen siendo construidos desde lo deficitario. O si esa invisibilización no estaba vinculada a la persistencia del discurso médico. "lo biológico no es externo a sino que está dentro de la cultura, y para discutir cómo la medicina clínica construye personas, pacientes, cuerpos, enfermedades y fisiología humana, empleo la frase "how medicine constructs its objects" para llamar la atención sobre aquellos "procesos formativos" distintivos a través de los cuales la medicina formula o constituye la dimensión del mundo a la cual el conocimiento médico se refiere (Good, 1994) $\mathrm{Y}$ en tal sentido, analizar las demarcaciones entre lo normal / anormal en tanto producción de sujetos concordantes con las necesidades del modo de producción, nos permite avanzar en la configuración de interrogantes que habiliten recorridos analíticos que abunden en profundidad.

Al redefinir los criterios de normalidad - en un contexto en el cual el biopoder se cruza con la lógica del consumo y adquiere una nueva dinámica asociada al mercado -, la enfermedad también se redefine: es un error de programación que debe ser corregido para reactivar la salud del alma y el cuerpo, tanto individuales como colectivos. Ya no es necesario identificar un origen patológico para los síntomas: basta apenas verificar su

\footnotetext{
${ }^{64}$ Estas afirmaciones son compartidas por Brogna 2006, Rosales, 2008; Ferreira, 2008; Ferrante 2008, quienes destacan la diferencia de los estudios sociales sobre discapacidad en habla hispana y los disabilys studies en Gran Bretaña.
} 
distancia con respecto al modelo considerado normal (Sibilia, 200:18)

En tal sentido, el siglo XXI recrea la discapacidad, los déficits que la originan como algo inmanente que sólo aparece en escena en la medida que se aleja de aquello que se supone normal. Pues entonces, si el cuerpo normal, con funcionamientos normales es quien actúa como condición de posibilidad de estar / siendo en el mundo contemporáneo claramente es el discurso médico el que hegemoniza las demarcaciones en disputa, sumado a la ampliación de los espacios de mercantilización que atraviesa el diseño de los dispositivos de atención.

A través de la violencia simbólica el Estado como detentador de una "economía política de la moral" (Scribano, 2007a) inculca en los cuerpos los esquemas de percepción, pensamiento y acción a partir del cual se opone al cuerpo sano/bello/hábil/bueno el cuerpo enfermo/feo/inhábil/malo. (Ferrante, 2009:21)

¿Pero todas las personas con discapacidad operan de manera idéntica frente a estas condiciones de estar siendo en el mundo contemporáneo? Ferrante (2009) asocia las disputas en torno a los modelos explicativos de la discapacidad, con la inmanente necesidad de asociar las prácticas de los sujetos con estos modelos. Y en ese sentido plantea que la discapacidad se presenta como modo de sufrimiento social, "que no encuentra su origen en la "falta de concientización de la ciudadanía" sino en una relación de dominación invisibilizada bajo la forma de enfermedad (Ferrante, 2009: 19). Nos preguntamos, ¿la corporización de la discapacidad en tanto realidad opresiva siempre aparece en experiencias de sufrimiento? ¿O es necesario tensar esa mirada con las trayectorias de los sujetos, quienes habitan los espacios sociales de manera diferencial y se 
conectan con los dispositivos de atención de manera singular? Por lo que ponemos en diálogo las trayectorias, los contextos y las intervenciones (Ferrante, 2013 y 2014) Al mismo tiempo, producimos un interrogante que, en manos de la perspectiva relacional, nos habilita el reconocimiento de modos diferenciales de producción de las realidades. $\quad \mathrm{Y}$ aquí relacionamos con lo que Boaventura de Sousa Santos (2006) denomina sociología de las ausencias, en las que plantea que existen cinco modos de producción de las ausencias: monocultura del saber y del rigor, monocultura de la naturalización de las diferencias, monocultura de la escala dominante y monocultura del productivismo capitalista. Estos modos producen al ignorante, al residual, el inferior, el local y el improductivo. Estas ideas nos invitaron a reflexionar que no se trataba de un problema del trabajo social, sino que está relacionada con la idea de colonialidad del saber y del poder que trabajamos en el capítulo uno.

"llegamos a la conclusión de que, probablemente, la razón que critica no puede ser la misma que piensa, construye y legitímalo qué es criticable" (de Sosa Santos, 2006:44) Producir desde el saber interventivo es una apuesta que atraviesa esta tesis, una puesta en valor del saber desde la práctica, desde "poner el cuerpo", desde transitar / experimentar la heterogeneidad del territorio. Por ello, traemos tres narrativas que aparecieron en el trabajo de campo, que evocan situaciones distintas en las que los sujetos toman posiciones diferenciales en relación a otros sujetos, a los dispositivos de atención y a las familias.

“Pablo no puede andar en la calle a esa hora”. Yo trataba
que ella entendiera que puede; "si vos lo viste, es porque
puede”, no me podía escuchar, ¿entendés?, y era el deseo de
protegerlo: “pero a vos no te importa nada”, "sí me
importa; ¿vos considerás que es riesgoso?, vamos a ver qué
hacemos con Pablo para que aprenda a manejarse con los 
riesgos. Pero puede, si de hecho lo viste”. No, era el deseo que eso no exista. (Entrevistas a TS - Código 213)

En esta entrevista retomaba el colega una discusión en el equipo de trabajo, del Centro de Día en el que ejerce la profesión, frente a un joven que por las noches deambulaba en el centro de la ciudad. Esta situación, era problematizada por el equipo en torno a la obligatoriedad de producir protecciones y la necesidad de construir autonomías. Estas situaciones demuestran la persistencia de miradas diferenciales en relación a la discapacidad, y cómo esto se singulariza.

Pasa que la junta del hospital público atraviesa a todas las clases, porque llega el que viene por el auto con franquicia, que se tiene que ver sometido... Nos pasó un par de veces: “¿por qué me preguntan tanto?”, esta cosa del "por qué, por qué”. El pobre que circuló por los servicios sociales está re contra cascoteado, y no sólo eso, sino que se expone. A otro perfil de pacientes, los incomoda más (Entrevista TS - código: 13)

Se tiene que ver sometido a nuestras miradas, miradas que desde el modelo bio - psico - social pretende dar cuenta integralmente de la situación del sujeto. El dominio herramental se pone a prueba frente al sujeto inesperado.

Y la coordinadora, enojada: "porque ustedes, que fomentan las parejas"; fomentar, nada; no hay cómo fomentarle al otro que ame, ni cómo impedirle al otro que ame, que esto es lo que yo digo siempre. Entonces me termina diciendo, escuchá la concepción, coordinadora de la institución, colega: "lo que pasa que, pobrecito, con todo lo que le toca 
en la vida encima tiene que sufrir esto". (Entrevista TS Código 213)

El diálogo que reproduzco en el párrafo anterior ejemplifica las miradas del otro sobre los sujetos frente a las experiencias vitales. ¿podemos evitar el sufrimiento del otro? ¿Ese sufrimiento sólo se trama por su situación de discapacidad? Surge la necesidad intelectual, ética y política de reconocer las prácticas opresivas, sin caer en el reconocimiento de que la vida en situación de discapacidad constituye una tragedia personal. Y tal como planteábamos en la introducción de esta tesis, creemos que todas las vidas merecen ser vividas más allá y más acá de las condiciones de salud.

Está bueno pensarlo desde ahí: desde que la gente tiene herramientas para afrontar esas situaciones y que no es que se les arruinó la vida por esto, digamos, sino que cada uno va haciendo su camino totalmente distinto, que tiene que ver también con la forma de ser previa de la familia.(Entrevista TS-Código 522)

La intervención trae a escena la heterogeneidad, las trayectorias diferenciales

¿cuál es el tema ahora? Dos personas hicieron la junta; realmente historias súper dolorosas: una, con un problema congénito, la otra, con un accidente. Albañiles, los dos extranjeros, con sus documentos, viviendo en el pais hace un tiempo pero no pueden hacer la pensión todavía, con todo lo que significa la cuestión cultural, ser el proveedor del hogar $y$ de golpe... No podíamos entender cómo seguía trabajando con esta limitación importantísima, ¿viste?, gente con una 
capacidad de adaptarse... Bueno, la verdad que en la entrevista... obvio que el Certificado único de discapacidad le corresponde y todo, pero vos decís: “este tipo que pasó de sostener a la familia, aun viendo un bulto, porque yo no sé cómo hacía la mezcla en la cuchara, pero hoy por hoy la pensión no”. ¿Cómo recuperar desde la autoestima hasta su lugar en el mundo? (Entrevista TS - Código 13)

La intervención profesional hace posible desatar procesos que habiliten caminos de autonomía, tomando a los marcos jurídicos, normativos y legales como abanico de posibilidades y no cómo respuestas unívocas. De otras entrevistas se instala la dimensión de autonomía de las prácticas de los agentes, en las afirmaciones asociadas a cómo las prácticas docentes, de los cuidadores, los enfermeros pueden alojar la inquietud frente a la asunción de riegos ó la anulación del otro como sujeto. ¿Cuánta decisión tienen los agentes de las organizaciones para sostener prácticas excluyentes?

Además la discapacidad no se cura. Es una cosa que jamás se cura. El que es débil mental va a ser débil mental hasta el día que se muera. No hay cura, mentira, no hay cura. Lo que hay que lograr es que sea más feliz. Que lo atraviese la libertad, que lo atraviese el arte, que lo atraviesen los amigos, que pueda coger en felicidad. (Entrevista TS Código 2329)

Los saberes acumulados de los colegas, con formas de nominar despojada de los conceptos de moda académico invitan a producir rupturas, a habilitarnos experiencias novedosas. La intervención profesional produce realidad, sujetos $\mathrm{y}$ encuentros. 


\begin{abstract}
"Pues es, exactamente, basándonos en esa irreductibilidad que podríamos proponer una reconstrucción del concepto de cura: curar a alguien será siempre luchar para la ampliación del COEFICIENTE de AUTONOMIA de esa persona en particular" De Sousa Campos, 2009:51
\end{abstract}

Del trabajo de campo surgen nociones vinculadas a la toma de la palabra de las personas en situación de discapacidad sobre su propia trayectoria, y referencias a cierta pasividad de algunos sujetos y cómo frente a esto los trabajadores sociales promueven protagonismos. Por lo que aparecen enlazados los modos de entender la discapacidad, el lugar en que se coloca al otro de la intervención, apareciendo en algunas entrevistas una tensión cuándo se advierte que las explicaciones estructurales de la discapacidad, termina borrando al sujeto.

El espectador también actúa, como el alumno o como el docto. Observa, selecciona, compara, interpreta. Liga lo que ve con muchas otras cosas que ha visto en otros escenarios, en otros tipos de lugares. Compone su propio poema con los elementos del poema que tiene delante. Participa en la performance rehaciéndola a su manera, sustrayéndose por ejemplo a la energía vital que ésa debería transmitir, para hacer de ella una pura imagen y asociar esa pura imagen a una historia que ha leído o soñado, vivido o inventado. Así, son a la vez espectadores distantes e intérpretes activos del espectáculo que se les propone (Ranciere, 2010:19)

Una de las narrativas traía una cuestión interesante en torno a las posiciones que ocupan los colegas frente a las demandas. Aparece esta idea de que: 
"las personas entienden como igual recibir un pañal, que haber generado que (xxxxxxx) sea accesible"(Entrevista TS 1515)

Ahora bien, desde la realización de esa entrevista continúe preguntándome ¿no será que efectivamente es lo mismo? O acaso no estamos frente al cumplimiento de un derecho, de un acceso, y aquello material a lo que se acceda es indistinto. Tal vez lo que tematiza esa narrativa es que algunos trabajadores sociales no quieren colocarse en la posición que históricamente estuvo colocado ¿pero, por qué? ¿Por qué no querer parecerse a un trabajador social? Y aquí retomamos los aportes del trabajo social anti - opresivo que postula el reconocimiento de las opresiones, y las necesidades de articular prácticas en torno a las emancipaciones. Y allí vuelve el interrogante ¿algunos colegas no quieren parecer a los trabajadores sociales, ó lo que no desean es asumir un lugar históricamente reservado de producción de sujetos dóciles?

"Esta ambigüedad de la solidaridad entre desiguales era lo que perturbaba a trabajadoras sociales como Jane Addams, o, más tarde, como mi madre" (Sennet, 2009:141)

En otras entrevistas aparecía una cuestión a destacar, la idea de que las personas con discapacidad son demandantes. Fue necesario de - construir los sentidos asociados a los modos de vinculación con los servicios sociales. Retomamos el aporte de Sennett (2009) quien plantea que necesario analizar la idea de respeto, y respeto mutuo, en contextos en los que la desigualdad se traduce en dudas sobre sí mismo. Y aquí retomo, del mismo autor, una cuestión pertinente:

"El acto de respetar el dolor ajeno es lo que confiere a los seres humanos una dignidad secular cuyo peso específico es 
afín al respeto de lo divino en las sociedades más tradicionales. La otra trayectoria de la sociedad secular moderna ha sido enfatizar la dignidad del trabajo" (Sennet, 2009:67)

La dignidad humana en occidente se produjo en dos pilares, el respeto al sufrimiento del otro y la dignidad del trabajo. Estas dos ideas tejen el tipo de relación que ha tenido el orden social con la discapacidad, y particularmente el trabajo social con el tema. El autor menciona que el reconocimiento mutuo de negocia en cada encuentro, en la relación entre el carácter personal y la estructura social.

\begin{abstract}
"la autonomía significa aceptar en los otros lo que no podemos entender en ellos. Al hacerlo, tratamos el hecho de su autonomía en igualdad de condiciones con la nuestra. La concesión de autonomía dignifica a los débiles, o a los extraños, los desconocidos; hacer esta concesión a los demás fortalece a la vez nuestro carácter
\end{abstract} (Sennett, 2009:264)

Otra cuestión interesante es la referencia que surgió en el trabajo de campo, al identificar a la discapacidad en tres dimensiones: como concepto, como padecimiento en términos sociales y cómo espacio de desarrollo profesional. Esto sintetiza la idea de campo de la discapacidad, en la que la disputa se coloca en relación a reconocer los padecimientos singulares que toman rostro en cada acto interventivo, y es leído en clave de injusticia social. Y al mismo tiempo, nos permite retomar la idea de autonomía como derecho, como postulado que se encarna en cada sujeto y que se trama en cada contexto social. 


\title{
2. - Temporalidades presentes en la configuración de la intervención en discapacidad
}

\author{
"Las narrativas son una manera primordial de organizar y \\ experimentar la temporalidad en la que se desarrolla la \\ experiencia de vivir. A diferencia de otras perspectivas, la \\ investigación narrativa presta una atención especial a la \\ manera en que se experimenta el tiempo en relación con los \\ sucesos que nos acontecen" (Perez - Samaniego V, Devis - \\ Devis J, Smith B, Sparkes, 2001:23)
}

¿Cómo construimos el tiempo de intervención? ¿Los encuadres institucionales actúan como único criterio de organización temporal? ¿En qué lugar colocamos el tiempo del otro / de los otros? Resulta de interés esta idea de la temporalidad de la narrativa. El diseño de nuestra investigación hizo posible que la trama discursiva coloque en un primer lugar el tiempo de la intervención. Y aquí se torna prioritaria la idea de conjugación de tiempos diversos, de trayectorias disímiles de los propios trabajadores/as sociales, de los sujetos de la práctica, de las lógicas organizacionales, de las políticas públicas, de los modelos estatales, de la fase del modo de producción. 

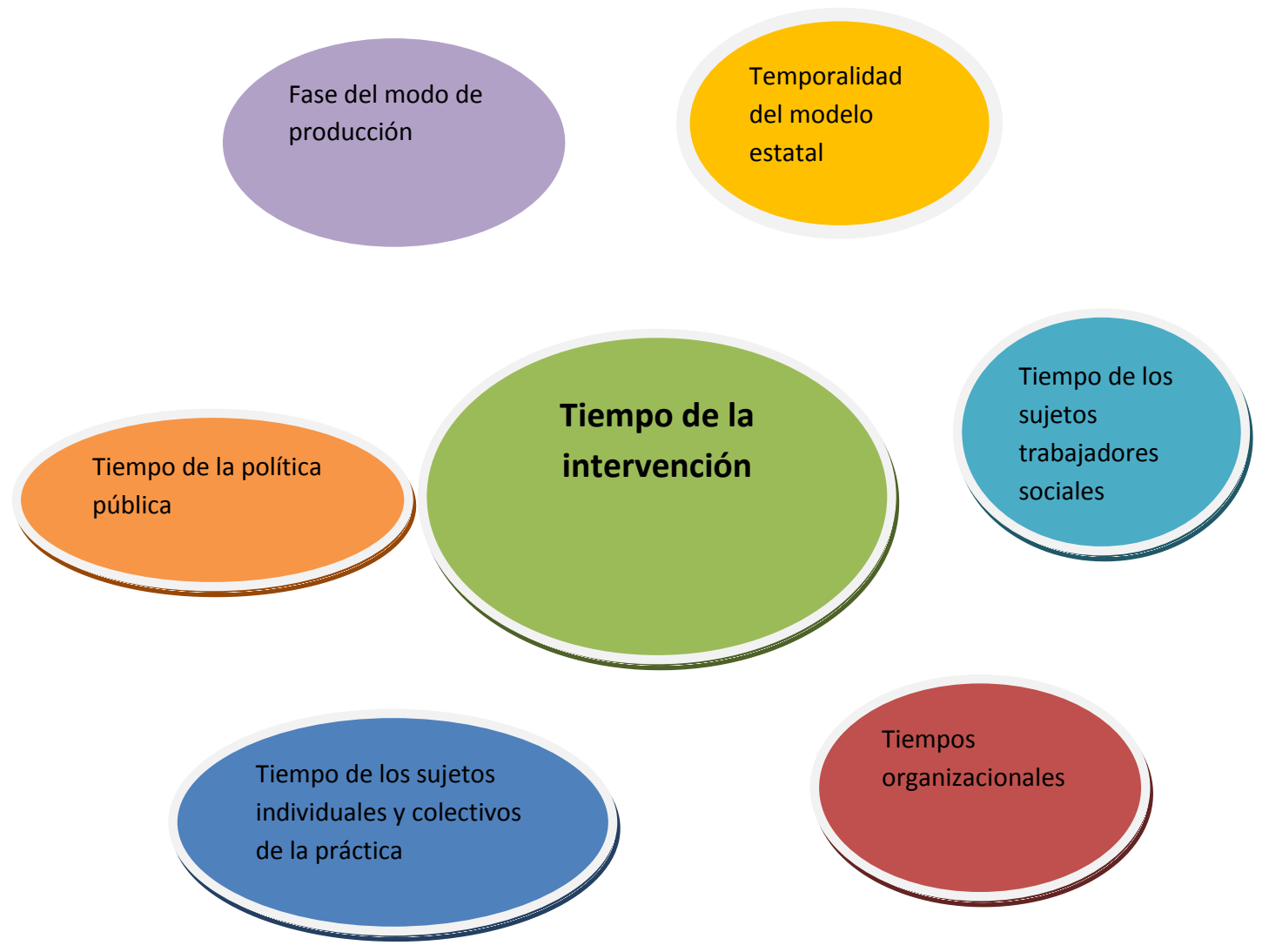

Un tiempo que no es lineal, que no le pertenece cabalmente a ninguno de los agentes en pugna. Un tiempo que es situado, que trama cotidianamente los modos en que es abordada la "cuestión social".

limita la intervención cuando hay una gestión donde el derecho de las personas con discapacidad no está siendo respetado; institucionalmente, cuando el encuadre tiene que ver con la enfermedad y no con la salud; profesionalmente, cuando no podés eh... no podés entender que tu ámbito de 
intervención está absolutamente ligado a otras profesiones o a otras acciones, a un encuadre que tenés que construir; $y$ después, qué sé yo, individualmente es esto, lo que te voy diciendo también: es justamente tener un aprendizaje en esto de tener una mirada tolerante, saber esperar los tiempos. Yo creo que discapacidad lo que me enseñó es eso: es aprender (Entrevista TS - código 2221)

Elias (1989) analiza el tema del tiempo comprendiéndolo como una clara invención de los hombres.

"para romper con las visiones esencialistas del tiempo, debe hablarse más bien de las diferentes maneras de temporalizarse por parte de los individuos (e incluso de las figuraciones sociales). (Guerra Manzo, 2005:137)

El reconocimiento del tiempo como configuración socio -cultural nos habilita a reconocer que el tiempo de la intervención profesional no es unívoco, ni naturalmente dispuesto.

Elias afirma que individuos de sociedades como las nuestras, dotados de una conciencia del tiempo tan enraizada, tan global y tan omnipresente, difícilmente entienden que otros hombres carezcan de la siempre despierta compulsión de preguntar por el tiempo. Esta individuación de la regulación social del tiempo porta en sí, de una forma casi paradigmática, los rasgos de cualquier proceso civilizatorio.(Guerra Manzo: 2005, 138) 
Y aquí aparece una oportunidad, en términos analíticos, de desplegar algunas ideas:

La temporalidad del modelo estatal: Tiempo que oscila entre el estado oligárquico, el populista ó intervencionista, el desarrollista, el liberal dictatorial, el democrático liberal, el neoliberal y el neo- intervencionista social. Estos momentos pautados por decisiones de configuración de lo público, del uso de los recursos, que acompasa con el tiempo de la lógica de circulación del capital y los actores sociales que disputan la inscripción de sus necesidades como cuestión de atención estatal. En este punto, podemos plantear que el tiempo que circunscribe el modelo estatal será parte de los condicionantes que operan en la intervención. El Trabajo Social ampliará las opciones de diseño de política, de innovación en la gestión de recursos, ú operará en pos de hacer visible aquellos sobre lo que no se interviene. Obviamente estas alternativas se podrían estar dando en forma simultánea.

Tiempo del modo de producción capitalista: el paso del modo de producción capitalista monopolista de estado al capitalista monopolista transnacional, con la consecuente financierización de la economía y el incremento de los espacios sociales que se convierten en garantes de rentabilidad. En este punto, es interesante la inclusión de análisis sobre la ampliación de espacios socio - ocupacionales del sub sector privado de salud y educativos que inciden de forma particular en la configuración de los tiempos de la intervención. Podríamos agregar que la lógica capitalista condicionan, también, los tiempos de la intervención.

Tiempo de la política pública: La configuración de la política pública, en tanto proyectos y actividades elaborados para satisfacer necesidades sociales de diferentes actores de la sociedad; construye una temporalidad en sus diferentes momentos de producción. Podríamos plantear que el momento de diseño de la política pública configura una singularidad que 
es antecedida por acciones de conflicto, con esto hacemos referencia a la inscripción como cuestión “a atender”. ¿por qué la discapacidad se instituye como objeto de la política? Campana (2012:28), retomando discusiones de las ciencias sociales, plantea que el estado actúa en la producción de los problemas sociales, en la delimitación de su propia responsabilidad, en la definición de los sujetos merecedores de sus acciones y de las condiciones para dicho merecimiento. Esto podríamos incluirlo en relación a las diferentes experiencias de la discapacidad que fueron inscribiéndose como cuestión social (empleo, salud, rehabilitación, educación, etc). Otro de los momentos de la política pública será el caracterizado por las diversas experiencias de implementación. Allí se abre un abanico insondable que nos permite desplegar las divergencias que se ponen en juego al cruzarse las lógicas de la política, con la de las organizaciones y de la propia intervención.

- Tiempo de los sujetos individuales y colectivos: este tiempo aparece conjugado con los asociados a la idea de curso vital ${ }^{65}$ que impugnan en algunas situaciones de discapacidad los criterios normalizadores en torno a lo esperable en cada década. Con esto señalamos cierta recurrencia narrativa en nombrar como "los chicos" a los sujetos adultos con discapacidad. Los tiempos del sujeto son variables, singulares, sujetados a una estructura psíquica y con criterios de verdad y realidad propios. Este tiempo situado del sujeto con discapacidad incide incisivamente en el tiempo de la intervención.

Por otra parte, tenemos a los sujetos colectivos en los que incluiremos tanto a las "familias de las personas con discapacidad" como a las organizaciones que los/as representan. En relación a las familias también las

\footnotetext{
${ }^{65}$ El paradigma de curso de la vida propone un análisis contextualizado del cambio en el que el desarrollo es producto del entrecruzamiento de un sistema de normas que lo regulan, con las mediaciones que el propio sujeto introduce como parte de un grupo social y con las herramientas que su cultura le provee. Lo distintivo del desarrollo humano en todos los estadios del curso vital sería su tendencia, o mejor dicho su naturaleza de cambio antes que su orientación a la estabilidad. (Yuni, 2011:33) Un aporte del paradigma del curso de la vida ha sido el de el de poner de relieve las variaciones no sólo intraindividuales sino también las interindividuales. (Yuni, 2011:34)
} 
podemos "leer" desde el concepto de curso vital para analizar las decisiones que cada unidad doméstica toma a lo largo de su propia trayectoria. Ese tiempo familiar también incide en el tiempo de la intervención. Y en cuanto a la acción colectiva de las personas con discapacidad, obviamente transita momentos diferenciales de acuerdo a las posiciones que tome frente a la lógica de colectivización, a las alianzas que teja con otras organizaciones y el propio estado. El tiempo de la acción colectiva se tramita en torno a los arraigos territoriales, a las lógicas representacionales que hegemonicen la vida organizacional. Por lo que podemos plantear, una vez más, que el tiempo de la acción colectiva también incide en el tiempo de la intervención.

Tiempo de las organizaciones: Para ilustrar esta idea temporal de las organizaciones iniciamos explicitando qué entendemos por ellas. "Los objetivos de las organizaciones no son estáticos ni necesariamente se conforman de la manera en que han sido explicitados formalmente; en la realidad pueden diferir y desviarse reflejando los intereses de quienes detenten su control. Son racionales en cuanto tienen patrones de acción con propósitos estructurados en un espacio temporal y espacial (situacional) alrededor del manejo de recursos técnico financieros y de la misma fuerza de trabajo humano, en el marco de obtención de objetivos deliberadamente establecidos, planeados y negociados. Las organizaciones constriñen el comportamiento de sus miembros, aunque no en forma absoluta, quedando un margen de discreción y negociación para las estrategias de acción individual y grupal, margen que depende del poder que cada miembro detenta por sobre otros miembros de la organización" (Paola, J y Danel P: 2009:53). Esta idea de constricción de las prácticas sociales pone en evidencia la performatividad de las organizaciones de cara al tiempo de la intervención. 
- Tiempo de los sujetos trabajadores sociales: en este punto pudimos advertir en el trabajo de campo que el tiempo de los sujetos que portan la titulación de trabajador social se torna diverso, y hasta divergente. Nos encontramos con colegas que cuentan entre 30 y 50 años de egresadas/os que enuncian un tiempo controlado, que crearon junto con otros, un tiempo de iniciación de lo que luego se fue institucionalizando como derecho. Este tiempo se modifica y diluye el control para los colegas que egresaron desde los años 90 a esta parte. Un tiempo que siempre nos es ajeno, que parece escurrirse pero en el que simultáneamente incidimos. También surge con fortaleza la idea de un tiempo singularizado y entrelazada con el propio curso vital. La experiencia de "ser trabajador social" aparece estrechamente cruzada con la propia experiencia familiar. (Ejemplos: adopción de un niño con discapacidad que conoció en una organización, experiencia de convivencia con jóvenes con discapacidad que implicaron migrar y dejar sus hijos al cuidado de abuelos, etc)

- Tiempo de la intervención: (Ludi, 2014:71) plantea que “el Trabajo Social interviene en relación a condiciones y obstáculos materiales y simbólicos que presentan los sujetos para su producción y reproducción social”. Esto supone un tiempo que conjuga varios tiempos, podríamos pensar que en modo sincrónico y diacrónico hacen posible un tiempo de intervenir. El campo de la discapacidad expresa estas simultaneidades temporales, que hacen síntesis en el tiempo de la intervención. No podríamos concluir una idea cabal en este apartado, ya que para pensar el tiempo de la intervención será necesario volver a poner en escena las narrativas de los/as colegas y analizar sus dichos que, no son sólo discurso, sino que recrean realidades de la intervención.

"El tema del tiempo me parece que es como un distintivo en discapacidad, el tiempo de comunicación requiere más 
paciencia, que por ahí con otros en otros campos no se da tanto y hasta paciencia con uno mismo si te se enoja no entenderle. A veces no es que uno siempre está predispuesto, a veces también decís, cuando sentís que no tenes elementos que no estas pudiendo, a mí me ha pasado, así que al final por ahí tiene que venir otro que sepa más." (Entrevistada TS código 1313)

Esta cuestión que trae la colega, nos invita a profundizar la idea de temporalidad de la intervención que nunca es propia, en con otros y asociada a los condicionamientos sociales que hacen posible que la intervención se dé de esta manera.

Se tienen dos sucesos que acaecen en el tiempo interior de los sujetos, por un lado el flujo de conciencia del trabajador social y por el otro el flujo de conciencia del otro sujeto interviniente. Estos dos momentos, son vividos en simultaneidad, marcados por el aspecto central, que los vincula, en este caso la intervención social. Se plantea además que esta simultaneidad que experimentan dos conciencias, es el punto de encuentro del nosotros, como una autentica relación social. (Rodríguez, 2011:317)

En el marco de esta temporalidad, propia, del otro, de ambos; surgieron en el trabajo de campo algunos tópicos con mayor recurrencia. Entendemos que las mismas están ancladas en algunas de las siguientes categorías, que configuran las claves de la intervención:

Familia: Para iniciar el análisis de este tópico surge la necesidad de explicitar la forma en que es conceptualizada la categoría de familia. En tal 
sentido, retomamos los aportes de Aquin y Gattino quienes desde una perspectiva relacional proponían.

Hablar de familia es hablar de estructura y dinámica. La característica que adopten ambos componentes del concepto, ayudan a dibujar la identidad de un grupo coresidente, en torno a la subsistencia y la reproducción social. En tanto estructura, la organización familiar constituye un campo de posiciones e intereses, que asume a una morfología contingente (histórica social) en el que se articulan las distintas posiciones de sus miembros de un sistema de uso, transferencia y control del poder en torno a actividades cotidianas. En tanto dinámica, la organización familiar va construyendo históricamente determinadas "reglas de juego" en base a las cuales explican la comunicación, el afecto, la insatisfacción, etc. .....la dinámica familiar se estructura en un tiempo y espacio articulando a sus miembros desde el género y la generación” (Aquin Gattino, 1999:15)

Esta idea supone un movimiento constante, dentro de determinados parámetros. Es sugerente esta perspectiva para poner en tensión las estrategias de intervención frente a las prácticas sociales que se desarrollan al interior de cada "unidad doméstica". La imagen de la familia de las personas con discapacidad se va tramando con ciertas expectativas frente a las reglas de juego de las que nos hablan las autoras antes mencionadas.

Las entrevistas han puesto en evidencia la centralidad que adquiere la categoría familia como materialidad de la intervención. 
"el monopolio de la familia es del trabajador social. A mí también me gusta eso, aclaro; yo también siento que son mios” (Entrevista TS código 213)

Esta idea se enlaza con las disputas que supone el trabajo en equipo, sobre la localización específica de la intervención. Esta afirmación debe ser situada en el escenario institucional desde dónde se pronuncia. Las instituciones asistenciales que brindan servicios diarios o permanentes disputan con las matrices asistenciales familiares. Podría relacionarse con la idea que propuse en mi tesis de maestría en el que investigaba a las residencias para mayores en situación de dependencia ${ }^{66}$. Uno de los tópicos que fueron analizados en relación a las familias era que los trabajadores sociales también generábamos intervenciones con ellas, varias veces caracterizadas como "censoras del amor filial".

\begin{abstract}
La institución al mismo tiempo que establece como cliente a satisfacer a las familias de los residentes las somete a un proceso de evaluación y ponderación de la intensidad de su amor familiar. Para esta tarea se convoca a un profesional específico, es decir a los Trabajadores Sociales. Podremos inferir que en la intervención Profesional del Trabajo Social somos interpelados para cumplir la función de “Censores del amor filial” (Danel, 2007:81)
\end{abstract}

Esta idea necesariamente debíamos ponerla en tensión con las narrativas de los/as colegas. ¿Es una tendencia de las intervenciones en dispositivos socio asistenciales? ¿Somos convocados para esto?

\footnotetext{
${ }^{66} \mathrm{La}$ tesis mencionada perseguía caracterizar las prestaciones brindadas en las instituciones de larga estadía, y el trabajo de campo arrojó que las mismas eran brindadas a personas mayores en situación de dependencia que podría ser interpelada desde los aportes del campo de la discapacidad. Para ampliar ver Danel, 2007.
} 
me dieron un premio institucional. $Y$ en las dos oportunidades les dediqué los premios a las familias de los discas, yo digo los discas, por las muchas veces que levantamos el dedito, ¿no? Yo siento que nosotros tenemos siempre listo para decir lo que hacen mal o lo que no hicieron, y nos cuesta muchísimo ver lo que han hecho bien, y lo que hacen bien. O sea, te traen un caso donde todos... pero esto nos pasa a los trabajadores sociales en todos los ámbitos, en caso de violencia intrafamiliar, en casos de... claro, es muy difícil no ver que está mal que al pibe lo lastimen pegándole, pero todo lo otro que hace esa familia por ese pibe, y que no quita lo malo que está esto, no lo ponemos sobre el tapete, ¿no? Siempre focalizamos en...” (Entrevista TS código 213)

en las religiosas mujeres es muy marcada esa necesidad maternal, y entonces "bueno, no, la familia no; nosotras somos la familia”. Entonces hubo que replantear: "no, no, la familia sigue siendo, hay que rescatar todas las que se puedan”. O sea, hay muchas familias que no. Yo me acuerdo, cuando yo empecé a trabajar en (ciudad x), la familia podía venir de visita solamente los domingos, al principio cada 15 dias. (Entrevista TS código 219)

¿Algo de los tiempos diferentes se pondrá en juego en estas dificultades que plantean los/as colegas? El tiempo familiar aparece signado por varios momentos, que podríamos pensar que no son universales. La OMS (1978) platea que el ciclo de vida familiar está caracterizado por: formación, extensión, extensión completa, contracción, contracción completa y disolución. Si bien nos diferenciamos de ideas homogeneizantes y normativas en torno a la construcción 
de la familia, pensamos que este "ciclo de vida familiar" podría ser pensado como curso de vida familiar, y que al igual que el curso de vida singular está sometida a presiones intersubjetivas, intrasubjetivas, culturales, económicas, etc. El momento en que se dé la inclusión de un miembro de la familia con discapacidad variará las respuestas que se anuden. El nacimiento de un hijo con discapacidad será tramitado en forma distinta si quienes cumplen la función ${ }^{67}$ materna y paterna están afianzados como pareja, si la notificación del diagnóstico es generado de forma clara y evitando discursos trágicos. Es decir, el nacimiento de un hijo con discapacidad será transitado de forma diferencial de acuerdo a situaciones intra - familiares, contextuales e históricas. ${ }^{68}$ Lo mismo podemos incluir si esta inclusión se dá por adquisición de la discapacidad en la infancia, juventud, adultez o vejez, las dinámicas que se desaten serán diferentes y por distintas variables.

Otro de los tópicos que ha surgido es el relacionado a ciertos procesos de aprendizaje / capacitación necesarios en la intervención enfocados a las familias. Varios/as de los/as colegas refieren que es necesario "formar a las familias" en el sentido de instrumentar, moldear ciertos comportamientos que les permitan mejorar las pautas de cuidado, de calidad de vida. Esto lo podríamos relacionar con los que Pantano, Nuñez y Arenaza (2012) mencionan como calidad de vida familiar.

Yo tengo un criterio: para mí a las familias hay que capacitarlas para atender a un discapacitado; hay que trabajar. $O$ alguien que tiene limitaciones, como un adulto mayor, hay que capacitar a las familias para eso. Y me parece que es un trabajo conjunto donde los médicos que intervienen, que puede ser un psiquiatra, un fisiatra, un

\footnotetext{
${ }^{67}$ Mencionamos como función materna y paterna a fin de evitar nociones de heteronormatividad.

${ }^{68}$ Para ampliar sobre este tema recomendamos Pantano, Nuñez y Arenasa, 2012, Ventiurello, 2014)
} 
clínico, y el trabajador social, tienen que laburar con la familia. Tienen que pautar y les tienen que enseñar a observar que hay una serie de cosas que las familias tienen que incorporar. Es dificil. No es imposible, pero es complicado. (Entrevista TS código 521)

Lo que surge en modo notorio es la necesidad de construir un ideal regulatorio que implique la puesta en acto de pautas que permitan una trayectoria familiar acorde. $\mathrm{Y}$ allí tomamos el concepto de trayectoria bourdieano:
"serie de las posiciones sucesivamente ocupadas por un mismo agente (o un mismo grupo) en un espacio en sí mismo en movimiento y sometido a incesantes transformaciones" (Bourdieu, 1977: 82)

Con esto queremos señalar que este ideal regulatorio oscila entre dos postulados:

- Pensar la trayectoria familiar como signada por situaciones de vulnerabilidad ocasionadas en forma exclusiva por la presencia de un miembro con discapacidad;

- Pensar la trayectoria familiar como expresión de tránsitos diferenciales vinculados a la condición de clase, de género, etaria, que supone la toma de decisiones, los accesos a bienes económicos, sociales y culturales y que a esto se suma la presencia de un miembro con discapacidad.

Estos postulados habilitarían distintas propuestas interventivas. Si consideramos que las trayectorias familiares están vinculadas a posiciones 
diferentes, las apuestas estratégicas serán más complejas, con elementos más diversos, enriquecidas. Por ejemplo: proponer la generación de institucionalidad a ciertas prestaciones que suelen ser arbitrarias. Con esto hacemos referencia a las prestaciones sociales destinadas a cubrir los costos de cuidados domiciliarios a adultos mayores en situación de dependencia, ó a aquellas vinculadas a generar cuidados progresivos de atención, ó a las asociadas a generar apoyos sociales que permitan una vida en comunidad. También las prestaciones destinadas a apoyar la escolaridad de niños incluidos en escuelas "comunes ó convencionales" ${ }^{\circ 9}$, sumando un personal de apoyo no docente que facilite la presencia, permanencia y egreso de los niños/as y jóvenes con discapacidad.

El tiempo de la intervención aparece como signando, dándole un compás al tiempo de la familia. De las narrativas de nuestros colegas surge de forma intensa esta idea:

Sentías que dependía de alguna manera un poco el futuro de esa familia, que ya venía un poco destruida, porque realmente nadie salió en ayuda de ellos, es decir, no hubo ningún dispositivo que pensara que cuando tenés un hijo con una discapacidad muy severa, a esa familia hay que cubrirla inmediatamente. Creo que no hay nada que se prevenga. Prevenir la salud familiar: todos los hermanos están destrozados, una madre que está quebrada desde la columna, quebrada literalmente, con parejas que se van desarmando con el tiempo, entonces venían cuando ya estaba todo agotado, y difícil de reponer, difícil de poder que tengan una mejor calidad de vida, ¿no? (Entrevista TS código 62)

\footnotetext{
${ }^{69}$ Hacemos referencia a las escuelas de educación primaria ó secundaria, distintas a la rama de educación especial que ha sido pensada en forma exclusiva para niños/as con discapacidad.
} 
De las reflexiones que fuimos generando en el trabajo de campo, aparece de manera interesante la referencia en torno a al uso de los recursos por parte de las familias y la co - responsabilidad de las instituciones para sostener un uso discrecional de los recursos de los sujetos con discapacidad. Con esto señalamos que muchas veces las instituciones brindan respuestas homogéneas, sin permitir la enunciación de las problemáticas.

Pero si conversamos, si entramos en una relación que no tenga el ánimo de hacer del otro un insulso semejante, quizá la diferencia valga la pena, quizá la diferencia sea lo que mejor narre lo humano. Y para eso tenemos que tener tiempo. No formas de nombrar: tiempo. No mejores o peores etiquetas: tiempo (Skliar, 2015:166)

Esta idea vinculada al tiempo, nos aleja de la normatividad familiar, y nos permite escuchar, dialogar, tramitar con los otros.

El tiempo de la familia que tiene entre sus miembros a una persona con discapacidad ¿es un tiempo con premura, con urgencias, con derechos vulnerados? Y aquí aparece otra idea a explorar ¿están siendo pensadas como sujetos de derechos las familias de las personas con discapacidad? ¿Estas familias, todo el tiempo son vulnerables?

una familia que no está bien sostenida, se puede transformar en un núcleo iatrogénico, se puede transformar... no sólo para el discapacitado sino para el conjunto familiar. (Entrevista TS código 521) 
Nuevamente aparece la necesidad de situar a algunas familias, en determinados momentos de su curso vital, presentando necesidades de respuestas urgentes y respetuosas.

Con la psicóloga pensamos que estaría bueno trabajar previamente esas cosas. Porque ahi entraba en juego... que las familias por ahi nos planteaban: los padres no querían hacerlos responsables a los hermanos para que no sea una carga para los hermanos, pero a su vez, por no involucrarlos, después desconocían toda la dinámica cotidiana de esta persona, entonces no sabían ni la medicación que tenían que tomar, ni los horarios, ni nada. (Entrevista TS código 522)

Claramente la inscripción de las necesidades de las familias aparece con arraigos diferenciales de acuerdo a múltiples variables (tipo de discapacidad, dispositivo frente al cual se responde, tipo de vínculo que se posee, momento del curso vital, etc). Y agregaríamos a la distribución de poder que históricamente tenga presente esa unidad doméstica ¿Qué lugar ocupa la persona con discapacidad en los procesos de toma de decisiones?

Hay muchos miedos por parte de la familia, eeee... los prejuicios también los tienen las familias, y mucho el que vaya de casa al centro de día y nada más, tiene que ver con esto, con... por ahi yo veo que, por suerte, en la mayoría no hay esto del ocultamiento, porque si todavía sigue habiendo familias que ocultan bastante y que prefieren que no salga ni siquiera a una institución así. Entonces, en general, en las familias hay bastante integración, no sé, en todo lo que es la vida social, pero todavía es como que esto de que puedan 
decidir ellos algunas cosas, no; como que todo... se toman las decisiones por arriba y... e incluso a mí lo que me choca es estando la persona presente, ¿no?; como que se habla del otro... (Entrevista TS código 522)

En el desarrollo de acciones propias de la intervención somos partícipes de escenas familiares en las que los procesos de toma de decisiones incluyen o excluyen a las personas con discapacidad. Decidimos tomar la idea de escena familiar para pensar un territorio en el que se desarrollan las prácticas sociales de los integrantes de la familia. Y aparecen, nuevamente, una multiplicidad de experiencias que tendrán que ver con cuestiones generacionales, de momentos en el curso vital, de género, de desigualdad. Esta circulación del saber / poder en la escena familiar puede ser replicada o modificada en los procesos de intervención.

$Y$ después, bueno, esto también de empezar a conocerlos, que uno por ahi se hace todas estas ideas previas; y cuando estás en la institución te relacionás con ellos de una forma y también empezás a conocer y ver esto: sus gustos, sus necesidades desde otro lado. No desde "bueno, ¿a ver qué es lo que plantea la familia?", sino ellos también qué están pidiendo, lo que están planteando, lo que están disfrutando o no; que también uno a veces hace propuestas que no tienen realmente ninguna repercusión, y está bueno decir "no". (Entrevista TS código 522)

$\mathrm{Y}$ en esta misma línea, pensando en la circulación de poder en la escena familiar es oportuno mencionar las cuestiones asociadas a la feminización del cuidado: 
En el marco de... en base a todo este recorrido y a las cartas que me mandaban y lo que decian, siempre habia una cuestión de género muy fuerte en la discapacidad o en enfermedades; cómo en la vejez las que se terminan haciendo cargo son la línea femenina. Es así. Es la que tiene más culpa, y además si uno lo va a llevar al plano más personal, yo me ocupé de mis viejos. Mi hermano me ayudaba pero. (Entrevista TS código 62)

El mandato social coloca a la mujer como la responsable exclusiva del cuidado, lo que constituye una de las inequidades que deben ser abordadas, resueltas. Y en tal sentido, señalamos que los procesos de intervención social deben aportar a la ruptura de prácticas sociales que reafirman de manera patriarcal los criterios de cuidado del otro. Siguiendo a Arias Campos (2007:26) planteamos que el cuidado es

"una práctica social sedimentada en la cultura de las
relaciones consigo mismo, con los otros y con el entorno. Su
abordaje contiene implicaciones multidimensionales (...)
configura una construcción social, dinámica contextual, que
incluye razonamientos, sentimientos, tradiciones, prácticas,
imaginarios y regulaciones valorativas, jurídicas y
políticas".

Por ello, es estimable que en la puesta en acto de la intervención social se refuten las certezas de la feminización del cuidado, aún cuando el escenario institucional se haya generado desde la ratificación del mandato patriarcal:

la función de la institución también es bastante de sostén y de acompañamiento a la familia. Ya nace por una mamá de 
un chico discapacitado que no encuentra una institución que la pueda abordar, ni que pueda contener a su chico, ni que la entienda a ella como madre. Entonces ésa es como que la función de la institución en sí. Y es como que la familia se súper referencia con eso. (Entrevista TS código 1525)

Y aquí aparece una combinación de los ejes de análisis, por una parte el de cuidado y por otra la vincularidad familiar. Es decir, la categoría de cuidado necesariamente la analizamos desde los modos en que "las familias" disponen las prácticas de reproducción social de sus miembros.

Creo que todas las reglas tienen cosas. Creo que la gente no está preparada, no para atender al discapacitado, para atender al hijo adulto. O sea, creo que el hijo adulto, aunque sea absolutamente normal, sea un científico, sea un estudioso, sea un profesor, esta familia de hoy no está preparada, no está interesada, no tiene los lazos para eso. No es un problema de estas familias de hoy, es una cuestión de un momento. Qué sé yo, yo me acuerdo en las casas de mis abuelos y eso, siempre había muchas tías solteras. (Entrevista TS código 2329)

La narrativa de la colega nos trae el interrogante ¿Cómo se construye el espacio privado? ¿Cómo se ponen en acto las estructuras y dinámicas de las familias? ¿cómo nos acercamos a la privacidad? ¿cómo leemos esas dinámicas?

en realidad se está focalizando mucho en la familia: si puede la familia realmente seguir haciéndose cargo de esa persona o no (Entrevista TS código 1525) 
Vamos en conjunto con la psicóloga. Primero para conocer, porque hay muchas familias que no se acercan; que se han acercado en un primer momento para las admisiones, y como entraron anteriormente a que nosotras trabajáramos ahí, es para conocer a la familia y no hay manera que se acerquen. Hay muy pocas familias que se acercan al centro de día y que son partícipes de los eventos del centro de día. Entonces para conocer a la familia, no sólo a los padres sino hermanos, bueno... (Entrevista TS código 1525)

Una de las cuestiones que surge fuertemente es que, para acercarnos y dar cuenta de las estructuras y dinámicas familiares, es necesario realizar una visita domiciliaria. La misma es una técnica utilizada desde los orígenes de la profesión, y nos animaríamos a plantear que es constitutiva de los orígenes de la profesión (visitadoras de higiene). ¿Qué implica poner el cuerpo en el espacio del otro? ¿Qué información logramos producir en acercarse al espacio del otro?

esta persona está en una familia, y no vas a trabajar solamente con el concurrente al centro de día sino también con la familia. Por ejemplo, estar viendo las condiciones de higiene y que una mujer" te diga: "este chico viene con un olor terrible y no lo podemos aguantar en el salón cerrado”, desde eso, los piojos, o problemas más graves que tienen que ver también con la higiene pero que repercutieron en una infección en un pie, en una uña, cosas así. Entonces trabajamos por ahi algunas cuestiones que tiene... ahi el trabajador social a veces como incluye otra variable: no es que la familia es descuidada, que no lo quiere, sino es que ninguno de la familia... Porque claro, vos lo conocés al

\footnotetext{
${ }^{70}$ Se refiere a una orientadora del centro de día, es decir personal de asistencia directa.
} 
hermano, lo conocés al padre, viste en qué condiciones también están, que no es que al chico lo descuidan por ser discapacitado sino que no tienen agua caliente en la casa, entonces en pleno invierno es difícil la higiene diaria como uno la plantea. Entonces, bueno, desde ahí; y desde ahí apelar, entonces, al derecho a una vivienda más digna, al acceso... que en general, bueno, con el certificado de discapacidad se accede a otras cosas que por ahí la familia solamente por ser pobre no accede. (Entrevista TS código 522)

En todas las entrevistas surge fuertemente un reconocimiento a la visita domiciliaria como una estrategia privilegiada, cómo una forma de aprehender los modos singulares en que cada unidad doméstica produce su realidad. Las visitas domiciliarias cómo técnica privilegiada de acercamiento "a la realidad del otro" aparece semantizada de forma distinta por los trabajadores sociales, y por los sujetos de la intervención. Podríamos agregar también por los decisores políticos u organizacionales. ¿Para qué situaciones se entiende necesaria una visita? ¿qué consensos se han arribado?

En cambio las familias, creo que sí; en algunas es que como que todavía está este imaginario de "vienen a mi casa para ver cómo es mi casa, y a ver qué pasa, y cómo me manejo”, entonces está lo del control social; pero también está lo de la posibilidad de recursos: entonces "si yo le muestro toda mi pobreza, me consigue algo más”. Entonces, bueno, es como que por ahi es el interjuego entre la confianza que se genera por un vínculo humano, y la necesidad de mostrarte todo lo mal que la estoy pasando para que puedas darme una respuesta, una solución a algo. Por ahí a mí lo que me 
pasó en el centro de día es que, al ser muy poquita la población, generás otro vínculo con la familia que después de los años, no te voy a decir una amistad, pero tenés otra relación de confianza que por ahi te pueden estar planteando cosas que también están buenas que surjan ahí; que por ahí no es en la primera entrevista, sino después de mucho tiempo. Incluso yo, que por ahi he ido a visitarlos después a alguna fiesta o algo, por ahí se te acercan con cariño, desde ese lugar, y te plantean: “ay, sí, porque te acordás que vos me conseguiste que pueda hacer el documento de los chicos, y ya me lo dieron, te cuento". Entonces como que desde ese lado hay cierto reconocimiento del rol profesional, por ahi desde un lugar también muy... como desde la historia, el imaginario del trabajo social, desde ese lugar, ¿no?, desde la asistencia y desde el control social. (Entrevista TS código 522)

La concepción positiva de poder (Foucault) nos permite asumir la producción de realidad que nuestras intervenciones generan. Las posiciones que tomamos en las intervenciones operan en la producción de un vínculo con el / los sujetos de la práctica. En tal sentido, el discurso que incluimos en párrafos anteriores nos permite evidenciar que no existe un único modo de "hacer las visitas". ¿Las hacemos para conocer con mayor rigurosidad las formas de organización doméstica de "los sujetos" ó para evaluar el uso adecuado de los tiempos y recursos?

Y aquí retomamos, una vez más, los aportes de la sociología / antropología desde los cuerpos ${ }^{71}$

\footnotetext{
${ }^{71}$ ¿Podríamos comenzar a proponer un trabajo social desde los cuerpos?
} 
Que el cuerpo no sólo sea sujeto de investigación sino herramienta y sujeto de conocimiento, lo que implica dar centralidad al cuerpo actuante del investigador o la investigadora. El fundamento de esta propuesta podemos encontrarla en la necesidad de reconocer y restituir la dimensión carnal de la existencia, con frecuencia olvidada en las ciencias sociales, y de alejarse de las concepciones dualistas de la existencia (Mora, 2009: 16)

En la visita domiciliaria, tal vez al igual que en el uso de otras técnicas (dimensión operativa - instrumental), conocemos desde el cuerpo. En general, las/os entrevistadas/os no referenciaron sus sensaciones en la realización de las mismas, no obstante en el proceso de indagación puse en juego mis propias experiencias de visitas. Contreras (2010:23) nos propone "Situarse desde la experiencia supone también la posición subjetiva, la forma en que es experimentado, sentido, vivido por alguien en particular". Conocer al otro, mirar su mirada, observar su modo particular de comunicarse, acompañar los padecimientos que originaron nuestras intervenciones, y otros aspectos que no necesariamente previmos con anterioridad. Pensar las prácticas de la intervención social como experiencia permite modificar el lugar desde dónde se analiza la misma.

Las determinaciones sobre el mundo (la diferenciación de las magnitudes, o la distinción de los objetos y las acciones) son adquiridas básicamente a través de las experiencias que hace el nuevo miembro de la especie con un mundo de objetos y acontecimientos que se constituye a partir de estas experiencias. (Roncancio Henao:2012:7)

La idea de experiencia, nos quita del lugar de identificación de concepciones para permitirnos vivirlas, transitarlas, que nos atraviesen. En la 
recuperación de entrevista de la colega codificada bajo el número 62, en la que refería que "sentías que dependía el futuro de esa familia" de su intervención de la articulación de respuestas, claramente esta idea del atravesamiento queda evidenciado.

Una de las entrevistadas planteaba que "el problema de esa familia es que no se organizan" y aquí nos preguntábamos cómo operaba la normatividad en los relatos de la intervención, si la misma la podemos en acto sólo para "los otros" o también opera en la toma de decisiones de nuestra cotidianeidad.

\begin{abstract}
Este modelo que hay hoy ha matado bastante al clientelismo; no te voy a decir que lo ha destruido, pero lo ha matado y lo ha simbolizado en alguna forma. Pero lo real es que la discapacidad fue un gran negocio para los que nunca se preocuparon por ese sector. Es decir, lo que yo veo es que la gente cobra la pensión pero al chico no lo va a ver, pero a mí no me preocupa, total el chico... comencé a cobrar, y muy bien, porque cobro los aranceles del PAMI. Y creo que esto hay que replantearlo. (Entrevista TS 2329)
\end{abstract}

¿qué cuestiones son las que se valoran en la intervención? ¿Cómo se tejen la tomas de decisiones en el espacio doméstico con las impulsadas por la política pública? ¿Cómo los modos de reproducción del capital son legitimados para los emprendimientos privados y puestas en duda para las unidades domésticas? Una de las entrevistadas presenta de un modo interesante estas lógicas interpuestas/ contrapuestas y entrelazadas. 


\section{Capítulo IV: Escenarios de la}

\section{intervención y su dimensión corporal}

"Mi cuerpo es la vez mio, en tanto carga con las huellas de un historia que me es personal y una s ensibilidad que me es propia, $p$ ero contiene también una demensión que se me escapa en patrte y remite a los simbolismos que dan carne al vínculo social, pero sin la cual ya no seria" (Le Breton, 2009:36) 


\section{1.- Condiciones y medio ambiente de trabajo}

Las condiciones de la intervención están vinculadas a las dimensiones materiales de la misma, a los ejes organizacionales y a los sentidos asociados al tema particular que se aborda. En esta tesis buscamos recuperar la mirada sobre los procesos de trabajo desplegados por los trabajadores sociales en el campo, dando cuenta de aquello que hace al oficio cotidiano. Este punto nos permitió recuperar los modos de gestión de la fuerza de trabajo, retomando las discusiones en torno a si los procesos de trabajo pre - establecidos se tiñen de rutina y en tal caso cómo es percibido por los colegas.

Sennett (2012:44) plantea que "La rutina puede degradar, pero también puede proteger; puede descomponer el trabajo, pero también puede componer una vida”. Esta reflexión alertó sobre los malestares que aparecían en las narrativas de los colegas, y la necesidad de insertarlo en las discusiones que sobre las condiciones de organización del trabajo habían permeado los últimos años. En tal sentido, la mirada sobre la flexibilidad como atributo destacable al ocupar un puesto de trabajo es revisada a la luz de las tensiones que se dan entre las condiciones dignas de trabajo, asociadas a la estabilidad, al salario acorde, y a la definición del puesto, y la fluidez en torno a los vínculos laborales.

Cuándo indagamos sobre las formas que adquiría la organización del trabajo, vinculado a la división social y técnica del mismo (qué espacio se asignaba al trabajo social en la organización, a quién se respondía frente a las demandas laborales, quién supervisaba la tarea, etc.) advertimos cambios sustanciales a lo largo del tiempo. Estos cambios afectaron las tareas prescriptas y la percepción de las mismas que corresponden al ejercicio de la profesión. En este punto se abordaron cuáles eran las tareas asignadas y cómo se ejecutaban. Y en vinculación a la construcción de pertenencia a la organización se recuperaron aquellos significados en torno a la Trama organizacional, a sus objetivos. El dominio sobre la tarea fue un eje surgido 
de las propias narrativas de los colegas, y esto sumado a cierta categorización que proponemos:

- Los egresados de las décadas de 1960 a 1980 manifiestan una certeza sobre su puesto de trabajo, asumiendo un lugar creativo en torno a correr los límites de lo dispuesto, aparece algo del orden de lo inaugural;

- Los egresados de 1990 a 2000 expresan cierto desencantamiento, pero asumen compromisos más allá de lo dispuesto por los empleadores,

- Los egresados de 2000 a la actualidad, expresan un aprisionamiento en torno a la posibilidad de desarrollar innovaciones en las tareas.

Obviamente no podríamos plantear que estas posiciones están vinculadas a apuestas individuales, sino que se relaciona a los cambios generados en las estructuras organizacionales. Estos tres grupos relacionan una inclusión laboral en el estado, el sub sector privado sin fines de lucro y el privado con fines de lucro, aunque en la actualidad los empleadores se presentan en forma simultánea. Destacamos que mayormente los egresados desde el año 2000 se desempeñan laboralmente en el sub sector privado (con o sin fin de lucro), lo que marca una escena institucional diferente, con pinceladas de colores diversos que explican los requerimientos a los profesionales. En el primer capítulo cuándo trabajamos los antecedentes de la política de discapacidad en nuestro país, planteamos que la sanción del Sistema Único de Prestaciones Básicas a favor de las personas con discapacidad marcó una forma novedosa en la generación de servicios especializados teñidos de mercantilización. Por lo que la idea de trayectoria profesional toma cuerpo al observar relacionalmente las condiciones de trabajo, las disposiciones subjetivas y las percepciones diferenciales en clave epocal. 
En el código implicancias / compromisos asociamos las miradas que los propios trabajadores sociales tienen de su propio desempeño, de cómo los implica el trabajo en este espacio social particular. Por ello, surgió la comparación con otras profesiones, la idea de un mayor poner el cuerpo de los colegas. En ese sentido, destacamos que quien lo trae con mayor fortaleza es un colega que está transitando una enfermedad y que su relato lo coloca en un lugar de gran protección a los otros.

Destacamos la intensa referencia que hicieron los entrevistados a la provincia, y su notable deterioro en la generación de políticas en el campo de la discapacidad. Esto llevó a una fuerte interpelación a los colegas que "transitan sin más" el espacio del no hacer.

E: Pero hacer los enlaces con el organismo que corresponde? ¿eso si lo hacen?

M: Nosotros, no.

E: ¿Lo hace el director?

M: Este director, no. Este director lo gira a las autoridades que están por encima de él, en calle (xxx). ¡Ay, qué difícil que es contestarte! me da vergüenza ajena (Entrevista TS código: 158)

Es complejo analizar estas restricciones a la intervención, sin colocarse en un lugar valorativo ¿qué haría yo si me tocara en un espacio profesional en el que el no hacer es la regla? ¿Qué capacidades poseemos los trabajadores sociales para revertir el diseño organizacional de restricción de las funciones estatales?

En relación al bloque de la intervención en tanto práctica social, situamos cuestiones en relación a: 
- Los propósitos de la intervención ¿para qué ejercemos?

- Las argumentaciones sobre las razones de la convocatoria al trabajador social para la intervención,

- Las matrices teóricas vigentes en la intervención.

En relación a la Singularidad de la intervención en ese espacio organizacional recuperamos intensamente las "distancias" entre el ideal y las condiciones concretas de práctica profesional. En cuanto a la duración y configuración del tiempo de trabajo, pudimos recuperar las sustanciales diferencias entre los trabajadores del sector público, privado, de las ONG. Una cuestión relevante ha sido la vinculada a la construcción del interés (retomando la noción de illusio (Bourdieu, 1995). ¿Qué lo motiva a trabajar allí? ¿Y con estos sujetos? ¿Qué posición ocupa en el campo? ¿Qué visualiza que está disputando?

En ese contexto, recuperar la Trayectoria profesional, y la relación con la temática, permitió analizar lo que en el punto anterior de este texto trajimos en relación al concepto de trayectoria. Las trayectorias laborales forman parte de la vida de los sujetos, de modo que su abordaje permite comprender los pasajes de una posición a otra en un período de tiempo; así, afirma Godard (1996) que un individuo no es una sola historia sino que se constituye a partir de - al menos cuatro historias: la historia residencial, familiar, de formación e historia profesional.

"En esta situación se le pide a la profesión que proporcione capital a los empresarios privados al contar con servicios destinados a satisfacer necesidades de los individuos, familias y comunidades privatizados, y que actúe como policía de los grupos marginados u oprimidos al echar a andar un molino que hace girar las ruedas del riesgo y la 
falta de seguridad a fin de asegurar su conformidad en medio de precarias circunstancias que no son dignas de llamarse lugares en los que viven personas. $Y$ aún así, se le pide que se ganen la vida a duras penas en esos espacios" (Dominelli, 2008:48)

La tensión inmanente que señala Dominelli viene siendo discutido desde hace varios años en la profesión, lo que ha habilitado esta línea denominada como trabajo social anti - opresivo el que postula hacer visible las situaciones de violencia simbólica y promover estrategias de emancipación.

Volviendo al tema de las condiciones, lo que emergió del análisis de las entrevistas son cuestiones propias de la relación salarial, sumado a los límites de la intervención. Límites que los da el contexto de contratación, los abanicos de posibilidades que se desatan en las organizaciones y las estrategias que los colegas se dan para ampliar sus márgenes de incidencia.

Podríamos identificar que en el sector público municipal ${ }^{72}$ y provincial la remuneración de los trabajadores sociales es baja, al igual que el resto de los profesionales, con salarios que llegan a ser del $50 \%$ de lo que perciben las colegas en el ámbito público nacional ó en algunas obras sociales. Esto implica un reconocimiento laboral exiguo, con condiciones de trabajo estables en cuanto a la continuidad laboral (en algunos casos) y con precariedad en la forma de contratación en otras. ${ }^{73}$

En el caso de los trabajadores del estado nacional y del Gobierno de la Ciudad Autónoma de Buenos Aires, el nivel salarial es superior y las condiciones

\footnotetext{
${ }^{72}$ Cuando en este párrafo refiero al nivel municipal lo hago en mención a los distritos de la región Capital de la provincia de Buenos Aires.

${ }^{73}$ En la provincia de Buenos Aires se han ampliado las becas post residencia en salud y otras formas de contratación que no generan aportes previsionales.
} 
de contratación son heterogéneas, que incluyen plantas permanentes, temporarias y becas.

Por su parte, en el sub sector privado no encontramos trabajo en relación de dependencia sino la prestación de servicios. Esto implica la figura de un trabajador autónomo que presta servicios profesionales a un oferente, por lo que la regulación de los honorarios profesionales queda sujeta a la capacidad de negociación del profesional.

Las lógicas de trabajador asalariado precarizado con las de un profesional libre que presta servicios a un empresario privado son diferentes, lo que supone apropiaciones singulares de los escenarios de la intervención.

En el focus group aparece la idea de condiciones laborales asociadas a la construcción de accesibilidad, ya que enlazan la idea de ejercicio de la profesión con un espacio laboral en el que el acceso a la información, a los recursos existentes y a la capacitación se tornan fundamentales. La imagen de un trabajador incluido, con buenas condiciones de trabajo es la que comparten las colegas como resguardo al ejercicio de la profesión. Al mismo tiempo, la propuesta del grupo relaciona las condiciones laborales - en tanto responsabilidad del empleador - sumando los modos de actuar de los profesionales en torno a responsabilizarse sobre el despliegue de prácticas que permitan acceder a la información, a los recursos y socializarlos con los sujetos de la práctica.

Esta tensión entre estructura y agencia que identificamos ha sido permanente en el recorrido encarado sobre las trayectorias profesionales, toda vez que no podríamos plantear taxativamente que aquellos trabajadores incluidos per se generen mejores condiciones de accesibilidad a los sujetos de la práctica. ¿qué opera en estos procesos? En esa línea, destacamos un punto 
fundamental que surgió en las entrevistas que está asociada a lo que trabajamos en el capítulo anterior, vinculado a la pregunta de cuándo se es trabajador social, ¿qué prácticas habilitan el rito de pasaje entre la formación y el ejercicio profesional? Nos referimos a la transmisión del "saber - hacer" por parte de una trabajador social que nos antecedió. Eso es un punto nodal a destacar, sobre todo si consideramos lo saludable que resulta saber que antes otros tomaron decisiones. Las referencias a las colegas que actuaron como referentes aparecieron con mucha afectuosidad, reconociendo a aquellas que con formaciones diferentes habilitaron el despliegue de técnicas, de destrezas, del saber - hacer profesional. Diferente era el relato de quienes carecieron de colegas que los inicien en la tarea, situación que se dio fundamentalmente en el sub - sector privado cuya antigüedad institucional es breve.

Una inferencia posible es que en aquellas instituciones que se erigen en pioneras del campo, centros de rehabilitación surgidos en la epidemia de poliomielitis y hogares asociados a instituciones tradicionales de la caridad cristiana, la transmisión del oficio está planificada sea a través de pasantías, residencias, prácticas a estudiantes de grado. Una idea fuerza ha sido que un trabajador que nos forma, nos marca el camino.

Asimismo otra cuestión que apareció en varias entrevistas es que la extensión en el tiempo en una misma institución brinda da un plafón que permite consolidar prácticas. Experiencia y trayectoria organizacional actúan como facilitadores de la intervención profesional.

La consolidación de la mirada profesional es valorada en términos positivos en pos de encarar articulaciones interdisciplinarias, lo que habilita un claro despeje entre las certezas profesionales y las dudas / interrogantes que sólo pueden ser abordadas con otros perfiles profesionales. 
Sennett (2009:35) señala que: "para que profesionales con educación superior y trabajadores no cualificados puedan hablarse libremente se necesita mucho tiempo y una gran dosis de confianza. (....) Esta cadena emocional de acontecimientos complica el precepto de "mostrar respeto" por alguien que ocupe un lugar más bajo en la escala social o económica”.

En tal sentido, esta cuestión que retomamos del autor mencionado la enlazamos con las referencias que planteaban nuestros entrevistados en torno a las dificultades que aparecían en las organizaciones en relación a la configuración de equipos de trabajo.

"poder establecer cuál es el rol del trabajador social, desde dónde, por qué estar involucrado en la historia clínica, qué importancia tiene tu evaluación continua, y poder aportar a la coordinación del equipo interdisciplinario" - (Entrevista TS código 1525)

La consolidación que permite el tiempo junto con la sutileza de lo cotidiano hace posible la proyección de equipos de trabajo que sostengan apuestas colectivas. En tal sentido, la valoración positiva de los entrevistados en relación a la sustentabilidad de los espacios laborales se torna en fundamento central para cruzar los reclamos por condiciones estables de trabajo y de salarios acordes a la profesionalización de las actividades, con la posibilidad que brinda la consolidación de equipos.

El autor mencionado (Sennett, 2009:38) aborda tres temas interesantes para incluir a los debates del trabajo social, por una parte lo que él denomina los efectos humillantes de la dependencia adulta instaurados en lo que Dubet llamará programa institucional. 
También analiza la diferencia entre el respeto por uno mismo y el reconocimiento de los otros, algo que ha sido analizado por Fernandez Moreno (2011) y Paulina Morales Aguilera y Beatriz Vallés González (2013) quienes recuperando los aportes de Axel Honneth visualizan las dinámicas sociales que se generan en torno al encuentro con otros. La dificultad de mostrar respeto mutuo allende las fronteras de la desigualdad.

Los aportes de Sennett, quien reflexiona las relaciones de respeto entre los agentes sociales, a partir de recuperar las experiencias de intervención de su madre, trabajadora social, se tornó en un soporte analítico fundamental de este trabajo de investigación.

Por otra parte, existe:

"una articulación perfecta entre la precarización del trabajo, la flexibilización de la legislación laboral y las políticas focalizadas. Y esta articulación tiene incidencia directa en nuestras intervenciones profesionales, en la doble condición de trabajadores y trabajadores sociales. Se impone una lógica que prioriza las resoluciones inmediatas, las intervenciones puntuales y precarias, una instrumentalidad volátil (...) Desde esta lógica, el mejor trabajador social es aquel que da una respuesta, no importa cuál, porque lo único que se valora es que se "solucione" (Guerra, 2012:20)

Condiciones de intervención en tanto trabajadores tramados en un proyecto organizacional, y político profesional permiten desplegar posicionamientos, apuestas y acciones profesionales. 
Siguiendo a Repetto (2009) planteamos que la vida política procesa la complejidad pública que se traduce en gestión de políticas sociales. El marco institucional, en tanto cristalización de los intereses en pugna operara como escenario y marco contenedor de las prácticas profesionales. En este punto se torna interesante la vinculación entre las condiciones de trabajo, los modos hegemonizados de inversión pública y las formas en que se dispone la organización de los servicios sociales.

En tal sentido, la recuperación de las discusiones que sobre institucionalidad social se han dado en los últimos años (Repetto, 2009; Repetto, Filgueira y Papadópolus, 2006; Rozas Pagaza, 2010) permite tramar la complejidad que asume la intervención en cada campo específico.

Otra de las cuestiones que es oportuno señalar son las narrativas asociadas a una concepción de trabajo social militante, la cual en algunas entrevistas es contrapuesta a la idea de trabajador asalariado. Se intenta pensar cuánto hay de valoración del espacio laboral vinculado a la discapacidad como algo voluntario y cuánto hay de militancia más amplia (que excede el tema de la discapacidad).

En producciones anteriores planteábamos:

¿Por qué hablamos de militante? Ser militante significa reconocer el desafí ético que supone el encuentro con el otro. Supone el reconocimiento de la política y el poder como constitutivos del campo académico, regulando lo que puede escucharse, mostrarse, generando lo que Butler llama «esquemas de inteligibilidad» (Danel, Katz; 2011:195)

La dimensión militante de la intervención reconoce antecedentes disciplinares en el movimiento de reconceptualización y se re edita en las 
actuales discusiones sobre los proyectos éticos - políticos en disputa. Esto lo podríamos relacionar con la idea vocacional que aparece en el sustento de cierta postura militante, y aquí retomo a Papili quien refiere que "lo vocacional forma parte del campo profesional, y agregaría como el de cualquier carrera, ya que corresponde a los anhelos, expectativas existenciales del sujeto, y a un imaginario profesional". (Papili, 2013:50)

¿Qué activa al posicionamiento militante? ¿Tiene que ver con el tema que se aborde? ¿Ó es constitutivo de la práctica profesional?

Para cerrar este apartado, hacemos propias las reflexiones de una de las entrevistadas quien planteaba que las condiciones de intervención están enlazadas a las condiciones de vida de los sujetos de la práctica. En tal referencia planteaba que la escasez de recursos ó propuestas de algunas instituciones que abordan el tema de la discapacidad, especialmente las vinculadas a las políticas de empleo, se reflejan en las respuestas acotadas en torno a políticas articuladas y las condiciones de empleo de los profesionales.

\section{2. - La voz de trabajadores sociales en torno a la discapacidad en situación interventiva}

Resulta complejo categorizar rígidamente la forma en que es presentada en clave discursiva - la discapacidad en relación a los procesos interventivos.

Por un lado recuperamos los sentidos asociados al modo en que tramitan las personas la etiqueta de la discapacidad, las formas en que construye su 
subjetividad más allá y más acá del diagnóstico, de la certificación. Esto permite identificar los posicionamientos que toman los sujetos frente a la intervención, lo que tensa la productividad de los procesos interventivos, ya que aquellos sujetos que producen una posición de discapacidad desde la autonomía resisten a ser colocados, encasillados, moldeado en ciertos lugares. Y al mismo tiempo, aquellos que construyen posiciones heterónomas se avienen a las prácticas institucionales sin más. Retomando la narrativa de la colega que comentaba las posiciones diferenciales que ocupan los usuarios de las juntas evaluadoras de discapacidad, en las que las relaciones de autonomía y heteronomía quedan plasmadas.

En clara relación con esta mirada sobre la propia situación de discapacidad asociamos los sentidos que vinculan los colegas en esa relación interventiva.

Está bueno pensarlo desde ahí: desde que la gente tiene herramientas para afrontar esas situaciones y que no es que se les arruinó la vida por esto, digamos, sino que cada uno va haciendo su camino totalmente distinto, que tiene que ver también con la forma de ser previa de la familia. (TS código 522)

yo antes de leer, decía que la discapacidad no aparecía. Yo no me veía nada raro porque estaba con mis amigos, pero cuando salía a la calle y me miraban distinto, ahí estaba la discapacidad. Yo creo que es eso, que tiene que ver con esto, que después le fui encontrando nombres como la normalidad, y la construcción social, política y cultural. A mí se me ha materializado de esa manera: cuando veía gente que se me reía, que me miraba. A mí no me parecía que era distinto porque podía compartir con cualquier otra persona. 
Por eso también lo menciono tanto, porque estoy absolutamente convencida de que para que haya una discapacidad hay un derecho que no está siendo considerado. (Entrevista TS código 65)

La intervención en discapacidad desde la idea de trayectorias diferenciales en contextos desiguales, dota de un avance sustantivo en los análisis de las situaciones particulares que se presentan en los servicios sociales y son abordadas por los agentes profesionales.

Surgió una idea de abordaje con impronta conductista, que no hace otra cosa que valorizar en clave capitalista algo que no necesariamente tendrá eficacia. ¿Es posible incluir la mirada de la eficiencia en los servicios sociales? ¿Todo puede ser medible en clave de rendimiento? De las notas de campo, surgía con frecuencia el malestar que generaba el requerimiento incesante de los funcionarios (de una) de las obras sociales sobre los resultados en clave prestacional de las intervenciones de los trabajadores sociales. ¿Toda intervención resulta finalmente una prestación otorgada? Por ejemplo: un servicio de centro de día, de cuidados en domicilio, una transferencia condicionada de ingresos, etc. ¿O es posible incluir otras dimensiones que pongan en valor a los procesos interventivos?

Instalamos la idea de la dimensión perceptual, vinculada a los aportes de Schutz (1970) y Merleau - Ponty (1962). La percepción nos conecta con el objeto o con el otro sujeto, Schutz plantea "tornarse hacia un objeto". ¿Cómo se decodifica la idea de no - conexión intersubjetiva? La percepción siempre es situada, ¿Cómo pensar entornos intersubjetivos en el que el otro sujeto no tiene deseo de conectarse, de percibir? Y si lo percibe ¿se le torna amenazante? 
Uno de los entrevistados planteaba que surgía la necesidad de diferenciar a los discapacitados de los accidentados, que si bien el origen de esta reflexión estaba más orientado a analizar las diferentes posiciones de discapacidad, nos llevó a re -pensar la idea de curso vital y trayectorias, que fue analizada en el capítulo III. Por su parte, la idea de la discapacidad que sobreviene, que irrumpe nos permitió bucear en el concepto de contingencia. En esa línea tomamos los aportes de Butler (2010) y observamos con precaución las discusiones que sobre precariedad de lo humano se sostenían. ¿Estas discusiones no esconden una normatividad corporal? ¿Cuánto de la tragedia individual esconde esta idea de la precariedad? En los relatos de las entrevistadas aparecía asaz esta idea del orden de lo trágico, de los interrumpido, de lo difícil de afrontar. ¿Esto supone una mirada disciplinar de la discapacidad como experiencia no deseada? O estamos presenciando la producción de un discurso que pone en evidencia las formas de sufrimiento social que presentan los agentes en situación de discapacidad en nuestras sociedades contemporáneas. Esta cuestión, se constituye en plafón de las narrativas de las colegas que argumentan la intervención en clave restitutiva. El estado, a través de la acción pública, debe garantizar estrategias redistributivas en clave económica, al tiempo que debe generar un discurso social que instale la idea de derecho social como constitutivo de la ciudadanía más allá de las características corporales de los ciudadanos.

La conmoción frente a las formas de sufrimiento social ha sido una constante en las narrativas de los colegas. Esto permitió diferenciar el malestar por la discapacidad en sí misma, de la indignación frente a las formas de opresión asociadas a la discapacidad. Señalamos que al mismo tiempo que aparecía esta cuestión, se sumaba una mirada centrada en los agentes, en su capacidad de posicionarse desde las potencialidades. Emotividad frente a la escucha. El dolor del otro tramitado en la escucha. La implicancia, la distancia y el compromiso que supone "cierta entrega"" 
Los procesos de construcción, circulación y reproducción de nuestras sensibilidades sociales condicionan y constituyen al menos tres procesos vinculados elípticamente: 1) las conexiones -y desconexiones- entre afecciones individuales, percepciones sociales y relaciones de clase, etnia, género y edad; 2) las disposiciones y dispositivos clasificatorios respecto a lo que se represente socialmente por "medio", "entorno", "naturaleza” y/o "planeta"; y 3) el diseño de las formas tecnológicas de vehiculizar, transportar $y$ dislocar el tiempo y el espacio. Como posible advertir lo que esta en juego no se limita a una mirada binaria de la sensibilidad que la agota en la aporía (ya muy escolástica) construida-biológica. (Scribano, 2010:255)

El aporte de Scribano nos invita a complejizar esas sensaciones del orden de lo íntimo, de la sensibilidad que creíamos individual. ¿Cuánto de la sensibilidad opera como motorización de las prácticas interventivas? ¿Cuánto de la percepción instala la configuración de las situaciones como complejas, que ameritan respuestas urgentes? ¿O acaso eso que se activa en una entrevista de guardia en un servicio social no es algo del orden de los cuerpos, que se racionaliza, que se operacionaliza para intervenir? "el cuerpo es una condición para nuestra existencia, una base de operaciones desde la que actuamos en el mundo, pero que a la vez, está colmado de significados” (Kogan, L : 2010:102)

Porque muchas veces uno tomaba la discapacidad como incapacitante y realmente no lo es. Hay, digamos, ejemplos de personas con discapacidad que tienen una fortaleza, una perseverancia, que son ejemplares, realmente ejemplares. $Y$ uno mismo se cuestiona, ¿no?; uno que se queja de muchas cosas, y ver estos ejemplos, te da muchísima fuerza para 
seguir adelante. Y también muestra un mensaje más: nada está perdido, que se puede mejorar; con mucho esfuerzo, pero se puede mejorar (Entrevista TS código 37)

Esta idea de la fortaleza, el esfuerzo, la perseverancia ¿no esconde las limitaciones estructurales, los accesos diferenciales de acuerdo a la clase de pertenencia? ¿ò habilita la inclusión de miradas desde la singularidad?

Por otra parte, surgió una idea fuerte en torno al "sentirse discapacitado" y cómo esto podría relacionarse con la idea de habitus de la discapacidad.

el habitus de la discapacidad: como estructura estructurada, es un producto histórico a través del cual el Estado inculca la concepción del cuerpo no legítimo definida por el campo médico; y como estructura estructurante determina el límite de lo pensable y lo no pensable y genera unas prácticas y unos juicios sistemáticos. Sobre esa imposición, el colectivo queda marcado con las señas de la "exclusión social" (Ferrante, Ferreira, 2010:90)

Esto se tornó en un aporte interesante para re pensar las prácticas sociales de los agentes, tramar sus tiempos, y los modos de acción. Y recuperar las miradas que insinúan la producción de cierta adscripción identitaria a partir de la portación del certificado. En tal sentido, las mediaciones se tornan sustentadoras de la mirada crítica que permite identificar modos singulares de transitar la vida en situación de discapacidad.

Por ello, es que recuperamos otro de los ejes centrales en el análisis de la intervención que está asociado a la idea de abordaje / seguimiento / procesos a largo plazo / abordajes diacrónicos. Aparece aquello que se hace, se tramita, se 
gestiona desde la intervención y lo que me acontece a mí como sujeto al ver, al ser espectadora de deterioros / dependencias / carencias.

Y por fuera yo lo que veo es que los trabajadores sociales en la temática de discapacidad todavía tienen el "chip” del modelo médico, de eso no hay dudas. No se animan, o no pueden, o no sé, habría que analizarlo, en muchos municipios, a pasar ese límite autoimpuesto o que te imponen desde distintos sectores, incluso en las mismas facultades a veces, de que vos tenés que llenar formularios nada más, pre-cocinados, enviados por ministerios o quien sea. Y que tienen esa gran oportunidad de estar en contacto con la realidad, y cuando digo la realidad es con las personas, y veo un déficit en cuanto a construir la política pública. A ver, ahi estoy pensando en mi historia (Entrevista TS Código 97)

En este punto, para polemizar fuertemente nos invita a romper con idealizaciones sobre lo posible, los compromisos asumidos que de tan heterogéneos se tornan injustos. ¿Por qué planteo esto? Apareció en forma recurrente referencias a pensar la intervención profesional como posible salto cualitativo en las trayectorias de los sujetos de las prácticas, algo del orden de la accesibilidad a partir del encuentro interventivo ${ }^{74}$. Pero esto no era asumido por todos, ni construido de manera lineal por el colectivo profesional. Para aquellos colegas que plantean pre eminencia de las restricciones por sobre las posibilidades, la asunción del salto cualitativo no aparece.

\footnotetext{
74 Esta relación que establecemos entre las trayectorias de los agentes en situación de discapacidad y los saltos cualitativos posibilitados por las intervenciones, ha sido ratificado en varias entrevistas de esta tesis y por lo manifestado otros investigadores que realizan trabajo de campo en el tema discapacidad, pobreza y vulnerabilidad. Especialmente señalo las apreciaciones que sobre el particular hiciera la Dra. Ferrante, a partir de los datos que surgiera en sus entrevistas sobre mendicidad en la Ciudad Autónoma de bs As y en el norte de Chile.
} 
En este punto sumamos una valoración recurrente sobre las redes armadas con otros colegas e instituciones a partir de la propia intervención, del propio prestigio interventivo, del respeto ganado frente al abordaje de algún caso. Sigue apareciendo la referencia institucional, con otras profesiones y la interdisciplina.

Las cuestiones que creo que facilitan, para mí más que todo es el conocimiento institucional de la zona: vivir en la zona $y$ tener los contactos y las referencias institucionales. Porque ante cada situación he podido lograr o llegar a ciertas cuestiones por ser del lugar y poder... bueno, le pasa algo a alguien y saber adónde acudir, tener un referente en ese lugar. Se le venció el certificado a alguien, y tener un referente en discapacidad. Todas esas cosas que van agilizando el trabajo. O situaciones de... problemáticas familiares en relación a maltrato o discusiones, bueno, tener contactos en Asesoría o en el Tribunal de Familia. Bueno, todas esas cosas que uno va consultando. Y más para mí, que por ahí yo no tenía tanta experiencia en discapacidad. (Entrevista TS código 1516)

Otra cuestión central ha sido el acompañamiento como un significante constante en los relatos. En algunos aparece mucho la idea de la grupalidad como sustento imprescindible de las acciones de las ONG, habida cuenta que los espacios profesionales en el sub sector privado tienden a ser más constreñidos.

Acompañar es mirar de otra manera a la persona y su historia, para que ella pueda verse de otra forma. Es creer en sus potencialidades, ayudarle a tomar conciencia y a desarrollarse, sea cual sea su estado actual. Acompañar es 
mediar entre las instituciones, más o menos burocratizadas de una sociedad y las personas que, por estar excluidas no puedan hacer valer sus derechos. (Funes y Raya,2001:33)

El aporte de los autores mencionados nos invita a instalar otro significante fuerte en las entrevistas que es el asociado a la configuración de proyectos de intervención, en los que la tramitación de las situaciones conflictivas son realizadas con el sujeto de la intervención. ¿Qué aspectos son los que se abordan? ¿Sólo las dificultades de accesibilidad (en sus múltiples dimensiones) son las que se toman?

¿Por qué hablamos de proyecto como dimensión instrumental del acompañamiento? La idea de pensar un proyecto supone la configuración de una imagen objetivo, de historizar las prácticas, de identificar las formas en que el orden social constriñe y las potencialidades que la singularidad despliega. Al mismo tiempo articular con las expectativas que construimos en torno a las apuestas individuales que "el otro" toma. Y la producción de certeza de que el otro, siempre será el otro y tomará decisiones más allá de nuestras sugerencias.

De violencia, abusada, el hijo más grande es hijo de su padre, vive acá, está viviendo en un refugio, la trajeron de Gral. (XXX) acá a La Plata a un refugio, no sé porque, hace años, después ella de ahí se va porque se junta con un hombre y tiene otra hija que es la bebe que tiene ahora. Que es por la que nosotras estamos interviniendo en este momento, es una nena que está en bajo peso, ella la saca desabrigada, ella está en la calle, bueno, un desastre. Para comunicarte con ella y entender lo que te está diciendo vos tenés que tener conocimiento minimamente de un recorrido a veces, porque no le entendés lo que te está explicando, 
porque no cualquier trabajador sabe cuáles son los trámites hay que hacer, a qué lugares tiene que ir, no sé, hay cuestiones que son específicas, te dice la oficina, la oficina, ¿cuál oficina? (Entrevista TS código 1313)

En la situación que mencioné anteriormente se puede visualizar cómo el acompañamiento es sinuoso, con recursos escasos (la mayor de las veces) con sujetos sufrientes ó padecientes. ¿Cuánto de lo restitutivo opera? ¿Cuánto de la emancipación? ¿Cuánto de rupturas ó saltos cualitativos? Y en qué medida las intervenciones profesionales logran generar o aportar a estos saltos.

Y en esa línea se instala sin más, la idea de gestualidad. La intervención profesional de los trabajadores sociales está integrada de sutiles actos, de miradas intercambiadas, de palabras enunciadas en contextos de entrevistas, de información compartida, de accesos habilitados. Skliar $(2009,2014)$ plantea que los pequeños gestos, los gestos mínimos, hacen sentir a cualquiera y cada uno su implicancia con lo común y lo común tiene que ver con lo público. Cuando el autor nos invita a revisar esos gestos mínimos, nos habilita reflexiones sobre aquello que pone en evidencia si el otro me importa, me conmueve, me habilita esfuerzos intelectuales para generar intervenciones.

Gestos (y creo que la mirada también es un gesto) que ayuden a la existencia del otro, a su afirmación, a su vitalidad, a su porvenir. Gestos, como la mirada, que son decisorios a la hora de intentar hacer algo con lo que se és (Skliar, 2009)

Volviendo a las ideas trabajadas en los capítulos anteriores, recuperamos las nociones de otredad, de sujeto, de autonomía que se configuraron como entramado sustancial para proponer una mirada de la discapacidad. Al tiempo, 
que la propuesta de un trabajo social anti -opresivo que construya un horizonte emancipador en su despliegue se sustenta en un paso, previo, con una pre noción, en un instante que habilita gestualidades. Cornú (2007) plantea que la hospitalidad es la que acoge a la mesa, es el conjunto de gestos y de ritos del umbral, de la entrada. Los gestos mínimos, son los que evidencian las apuestas estratégicas, los compromisos ético - políticos. ¿Cómo pensar una implicancia política grandilocuente si me despreocupo que el sujeto de la práctica me espera 3 horas para que lo atienda? ¿Cómo sostener un discurso de emancipación si no me importan los modos en que transita el sujeto por la organización? Las formas en que es tratado, la manera en que es higienizado en un hogar, si se respeta o no la intimidad, todo esto hace a la dimensión de gestualidad mínima. Con esto queremos señalar, que esos gestos no son sólo de nuestra intervención sino que transversalizan las prácticas de las organizaciones.

Uno de los entrevistados planteaba que en las organizaciones se sostienen disputas sobre qué cuestiones les corresponde hacer a los trabajadores sociales en forma exclusiva y la división con los “meros trámites, las tareas de administrativas". Y en este punto, que resultó recurrente se tematizó nuestra idea de la central disputa en la que se juega ó jugaría el prestigio profesional. En el capítulo II retomábamos la multiplicidad de acciones que los trabajadores sociales sostenemos, con un claro dominio herramental de la profesión. Las 


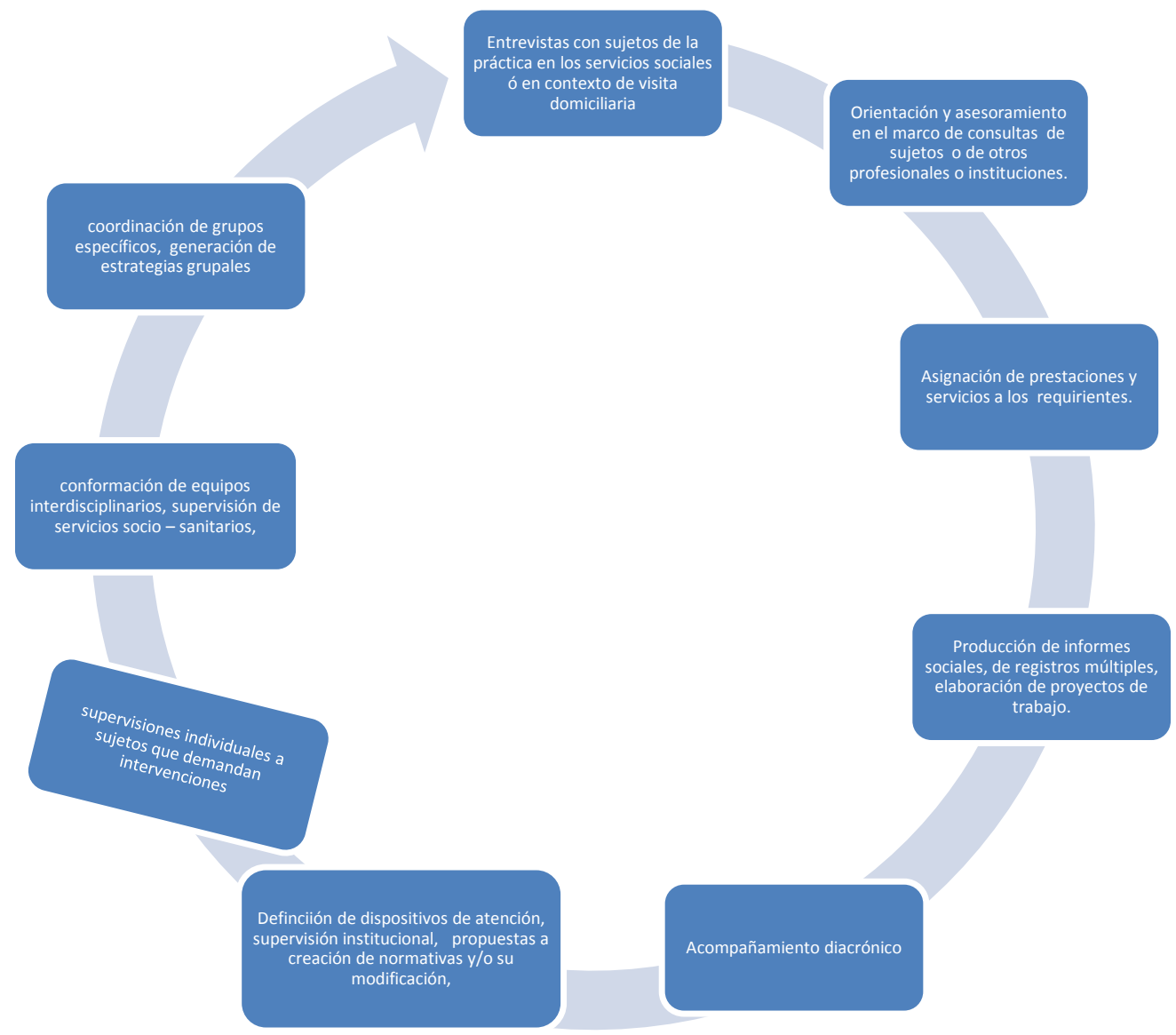

En estas actividades mencionadas, la escucha vuelve a aparecer, en esta oportunidad disputando el significante a los psicólogos ${ }^{75}$. En este punto apareció con énfasis la idea de escucha, enlazada a la de contención como constitutiva de la misma. Y en esa escucha, surgió la idea de construcción de los límites de la intervención, de los encuadres de la demanda. No es cualquier conversación la que se dá en los servicios sociales, sino un tipo de relación social en el que la

\footnotetext{
${ }^{75}$ En varias entrevistas apareció fuertemente la disputa con "los profesionales de la psicología" en torno a la categoría de escucha. Asimismo, en las organizaciones surgió como práctica habitual que frente al conflicto se derivaba al servicio social ó al psicólogo como forma de tramitación del conflicto.
} 
fluidez del discurso está enfocado a una particular relación, a la que podríamos denominar de asistencia. La recuperación de la narrativa del sujeto que demanda, se realiza en pos de reconstruir su historia, trayectoria, y tendiente a construir en forma conjunta un proyecto interventivo. El acompañamiento, categoría que habilita tránsitos autónomos, sólo es posible con dispositivos de escucha.

Y aquí retomamos:

La palabra, la mirada y la escucha son instrumentos clave en las diferentes metodologías de intervención social, forman parte de un mismo proceso y sólo podrían ser diferenciadas para un análisis individualizado de cada una de ellas. Así, un oído atento, un habla adecuada y el reconocimiento y manejo de silencios oportunos son parte de la construcción de la escucha como un proceso relacional cargado de sentido (....) escuchamos en contextos $y$ escenarios que tienen sus propias tonalidades, sonidos y silencios, éstos constituyen el telón de fondo de ese acto. Pueden ser hostiles o acogedores, facilitando u obstruyendo la interacción de quienes hablan (Carballeda, 2015)

Aparece una referencia valorizando a la visita, en la que se refiere que "no es lo mismo sentarse y escuchar que ver". La entrevista en contexto de visita domiciliaria adquiere una particular dimensión, una textura diferencial. Y aquí instalamos otra discusión: 

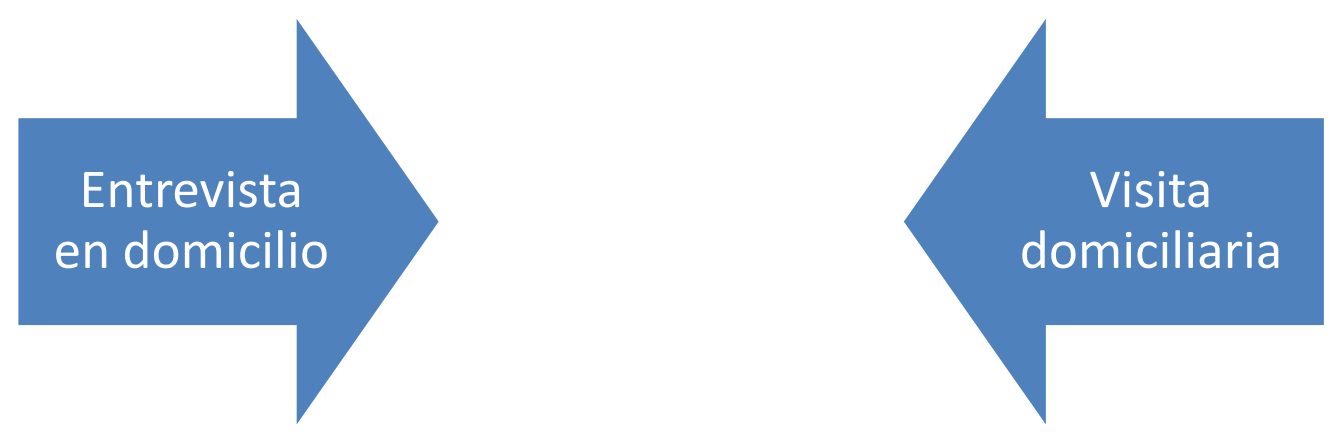

Los entrevistados planteaban sentidos asociadas a la visita en este sentido:

la visita domiciliaria es una acto profesional que nos define. No se trata de una técnica en si misma, toda vez que este acto se compone de varias técnicas: la entrevista(con sus recursos específicos, subtécnicas y habilidades), y la observación en sus distintas formas(participante, estructuradas, no estructurada, focal...) (Gonzalez Calvo, 2003:66)

La visita como algo más que una técnica, en la que no sólo se desarrolla la competencia asociada a la entrevista sino que operan otros procesos que suponen destreza herramental. Al mismo tiempo, el ingreso a la cotidianeidad e intimidad de los sujetos de la práctica nos coloca en un espacio / tiempo privilegiado, toda vez que lo que acontece en esa visita no se traduce en informes textuales, sino que se produce una co - escritura de aquello que se narra. La visita domiciliaria, como patrimonio del trabajo social, habilita el depliegue de la materialidad de la intervención, leída desde las cuatro funciones esenciales que planteamos como asistencia, gestión, educación y cuidado. Las mismas suponen rupturas epistemológicas y epistemofílicas a partir del 
reconocimiento de la corporalidad. En tal sentido, podríamos hipotetizar que la visita en domicilio se instala como una forma de reconocimiento, tanto como sujeto de derecho ó como ciudadano a controlar. ¿Cuáles son las motivaciones de la visita? ¿Quién coloca esas motivaciones?

Cuando vos entrevistás ... citás en sede, en tu escritorio, con el interno que te llama y no sé qué, la relación se da de una manera. Cuando vos llegás al rancho, tratando de no pisar la cagada del perro, vos sos visitante: el local es el otro. Y además es hermoso porque te dan mate, comés tortas fritas. Bien, entonces yo dije "sigo haciendo visitas" (Entrevista TS código 213)

En el cuadro siguiente recuperamos el valioso aporte de Cazorla Becerra, Ketty y Fernández Hormachea, Jemima (2009) quienes realizan un pormenorizado análisis del tipo de visitas que se realizan, y si las motivaciones de las mismas están vinculadas al desarrollo de prácticas de investigación y/o intervención profesional. Y aquí vuelve a aparecer la tensión inmanente entre las posibilidades de ejercicio de la profesión con autonomía y las contricciones que los escenarios imponen.

\begin{tabular}{||c|c|c||}
\hline \hline ENFASIS & INVESTIGACIÓN & INTERVENCIÓN \\
METODOLÓGICO & & \\
\hline TIPOS DE VISITA & & \\
DOMICILIARIA & & \\
\hline
\end{tabular}




\begin{tabular}{|c|c|c|}
\hline Asistencial & $\begin{array}{l}\text { El objetivo de indagar información } \\
\text { de carácter socio - familiar para la } \\
\text { gestión de bienes y servicios, } \\
\text { evidencia un énfasis investigativo. }\end{array}$ & $\begin{array}{l}\text { La entrega de bienes y } \\
\text { servicios provoca un cambio } \\
\text { de primer orden en la familia a } \\
\text { nivel estructural. }\end{array}$ \\
\hline Asesoría técnica & $\begin{array}{l}\text { Pesquisa de los antecedentes de } \\
\text { riesgo o protección presentes en un } \\
\text { contexto domiciliario }\end{array}$ & $\begin{array}{l}\text { A partir de los antecedentes } \\
\text { recopilados se proponen rutas } \\
\text { de intervención profesional } \\
\text { para los actores externos. }\end{array}$ \\
\hline Socioeducativa & $\begin{array}{l}\text { Se identifican los intereses o } \\
\text { necesidades educativas de un } \\
\text { determinado grupo. }\end{array}$ & $\begin{array}{l}\text { A través de los intereses o } \\
\text { necesidades identificados es } \\
\text { posible ejecutar sesiones } \\
\text { socioeducativas pertinentes. }\end{array}$ \\
\hline Intervención & $\begin{array}{l}\text { Al realizar la intervención } \\
\text { profesional se propician cambios, } \\
\text { pero paralelamente se profundiza la } \\
\text { información para el proceso de } \\
\text { investigación diagnóstica de la } \\
\text { familia. }\end{array}$ & $\begin{array}{l}\text { Generando espacios de } \\
\text { comunicación entre los } \\
\text { distintos subsistemas del } \\
\text { grupo familiar, se propician } \\
\text { cambios de segundo orden, } \\
\text { que surgen a partir de las } \\
\text { propias reflexiones y toma de } \\
\text { decisiones de los participantes. }\end{array}$ \\
\hline $\begin{array}{l}\text { Evaluativa y de } \\
\text { seguimiento }\end{array}$ & $\begin{array}{l}\text { Se investiga acerca del grado de } \\
\text { cumplimiento e impacto alcanzado } \\
\text { por los objetivos de intervención. }\end{array}$ & $\begin{array}{l}\text { Al compartir los resultados } \\
\text { evaluativos con los actores } \\
\text { participantes, se genera la } \\
\text { posibilidad de propiciar } \\
\text { cambios a partir del análisis }\end{array}$ \\
\hline
\end{tabular}




\begin{tabular}{||l|l|l||}
\hline & & del proceso experimentado. \\
\hline
\end{tabular}

Cuadro elaborado por Cazorla Becerra, Ketty y Fernández Hormachea, Jemima (2009)

El cuadro sistematiza de manera interesante cómo la visita habilita acciones más allá de la actividad en sí misma, y que siempre tiene un objetivo previo. No obstante, entendemos que la misma no viene siendo valorada de manera positiva por parte de los colegas, a partir de la valoración negativa que se asocia a los mecanismos de control social.

nosotros teníamos dividida toda la zona capital: sur, norte, noreste. Y también por la provincia. Nosotros íbamos a las casas. Un poquito de reconceptualización tiró abajo eso porque decía que pareciamos controladoras sociales (Entrevista TS código 62)

Y esta valoración negativa se vincula (de acuerdo a lo que surge en el trabajo de campo) a la imposibilidad de hacer visitas desde algunas las organizaciones privadas.

Entonces como que no se sabe mucho: “¿y a qué querés ir a una visita, si no hay nada que autorizar, si no hay nada...?" O como ellos no solicitaron nada, es como que también te ponen: “¿para qué venís a una visita?” Entonces, bueno, nada, instaurar lo que sería dentro del campo de la discapacidad por qué querés hacer una visita, para qué, con qué objetivo, tanto para la institución como para la familia (Entrevista TS código 1525) 
El sinsentido de la visita, desde dispositivos que construyen una totalidad de respuesta a la persona con discapacidad no es incongruente. La visita nos habilita a conocer otras escenas, otros tópicos en los que el sujeto despliega prácticas, pensando en trayectorias sociales mixtas, no sólo en dispositivos especializados. Se torna fundamental conocer las características urbanísticas, de accesibilidad, la red social vecinal, los recursos comunitarios, las barreras sociales y edilicias. Al fin y al cabo, la visita se inscribe en la idea de territorio. Y allí sumamos esta idea de que"es posible pensar que la territorialidad se construye de forma discursiva". (Carballeda, 2015:1), y nos preguntamos ¿la narrativa que sustenta los informes sociales post - visita domiciliaria, no operará en esta construcción de la territorialidad?

Y para cerrar esta cuestión de la visita, la enlazamos con la idea de abordaje social como acción central en contrapunto con la búsqueda de recursos. Los colegas planteaban que la mirada social hacia la profesión, en las instituciones públicas está circunscripta a la asignación de recursos, perdiéndose de vista las funciones de asistencia, gestión, educación y cuidado. Y frente a esto surge un nuevo interrogante ¿en qué función incluiríamos el acompañamiento ó abordaje? ¿Qué materialidad adquiere la intervención más allá y más acá de la asignación de recursos?

Y retomamos una afirmación de una colega, asumiendo una cuestión interesante "ahora la institución somos nosotros" (TS código 225). Esta fuerte enunciación implica en sí misma la responsabilización por la institución de la que formamos parte. Lejos de desconocer las limitaciones que operan, lo que pone en relevancia es la necesidad de asumir compromisos emancipatorios. 
En el focus group lo que aparece es la inclusión en los últimos diez años ${ }^{76}$ de un tipo de estrategia de trabajo, de articulación inter - institucional que permitió la generación de condiciones de accesibilidad. Los entrevistadas planteaban "intervenciones más difusas, no destinadas a un paciente en especial, sino intervenciones que tienen que ver con crear otro tipo de condiciones de inclusión social" (Focus Group) Esta cuestión instala en el plano cotidiano, la idea de inclusión social. Ya no se centra en el sujeto el déficit, sino que se generan prácticas tendientes a construir condiciones sociales de accesibilidad. Ahora bien, la pregunta que se instala incisivamente es si estas directrices se mantendrán más allá de la gestión actual. ${ }^{77}$

Otro desafío interesante se genera en la ocupación de espacio fundamental en las juntas certificadoras de discapacidad. ¿ Qué lugar ocupa el TS? para qué estamos? No es orientación, sino que es para dar una opinión fundada sobre la situación de discapacidad y si el entorno se constituye en discapacitante. Hay una valoración en torno a la dificultad de los trabajadores sociales en jugarse con una opinión. En el capítulo II planteábamos que la junta evaluadora determina si existe o no una discapacidad teniendo como parámetro lo establecido en las normativas vigentes. ¿Qué procesos están haciendo falta que se desaten para que la apropiación de las juntas sean de manera más homogénea? ¿Por qué las disputas en clave interdisciplinaria se dan con intensidad variable?
Es lo que nos pasa en particular en el servicio social: todo aquello que tiene que ver con los obstáculos al acceso, los obstáculos a la cobertura de las necesidades o de las expectativas de la persona, o su familia, o su soledad, yo

\footnotetext{
${ }^{76}$ Los diez años refieren al período 2004 - 2014, coincidente con la gestión del Ministerio de Desarrollo Social de la nación por parte de la Dra. Alicia Kirchner (trabajadora social).

${ }^{77} \mathrm{La}$ discusión eterna está asociada si se ha logrado la institucionalidad suficiente que permita el desarrollo de políticas de estado que se sostengan a lo largo del tiempo.
} 
creo que necesariamente tenemos que intervenir (Entrevista TS código 13)

\section{3. - Los cuerpos en escena, de la conmoción a las disputas de sentido}

Para culminar el presente capítulo vamos a traer las discusiones sobre la dimensión corporal presente en la intervención profesional. Comprendemos que el análisis de cómo se ponen en escena los cuerpos, cómo operan los procesos vinculados a la conmoción frente al sufrimiento social del otro, de las situaciones de opresión de las que somos testigo y las disputas de sentido que sostenemos.

Los estudios sobre cuerpo los podríamos agrupar en tres fuentes analíticas (Mora, 2010):

- los que se entiende al cuerpo como producto de un conjunto de sistemas simbólicos

- los que se hace hincapié en la regulación de los cuerpos, con una gran influencia foucaultiana.

- Cuerpo como punto de partida metodológico, antes que objeto de estudio. La idea de cuerpo como ser - en - el mundo de Merleau Ponty será una influencia central.

¿Desde dónde pensamos los cuerpos? Desde los tres aportes teóricos, habida cuenta que entendemos que el cuerpo es nuestro punto de vista metodológico, considerando que en la intervención ponemos el cuerpo 
constantemente, y desde esa corporalidad percibimos el mundo social. Y al mismo tiempo, esas percepciones están reguladas (relacionado al concepto de habitus) por lo que la indignación, el asombro que ponemos en acto en la intervención con los posibles y los pensables en determinado espacio - tiempo. Y por otra parte, los sistemas simbólicos claramente asignan sentidos a determinados funcionamientos corporales, a las proximidades entre los cuerpos de los trabajadores sociales y los sujetos de las prácticas, etc.

El orden social se inscribe en los cuerpos a través de esta confrontación permanente, más o menos dramática, pero que siempre otorga un lugar destacado a la afectividad y, más precisamente, a las transacciones afectivas con el entorno social. (Bourdieu, 1999:186)

Esta cuestión de la afectividad, las transacciones afectivas, inscriptas en los cuerpos es un dato insoslayable para pensar la intervención profesional en tanto práctica social. Varias entrevistas planteaban que en los dispositivos centros de día el lugar de los trabajadores sociales era "un poco adentro y bastante a fuera" esto constituía un lugar paradojal, en el que no podríamos plantear en término de no lugar (Augé, 1992) ya que la interacción está garantizada. No obstante, el no lugar es configurado en tanto estrategias de desinterés sobre el adentro que protagonizan muchas veces los propios colegas. "nosotros no sabemos de las patologías, así que mejor trabajamos el afuera" (notas de campo)

lo que yo les planteé a ellos en ese momento fue por ahí ser un poco el vínculo entre la institución y las familias, por un lado, en relación a las actividades que se hacen en el centro de día, como para que eso tenga un correlato también en la familia y viceversa. Por otro lado, todas las cosas que tienen que ver con la situación socioeconómica de las familias: 
cómo ir viendo esas situaciones e ir abordándolas.

(Entrevista TS código 1516)

Ahora bien, ese lugar intersticial en el que se produce la intervención en las organizaciones asociadas a dispositivos de atención, nos recuerda las discusiones del trabajo social alternativo que nos trajo el retorno democrático de la década del 80. El mismo tenía entre sus "rasgos más saltantes (........) el Trabajo Social Alternativo apuntan a la formación de un sujeto social popular con potencialidad de transformación social, creativa y productiva, donde los criterios técnicos para proponer opciones de asistencia y bienestar que sean eficaces y factibles cobran un especial y renovado relieve" (Maguina y Varas, 1988:5)

El trabajo social tiene un amplio recorrido en la discusión sobre el espacio de intervención, por lo que las discusiones sobre la resignificación de la demanda, las rupturas con los roles asignados son un capital específico del propio campo disciplinar.

Retomando lo que plantea Bourdieu (1999) en torno a la afectividad, como motor de la vincularidad, relacionamos:

si me plantean hacer un informe social, bueno, ¿pero qué es el informe social?, como cuestionar esto: ¿es lo mismo hacer un informe social en una oficina que concurrir al domicilio?, ¿es lo mismo un informe social que responden preguntas cerradas, completando una fichita, que poder tener una conversación más o menos amena con la familia y también estar escuchando lo que el otro quiere contarnos? Porque muchas veces, a mí me pasó, que vas con ciertos ejes de entrevista, y el otro por ahí se va para otro lado porque era necesario para esa persona decírtelo. Y generás un 
vínculo de confianza que te permite abordar un montón de cosas, que si vos lo limitás diciendo: "no, mirá, eso no me corresponde porque yo vengo por el centro de día, entonces esto lo tenés que hablar... es una cuestión familiar, hablalo con otro trabajador social”, y no. (Entrevista TS código 522)

La intervención supone vincularidad, encuentro, reconocimiento. El análisis situacional de los sujetos de intervención es posible a partir de la disposición a la escucha, una "escucha que es diferente" como plantearon casi todos los entrevistados. En este punto, destacamos que reiteradamente el particular modo que nos disponemos a la escucha, y que no es sólo escucha sino que es tramitación de demandas, configuración de proyectos de intervención, al fin y al cabo acompañamiento.

Y el mismo, se realiza desde varias dimensiones: capacidad intelectual, dominio herramental y corporalidad. Siguiendo a Contreras (2010) planteamos que es el cuerpo el lugar en el que se inscribe la historicidad, los sentimientos y pensamientos, por lo que la posibilidad de realizar una lectura analítica de esto es a través de la captura de la experiencia.

Cuando nosotros delineamos esto del proyecto institucional que yo te decía, cuando me hice cargo, uno de los ejes del proyecto es que todas las intervenciones que se realizan desde el dispositivo (xxxx) conllevan un fin terapéutico, ¿no?, que es este de la subjetividad, de promover la vinculación con el otro. Entonces nosotros decimos que lo que hace la cocinera tiene que ver con lo terapéutico; cómo el chofer ayuda a subir tiene que ver con lo terapéutico; el plan que traza el psicólogo tiene que ver con lo terapéutico. 
Todo lo que tenga que ver con lo terapéutico depende de mí, ¿me entendés? En realidad fue una movida política esa; que no tenía que ver con que dependa de mí porque la verdad que es un embole; ¿viste?, a algunos les gusta llevarse los laureles y no la carga de... Pero sí un poder... el caballo delante del carro: acá lo que nos interesa es lo que hacés, ¿se entiende?, porque sino "a este chico no lo puedo subir porque la silla de ruedas es muy ancha y no entra en la traffic", "cambiá la traffic, acá lo que nos interesa es el fin terapéutico”. Entonces, desde ese lugar, todo termina dependiendo de la dirección técnica. (Entrevista TS código 213)

La recuperación de esta entrevista nos parece central, habida cuenta que la misma despliega los procesos inmanentes de la intervención. ¿Interesa lo terapéutico en tanto medicalización? ¿O lo que aparece es la construcción de una narrativa que viabilice la producción de sentidos en clave de autonomía?

Por último, planteamos que la corporalidad es enlazada a las disposiciones espaciales de los servicios sociales. En las entrevistas surgió, vinculado a las condiciones y medio ambiente de trabajo, intensidades variables en torno a la calidad de los espacios de trabajo. En general, en los dispositivos de atención del sub sector privado los gabinetes / consultorios eran compartidos por lo que se presentaba cierta dificultad de sostener entrevistas en marcos de intimidad. En el capítulo anterior planteábamos que la temporalidad era un vector importante en la intervención, por lo que sumaremos el vector espacial para seguir pensando la misma.

Merlau Ponty (1962), desde la fenomenología, plantea que el cuerpo humano es él mismo un sujeto y que este sujeto es necesariamente un sujeto 
corporizado. Esto ha permitido evitar el pensar exclusivamente desde una semántica interpretativa alejada de la propia percepción corporal. Cuando los trabajadores sociales ponemos el cuerpo en la realización de visitas domiciliarias, evidencian los conceptos de cuerpo vivido y la producción de espacialidad. Supone una idea de localización de las prácticas sociales y un lugar diferencial al cuerpo.

Las sensaciones frente a la opresión, la indignación frente al avance de la medicalización tuvieron un locus corporal. Allí establecimos un vínculo nuevamente con Csordas cuando plantea que es "Un campo metodológico indeterminado definido por la experiencia perceptual y por los modos de presencia y compromiso en el mundo" (Csordas, 1999:145)

Apareció en las entrevistas la idea de dejar capacidad instalada, que si se genera un emprendimiento lo que corresponde es que las personas con discapacidad se autonomicen, salgan de la esfera institucional y sostengan tal emprendimiento. En la entrevista a una de las pioneras, aparece muy fuerte es la mirada estratégica para gestionar las organizaciones. La construcción del problema, la colectivización e implicancia en la búsqueda de respuestas. 


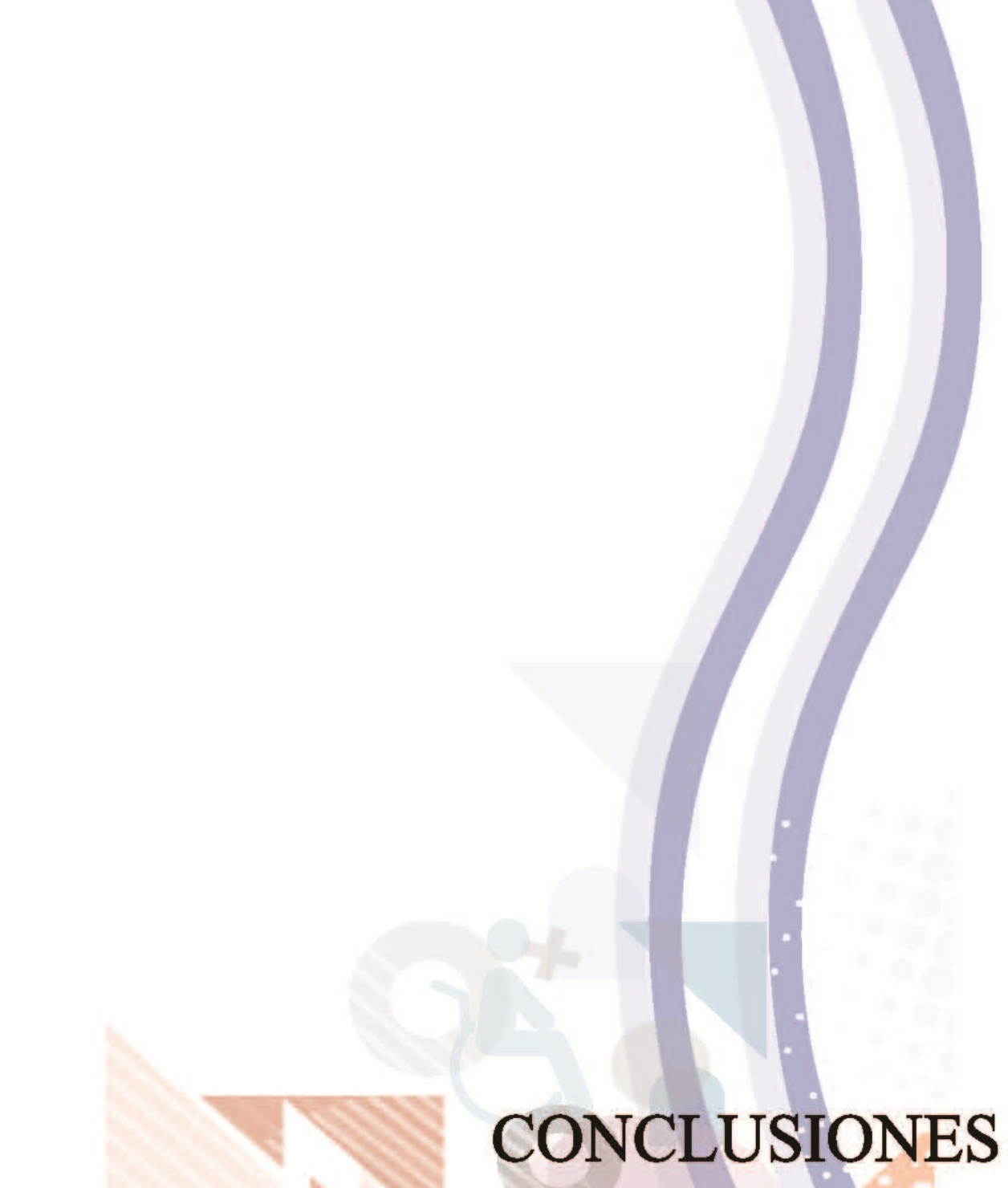
actúa simbólicamente. No sólo es un espectáculo sino el ejercicio de un poder. En ciertas condiciones, oculta un temible poder de metamorfosis. La mirada de un actor $p$ osada en otro es siempre una experiencia afectiva. (Le Breton, 2009:195) 
El proceso de producción de la tesis ha sido intenso, multidireccional y posibilitó un crecimiento personal e intelectual que no es propio, sino resultante de los múltiples encuentros que con colegas he mantenido en este tiempo. Colegas trabajadores sociales, sociólogos, antropólogos, profesores y estudiantes. Nuestro objetivo ha sido caracterizar y analizar los procesos de intervención profesional de los trabajadores sociales en el campo de la discapacidad. En tal sentido, hemos recuperado los antecedentes históricos que entendimos operaron en la configuración del tema discapacidad como asunto público y consecuentemente la producción del espacio socio - ocupacional del trabajo social. En el primer capítulo identificamos dos momentos de la producción de la política de discapacidad, uno asociado a procesos de modernización / desarrollo en el que la discapacidad aparece como objeto de asistencia / custodia / atención y otro vinculado a la mercantilización en el que la discapacidad medicalizada se constituye en un punto más de ampliación del excedente (con líneas de continuidad y ruptura). Analizamos la categoría de campo de la discapacidad, desde la perspectiva relacional, en la que problematizamos el capital específico en juego asociado a la definición de discapacidad. Y esto lo vinculamos a las disputas que los trabajadores sociales vienen sosteniendo en el campo. También sumamos la idea de modelos para pensar las formas en que ha sido pensada y abordada, por lo que propusimos:

- Modelo médico de la discapacidad, que incluía al sub - modelo individual y sub modelo rehabilitador.

- Modelo social de la discapacidad, que incluía al sub modelo bio psico social y al sub modelo de diversidad funcional.

Estas dos dimensiones de análisis, la historización de la producción de políticas de discapacidad y el análisis del campo homónimo, habilitaron reflexiones que permitieron reconocer las trayectorias profesionales que se desplegaron en el campo. 
Estas cuestiones fueron puestas en diálogo con las discusiones sobre la cuestión social contemporánea y sus múltiples concepciones en disputa en el trabajo social. En tal sentido, tramamos la idea de matrices teóricas del trabajo social y cómo cada una de ellas nos permitía re - pensar la forma en que estaba siendo ideada la discapacidad. Por lo que el atravesamiento por el positivismo, el funcionalismo estructural, la dialéctica y la tecnocracia liberal nos permitieron observar las formas en que el trabajo social viene disputando sentidos sobre su hacer, sus posiciones e intervenciones.

Volviendo a las disputas sobre la cuestión social, la desigualdad y el rol estatal en el proceso de producción de lo público, trajimos a discusión las paradojas entre el mercado y la ciudadanía en la configuración de protecciones sociales. Con este punto, señalamos que se torna aún más paradojal en este Enero 2016, a pocos días de la asunción del nuevo gobierno, en las que las señales vienen siendo poco alentadoras en relación a los procesos de ciudadanización. ${ }^{78}$

En ese apartado incluimos discusiones en clave de protección social como derecho, la necesidad regulatoria del estado y las escenas que se asocian al trabajo. Y por ello, las discusiones sobre la autonomía y los sistemas de protección social tomaron espesor. En tal sentido, la inclusión de la idea de la profesión que se ocupa de los otros (Dubet, 2007) permitió seguir tensando las apuestas necesarias para generar intervenciones en clave emancipadora, o mejor dicho las que efectivamente los colegas han generado, intensificado y hecho posible. La idea de cuidados como dominio presente en las intervenciones empieza a surgir del trabajo de campo, por lo que fue un eje que se retomó en las

\footnotetext{
${ }^{78}$ La vice - presidente de la nación, Michetti es usuaria en sillas de ruedas y una de las primeras acciones que efectivizó fue la interrupción de contratos a trabajadores del Senado Nacional. Entre los 2000 despedidos, sin justa causa, se encontraba un número significativo de trabajadores en situación de discapacidad. Esta acción si bien fue retrotraída, dejó en evidencia la toma de decisiones prejuiciosas e infundadas de la nueva administración estatal. Por otra parte, los compromisos que la nueva gestión asume con el mercado de valores, la desregulación de la economía, y la apertura a las importaciones inaugura una acción estatal debilitada, de cara a los sistemas de protección social.
} 
líneas siguientes en las que la idea de trabajo / profesionalización se hicieron presentes para seguir profundizando.

Otro de los puntos más relevantes ha sido el vinculado al interrogante ¿Cuándo nos convertimos en trabajadores sociales? Y surgió fuertemente la hipótesis que lo que nos constituye en trabajadores sociales es la intervención ${ }^{79}$, habida cuenta que entendemos que la misma habilita rupturas epistemológicas.

Del mismo modo, la interpretación de las funciones del trabajo social asistencia, gestión y educación - han permitido bucear en el dominio herramental que los trabajadores sociales desplegamos, al tiempo que volvimos a incluir al cuidado como otra de las funciones, en la que el mismo fue pensado desprivatizado y desfemenizado (Angelino, 2014)

Destaco otra de las hipótesis que surge del trabajo de campo, en el que entendemos que la mirada estereotipada y culpabilizadora que suelen tener las producciones de la autodenominada perspectiva histórico - crítica ha profundizado la distancia entre los intelectuales legitimados y los profesionales que traman cotidianamente al trabajo social. Esto ha sido recurrentemente señalado, en afirmaciones asociadas al enojo, a la de quienes se han sentido desprestigiados. Si bien estos enfados podrían responder a ciertas prácticas docentes, lo que nos alerta es la necesidad de poner en valor la intervención, en tanto espacio de producción de discursos, de realidades, de accesibilidades.

En relación a las rupturas epistemológicas que mencionamos, instala la idea de objeto de intervención en tanto objeto teórico construido en el que se ponen en juego múltiples dimensiones. En tal sentido la búsqueda teórica ha sido que en el encuentro con los colegas - y en las entrevistas de control - se genere una escucha/mirada atenta que permita identificar momentos claves,

\footnotetext{
${ }^{79}$ Intervención como instancia post formación académica
} 
nudos críticos y otros aspectos que transciendan las percepciones individuales y nos permitan dar cuenta de la trayectoria que el trabajo social ha venido teniendo en el campo que nos ocupa.

Producir desde el saber interventivo es una apuesta que atraviesa esta tesis, una puesta en valor del saber desde la práctica, desde "poner el cuerpo", desde transitar / experimentar la heterogeneidad del territorio.

Por lo tanto, en el tercer capítulo avanzamos en los ejes de autonomización de las personas en situación de discapacidad en relación a las narrativas de los colegas, los aportes de la profesión en clave emancipatoria y las discusiones sobre el fundamento mismo de la intervención, a su magma. En ese mismo orden de ideas, tomó relevancia el concepto de trayectorias (en clave bourdiana) para pensar las vidas de las personas en situación de discapacidad que se incluían en tanto sujetos de prácticas profesionales. Por lo que la revelación estuvo enlazada a que los afrontamientos de las barreras eran diferenciales, y esto se relacionaba con la posición que se ocupa en la estructura social, los capitales a los que se accede, a la estructura de posibilidades que se despliega en sociedades desiguales. La discapacidad como experiencia vital, que habilita inusuales recorridos institucionales a algunos agentes sociales. Estos recorridos, propician el encuentro con los profesionales que se ocupan de los otros, entre ellos los trabajadores sociales. La lectura post - estructuralista para pensar la categoría de sujeto, nos habilitó idealizaciones en torno al ejercicio del poder, presente en la intervención profesional. Esto permitió poner en valor la tensión que sostiene la intervención en relación a la autonomía y heteronomía, a las posibilidades de desandar procesos autónomos y de adultización. Los aportes del Trabajo Social anti - opresivo nos invitaron a visualizar las prácticas opresivas sin caer en comprender que la vida en situación de discapacidad sea una tragedia en sí misma. La intervención como posibilidad, como la apertura a nuevas prácticas sociales, en marco de disputas de sentidos sobre la discapacidad, los derechos, 
las prácticas, las decisiones, etc. El diálogo con Sennet (2009) también fue un aporte interesante para profundizar sobre la intervención como práctica social.

Otro de los hallazgos de esta tesis, está en estrecha relación a la categoría de tiempo. El mismo en el proceso de conceptualización se pluralizó, por lo que comenzamos a hablar de temporalidades presentes en la intervención. Allí colocamos como principales temporalidades que operaban, el tiempo del modo de producción, del modelo estatal, de la política pública, de las organizaciones, de los sujetos individuales y colectivos de la práctica profesional, el de los sujetos trabajadores sociales y el tiempo mismo de la intervención.

Partimos, siguiendo a Valencia García (2014:2) quien platea que “el tiempo es la manera de ser de las cosas -su cadencia, su ritmo, su orientación temporal, etc." por lo que hacer visible esta dimensión de la intervención nos permitió tramar las narrativas de los colegas con discusiones, a nuestro entender, insuficientemente exploradas en el trabajo social. Por ello, la mirada sobre el tiempo propio, del otro, de los otros, nos permitió volver sobre las discusiones del espacio público, el privado y la necesidad de romper con la feminización de la responsabilidad del cuidado. Las discusiones sobre familia, calidad de vida familiar y curso vital, se instalaron en estas páginas. Asimismo, la relación con el espacio privado la realizamos con el dominio herramental de la visita domiciliaria.

Por otra parte, en el cuarto capítulo planteamos discusiones sobre los escenarios de la intervención y su dimensión corporal, ejes que se tornaron fundamentales. Por ello, verificamos cuáles eran las condiciones y medio ambiente de trabajo en el que se despliegan las intervenciones en el campo de la discapacidad. Señalamos las diferencias en clave temporal en relación al inicio del ejercicio profesional, que en vínculo con lo abordado en "el tiempo del modelo estatal" tornó espesor más allá de las decisiones individuales. Las 
diferencias salariales, la estabilidad / inestabilidad laboral vinculado a la forma de contratación, nos dieron pistas para interrogarnos y plantear que la imagen de un trabajador incluido, con buenas condiciones de trabajo es la que comparten las colegas como resguardo al ejercicio de la profesión. Al mismo tiempo, la propuesta del grupo relaciona las condiciones laborales - en tanto responsabilidad del empleador - sumando los modos de actuar de los profesionales en torno a responsabilizarse sobre el despliegue de prácticas que permitan acceder a la información, a los recursos y socializarlos con los sujetos de la práctica.

La noción de trayectoria laboral nos permitió identificar cómo aparecía enlazada la misma con la historia familiar, residencial y de formación. Los colegas planteaban un entramado entre sus decisiones personales y las asociadas al ejercicio de la profesión.

Asimismo, apareció otro eje fundamental para pensar la intervención y ensayando respuestas al interrogante que quedó de párrafos precedentes ¿cuándo soy trabajador social? ¿Cómo se da el rito de pasaje? Y allí apareció un tema central, asociado a la transmisión del "saber - hacer" por parte de una trabajador social que nos antecedió. Las referencias a colegas que actuaron como referentes aparecieron con afectuosidad, reconociendo a aquellas que con formaciones diferentes habilitaron el despliegue de técnicas, de destrezas, del saber - hacer profesional. Diferente era el relato de quienes carecieron de colegas que los inicien en la tarea, situación que se dio fundamentalmente en el sub - sector privado cuya antigüedad institucional es breve. Una inferencia posible es que en aquellas instituciones que se erigen en pioneras del campo, centros de rehabilitación surgidos en la epidemia de poliomielitis y hogares asociados a instituciones tradicionales de la caridad cristiana, la transmisión del oficio está planificada sea a través de pasantías, residencias, prácticas a 
estudiantes de grado. Una idea fuerza ha sido que un trabajador que nos forma, nos marca el camino.

En claro vínculo con el "clima de época" surgió la referencia al trabajo social militante y a la idea de la militancia en el campo de la discapacidad, la que fue interrogada, puesta bajo sospecha a fin de develar si no se trataba de una nueva forma que tomaba la idea de ayuda en clave cristiana. Claramente, nuestra interpretación resultó asociada a que la militancia, en tanto posición ética en torno al otro, es constitutiva de la profesión.

Las que surgieron fueron ideas en torno a la discapacidad en clave interventiva, asociada al concepto de trayectorias diferenciales en contextos desiguales. $\quad \mathrm{Y}$ allí se habilitó para instalar la idea de conmoción, de complejización de sensaciones del orden de lo íntimo, de la sensibilidad que creíamos individual. ¿Cuánto de la sensibilidad opera como motorización de las prácticas interventivas? ¿Cuánto de la percepción instala la configuración de las situaciones como complejas, que ameritan respuestas urgentes? ¿O acaso eso que se activa en una entrevista de guardia en un servicio social no es algo del orden de los cuerpos, que se racionaliza, que se operacionaliza para intervenir? "el cuerpo es una condición para nuestra existencia, una base de operaciones desde la que actuamos en el mundo, pero que a la vez, está colmado de significados" (Kogan, L: 2010:102)

Emotividad frente a la escucha, indignación frente a la injusticia, a la opresión, operan cómo razón de ser de la intervención. Obviamente, en escenarios sociales regulados, en los que la ley opera como habilitación ó restricción. En las entrevistas con los colegas aparecía con intensidad la idea de las rupturas que se generaban en torno a las concepciones de discapacidad, los avances, las habilitaciones, etc. 
Otro eje, que sumamos a las funciones de la profesión es el de acompañamiento, que podría leerse en clave de cuidado. El mismo instala la idea de autonomía, y se traduce cifradamente con la noción de proyecto de intervención en el que se decide con los otros, las apuestas no son las de los trabajadores sociales en forma exclusiva sino que supone prácticas de negociación, de sopesar alternativas, de al fin de cuentas decidir en tanto sujeto emancipado. Y lo que habilita esa posición es la intervención. Por ello, la imagen de la escucha del trabajo social es una escucha para la acción, para la intervención, con un pasaje reflexivo inmanente. La dimensión herramental del trabajo social es analizada a partir de re - pensar las visitas en domicilio, sus objetivos.

Cómo planteamos que el tiempo es un vector importante para pensar la intervención, asimismo lo es la dimensión espacial iniciando esto desde la misma corporalidad. No tenemos un cuerpo, sino que somos un cuerpo por lo que es insoslayable traerlo a discusión en esta tesis.

Para finalizar, retomamos nuevamente los aportes de B de Souza santos (2010) quien plantea que existen seis espacios estructurales en los que se generan distintas formas de poder y los identifica como espacios - tiempos: doméstico, de producción, de la comunidad, del mercado, de la ciudadanñia y mundial. Loque nos señala el autor, es que para pensar en clave emancipatoria debemos comprender los diferentes espacios - tiempos en los que las interacciones se pueden presentar de manera opresiva.

"Estas son las formas fundamentales de poder. Probablemente hay otras, pero patriarcado, explotación, fetichismo de las mercancías, diferenciación desigual, dominación e intercambio desigual son, a mi juicio, 
instrumentos analíticos que pueden verse como modos de producción de poder y de saber" (de Souza Santos, 2006:53)

Esto nos invita a pensar la multiplicidad de rupturas que son necesarias generar, y que atraviesan los procesos interventivos. Cuándo señalamos que la emancipación se hace presente en las decisiones de los proyectos interventivos, lo hacemos incluyendo algunas de estas opresiones que se rompen, que se desligan. Un trabajo social anti- opresivo pone especial atención a estas ligaduras, a estas ataduras y pone en acción el acompañamiento en una trayectoria que siempre es del otro.

Queda pendiente compartir una multiplicidad de líneas de análisis que identificamos cómo áreas de vacancia en las relaciones entre intervención profesional, campo de la discapacidad, trayectorias sociales y sistemas de protección social. Una de ellas es la presencia de profesionales de trabajo social en situación de discapacidad ejerciendo la profesión en este campo. Esto lo relacionamos con el clásico texto de Mike Oliver (1998) y los prejuicios que operan en torno a si la experiencia de discapacidad corporizada habilita ó restringe miradas profesionales críticas.

Otro de los temas vacantes es el vinculado a las relaciones de interdisciplinariedad que se dan en las organizaciones, entendemos que la pretensión de integralidad que supone la mirada inter ó transdisciplinaria no es otra cosa que la búsqueda opresiva de poder dar cuenta cabalmente del otro.

También un área de vacancia es la recuperación de las relaciones que se dan entre las organizaciones de la sociedad civil en torno a las disputas por la autonomía de las personas en situación de discapacidad. La vinculación entre la literatura de ciencias sociales en torno a la acción colectiva y las experiencias regionales es un tema poco explorado. 
Y por último, creemos necesario dejar asentado la necesidad de indagar aún más las relaciones entre los tipos de participación reivindicativa sectorial, propio de los movimientos sociales del retorno democrático (década del 80) con la experiencia del frente de Lisiados Peronistas.

Esta tesis puso en diálogo las prácticas interventivas, las trayectorias profesionales y singulares; asumiendo como propios los desafíos colectivos que el trabajo social ha encarado en los últimos años.

Enero 2016 


\section{BIBLIOGRAFÍA TESIS}


○ Abramovich, V (2006) "Una aproximación al enfoque de derechos en las estrategias y políticas de desarrollo”. Revista de la Cepal, nº 88 (pp. 35 a 50)

http://repositorio.cepal.org/bitstream/handle/11362/11102/088035050_e s.pdf? sequence $=1$ (consultado enero 2014)

- Alvarez, A (2015) Los desafíos médicos, sociales e institucionales que dejó la poliomielitis: la rehabilitación integral en la Argentina de mediados del siglo XX. História, ciências, saúde - manguinhos. rio de janeiro, v.22, n.3, jul.-set. 2015, p.941-960 en: http://www.scielo.br/scielo.php?script $=$ sci abstract\&pid $=\mathrm{s} 0104$ $\underline{59702015000300941 \& \operatorname{lng}=\mathrm{en} \& \mathrm{nrm}=\mathrm{iso \& t} \operatorname{lng}=\mathrm{es}} \quad-\quad$ consultado diciembre 2015)

○ Alvarez, R (2011) "Prólogo" En: Merlaeu Ponty La fenomenología y las ciencias humanas. Prometeo Libros. Bs As

○ Angelino, A (2014) "Mujeres, ética del cuidado y discapacidad". En: Actas de VIII Jornadas nacionales discapacidad y derechos humanos "Avances y barreras en la construcción de una universidad accesible". Universidad Nacional De General Sarmiento.

- Aquin, N (2003) El trabajo Social y la identidad profesional. REVISTA PROSPECTIVA / UNIVERSIDAD DEL VALLE / 2003 / No 8 http://bibliotecadigital.univalle.edu.co/bitstream/10893/1183/1/Prospect iva\%208\%2cp.99-110\%2c2003.pdf (marzo 2015)

- Argumedo, A (2009) Los silencios y las voces de América Latina: notas sobre el pensamiento nacional y popular. Primera edición- $7^{\mathrm{a}}$. $\mathrm{Re}$ - impresión - bs As. Colihue 
- Arias Campos, R (2007) "Aportes de una lectura en relación a la ética del cuidado y los derechos humanos para la intervención social en el siglo XXI". Revista de Trabajo Social, Facultad de Ciencias Humanas, Universidad Nacional de Colombia.

- Arias, A J (2012) Pobreza y modelos de intervención: aportes para la superación del modelo de asistencia y promoción. CABA Espacio Editorial.

- Barnes, C. (1998). Las teorías de la discapacidad y los orígenes de la opresión de las personas discapacitadas en la sociedad occidental. En L. Barton (Ed.), Discapacidad y sociedad (pp. 59-76). Madrid: Morata/Fundación Paideia. 14

○ Barnes, C. y Mercer, G. (1997). Breaking the mould? An introduction to doing disability research. En C. Barnes y G. Mercer (Eds.), Doing disability research (pp. 1-14). Leeds, Inglaterra: Disability Press.

○ Barnes, C., Mercer, G. y Shakespeare, T. (1997). Exploring disability. A sociological introduction. Cambridge, United Kingdom: Polity Press.

- Barton, L. (1998b). Sociología y discapacidad: algunos temas nuevos. En L. Barton(Ed.), Discapacidad y sociedad (pp. 19-33). Madrid: Morata/Fundación Paideia.

○ Barton, L. (Comp.) (1998a). Discapacidad y sociedad. Madrid: Morata/Fundación Paideia. [Original en inglés en 1998: Disabiliy and society: emerging issues and insights. . London: Addison Wesley Longman]

- Barton, Len (2009) Estudios sobre discapacidad y la búsqueda de la inclusividad. Observaciones. En: Revista de Educación, 349. Mayoagosto 2009, pp. 137-15

- Belvedere, C (2012) Un discurso del dualismo en la teoría social contemporánea. Una crítica fenomenológica. Eudeba, bs As. 
○ Bellini, J.L. y Rumrill, P.D. (1999). Research in rehabilitation counseling . Springfield, Illinois: Charles C. Thomas.

o Benavidez E y Vall A (2010( Discapacidad en Argentina. - - Trabajo final del Curso Curso Anual de Auditoría Médica "Hospital Alemán" 2010

En: http://auditoriamedicahoy.net/biblioteca/Discapacidad\%20Benavidez.pd $\underline{\mathrm{f}}$

- Bhabha, H (2002) El lugar de la cultura. Edirorial Manantial. Bs As

- Blasco E. (2002). La nueva mirada sobre la discapacidad - Reflexiones sobre la ley 24.901. Apuntes de Cátedra

- Blasco E. (2008) "Los estudiantes universitarios y su percepción de la discapacidad”. En: Pantano, L Edit. Universidad Católica Argentina

○ Bolstanki, L. (1975). Los usos sociales del cuerpo. Buenos Aires: Ediciones Periferia. [

- Bonfiglio, Giovanni Desarrollo de la comunidad y trabajo social: ensayo bibliografía. Celats Ediciones, 1982

○ Bourdieu, P (1963) "La société traditionnelle. Attitude à l'égard du temps et conduite économique", Sociologie du travail 5: 24-44

- Bourdieu, P, Chamboredon J y Passeron J (2004) El oficio del sociólogo. Presupuestos epistemológicos. $1^{\circ}$ Edición. $1^{\circ}$ Reimpresión. Siglo XXI. Buenos Aires

○ Bourdieu, P. (1977) La Ilusión Biográfica. Razones Prácticas. España, Anagrama, Colección

○ Bourdieu, P. (1980) "El sentido práctico". Ed. Siglo Veintiuno, Argentina.

○ Bourdieu, P. (1990) "Algunas propiedades de los campos". En: Sociología y cultura. México: Grijalbo. 
○ Bourdieu, P. (1991) “Estructura, habitus y prácticas". En: El sentido práctico. España: Taurus Humanidades.

○ Bourdieu, P. (1997) "Razones prácticas. Sobre la teoría de la acción”. Ed. Anagrama, España.

○ Bourdieu, P (1999) "El conocimiento por cuerpos". En Meditaciones pascalianas, Barcelona, Anagrama, 1999

○ Bourdieu, Pierre (2006) Autosocioanálisis de un sociólogo. Anagrama, Barcelona

○ Bourdieu, Pierre y Loïc J. D. Wacquant (1995) Respuestas. Por una antropología reflexiva. México: Grijalbo.

○ Brégain G. (2010), «El Estatuto del derecho bajo la dictadura argentina (1976-1983) : El caso del derecho de las personas con discapacidad», CD Anales del Primer Encuentro Nacional Interdisciplinario de Derechos Humanos y Sociedad Civil, Montevideo, 24, 25 y 26 de noviembre de 2010 .

- Bregain G (2012) Historiar los derechos a la rehabilitación integral de las personas con discapacidad en Argentina (1946-1974). En: Pantano L (comp)Discapacidad e Investigación: aportes desde la práctica. Buenos Aires: EDUCA

- Brogna, P (2006) Posición de discapacidad: los aportes de la Convención. En: http://biblio.juridicas.unam.mx/libros/5/2468/11.pdf (consultado noviembre 2015)

- Butler J, Laclau E y Zizek S (2011) Contingencia, Hegemonia, Universalidad. Fondo de cultura Económica. Bs As

○ Butler, Judith (2010) Cuerpos Que Importan. Editorial Paidós. Primera Reimpresión. 
- Campana, M (2012) Medicalizar la asistencia, asistencializar la salud. Prohistoria Ediciones. Rosario

○ Carballeda, A (2010) "La intervención en lo social como dispositivo. Una mirada desde los escenarios actuales". En: Revista TRABAJO SOCIAL UNAM. VI Época • Número 1 - diciembre 2010 Ciudad de México [p. 46 - 59]

○ Carballeda A (2014) "Del desorden de los cuerpos al orden de la sociedad”. Tercera Edición: Digitales Margen, (Consultado Abril 2014 http://www.margen.org/suscri/libro/cap1.html ó chrome://epubreader/content/reader.xul?id=1

- Carballeda, A (2014) La Accesibilidad y las Políticas de Salud. En: http://www.edumargen.org/docs/curso58-1/unid01/apunte02_01.pdf

- Carballeda A (2015) La escucha como proceso, Una perspectiva desde la intervención social. http://www.margen.org/wp/?p=2036 (enero 2016)

○ Carrillo, R (1952) Plan Sintético de Salud Pública 1952 - 1958 Dr. Ramón Carrillo. En: Honorable Cámra de Diputados de la Nación. http://www1.hcdn.gov.ar/dependencias/dip/documentos/DG.109.05.00-1.pdf (marzo 2016)

○ Casas F "Calidad de Vida y calidad humana". En: revista Papeles del Psicólogo. ISSN 0214 - 7823. Noviembre 1999 - No 74 En: http://www.papelesdelpsicologo.es/imprimir.asp?id=812 (consulta abril 2014)

- Castel, R La Metamorfosis de la cuestión social. Una crónica del asalariado. $1^{\mathrm{a}}$. Edición, $5^{\mathrm{a}}$. Reimpresión. Paidós. Buenos Aires.

○ Cazzaniga, S (2004) "La formación de los Trabajadores Sociales en el actual contexto". En: Revista Escenarios n ${ }^{\circ} 8$ Escuela Superior de 
Trabajo Social.

- Cazzaniga, S (2007) Hilos y nudos. La formación, la intervencion y lo politico en el trabajo social. Espacio Editorial. Bs As.

o Cazorla Becerra, K y Fernández Hormachea, J (2009) Reflexiones en torno a la visita domiciliaria como técnica de trabajo social. Mimeo. En: https://trabajosocialudla.files.wordpress.com/2009/06/reflexionesen-torno-a-la-visita-domiciliaria.doc

- Colángelo A La mirada antropológica sobre la infancia. Reflexiones y $\begin{array}{llll}\text { perspectivas } & \text { de abordaje. }\end{array}$ http://www.me.gov.ar/curriform/publica/oei_20031128/ponencia_colan gelo.pdf (junio 2014)

o Conrad, P. (1982) "Sobre la medicalización de la anormalidad y el control social”. En D. INGLEBY (ed.): Psiquiatría crítica. Barcelona, Editorial Crítica.

- Cornu, Laurence (2007). Lugares y compañías. En Jorge Larrosa (ed.) Entre nosotros. Sobre la convivencia entre generaciones (pp. 51-65). Barcelona: Fundació Viure i Conviure, 2007

○ Contreras D y Pérez de Lara (2010) “La experiencia y la investigación educativa”. En Contreras y Pérez de Lara (Comp.) Investigar la experiencia educativa. Madrid, Editorial Morata

o Contreras, J y Pérez de Lara, N (2010) Investigar la experiencia educativa. Introducción y Cap $1^{\mathrm{o}}$ "La experiencia y la investigación educativa" Ediciones Morata, Madrid

○ Csordas, T (2010) "Modos somático de atención”. En: CITRO (Comp.) Cuerpos Plurales. Antropología de y desde los cuerpos. Editorial Biblos. Bs As.

○ Daich D - comp - (2014) primer Coloquio Latinoamericano de 
Antropología feminista. Librería de Muejeres Editora, Buenos Aires.

- Danel, P y Katz S (2004) Aproximación al campo de la discapacidad y sus luchas. Actas digitales de III Jornadas Universidad y Discapacidad. Paraná. UNER.

- Danel, P y Katz, S (2005) Formación Profesional de los Trabajadores Sociales y Campo de la discapacidad. Argentina. La Plata. 2005. Encuentro. Encuentro Latinoamericano de Trabajo Social. La Formación y la Intervención Profesional en la sociedad contemporánea: Hacia la construcción de un proyecto ético político?. UNLP

- Danel, P (2007) Tesis de Maestría: Las prestaciones de los geriátricos en la provincia de Buenos Aires. El caso de los Hogares de la Plata y Chascomús.

En: http://sedici.unlp.edu.ar/bitstream/handle/10915/29366/Documento co mpleto_.pdf? sequence $=1$ (consulta noviembre 2015)

○ Danel, P y Katz, S (2008) Campo de la discapacidad: sus disputas, avances, retrocesos en el vínculo con la Universidad. Argentina. Tucumán. 2008. Jornada. V Jornadas Nacionales Universidad y Discapacidad. De la exclusión a la inclusión social. Comisión Interuniversitaria de Discapacidad y Derechos Humanos y Universidad Nacional de Tucumán

○ Danel, P (2013) “Intervenciones de los trabajadores sociales en el campo de la discapacidad" En: actas digitales de las X Jornadas de Sociología UBA. $\quad$ http://sociologia.studiobam.com.ar/wpcontent/uploads/ponencias/1009.pdf

- Danel, P y Favero Avico A (2014) Discusiones desde las prácticas sociales sobre la discapacidad, entendida como concepto y campo. En: Actas digitales de IX Jornadas de Investigación, Docencia, Extensión y Ejercicio Profesional -FTS -UNLP ISBN: 978-950-34-1144-5 (http://www.trabajosocial.unlp.edu.ar/jideep)

○ Davis, L.J. (1997a). The disability studies reader. . NewYork: 
Routledge. Davis, L.J. (1997b). Introduction. En L.J. Davis (Ed.), The disability studies reader (pp. 1-6). NewYork: Routledge.

- De la Vega, E (2010) Anormales, deficientes y especiales. Genealogía de la educación especial. Noveduc. Bs As

- De Martino, M y Espasandin C Notas teóricas sobre prácticas profesionales. En: Revista Plaza Pública. F Tandil, Año 6 № 9, Julio de 2013

ISSN

$1852-2459$

https://revistaplazapublica.files.wordpress.com/2014/02/3.pdf

○ De Sousa Santos, B. (2001) "Los nuevos movimientos sociales" En: Observatorio Social de América Latina, N 5, Buenos Aires. Págs. 177184

- De Sousa Santos B (2006) Renovar la teoría crítica y reiventar la emancipación social. Clacso, bs As

- De Sousa Santos, B. (2010) Descolonizar el saber, reinventar el poder. Uruguay: Trilce Editorial.

- Del Grosso A - coordinador -(2014) La capacidad jurídica de las personas con discapacidad. - 1a ed. - Ciudad Autónoma de Buenos Aires: Ministerio de Justicia y Derechos Humanos de la Nación. Secretaría de Derechos Humanos. http://www.jus.gob.ar/media/2694587/publicacion_discapacidad_jornad as de discapacidad.pdf (consultado noviembre 2015)

○ Dell'Anno, A. (1998) "Política Social y Discapacidad. Sujeto y contexto". Universidad Nacional de Mar del Plata. Lumen-Humanitas

o Dell Anno A (comp) (2004) En alternativas de la diversidad social: Las personas con discapacidad. Editorial Espacio, bs as

o Derrida, J (1997) Sobre la hospitalidad. Entrevista en Staccato, programa televisivo de France Culturel producido por Antoine Spire, 
del 19 de diciembre de 1997, traducción de Cristina de Peretti y Francisco Vidarte en DERRIDA, J., ¡Palabra!, Trotta, 2001, pp. 49-56.

○ Dominelli y Mc. Leod (1999) Trabajo Social feminista. Cátedra; Edición. Valencia

○ Dominelli L (2008) Más allá del análisis de la pobreza: narrativas desatendidas en el pensamiento marxista : comentario a la ponencia central de José Paulo Netto. En: Revista Trabajo Social n 74, Agosto 2008, ISSN 0716-9736 pp 47 a 50

○ Dominelli L (2010) An uncaring profession? An examination of racism in social work. En: Journal of Ethnic and Migration Studies. Volume $\underline{15}$, Issue 3 , Race and the health and social services

○ Dukuen, J (2014) Génesis de una antropología fenomenológica de la temporalidad en Bourdieu. En: Actas digitales del XI Congreso Argentino de Antropología Social Rosario, 23 al 26 de Julio de 2014 http://www.11 caas.org/ (consultado Noviembre 2015)

○ Durán, R., Delgado, J.F. y Dengra, R. (1995). Trabajo interdisciplinar en personas con discapacidad. En M.A. Verdugo (Ed.), Personas con discapacidad. Perspectivas psicopedagógicas y rehabilitadoras (12011284). Madrid: Siglo Veintiuno.

○ Elias, N (1989) Sobre el tiempo, FCE, Madrid.

- Esteban, María Luz (2006) El Estudio de la Salud y el Género: Las Ventajas de un Enfoque Antropológico y Feminista. En: Revista Salud Colectiva. Bs As. $(9-20)$

- Facultad de Trabajo Social UNLP "Un largo camino en el reconocimiento de nuestro propio campo de saber. En: http://www.trabajosocial.unlp.edu.ar/resena historica

- Fernández Moreno, A Jóvenes con discapacidades: sujetos de reconocimiento. Tesis de Doctorado en Ciencias Sociales, niñez y 
juventud. Universidad de Manizales, Colombia http://bibliotecavirtual.clacso.org.ar/Colombia/alianza-cinde-

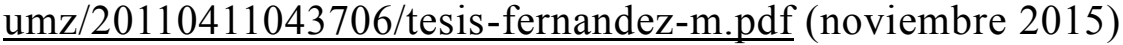

○ Ferrante, C. (2008): «Cuerpo, discapacidad y posición social: una aproximación indicativa al habitus de la discapacidad en argentina". Revista Intersticios: Revista Sociológica de Pensamiento Crítico. Pp. 173 a $185-\underline{\text { http://www.intersticios.es }}$

- Ferrante C (2009) Cuerpo, discapacidad y violencia simbólica: un acercamiento a la experiencia de la discapacidad motriz como relación de dominación encarnada. En: [www.accioncolectiva.com.ar] Boletín Onteaiken No 8 - Octubre 2009

- Ferreira, M y Ferrante, C..(2010) El habitus de la discapacidad: la experiencia corporal de la dominación en un contexto económico periférico. Política y Sociedad, Norteamérica, 47, mar. 2010. Disponible en:

$<\underline{\text { http://revistas.ucm.es/index.php/POSO/article/view/POSO1010130085A }}$ /21688>. Fecha de acceso: 05 ene. 2016.

- Ferreres, C (2002) "El rol de la CTA en la lucha por el reconocimiento de los derechos de las personas con discapacidad. La articulación con otras organizaciones sociales y de personas con discapacidad”. En Eroles y Ferreres (2002) La discapacidad, una cuestión de derechos humanos. Espacio Editorial. Buenos Aires

- Figari Ca y Scribano A (comp.) (2009) Cuerpo(s), Subjetividad(es) y Conflicto(s). Hacia una sociología de los cuerpos y las emociones desde Latinoamérica. Colección CLACSO COEDICIONES / CICCUS. (http://bibliotecavirtual.clacso.org.ar/ar/libros/coedicion/scribano/) consultado feb 2014

- Fígari, C (2012) Paradigma del funcionamiento y la discapacidad en un 
entorno comunitario. En: Ponencias de Jornadas Nacionales de Salud Mental y Comunidad: Enlazando salud, prácticas comunitarias. http://www.coper.org.ar/datos/fotos/200_1.pdf (Noviembre 2015)

○ Finkelstein, V. (Ed.) (1980). Attitudes and disabled people . NewYork: World Rehabilitation Fund.

- Foucault, M. (1993) Historia de la .medicalización... En La vida de los hombres infames. Buenos Aires/Montevideo, Editorial Altamira/Nordan Comunidad.

○ Foucault, M (2005) Vigilar Y Castigar. Siglo XXI.

○ Foucault, M. (1999) "Las redes del poder" En: Ferrer Ch. (comp.) El lenguaje libertario. Buenos Aires: Altamira

- Fraser, N (2000) "Nuevas reflexiones sobre el reconocimiento". Revista virtual: "New Left Review" nro 4. En: http://newleftreview.es/4 Editorial: Akal. Madrid, España

- Funes, J y Ray (2001) El acompañamiento y los procesos de incorporación social. Guía para su práctica. Gobierno Vasco: Federación Sartu

- Gabrinetti, M (2006), "Representaciones sociales sobre el futuro y el progreso", en Revista Escenarios, $\mathrm{N}^{\circ} 11$, FTS - UNLP, Espacio Editorial. Buenos Aires, Argentina.

- Gabrinetti, M. y Ros. C. "Representaciones del trabajo en empleados públicos", en Domínguez Mon,A y otros (comp.) "La salud en crisis. Un análisis desde la perspectiva de las ciencias sociales". III Jornadas Interdisciplinarias de salud y población, Ed. Dunken, Bs.As., 2000.

- Galak, E. (2010) El concepto cuerpo en Pierre Bourdieu: Un análisis de sus usos, sus límites y sus potencialidades [en línea]. Tesis de posgrado. Universidad Nacional de La Plata. Facultad de Humanidades y Ciencias 
de

la

Educación.

Disponible

en:

http://www.memoria.fahce.unlp.edu.ar/tesis/te.453/te.453.pdf

- García Godoy, B; Manes, R; Murdocca L y Robles C “Matrices teóricas de inscripción del proceso metodológico en Trabajo Social" En: Ana Arias, Elena Zunino, Silvana Garello (comps) EL PROCESO METODOLÓGICO Y LOS MODELOS DE INTERVENCIÓN PROFESIONAL. La impronta de su direccionalidad instrumental y su revisión conceptual actual. CABA Departamento de Publicaciones de la Facultad de Derecho y Ciencias Sociales de la Universidad de Buenos Aires, 2013. E-Book. ISBN 978-987-28642-3-1

○ Giménez, G. (2007) Estudios sobre la cultura y las representaciones sociales. Guadalajara: CONACULTA/ITESO. Capítulo I "La concepción simbólica de la cultura”.

○ Giménez, G. (1996) “Estudios sobre las Culturas Contemporáneas “Universidad de Colima pcultura@cgic.ucol.mx ISSN (Versión impresa): MÉXICO.

- Godard, F. (1996), "Usos de las historias de vida en las ciencias sociales”, Cuadernos del Cid, Serie II. Bogotá, Colombia.

- Gonzalez Calvo, V (2003) La visita domiciliaria, una oportunidad para el conocimiento de la dinámica relacional de la familia. En: Revista Servicios Sociales y Política Social. Nº61 p.63 -86 2003 Consejo General de Colegios de Diplomados en Trabajo Social. Madrid.

- Grassi, E (1989) La mujer y la profesión de asistente social. El control de la vida cotidiana. Editorial HVMANITAS, Buenos Aires.

○ Gregory, R.J. (1997). Definitions as power. Disabiliy and Rehabilitation, 19, 487-489. 15

○ Grinyer, A. (2002). 'The Anonymity of Research Participants: Assumptions, Ethics and Practicalities', Social Research Update (38): 
Disponible en http://sru.soc.surrey.ac.uk/SRU36.pdf (consulta: 25 noviembre de 2015).

○ Guber, R. (2005) El salvaje metropolitano. Buenos Aires: Paidós.

○ Gudmundsdottir, Sigrum (1998) "La naturaleza narrativa del saber pedagógico sobre los contenidos". En: Hunter McEwan y Kieran Egan (comps.) La narrativa en la enseñanza, el aprendizaje y la investigación. Bs As Amorrurtu editores.

○ Guerra Manzo (2005) Norbert Elias y Fernando Braudel: dos miradas sobre el tiempo. En: revista Argumentos, núm. 49, pp. 123-148 Universidad Autónoma Metropolitana Unidad Xochimilco Distrito Federal, México

○ Gutiérrez, A. (1997) "Pierre Bourdieu. Las prácticas sociales”. Editorial Universitaria Universidad Nacional de Misiones y Dirección General de Publicaciones. Universidad Nacional de Córdoba. Argentina.

- Harvey, D (1998) La condición de la posmodernidad. Investigación sobre los orígenes del cambio cultural. Amorrortu Editores, Bs As

○ Healy, K (2000) Trabajo Social: Perspectivas contemporáneas. Editorial Morata . Madrid

○ Herrenstein-Smith, B. (1981) «Narrative versions, narrative theories», en W. Mitchell, ed., On narrative (págs. 209-32), Chicago: University of Chicago Press.

○ Hochschild, A. (1990) "The second shift”, Avon Books. EEUU, 1990

○ Iriart, C.; Merhy, E.E.; Waitzin, H. (2000) La atención gerenciada en América Latina. Transnacionalización del sector salud en el contexto de la reforma. Cad. Saude Publica.

○ Jackson, M (2010) "Conocimiento del cuerpo" En: CITRO (Comp.) Cuerpos Plurales. Antropología de y desde los cuerpos. Editorial Biblos. Bs As. 
○ Janin, Beatriz (2010) "La medicalización de la infancia". En: Cannellotto A y Luchtenberg E (coord.) Medicalización y sociedad. UNSAM Edita. San Martín

o Jelin, E (1986) "Otros silencios, otras voces: el tiempo de la democratización en la Argentina”. En: Calderón Gutiérrez F (comp.) Los movimientos sociales ante la crisis. Buenos Aires, UNU/CLACSO/IISUNAM,

- Joly, E (2008) Discapacidad y empleo: Por el derecho a ser explotados. Le Monde Diplomatique (El Dipló), Edición Cono Sur, Octubre 2008, Año X, Número 112, páginas 34-36.

○ Katz, S y Danel, P (comp.) 2011 Hacia una universidad accesible : construcciones colectivas por la discapacidad. - 1a ed. - La Plata : EDULP Universidad Nacional de La Plata, 2011

○ Kogan L (2010) Hacia una teoría del cuerpo vivido y la identidad del yo. En: Scribano A y Lisdero M (2010) Sensibilidades en juego: miradas múltiples desde los estudios sociales de los cuerpos y las emociones. CEA-CONICET$1 \mathrm{a}$ ed. http://www.accioncolectiva.com.ar/sitio/libros/Sensibilidades.pdf (enero 2016)

- Larrosa, (2014) Deseo de realidad. Algunas notas sobre experiencia y alteridad para comenzar a desenjaular la investigación educativa. En: Material didáctico del Diploma Superior dePedagofías de las Diferencias Flacsco.

○ Laurence Cornu (2008) Lugares y compañías. En Jorge Larrosa (ed.) Entre nosotros. Sobre la convivencia entre generaciones. Editorial: Fundación Viure i Conviure. Barcelona

○ Le Breton, D. (2006) Antropología del cuerpo y modernidad. Buenos Aires: Nueva Visión. 
http://www.artemisanoticias.com.ar/images/FotosNotas/MujMig2011.pdf

- Le Breton, D (2009) Las pasiones ordinarias. Antropología de las emociones. Nueva Visión Editores. Bs As.

- Ludi, M del C "Notas para pensar el espacio curricular ligado a prácticas pre-profesionales en Trabajo Social”. En: Lera, , Carmen Inés (Comp.) 2014 Debates y proposiciones de Trabajo Social en el marco del Bicentenario. - 1. ${ }^{a}$ ed. - Paraná. Universidad Nacional de Entre Ríos. UNER. Facultad de Trabajo Social., 2014.

○ Ludi, MC (2011) "Envejecer en el actual contexto. Problemáticas y desafíos”. En Revista Cátedra Paralela Nº 8. ISSN 1669- 8843

○ Lukács, G. (2004) Ontología del Ser Social. El Trabajo. Buenos Aires: Ediciones Herramienta

- Maguiña A y Varas N (1988) Bienestar social y Trabajo Social Alternativo. En: Revista Acción Crítica, \# 23. Agosto 1988. Lima - Perú Publicación del Centro Latinoamericano de Trabajo Social y de la Asociación Latinoamericana de Trabajo Social. http://www.ts.ucr.ac.cr/binarios/accioncritica/ac-cr-023-04.pdf $\quad$ (enero 2016)

○ Mareño Sempertegui M y Masuero F (2010) "La discapacitación social del diferente". En: Revista intersticios. Revista Sociológica delpensamiento crítico. (pp $95-105)$

- Mareño Sempertegui, M (2015) Inclusión laboral de personas catalogadas como discapacitadas. Algunas reflexiones para un debate necesario. En: Revista Trabajo y Sociedad Sociología del trabajo - Estudios culturales Narrativas sociológicas y literarias NB - Núcleo Básico de Revistas Científicas Argentinas (Caicyt-Conicet) № 25, Invierno 2015, Santiago del Estero, Argentina $\quad$ ISSN 1514-6871

www.unse.edu.ar/trabajoysociedad (consulta febrero 2016) 
○ Marks, D. (1997a). Models of disability. Disability and Rehabilitation , $19,, 85-91$.

○ Marks, D. (1997b). Who needs models ? Disability and Rehabilitation, $19,492-495$.

○ Martinelli, M. L (1997) Servicio Social: identidad y alineación, Cortez, Sao Paulo

- Matus Sepúlveda, Teresa. (2006) Apuntes sobre intervención social. Material del seminario «Propuestas contemporáneas en Trabajo Social». Mendoza, Facultad de Ciencias Políticas y Sociales, Universidad Nacional de Cuyo, Mayo de 2006

○ Mauss M (1973) “Techniques du Corps” en: Sociologie et Anthropologie, Paris

○ Mauss, M (1979) "las ltécnicas del cuerpo" y "La noción de persona" en: Socioología y Antropología. Madrid. Tecnos (pp.309 - 316 y 337-356)

○ Merlau - Ponty (1962) Phenomenology og percepción, Londres. Routledge.

○ Míguez, M N (2009). La sujeción de los cuerpos dóciles. Medicación abusiva en la niñez de contexto crítico. XXVII Congreso de la Asociación Latinoamericana de Sociología. Asociación Latinoamericana de Sociología, Buenos Aires

○ Mora, S (2009) “EL CUERPO INVESTIGADOR, EL CUERPO INVESTIGADO. Una aproximación fenomenológica a la experiencia del puerperio. En: revista Colombiana de Antropología. Volumen 45 - Enero / julio $2009 \quad$ pp. $\quad 11 \quad$ a 137 http://www.icanh.gov.co/recursos_user/rca_45_1.pdf (consulta enero 2015)

- Mora, S (2010) Tesis de Doctorado: El cuerpo en la danza desde la antropología. Prácticas, representaciones y experiencias durante la formación en danzas clásicas, danza contemporánea y expresión corporal. 
En:

http://sedici.unlp.edu.ar/bitstream/handle/10915/27179/Documento comp leto.pdf? sequence $=3$ (octubre 2015)

- Mora, S a (2013) Corporalidades Reflexivas, Resistencias Encarnadas. En: Revista Question ISSN 1669-6581 - Vol. 1, N. 38 (otoño 2013) (pp.30

a

http://sedici.unlp.edu.ar/bitstream/handle/10915/29714/Documento comp leto.pdf? sequence $=1$

- Morales Aguilera, P y Vallés González B (2013) Discapacidad y reconocimiento: reflexiones desde el prisma de Axel Honneth. En: Dilemata, año 5, no $13(189-213)$

○ Muyor Rodríguez, J (2012) “La (con)ciencia del Trabajo Social en la discapacidad: Hacia un modelo de intervención social basado en derechos" En: Documentos de Trabajo Social · nº49 · ISSN 1133-6552 / ISSN Electrónico 2173-8246 (Colegio de Trabajo social Málaga)

- Necchi S, Suter M y Gaviglio A (Comp.) (2014) Personas con discapacidad: su abordaje desde miradas convergentes. Universidad nacional de Quilmes. Bernal

- Neffa, J.C. (coord.) (2001) "Telegestión: su impacto en la salud de los trabajadores", Asociación Trabajo y CEIL/PIETTE/CONICET/FOEESITRA, Argentina.

○ Noguera Fernandez, A «Andrés Piqueras Infante, La opción reformista: entre el despotismo y la revolución, Anthropos, Madrid, 2014, 222 p. », Polis [En línea], 41 | 2015, Publicado el 21 septiembre 2015, consultado el 24 noviembre 2015. URL : http://polis.revues.org/11144

○ Norelly Soto Builes HOLOGRAMÁTICA - Facultad de Ciencias Sociales - UNLZ - Año V, Número 8, V1 (2008), pp. 3-22 www.hologramatica.com.ar o www.unlz.edu.ar/sociales/hologramatica 
ISSN 1668-5024 12

- Nussbaum, M (2012) Las fronteras de la justicia. Paidós, Bs As

- Oliva A y Gardey M (2014) Componentes de la asistencia profesional del Trabajo Social. En: Mallardi M (Comp.) Procesos de intervención en trabajo social : contribuciones al ejercicio profesional crítico . - 1a ed. La Plata : Colegio de Asistentes Sociales o Trabajadores Sociales de la Provincia de Buenos Aires.

- Oliva, A "La formación de visitadoras y asistentes sociales". En: Trabajo Social y lucha de clases. Imago Mundi,

- Oliva, A (2006) Antecedentes del trabajo social en Argentina:asistencia y educación sanitaria. En: Trabajo Social No. 8, (2006) páginas 73-86 Revista del Departamento de Trabajo Social, Facultad de Ciencias Humanas, Universidad Nacional de Colombia

○ Oliver, M. (1990). The politics of disablement . Londres: Macmillan

- Oliver, M. (1992). Changing the social relations of research production. Disability, Handicap, and Society, 7 (2), 101-114.

- Oliver, M. (1998). ¿Una sociología de la discapacidad o una sociología discapacitada? En L. Barton (Ed.), Discapacidad y sociedad(pp. 34-58). Madrid: Morata/Fundación Paideia.

○ Pantano, L. (1996) “Barreras culturales a la integración”. En Actualidad y futuro de la integración de las personas con discapacidad. Universidad nacional de Mar del Plata

- Papili, G (2013) La interpretación del Movimiento de Reconceptualización en Trabajo Social: temas a debatir. En: Revista Debate Público Año 3 - Nro. 6 - $\quad$ pp. 146 a 154 http://trabajosocial.sociales.uba.ar/web_revista_6/PDF/13 Papili.pdf

- Parra G (2004) Aproximaciones al desarrollo del Movimiento de 
Reconceptualización en América Latina. Aportes a la comprensión de la contemporaneidad del Trabajo Social. Presentado en: XVIII Seminario Latinoamericano de Escuelas de Trabajo Social. La cuestión Social y la formación profesional en Trabajo Social en el contexto de las nuevas relaciones de poder y la diversidad latinoamericana. San José, Costa Rica, 2004 http://www.ts.ucr.ac.cr/binarios/congresos/reg/slets/slets-018042.pdf (marzo 2014)

○ Pena - Trapero, Bernardo (2009) "La medición del Bienestar Social: una revisión crítica”. Revista Estudios de Economía Aplicada, 2009: 299-324 Vol. 27-2 . ISSN 1697-5731 (online) - ISSN 1133-3197 (print). Consultado abril 2014 (http://www.revista-eea.net/documentos/27206.pdf )

○ Perez - Samaniego V, Devis - devis J, Smith B, Sparkes A La investigación narrativa en la educación física y el deporte: qué es y para qué sirve. En: Revista En Foco Porto Alegre, v. 17, n. 01, p. 11-38, janeiro/março de 2011 - Consultado enero 2015: http://seer.ufrgs.br/Movimento/article/viewFile/17752/13844

○ Piqueras, A. (2002) "La identidad". En: De la Cruz, I. y otros. Introducción a la antropología para la intervención social. Valencia: Tirant Lo Blanch.

- Planella Jordi y Pié Asun (2012) Militancia y diversidad funcional. Editorial UOC. Barcelona.

○ Planella Ribera Jordi (2005) "Discapacidad intercultural: una mirada antropológica”. En Cuadernos interculturales. Año 5 nº 9 pp. 119 - 133

○ Quijano, A. (2000) "Colonialidad del Poder, Eurocentrismo y América Latina”. En Edgardo Lander (Comp.) Colonialidad del Saber, Eurocentrismo y Ciencias Sociales, Buenos Aires, CLACSO-UNESCO.

○ Ramacciotti, K (2009), La política sanitaria del peronismo, Buenos Aires: 
Editorial Biblos.

- Ranciere, J (2010) El espectador emancipado. Ellago Ediciones, S. L. Castellón

○ Raya Diez, E y Manuel (2014) “Acompañar los procesos de inclusión social. Del análisis de la exclusión a la intervención social”. Revista Trabajo Social 16: 143-156. Bogotá: Departamento de Trabajo Social, Facultad de Ciencias Humanas, Universidad Nacional de Colombia.

- Raya Díez, E., y Caparrós Civera, N. (2014): «Acompañamiento como metodología de Trabajo Social en tiempos de cólera». Cuadernos de Trabajo Social, 27(1): 81-91.

o Repetto, F (2009) "El marco institucional de las políticas sociales: posibilidades y restricciones para la gestión social. En: Chiara M y Di Virgilio M (Organizadoras) Gestión de la política Social. Prometeo Libros. Bs As.

- Rodríguez, R (2011) La estructura temporal de la intervención del trabajo social. En: Tabula Rasa. Bogotá - Colombia, No.14: 311-322, enerojunio 2011 ISSN 1794-2489

○ Roncacio Henao, L (2012) "La noción de experiencia en la investigación social. Aportes desde la teoría de Norbert Elias y desde la Teoría Histórico-Genética de la cultura." En: Actas de XIV Simpósio Internacional Processos Civilizadores: "Civilização, fronteiras e diversidade" en Bogotá

○ Rozas Pagaza, M (2010) La intervencion profesional un campo problematico tensionado por las transformaciones sociales, económicas y políticas de la sociedad contemporánea. En: O Social em Questão - Ano XIII - $\mathrm{n}^{\mathrm{o}} 24$ - Jul-Dez 2010 http://osocialemquestao.ser.puc-rio.br/media/osq24_pagaza 4.pdf (enero 2016) 
- Rozas Pagaza, Margarita (2012) Ponencia presentada en el marco de las Jornadas: "Ciencias Sociales y Política en Argentina, Organizadas por el Consejo de Decanos Facultades de Ciencias Sociales y Humanas. Con apoyo de CONIC

- Samntarrone M F y Kaufmann C (2005) Los discapacitados sociales. La Política de Educación Especial durante la última Dictadura argentina. En: CULTURA, LENGUAJE Y REPRESENTACIÖN. REVISTA DE ESTUDIOS CU1,TURALPS DE LA UNIVERSITAT JAUME I I VOL 11 $\backslash 2005$, pp. $75-88$

- Sanchís, N y Rodríguez Enríquez C (Coord.) Informe de Invetsigación: Cadenas Globales de Cuidados. El papel de las migrantes paraguayas en la provisión de cuidados en Argentina. Onu Mujeres En: http://www.artemisanoticias.com.ar/images/FotosNotas/MujMig2011.pdf

- Sandel, M (2000) El liberalismo y los límites de la justicia. Barcelona, Gedisa.

○ Scribano, A (2010) “Cuerpo, Emociones y Teoría Social Clásica: Hacia una sociología del conocimiento de los estudios sociales de los cuerpos y las emociones" En: GROSSO; JL y Boito MG (comp.) Cuerpos y Emociones desde América Latina. CEA-CONICET- 1a ed. E - book : http://www.accioncolectiva.com.ar/sitio/libros/CuerpoyEmociones.pdf (marzo 2014)

- Scribano, A (2010) Las sensibilidades prohibidas: el epílogo de un libro sobre la transformación social. En: Scribano A y Lisdero $M$ Sensibilidades en juego: miradas múltiples desde los estudios sociales de los cuerpos y las emociones. CEA-CONICET- 1a ed. http://www.accioncolectiva.com.ar/sitio/libros/Sensibilidades.pdf (enero 2016)

○ Scheper-Hughes, N., Lock, M. (1987). The Mindful Body: a prolegomenon to future work in medical anthropology. Medical 
Anthropology Quarterly . 1, 1, 6-41

- Schutz, A (1970) On Phenomenology and social relation. University of Chicago. Press

○ Schvarstein, L. (2005) "Dialéctica del contrato psicológico del sujeto con su organización” en "Trabajo y subjetividad. Entre lo existente y lo necesario" Ed. Paidós.

- Scelsio, J Diálogos y confrontaciones respecto a las tendencias críticas en el Trabajo Social. En: revista Debate Público Año 3 N 6. Carrera de $\begin{array}{llll}\text { Trabajo } & \text { Social } & \text { FCS }\end{array}$ http://trabajosocial.sociales.uba.ar/web_revista_6/PDF/08_Scelsio.pdf (consultado febrero 2016)

- Sennett, R (2009) El respeto. Sobre la dignidad del hombre en un mundo desigual. Editorial Anagrama, Barcelona

- Seoane Toimil, I (2012) Tesis de maestrái en Trabajo Social "Subjetividades sitiadas. Intervenciones en la infancia en tiempos de vacilación de la ley. Escenarios institucionales en la ciudad de La Plata" Facultad de Trabajo Social, UNLP. En: http://sedici.unlp.edu.ar/handle/10915/31538 (consulta febrero 2016)

- Siede MV Trabajo Social y mundo del trabajo: Reivindicaciones laborales y condiciones de la intervención. La Plata. Productora del Boulevard, 2012

○ Simone Cecchini, Fernando Filgueira, Rodrigo Martínez, Cecilia Rossel (2015) Instrumentos de protección social. Caminos latinoamericanos hacia la universalización. Comisión Económica para América Latina y el Caribe (CEPAL) Santiago, julio de 2015

○ Skliar C (2009) "Educar la mirada: entrevista a Carlos Skliar". Revista $\begin{array}{llllll}\text { Sin } & \text { Puntero. } & \text { N } & 3 & \text { Julio } & 2009\end{array}$ www.laescuelaylosjóvenes.blogspot.com.ar/2010/02/educar-lamirada.html 
○ Skliar, Carlos (2014) “Clase 6: La infancia, la niñez, las Interrupciones" En: Flacso Virtual, Curso Diplomatura Diploma Superior en Pedagogías de las diferencias - Cohorte 04.

○ Skocpol, T. (1995) Social Policy in the United States. Future Possibilities in Historical Perspective. Princeton University Press, Princeton

○ Smith, P. (1999). Ideology, politics and science in understanding developmental disabilities. Mental Retardation, 104, , 71-72

○ Sosa, L M. (2012) Educación corporal y diversidad: La inclusión de niños y niñas con discapacidad en las prácticas corporales [en línea]. Trabajo final de grado. Universidad Nacional de La Plata. Facultad de Humanidades y Ciencias de la Educación. Disponible en: http://www.memoria.fahce.unlp.edu.ar/tesis/te.724/te.724.pdf

- Stepan, A (1978) State and Society: Perú in Comparative Perspective, Princeton, Princeton University Press, 1978, pp. 73 - 80.

○ Strauss, A. y Corbin, J. (1990). Basics of Qualitative Research: Grounded Theory Procedures and Techniques. Newbury Park: Sage

- Testa D. (2012) La lucha contra la poliomielitis: una alianza médicosocial, Buenos Aires, 1943. Salud Colectiva. 2012;8(3):299-314.

- Terzaghi, M y Maciel, F. Algunas reflexiones sobre infancia y discapacidad. S/D

- Testa, D (2012) La lucha contra la poliomielitis: una alianza médicosocial, Buenos Aires, 1943. Revista Salud Colectiva, v.8, n.3, p.299-314. 2012

- Todorov Tzvetan (1966) Les catégories du récit littéraire. In: Communications, 8, 1966. pp. 125-151

○ Tsing, A In the Realm of the Diamond Queen: Margin- ality in an Outof-the-Way Place. Princeton: Princeton University. Press, 1993

○ Urbano, C. Yuni, J. 2005. Psicología Del Desarrollo. Enfoques y 
perspectivas del ciclo vital. Editorial brujas. Córdoba. Argentina

- Valmaseda, M. (1995). Las personas con deficiencia auditiva. En M.A. Verdugo (Ed.), Personas con discapacidad: perspectivas psicopedagógicas y rehabilitadoras (pp. 223-271). Madrid: Siglo Veintiuno.

○ Vallejos, I. (2002) “El Otro 'anormal"”. En: Cuadernillo Desde el Fondo. Facultad de Trabajo Social - UNER. Paraná, Año VII - No 27

○ Valencia Garcia, G (2014) "La construcción del tiempo y la idea de emergencia en el análisis socio - histórico”. En: Actas Digitales de IV Encuentro Latinoamericano De Metodología De Las Ciencias Sociales "La investigación social ante desafíos transnacionales: procesos globales, problemáticas emergentes y perspectivas de integración regional”- FHCE - UNLP

- Vanegas García, J y Gil Obando L (2007) La Discapacidad, Una Mirada Desde La Teoria De Sistemas Y El Modelo Biopsicosocial. En: Revista Hacia la Promoción de la Salud, Volumen 12, Enero - Diciembre $\begin{array}{lllll}2007, & \text { págs. } & 51 & - & 61\end{array}$ http://www.scielo.org.co/pdf/hpsal/v12n1/v12n1a04.pdf (julio 2015)

- Vazquez García, F (2015) Georges Canguilhem y la biopolítica de las discapacidades. Revista SOCIOLOGÍA HISTÓRICA 5/2015: 93-126 file://C:/Users/Paula/Downloads/232451-857631-1-PB.pdf

- Verdugo, M.A. (1993). Integración comunitaria y formación de los profesionales. En La integración social de los minusválidos (pp.62-73). Madrid: Escuela Libre Editorial, Fundación ONCE.

○ Verdugo, M.A. (1995). Personas con deficiencias, discapacidades y minusvalías. En M. A. Verdugo (Comp.), Personas con discapacidad. Perspectivas psicopedagógicas y rehabilitadoras (pp. 1-35). Madrid: Siglo Veintiuno.

○ Verdugo, M.A. (1999). Marco conceptual de la psicología de la 
rehabilitación. En Á. Ruano, J.M. Muñoz y C. Cid (Eds),

- Vidal Molina, P F « La teoría de la justicia social en Rawls », Polis [En línea], 23 | 2009, Publicado el 27 julio 2011, consultado el 19 noviembre 2015. URL : http://polis.revues.org/1868 ; DOI : 10.4000/polis.1868

- Weber, C (2013) Desafíos actuales en el campo de la salud mental: perspectivas y estrategias profesionales. En: Estrategias - Psicoanálisis y Salud Mental; año 00, no. $01 \quad$ (pp $76 \quad$ a 78 ) http://sedici.unlp.edu.ar/bitstream/handle/10915/30582/Documento comp leto_pdf?sequence $=1$ (noviembre 2015)

○ World Health Organization (1980). International Classification of Impairments, Disabilities and Handicaps (ICIDH). A manual of classification relating toconsequences of diseases. . Ginebra: Author. (Trad. cast.: Clasificación internacional de deficiencias, discapacidades, y minusvalías. Manual de clasificación de las consecuencias de la enfermedad. Madrid: Instituto Nacional de Servicios Sociales, 1983)

Web consultadas:

- $\quad$ http://www.arinfo.com.ar/notix/noticia/00229 ellos-y-ellas-tambin-sondesaparecidos.htm

- $\quad$ http://www.foropro.org.ar/informe.html,

- Primer Informe País

http://www.villaverde.com.ar/es/assets/investigacion/discapacidad/informepais1.pdf 
ANEXO I 


\section{Interlocutores de la investigación}

\begin{tabular}{|c|c|c|c|c|}
\hline $\mathbf{N}^{\mathbf{0}}$ & Fecha & Tipo de organización & $\begin{array}{c}\text { Año de } \\
\text { egresado } \\
\text { e } \\
\text { institució } \\
\text { n (aprox) }\end{array}$ & $\begin{array}{c}\text { Codificaci } \\
\text { ón }\end{array}$ \\
\hline 1 & $\begin{array}{l}\text { Sept. } \\
2012\end{array}$ & $\begin{array}{l}\text { Organización no } \\
\text { Gubernamental, que } \\
\text { brinda servicios de } \\
\text { escuela, hogar, centro de } \\
\text { día. Su financiamiento } \\
\text { está brindado por la obra } \\
\text { social provincial y áreas } \\
\text { de infancia de diversos } \\
\text { gobiernos (nacional, } \\
\text { municipales, } \\
\text { provinciales). } \\
\text { trayectoria data de } 30 \\
\text { años, por lo que los } \\
\text { cambios que ha tenido han } \\
\text { sido varios y algunos } \\
\text { controversiales. } \\
\text { Institución se emplaza en } \\
\text { el interior de la Provincia } \\
\text { de Buenos Aires, con } \\
\text { 32.761 habitantes. }\end{array}$ & $\begin{array}{c}\text { UNLP - } \\
1965\end{array}$ & 2329 \\
\hline 2 & $\begin{array}{l}\text { Oct. } \\
2012\end{array}$ & $\begin{array}{l}\text { La institución depende del } \\
\text { área de Infancia del } \\
\text { Ministerio de Desarrollo } \\
\text { Social de la Provincia de } \\
\text { Buenos Aires. Se trata de } \\
\text { un instituto de menores } \\
\text { especializado en el } \\
\text { abordaje de jóvenes con } \\
\text { discapacidad mental. Este } \\
\text { tipo de Hogares han sido }\end{array}$ & $\begin{array}{l}\text { Egresada } \\
\text { en el } \\
\text { extranjer } \\
\text { o, } \\
\text { validado } \\
\text { en } \\
\text { Argentin } \\
\text { a en la } \\
\text { década }\end{array}$ & 1625 \\
\hline
\end{tabular}




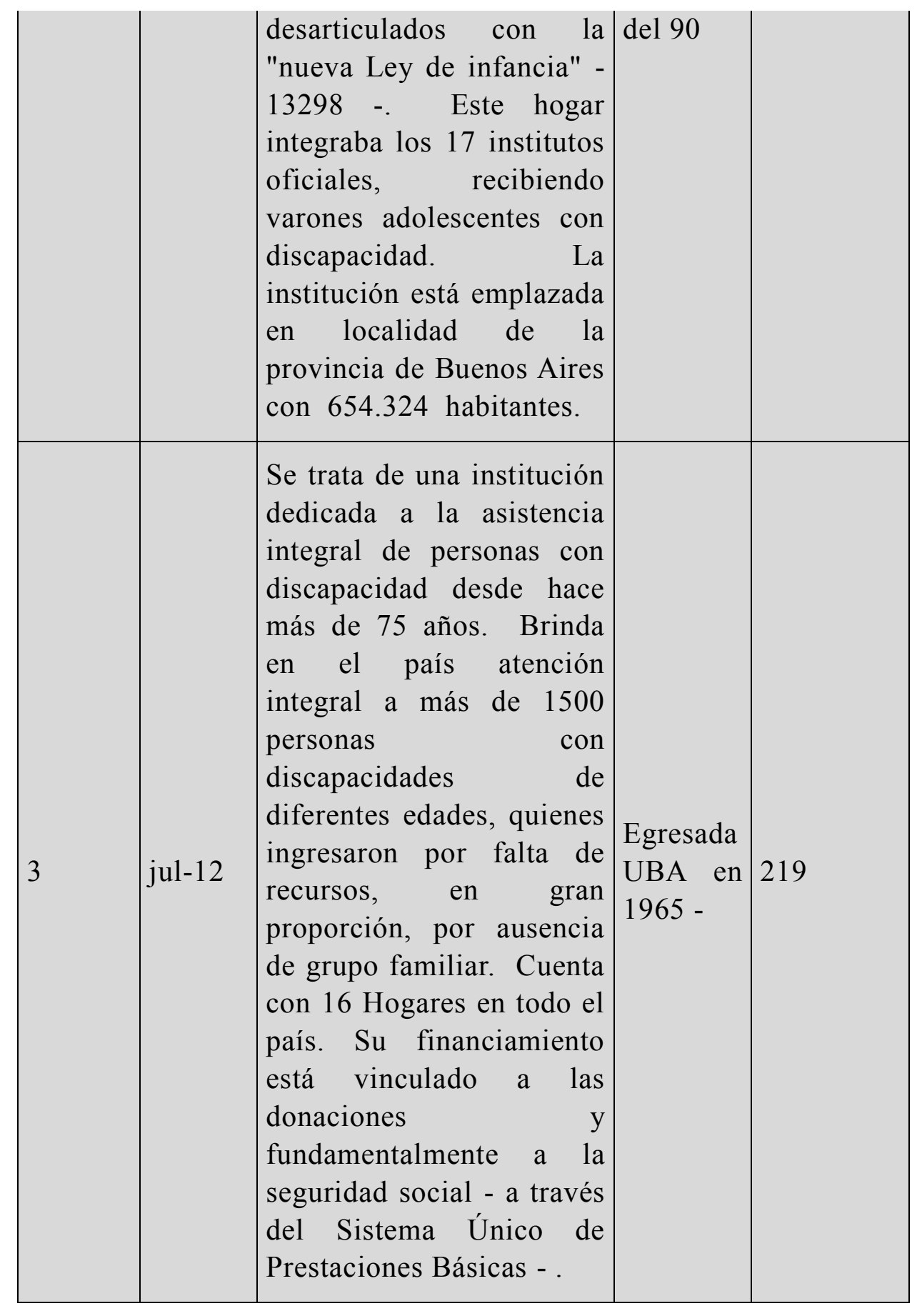




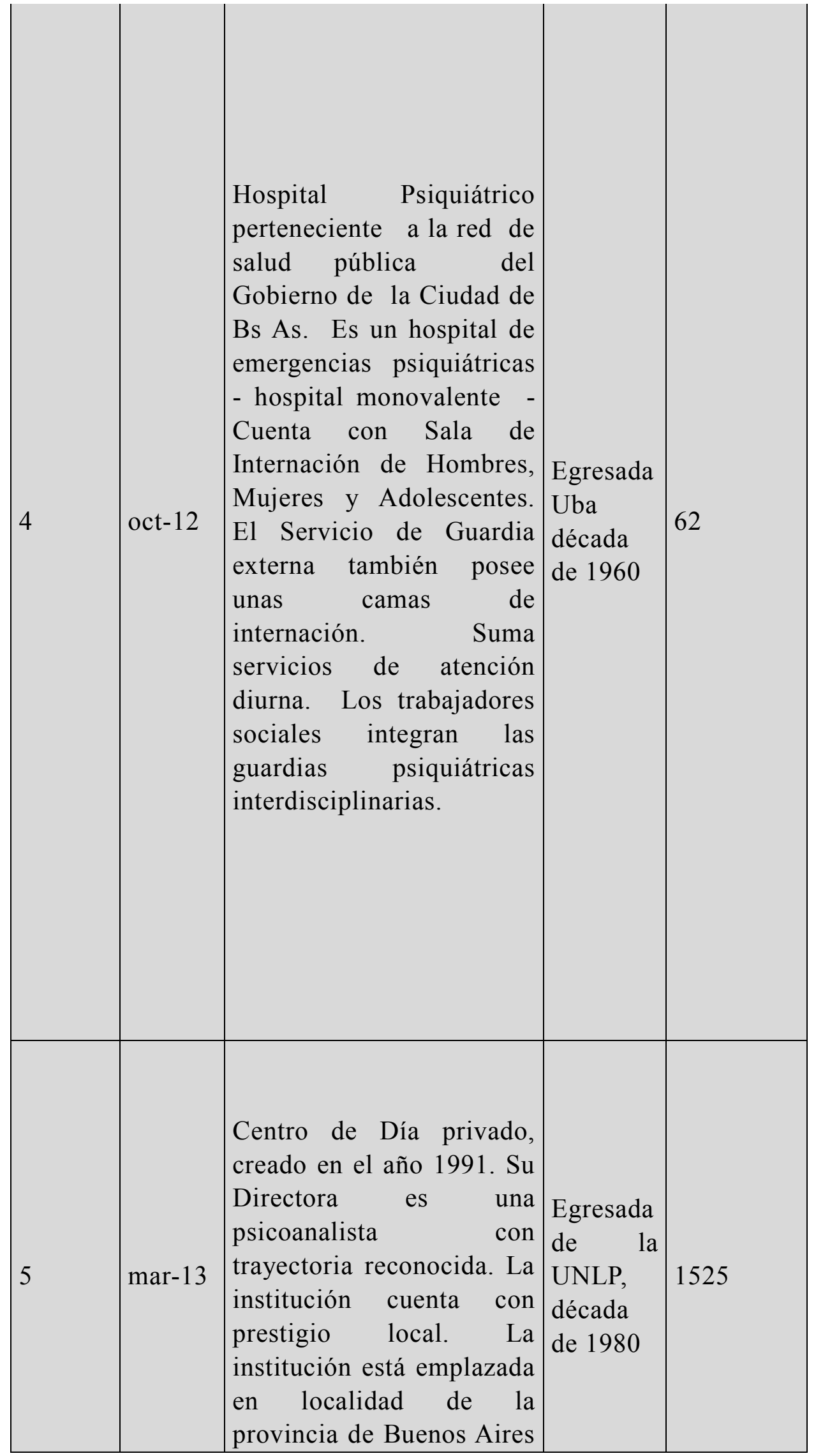




\begin{tabular}{|c|c|c|c|c|}
\hline & & con 654.324 habitantes. & & \\
\hline 6 & abr-13 & $\begin{array}{l}\text { Trabajador Social que se } \\
\text { desempeña en el ámbito } \\
\text { legislativo, } \\
\text { aportes a la Comisión de } \\
\text { Discapacidad, Salud y } \\
\text { Educación de la cámara } \\
\text { alta. Es un referente } \\
\text { nacional del tema } \\
\text { discapacidad. }\end{array}$ & $\begin{array}{l}\text { Egresado } \\
\text { UBA, } \\
\text { década } \\
\text { del } 80\end{array}$ & 97 \\
\hline 7 & mar-13 & $\begin{array}{l}\text { Asociación Civil sin fines } \\
\text { de lucro, que desarrolla } \\
\text { tareas desde hace } 55 \text { años. } \\
\text { Prestar servicios } \\
\text { educativos, laborales, } \\
\text { centro de día y Hogar. La } \\
\text { institución está emplazada } \\
\text { en localidad de la } \\
\text { provincia de Buenos Aires } \\
\text { con } 654.324 \text { habitantes. }\end{array}$ & $\begin{array}{l}\text { Egresada } \\
\text { de la } \\
\text { Escuela } \\
\text { de Salud } \\
\text { Pública } \\
\text { de la } \\
\text { provincia } \\
\text { de Bs } \\
\text { As, } \\
\text { década } \\
\text { del } 80\end{array}$ & 2221 \\
\hline 8 & mar-13 & $\begin{array}{l}\text { El Hospital es pediátrico, } \\
\text { público de la Provincia de } \\
\text { Bs. As. Establecimiento de } \\
\text { referencia a nivel } \\
\text { provincial ya que } \\
\text { concentra desarrollo de } \\
\text { prácticas de salud de } \\
\text { calidad. La entrevistada } \\
\text { también se desempeñó en } \\
\text { Centro de } \\
\text { "Rehabilitación" } \\
\text { autodenominan, pero es } \\
\text { un centro de día creado en } \\
\text { 1991. Su organización } \\
\text { está emplazada en la } \\
\text { dinámica familiar de su }\end{array}$ & $\begin{array}{l}\text { Egresada } \\
\text { UNLP, } \\
2002\end{array}$ & 522 \\
\hline
\end{tabular}




\begin{tabular}{|c|c|c|c|c|}
\hline & & 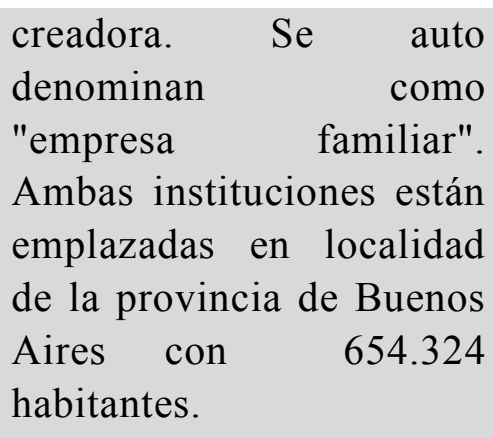 & & \\
\hline 9 & feb-13 & $\begin{array}{l}\text { Centro de } \\
\text { "Rehabilitación" } \\
\text { autodenominan, pero es } \\
\text { un centro de día creado en } \\
1991 \text { Su organización } \\
\text { está emplazada en la } \\
\text { dinámica familiar de su } \\
\text { creadora. Se auto } \\
\text { denominan } \\
\text { "empresa familiar". La } \\
\text { institución está emplazada } \\
\text { en localidad de la } \\
\text { provincia de Buenos Aires } \\
\text { con 654.324 habitantes. }\end{array}$ & $\begin{array}{l}\text { Egresada } \\
\text { UNLP } \\
\text { alrededor } \\
\text { de } 2008\end{array}$ & 1525 \\
\hline 10 & abr-13 & $\begin{array}{l}\text { Se trata de una institución } \\
\text { creada en 1991, } \\
\text { Asociación que cuenta } \\
\text { con prestigio regional. } \\
\text { Desarrolla servicios de } \\
\text { centro de Día, Hogar y } \\
\text { taller protegido. } \\
\text { La localidad del interior } \\
\text { de la provincia de Buenos } \\
\text { Aires, cuenta con } 94333 \\
\text { habitantes. }\end{array}$ & $\begin{array}{l}\text { Egresado } \\
\text { UNLu, } \\
\text { década } \\
\text { del } 90\end{array}$ & 213 \\
\hline 11 & may-13 & 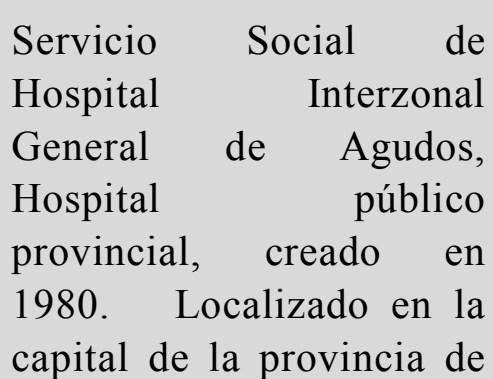 & $\begin{array}{l}\text { Egresada } \\
\text { UNLP, } \\
\text { década } \\
\text { del } 90\end{array}$ & 13 \\
\hline
\end{tabular}




\begin{tabular}{|c|c|c|c|c|}
\hline & & $\begin{array}{l}\text { Bs As con } 654324 \\
\text { habitantes. No obstante, es } \\
\text { de referencia inter zonal. }\end{array}$ & & \\
\hline 12 & 2015 & $\begin{array}{l}\text { Trabajadora Social que se } \\
\text { desempeñó } \\
\text { funcionaria de obra social } \\
\text { nacional en el área } \\
\text { específica. Actualmente } \\
\text { se desempeña en una } \\
\text { entidad privada sin fin de } \\
\text { lucro, destinada al } \\
\text { deporte. La ciudad en la } \\
\text { que trabaja tiene } \\
2.890 .151 \text { habitantes. }\end{array}$ & $\begin{array}{l}\text { Egresada } \\
\text { UBA, } \\
\text { década } \\
\text { del } 80\end{array}$ & 1319 \\
\hline 13 & may-13 & $\begin{array}{l}\text { Integrante de la Junta } \\
\text { Certificadora } \\
\text { Discapacidad de Hospital } \\
\text { Zonal de Agudos, de } \\
\text { dependencia Provincial, } \\
\text { sito en localidad del } \\
\text { interior de la provincia de } \\
\text { Buenos Aires con } 88470 \\
\text { habitantes. }\end{array}$ & $\begin{array}{l}\text { Egresada } \\
\text { Escuela } \\
\text { Lodigian } \\
\text { i } \\
\text { (Caritas), } \\
\text { década } \\
\text { del } 2000\end{array}$ & 37 \\
\hline 14 & jun-13 & $\begin{array}{l}\text { Integrante de la Junta } \\
\text { Certificadora } \\
\text { Discapacidad, en Hospital } \\
\text { Monovalente en Salud } \\
\text { mental, localizado en la } \\
\text { capital de la Provincia de } \\
\text { Bs As. El Hospital es de } \\
\text { referencia inter - zonal. }\end{array}$ & $\begin{array}{l}\text { Egresada } \\
\text { UNLP, } \\
\text { década } \\
\text { del } 90\end{array}$ & 225 \\
\hline 15 & jul-05 & $\begin{array}{l}\text { Centro de Día } \\
\text { perteneciente a una } \\
\text { Asociación sin fines de } \\
\text { lucro creada en 1993. Ha } \\
\text { recibido aportes del estado } \\
\text { provincial para la } \\
\text { adquisición de la vivienda, } \\
\text { y actualmente se financia }\end{array}$ & $\begin{array}{l}\text { Egresada } \\
\text { UNLP, } \\
\text { década } \\
\text { del } 90\end{array}$ & 15625 \\
\hline
\end{tabular}




\begin{tabular}{|c|c|c|c|c|}
\hline & & $\begin{array}{l}\text { con los aportes de obra } \\
\text { social provincial. }\end{array}$ & & \\
\hline 16 & may-13 & $\begin{array}{l}\text { Obra Social de los } \\
\text { empleados públicos del } \\
\text { estado. Simultáneamente } \\
\text { es un sistema abierto y } \\
\text { arancelado ofrecido a } \\
\text { toda la población de la } \\
\text { Provincia de Buenos } \\
\text { Aires. Tiene } 58 \text { años de } \\
\text { antigüedad, } 1.904 .112 \\
\text { afiliados }\end{array}$ & $\begin{array}{l}\text { Egresado } \\
\text { de la } \\
\text { Escuela } \\
\text { de Salud } \\
\text { Pública } \\
\text { del } \\
\text { Ministeri } \\
\text { o de } \\
\text { Salud de } \\
\text { la } \\
\text { Provinci } \\
\text { a de } \\
\text { Buenos } \\
\text { Aires }\end{array}$ & 521 \\
\hline 17 & $\begin{array}{l}\text { sept. } \\
2013\end{array}$ & 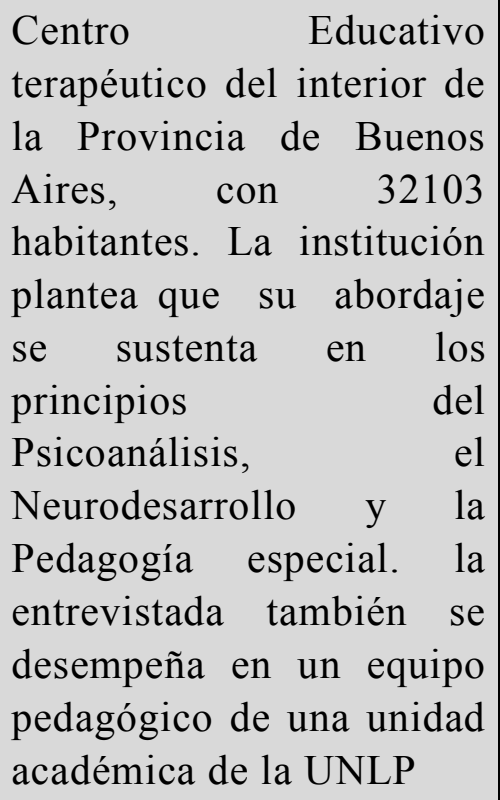 & $\begin{array}{l}\text { Egresada } \\
\text { UNLP, } \\
\text { década } \\
\text { del } 2000\end{array}$ & 65 \\
\hline 18 & 2014 & $\begin{array}{l}\text { Hospital especializado en } \\
\text { rehabilitación } \\
\text { perteneciente a la red de } \\
\text { salud pública del } \\
\text { Gobierno de la Ciudad de } \\
\text { Bs As. El Hospital brinda }\end{array}$ & $\begin{array}{l}\text { Egresada } \\
\text { s en la } \\
\text { UBA } \\
\text { desde } \\
1960 \\
\text { hasta la }\end{array}$ & 78 \\
\hline
\end{tabular}




\begin{tabular}{|c|c|c|c|c|}
\hline & & $\begin{array}{l}\text { atención } \\
\text { especializada } \\
\text { rehabilitación en lo que } \\
\text { hace a en } \\
\text { adolescentes, adultos y } \\
\text { mayores, a fin de asegurar } \\
\text { al núcleo de la población } \\
\text { y su reintegración en } \\
\text { mejores condiciones } \\
\text { físicas - sociales - } \\
\text { funcionales. . }\end{array}$ & $\begin{array}{l}\text { década } \\
\text { del } 2000\end{array}$ & \\
\hline 19 & 2014 & $\begin{array}{l}\text { Áreas de Infancia y } \\
\text { discapacidad del } \\
\text { Ministerio de Desarrollo } \\
\text { Social de la Provincia de } \\
\text { Buenos Aires. Áreas que } \\
\text { han modificado en estos } \\
33 \text { años desde el retorno a } \\
\text { la democracia. Desde este } \\
\text { Ministerio se generan las } \\
\text { directrices en la materia } \\
\text { para todo el territorio de } \\
\text { la provincia, que cuenta } \\
\text { con 15.482.751 habitantes, } \\
\text { de los que el } 12 \% \text { presenta } \\
\text { limitación ó dificultad } \\
\text { permanente. }\end{array}$ & $\begin{array}{l}\text { Egresada } \\
\text { de la } \\
\text { Escuela } \\
\text { de Salud } \\
\text { Pública } \\
\text { del } \\
\text { Ministeri } \\
\text { o de } \\
\text { Salud de } \\
\text { la de } \\
\text { Provinci } \\
\text { a de } \\
\text { Buenos } \\
\text { Aires, en } \\
\text { la década } \\
\text { del } 80\end{array}$ & 1313 \\
\hline 20 & 2014 & $\begin{array}{l}\text { Trabaja en un área } \\
\text { destinada al abordaje de } \\
\text { situaciones } \\
\text { discapacidad de }\end{array}$ & $\begin{array}{l}\text { Egresada } \\
\text { UNLP, } \\
\text { década } \\
\text { del } 2000\end{array}$ & 316 \\
\hline
\end{tabular}




\begin{tabular}{|c|c|c|c|c|}
\hline & & $\begin{array}{l}\text { tareas desde hace } 55 \text { años } \\
(1960) \text { en la misma } \\
\text { ciudad. Presta servicios } \\
\text { educativos, laborales, } \\
\text { centro de día y Hogar. }\end{array}$ & & \\
\hline 21 & jul-13 & $\begin{array}{l}\text { Trabaja en un área } \\
\text { destinada al abordaje de } \\
\text { situaciones } \\
\text { discapacidad de una } \\
\text { Universidad nacional. En } \\
\text { la misma evalúan los } \\
\text { accesos a becas, y la } \\
\text { búsqueda de apoyos } \\
\text { suficientes y oportunos } \\
\text { para generar inclusiones } \\
\text { educativas. }\end{array}$ & $\begin{array}{l}\text { Egresado } \\
\text { década } \\
\text { del } 2000 \\
\text { en } \\
\text { Universi } \\
\text { dad } \\
\text { nacional } \\
\text { de } \\
\text { Córdoba }\end{array}$ & 1515 \\
\hline 22 & jul-13 & $\begin{array}{l}\text { Consejo Provincial de } \\
\text { Discapacidad ha sido } \\
\text { creado por el Articulo 5to } \\
\text { de la Ley } 10.592 \text { y su } \\
\text { Decreto Reglamentario } \\
1149 / 90 \text {. } \\
\text { creado prganismo ara asesorar al } \\
\text { Poder Ejecutivo en el } \\
\text { ejercicio de sus facultades } \\
\text { privativas, con el objeto } \\
\text { de promover e } \\
\text { implementar una política } \\
\text { integral sobre el tema en } \\
\text { la Provincia. El Conejo } \\
\text { tuvo momentos de } \\
\text { actividad intensa, en el } \\
\text { que generaron las } \\
\text { directrices en la materia } \\
\text { para todo el territorio. El }\end{array}$ & $\begin{array}{l}\text { Egresada } \\
\text { UNLP, } \\
\text { año } 1992 \\
\text { (primer } \\
\text { cohorte } \\
\text { de título } \\
\text { de } \\
\text { Licencia } \\
\text { dos) }\end{array}$ & 158 \\
\hline
\end{tabular}




\begin{tabular}{|c|c|c|c|c|}
\hline & & 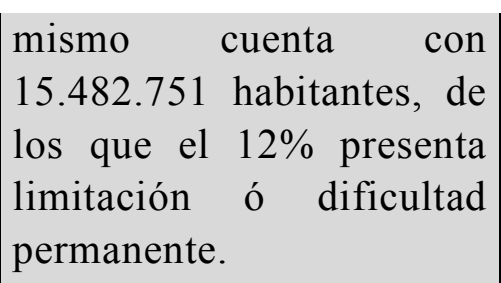 & & \\
\hline 23 & 2014 & $\begin{array}{l}\text { Docente en situación de } \\
\text { discapacidad, que se } \\
\text { desempeña en el área de } \\
\text { Deportes de la provincia } \\
\text { de Buenos Aires. Su } \\
\text { ingreso laboral está } \\
\text { asociado al cumplimiento } \\
\text { del porcentaje establecido } \\
\text { en la Ley 10592, } \\
\text { generando estrategias de } \\
\text { inclusión laboral en el } \\
\text { estado provincial. }\end{array}$ & $\begin{array}{l}\text { ENTRE } \\
\text { VISTA } \\
\text { GRUPO } \\
\text { CONTR } \\
\text { OL }\end{array}$ & 82 \\
\hline 24 & 2013 & $\begin{array}{l}\text { Programa de Inclusión } \\
\text { Laboral del Ministerio de } \\
\text { Trabajo de la Provincia de } \\
\text { Buenos } \\
\text { Actualmente } \\
\text { desempeña en } \\
\text { Ministerio de } \\
\text { Social de la nación. } \\
\text { Sol }\end{array}$ & $\begin{array}{l}\text { Egresada } \\
\text { UNLP, } \\
\text { década } \\
\text { del } 2000\end{array}$ & 159 \\
\hline 25 & 2013 & $\begin{array}{l}\text { Centro de Rehabilitación } \\
\text { que se generó en localidad } \\
\text { de la provincia como } \\
\text { respuesta en la década del } \\
50 \text { a la epidemia de } \\
\text { poliomielitis. Es una } \\
\text { ONG prestigiosa en la } \\
\text { ciudad, que ha gestionado } \\
\text { en forma articulada con la } \\
\text { provincia de Bs As } \\
\text { muchos programas. }\end{array}$ & $\begin{array}{l}\text { Egresado } \\
\text { UNLP, } \\
\text { década } \\
\text { del } 2000\end{array}$ & 218 \\
\hline
\end{tabular}




\begin{tabular}{|c|c|c|c|c|}
\hline 26 & 2013 & $\begin{array}{l}\text { Intelectual en situación de } \\
\text { discapacidad que integra } \\
\text { una ONG con amplio } \\
\text { desarrollo reivindicativo } \\
\text { en nuestro país. }\end{array}$ & $\begin{array}{l}\text { ENTRE } \\
\text { VISTA } \\
\text { GRUPO } \\
\text { CONTR } \\
\text { OL }\end{array}$ & 611 \\
\hline 27 & 2013 & $\begin{array}{l}\text { Centro de Día } \\
\text { perteneciente a una ONG } \\
\text { que brinda servicios a } \\
\text { jóvenes con discapacidad } \\
\text { mental. Está emplazado en } \\
\text { una localidad del } \\
\text { conurbano sur, que cuenta } \\
\text { con 426.005 habitantes. }\end{array}$ & $\begin{array}{l}\text { Egresada } \\
\text { UNLP, } \\
\text { década } \\
\text { del } 2000\end{array}$ & 1516 \\
\hline
\end{tabular}

\section{Presentación de datos de interlocutores}

En el presente apartado se graficarán las características de los entrevistados:

- Espacios socio - ocupacionales de entrevistados por empleador 


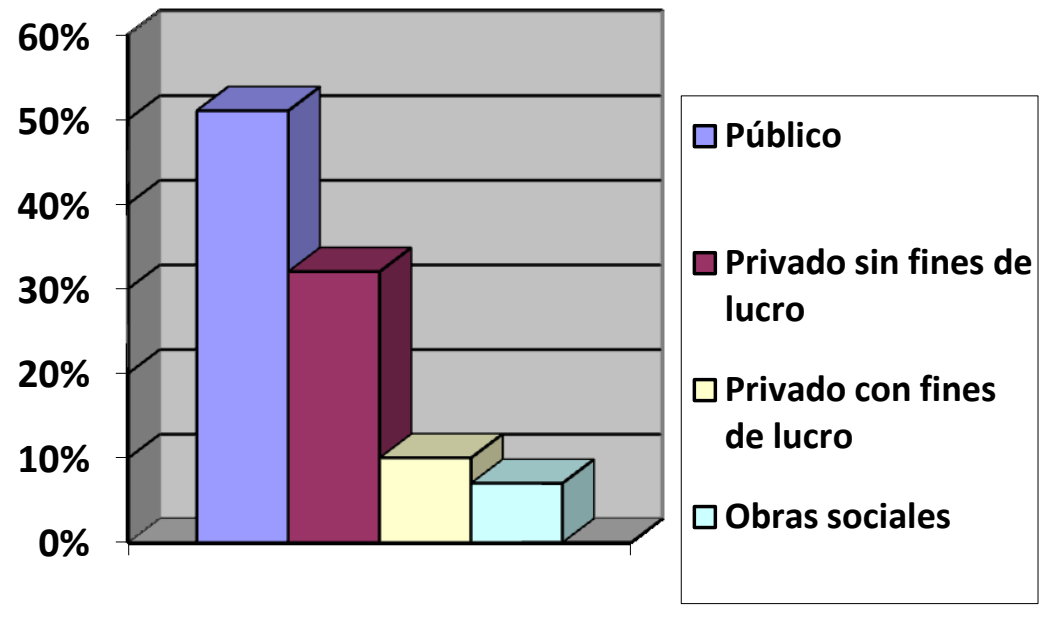

- Distribución por tipo de empleador estatal

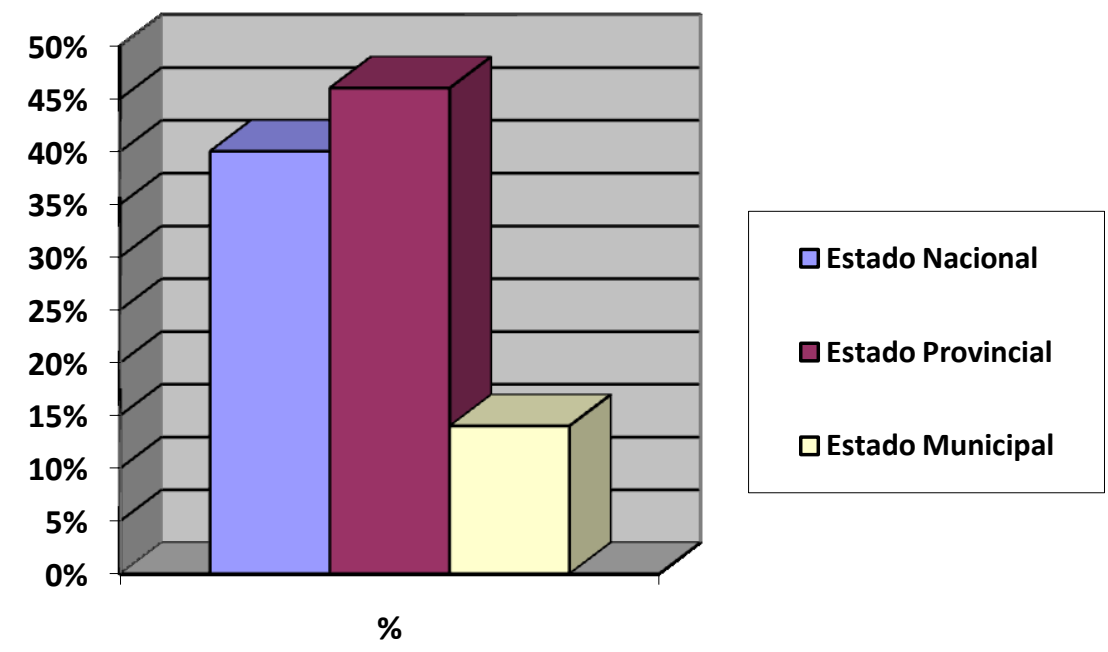




\section{- Distribución por género}

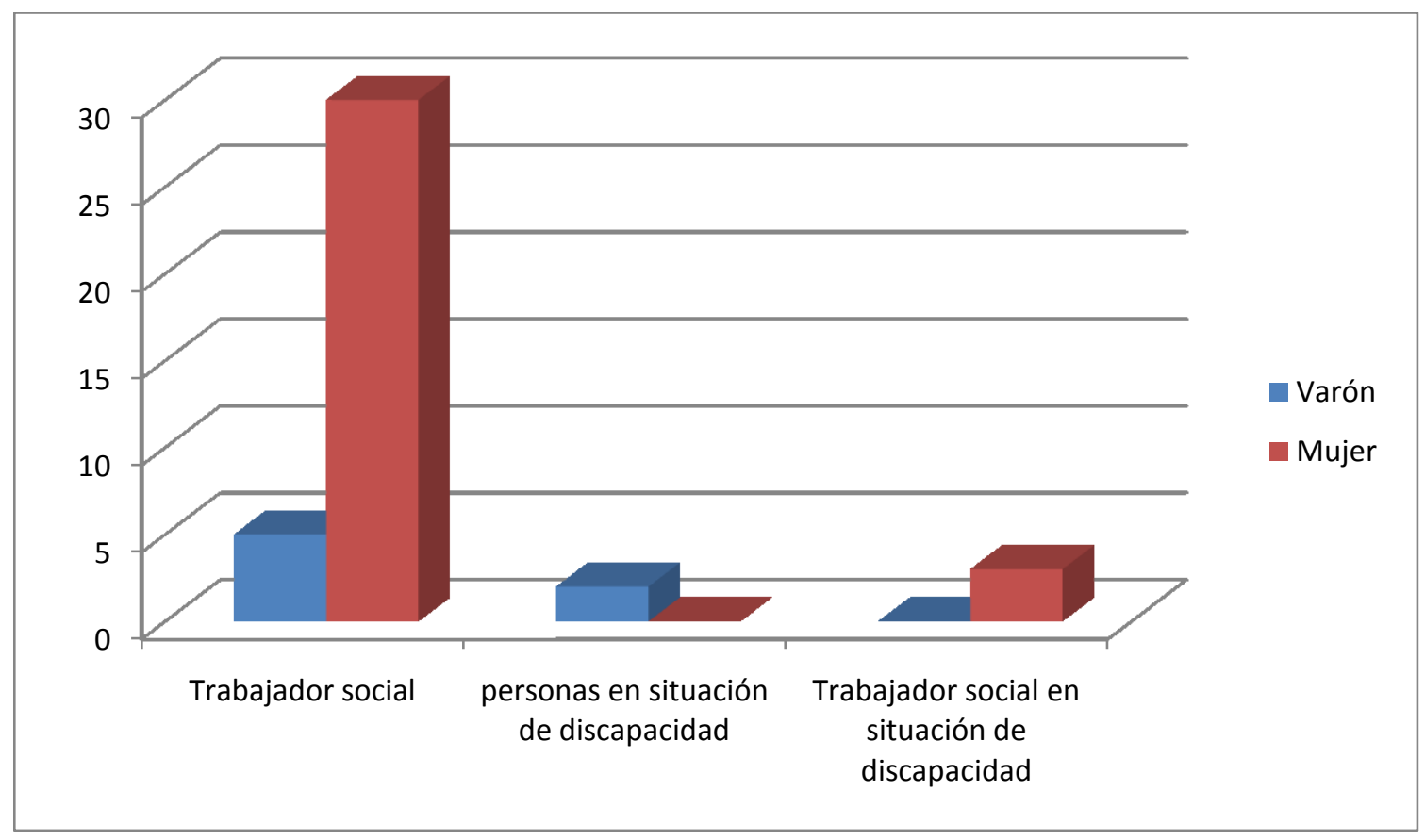

Del gráfico anterior surge la continuidad en el rasgo feminizado de la profesión, lo que ha sido analizado por Grassi (1989) en su clásico texto.

Los trabajadores sociales entrevistados pertenecen en un $85 \%$ al género femenino y un $15 \%$ al masculino. En el focus group, la totalidad del servicio social hospitalario era femenino.

Otra cuestión que no hemos presentado con tanta profundidad, ya que excede los objetivos de investigación es la pertenencia de 3 de los 35 trabajadores sociales entrevistados al colectivo de discapacidad. De estas tres colegas, una de ellas es militantes del tema y las otras no han canalizado su participación política en este tema. En las conclusiones se destaca este tema cómo una posible vía de indagación pendientes. 


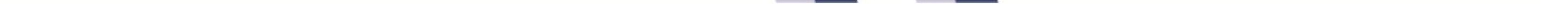

